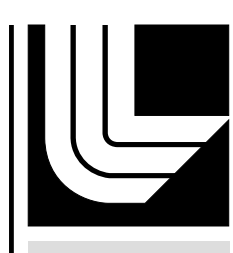

LA W RENCE LIVERMORE N A TIO NAL LABORATORY

Disposal Systems Evaluation Framework DSEF Version 3.0 User Manual

H. R. Greenberg, J. A. Blink, M. Sutton, T. A. Buscheck

August 23, 2013 
This document was prepared as an account of work sponsored by an agency of the United States government. Neither the United States government nor Lawrence Livermore National Security, LLC, nor any of their employees makes any warranty, expressed or implied, or assumes any legal liability or responsibility for the accuracy, completeness, or usefulness of any information, apparatus, product, or process disclosed, or represents that its use would not infringe privately owned rights. Reference herein to any specific commercial product, process, or service by trade name, trademark, manufacturer, or otherwise does not necessarily constitute or imply its endorsement, recommendation, or favoring by the United States government or Lawrence Livermore National Security, LLC. The views and opinions of authors expressed herein do not necessarily state or reflect those of the United States government or Lawrence Livermore National Security, LLC, and shall not be used for advertising or product endorsement purposes.

This work performed under the auspices of the U.S. Department of Energy by Lawrence Livermore National Laboratory under Contract DE-AC52-07NA27344. 


\title{
DiSPOSAL SYSTEMS EVALUATION FRAMEWORK DSEF VERSION 3.0 USER MANUAL
}

\author{
Used Fuel Disposition Campaign \\ Level 4 Milestone (M4): M4FT-13LL08060323
}

Generic Engineered Barrier System Evaluation

(Work Package FT-13LL080603)

\author{
Harris R. Greenberg, James A. Blink, Mark Sutton and Thomas A. Buscheck \\ Lawrence Livermore National Laboratory
}

AUgust, 2013

LLNL-TR-629812 REV. 1 
This document was prepared as an account of work sponsored by an agency of the United States government. Neither the United States government nor Lawrence Livermore National Security, LLC, nor any of their employees makes any warranty, expressed or implied, or assumes any legal liability or responsibility for the accuracy, completeness, or usefulness of any information, apparatus, product, or process disclosed, or represents that its use would not infringe privately owned rights. Reference herein to any specific commercial product, process, or service by trade name, trademark, manufacturer, or otherwise does not necessarily constitute or imply its endorsement, recommendation, or favoring by the United States government or Lawrence Livermore National Security, LLC. The views and opinions of authors expressed herein do not necessarily state or reflect those of the United States government or Lawrence Livermore National Security, LLC, and shall not be used for advertising or product endorsement purposes.

This work performed under the auspices of the U.S. Department of Energy by Lawrence Livermore National Laboratory under Contract DE-AC52-07NA27344. 


\section{Revision History}

LLNL-TR-629812 - March 2013 - Original issue of User Manual for DSEF Version 2.1

LLNL-TR-629812 Rev. 1 - August 2013 - Updated for DSEF Version 3.0

- Extensive revision of disposal system cost model including updated Inputs and Cost Calculation worksheets

- Increased number of cases in the Case Library from 300 to 721, including 4 new Case Catalog sections for easy access to the new cases

- The addition of two new Mathcad thermal-analytical models

o A model to determine required ventilation time to meet specific temperature acceptance criteria using an iterative convergence model

o A model allowing temperature-dependent and time-dependent properties of the Engineered Barrier System layers of the thermal analytical model 


\section{Table of Contents}

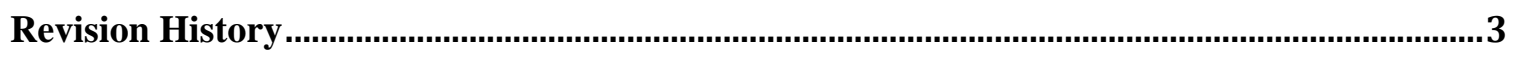

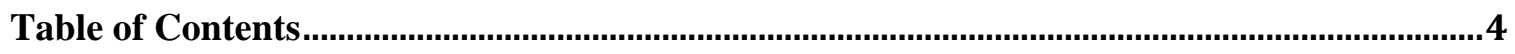

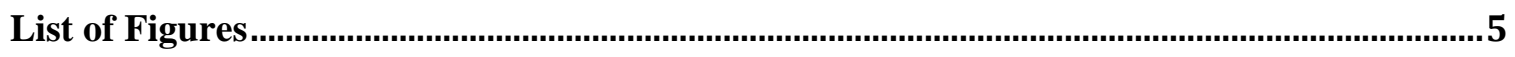

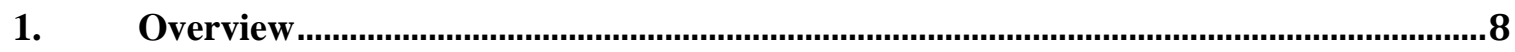

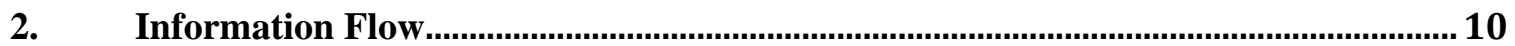

3. Finding Your Way Around - the NAVIGATION, README, LISTS and REV HISTORY

Worksheets............................................................................................................................ 12

4. Getting Started - Working with the DSEF Workbook .............................................. 14

5. The Starting Point to Define an Analysis Case - the INPUTS Worksheet .................. 17

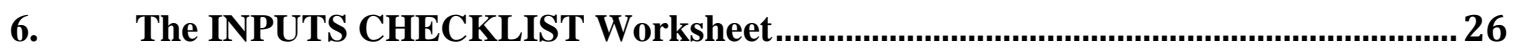

7. Reviewing Previous Analyses - the CASE LIBRARY and the THERMAL-INTERPOLATE

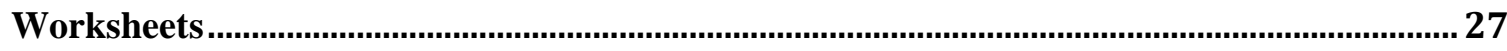

8. Getting a Quick Overview of the Latest Analysis - the RESULTS and the THERMAL-

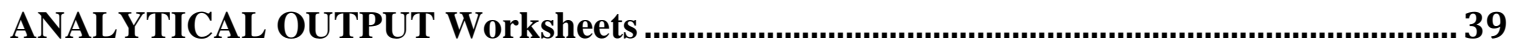

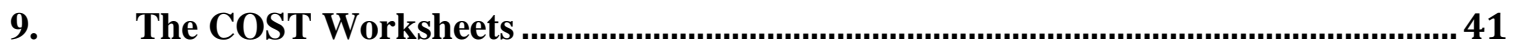

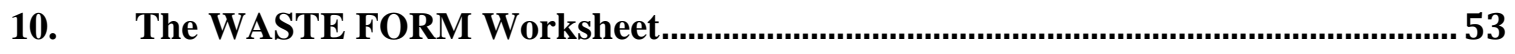

11. Defining Thermal Data Inputs and Outputs -the THERMAL Worksheets ............. 56

12. Finding and Comparing Material Properties - the MATERIALS Worksheets........ 58

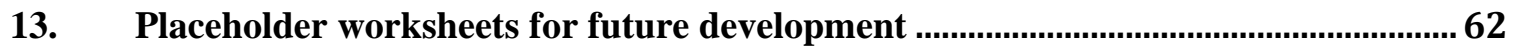

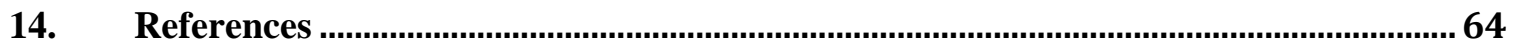

Appendix A - Setting up Excel to Allow the DSEF Macros to Work ........................................ 65

Appendix B - The Mathcad Thermal-Analytical Component of DSEF ................................. 68

B.1 Using the Mathcad models in conjunction with the DSEF Excel file.....................................69

B.2 The Mathcad parametric analysis and iterative convergence model - parametric study example

B.3 The Mathcad parametric analysis and iterative convergence model - iterative convergence

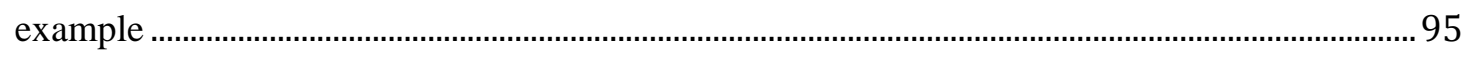

B.4 The Mathcad model with temperature and time dependent EBS thermal properties ....... 119 


\section{List of Figures}

Figure 1- DSEF Input-Process-Output diagram .............................................................................................

Figure 2 - Example of the information flow in DSEF ……............................................................................11

Figure 3 - Using the Excel tab navigation bar ............................................................................................. 12

Figure 4 - The two lists of worksheets in the NAVIGATION worksheet .........................................................13

Figure 5 - A drop-down list to select the waste form.................................................................................. 15

Figure 6 - A spinner control to select the number of assemblies in a waste package .....................................15

Figure 7 - An example of some of the cross-checks and cautions displayed in the INPUTS worksheet ....17

Figure 8 - An example of one of the ways DSEF lets you use data from the case library, or override the

data with user input ............................................................................................................................. 18

Figure 9 - Example of repository level cost input data with Carter/Hardin example case data.....................22

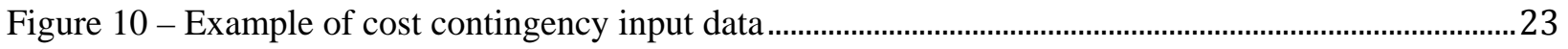

Figure 11 - Example of comparison of thermal results against thermal constraints from the RESULTS

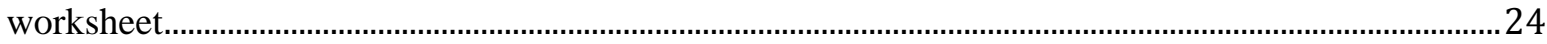

Figure 12 - Example of parametric study input data from Step 13 on the INPUTS worksheet....................25

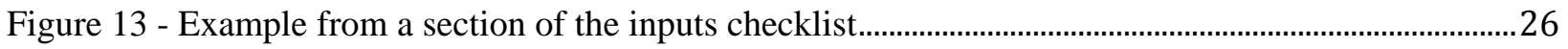

Figure 14 - The data fields used in the CASE LIBRARY ..................................................................................28

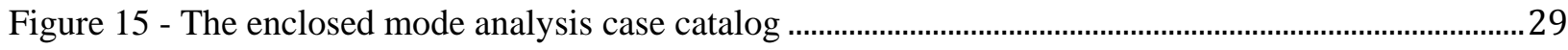

Figure 16 - The open mode analysis base case catalog ……...........................................................................3

Figure 17 - The open mode sensitivity studies case catalog ................................................................................ 31

Figure 18 - Case number catalog for repository layout and required ventilation trade studies in clay/shale

(1 of 2) 32

Figure 19 - Case number catalog for repository layout and required ventilation trade studies in clay/shale

(2 of 2).

Figure 20 - Case number catalog for scoping thermal analysis of alternative DPC disposal concepts in clay/shale (subset 1 ).

Figure 21 - Case number catalog for scoping thermal analysis of alternative DPC disposal concepts in clay/shale (subset 2)... 35

Figure 22 - Side-by-side case comparison table .37 
Figure 23 - The template for variable interpolation between relevant cases .....................................................38

Figure 24 - Summary of waste package numbers for the 5 example cost cases...............................................43

Figure 25 - Summary of mined opening length and volume for the 5 example cost cases.............................44

Figure 26 - Summary of shaft and ramp quantities for the 5 example cost cases ...........................................4 44

Figure 27 - Cost example case 1 - crystalline (enclosed) repository drift panel detail summary..................45

Figure 28 - Cost summary table example as shown on the RESULTS worksheet ........................................47

Figure 29 - Cost summary table comparing Carter/Hardin Case 1 (Crystalline Enclosed) results with

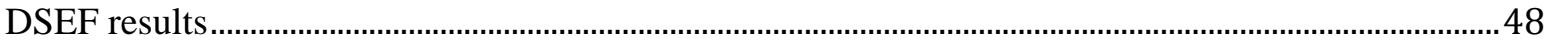

Figure 30 - Cost summary table comparing Carter/Hardin Case 2 (Salt Enclosed) results with DSEF results.

Figure 31 - Cost summary table comparing Carter/Hardin Case 3 (Clay/Shale Enclosed) results with

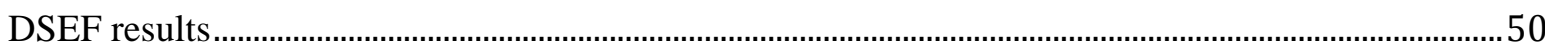

Figure 32 - Cost summary table comparing Carter/Hardin Case 4 (Clay/Shale Open) results with DSEF

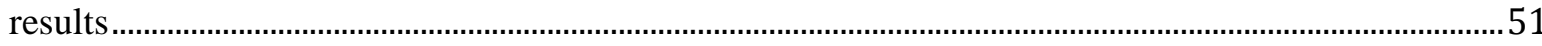

Figure 33 - Cost summary table comparing Carter/Hardin Case 5 (Sedimentary Open) results with DSEF results. .52

Figure 34 - Tables from the WASTE FORM worksheet ……..............................................................................5 54

Figure 35 - WASTE FORM worksheet - calculated waste form outer radius lookup table ...........................55

Figure 36- Example of parametric study plots on the THERMAL-ANALYTICAL OUTPUT worksheet57

Figure 37 - Example transient output data plotted in the THERMAL-ANAL YTICAL OUTPUT

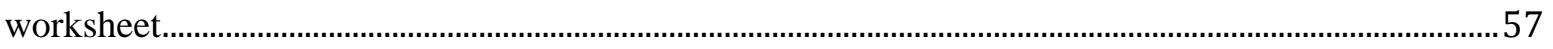

Figure 38 - Decay heat data built-in to the THERMAL-SOURCE worksheet.................................................58

Figure 39 - Examples of decay heat update caution and confirmation prompts...............................................58

Figure 40 - The first step - selecting the materials data to plot...........................................................................60

Figure 41 - Example output of the materials data plotting macro..........................................................................60

Figure 42 - Example of data structure in the MATERIALS-THERMAL PROPERTIES worksheet ..........60 Figure 43 - Example of data structure in the MATERIALS-TRANSPORT PROPERTIES worksheet .....61 
List of Acronyms

$\begin{array}{ll}\text { ANL } & \text { Argonne National Laboratory } \\ \text { DOE } & \text { Department of Energy } \\ \text { DSEF } & \text { Disposal Systems Evaluation Framework } \\ \text { EBS } & \text { Engineered Barrier System } \\ \text { EC, E-Chem } & \text { Electro-Chemical (with -C or -M indicate } \\ & \text { form } \\ \text { GWd/MT } & \text { Gigawatt (thermal) - days per Metric Ton } \\ \text { HLW } & \text { High-Level nuclear Waste } \\ \text { LLNL } & \text { Lawrence Livermore National Laboratory } \\ \text { MOX } & \text { Mixed Oxide Fuel } \\ \text { NBS } & \text { Natural Barrier System } \\ \text { PWR } & \text { Pressurized Water Reactor } \\ \text { ROM } & \text { Rough Order of Magnitude } \\ \text { SNL } & \text { Sandia National Laboratories } \\ \text { UFD } & \text { Used Fuel Disposition } \\ \text { UOX } & \text { Uranium Oxide Fuel } \\ \text { UOX-40 } & \text { UOX with 40-GWd/MTU burnup } \\ \text { UOX-60 } & \text { WOX with 60-GWd/MTU burnup } \\ \text { Visual Basic for Applications }\end{array}$




\section{Overview}

The Disposal Systems Evaluation Framework (DSEF) has been developed at Lawrence Livermore National Laboratory (LLNL) to formalize and facilitate the development and documentation of repository conceptual design options for a range of waste forms, geologic environments, repository design concepts, and repository operating modes. DSEF is one component of the Engineered Barrier System (EBS) family of work packages at several national laboratories led by Sandia National Laboratories (SNL), in support of the DOE Office of Nuclear Energy, specifically of the Used Fuel Disposition (UFD) Campaign within the Office of Used Nuclear Fuel Disposition Research and Development (NE-53).

DSEF is a knowledge management system that allows the user to intelligently access and draw data from a case library of hundreds of completed thermal analyses (currently 721 cases in the library), and draw input from databases of material properties and repository development cost data (currently the data in these databases are drawn from more than 100 references).

The core functionality of DSEF is provided by a Microsoft Office Excel 2010 workbook with macros and form controls that create a structured environment and walk the user through the steps of creating the input data required to perform disposal system evaluations internally and by interfacing with external programs. The user can choose to work with built-in data from the case library of previous analysis cases, from the material property databases, or can define their own input descriptions and data.

DSEF uses the Excel worksheet protection (implemented on a sheet by sheet basis) to prevent inadvertent over-writing of formulas with data. When worksheet protection is enabled, the user can see all underlying formulas, and enter data in unprotected cells (the unprotected cells generally correspond to the yellow highlighted cells). Worksheet protection also prevents restructuring the files (adding or deleting rows or columns) and changing the formatting, as well as preventing access to the Visual Basic Editor to prevent modification of the macros. If the user needs to modify the worksheet structure, formulas, or macros, they can contact LLNL to get the password to unprotect the worksheets. However, care should be taken in making any modifications, since the macros and formulas are dependent in some cases on the current structure, range names, and macro subroutines

DSEF is set up to retrieve the results of external thermal analysis program runs, summarize them graphically, and provide a template for adding the new results to the Case Library. The Case Library worksheet in DSEF is set up to create a Case Library data record for each new analysis case, at the top of the list of prior cases. Therefore, a separate DSEF file (with unique name) should be saved for each run that is to be archived. Users should submit a copy of their DSEF files to LLNL so that their results can be added to the overall Case Library and made available to other laboratories and stakeholders. LLNL will maintain the DSEF Case Library and make the most current files available on the SNL SharePoint site. The Revision History sheet documents the file evolution.

One of the key objectives of DSEF is to allow the user to compare the results of thermal analyses to the thermal constraints of the design components. These comparisons can then be used to consider design, layout, and operating mode modifications to find combinations that can meet the thermal constraints for a given combination of waste form, geologic medium, surface storage time, and system concept of operation. 
DSEF has built-in capabilities to allow a user to graphically compare and contrast material property data, with statistical data summaries for the selected data sets. This is done at the push of a control button, where the user can then select a range or a collection of individual sets of data for comparison, with the freedom to select the placement location of the comparison plot.

As part of the assessment of design concept feasibility, DSEF includes the capability to evaluate the costs of repository design, licensing, construction, maintenance, closure and performance confirmation based on the methodology defined in Carter 2012 and Hardin 2012b. The costs also include waste packages and program integration costs. Similar to the thermal analysis Case Library, DSEF includes five sets of cost data input values from the five generic repository design cases defined in Carter 2012 and Hardin 2012b as example reference cases. The cost data for these five cases can be displayed on the INPUTS worksheet as examples of the cost calculations documented in the subject references, and they can be used directly or over-ridden by user supplied input to analyze different repository design concepts.

Interfaces with various repository analysis codes are possible for further DSEF development. Version 3.0 currently provides input to, and retrieves output data from; several Mathcad Version 15 thermal-analytical models developed at LLNL (see Appendix B).

This User Manual describes the structure and use of the various types of worksheets contained in the DSEF Version 3.0 workbook. Most of the worksheets are fully operational. Some worksheets are placeholders pending potential future development. A Beta test Version 2.0 of the software was delivered previously to the SNL Lead, Carlos Jove-Colon, and the DOE Manager, William Spezialetti; their comments greatly improved the software and this User Manual. The DSEF Version 2.0 Beta Test Excel file and the draft DSEF Version 2.0 User Manual delivered in September and August 2012 respectively met the requirements of Deliverable M4FT-12LL0806043. The DSEF Version 2.1 Excel spreadsheet, Mathcad thermal-analytical model, and the original issue of the DSEF User Manual for Version 2.1 (LLNL-TR-629812 were issued as in March 2013, and posted to the SNL SharePoint server for distribution. 


\section{Information Flow}

As in the DSEF Version 1.0 Progress Report (Sutton 2011), waste forms are examined with respect to three fuel cycles: open (once through), modified open (partial recycle), and closed (full recycle). The six heat-producing waste types from these cycles (one from open, two from modified open, and three from closed) are identified as examples with dimensions, mass, reactor burnup and decay heat properties. Seven disposal environments were initially identified, with the four key mined and saturated repositories (granite, salt, clay/shale and deep borehole) being part of the base case for DSEF evaluations. Together with six fuel types and four pre-emplacement aging times (10, 50, 100, and 200 years), 120 base case models were proposed (including 1 and 4-PWR-assembly options for SNF waste packages in granite, clay, and salt). Additional repository concepts, geological environments, operating modes, waste packages sizes, and spent fuel burnup cases were analyzed and documented in DSEF Version 2.1 (expanding the number of cases in the Case Library to 300) and in Version 3.0 (expanding the number of cases to 721).

Figure 1 is a high-level overview of the structure and approach that is implemented in DSEF to help the user gather the necessary input data, define an analysis case, and compare results to design constraints. It is used in an iterative manner to focus in on feasible repository design concepts for a given combination of heat generating high-level radioactive waste in a given geologic medium using selected repository design and operating concepts.

Figure 1- DSEF Input-Process-Output diagram

\section{INPUTS}

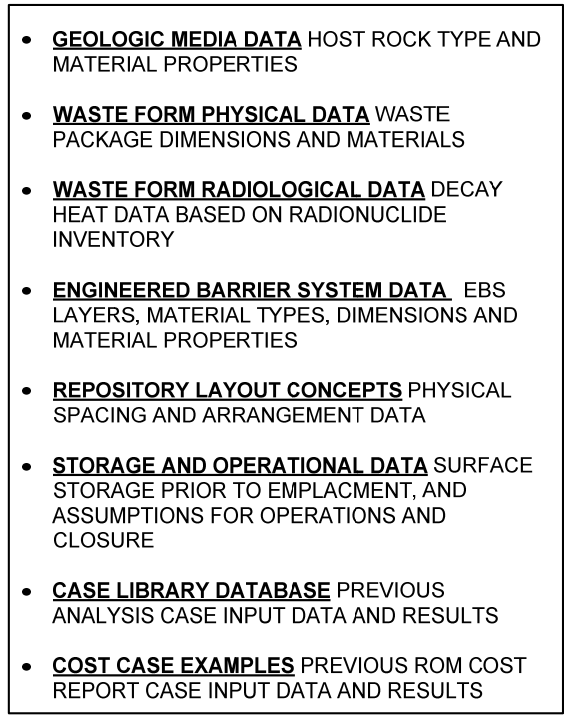

Notes:

${ }^{\star \star N}$ Not currently implemented in DSEF VERSION 3.0.

\section{PROCESS}

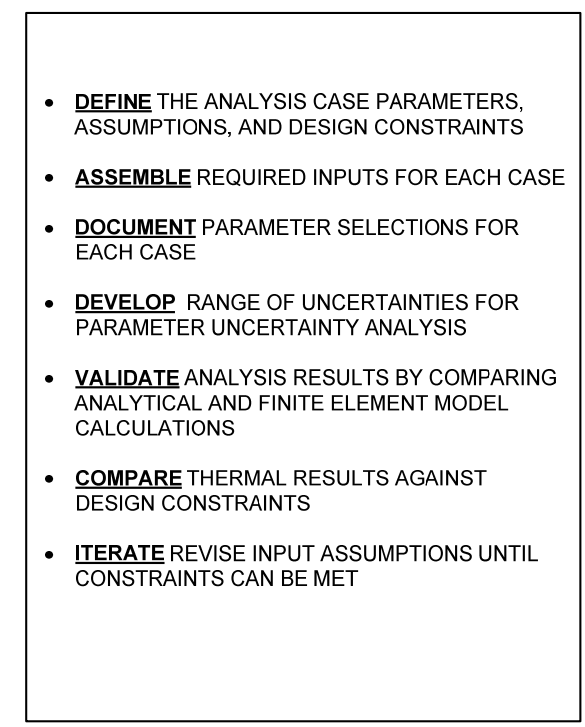

OUTPUT

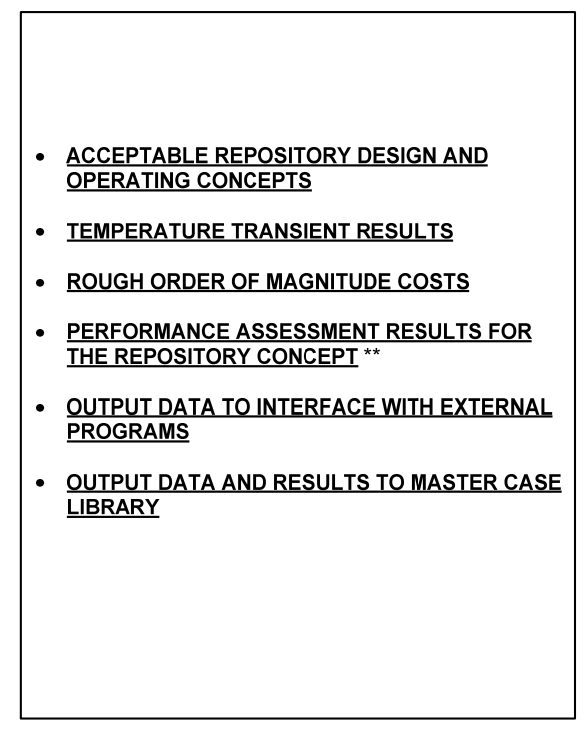


Figure 2 shows the detailed information flow in DSEF that implements the approach defined in the inputprocess-output diagram shown in Figure 1. It shows how DSEF can be used to identify feasible repository disposal concepts. TruGrid and DIABLO are used as examples of interfacing external analysis programs. The user could easily substitute CUBIT for the TruGrid as an alternate mesh generation program, and SINDA-G, ARIA, ALBANY, TOUGH2 or TOPAZ for DIABLO as other possible finite element model thermal analyzers.

Figure 2 - Example of the information flow in DSEF

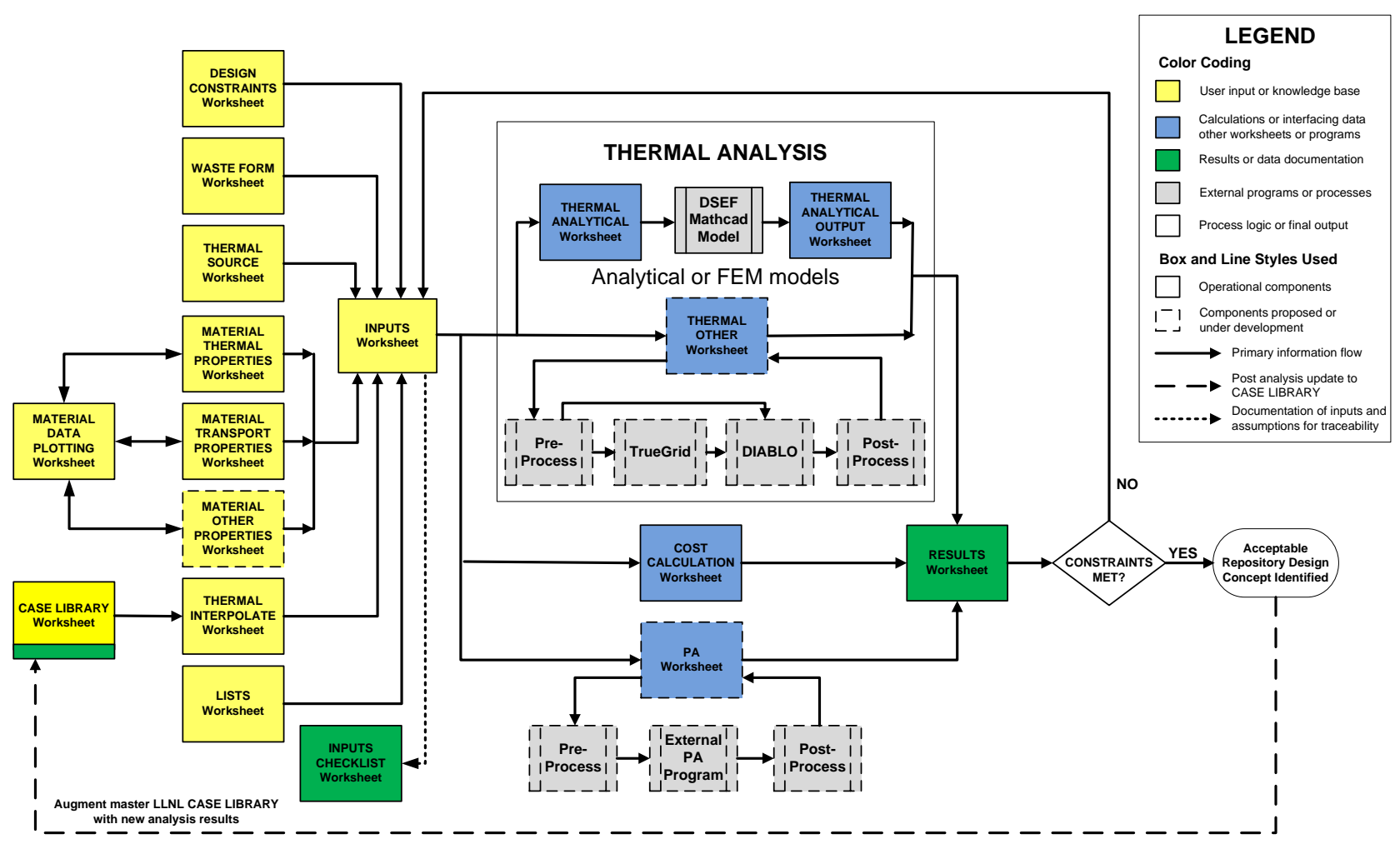




\section{Finding Your Way Around - the NAVIGATION, README, LISTS and REV HISTORY Worksheets}

Hyperlinks are available throughout the worksheets in the DSEF workbook to help you navigate quickly to related input and data source pages. The NAVIGATION worksheet in DSEF is the first worksheet tab, which allows users to quickly move to any worksheet and can be found by clicking on the Excel control for scrolling through the worksheet tabs. It is shown in Figure 3, with the arrow pointing to the "go to the first tab” button. Clicking on that will always take you to the NAVIGATION worksheet.

Figure 3 - Using the Excel tab navigation bar

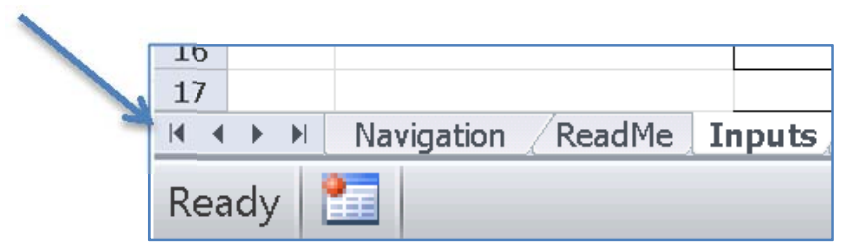

On the NAVIGATION worksheet, there are two lists as shown in Figure 4. The list on the left shows the names of the worksheets in the sequence that they appear in the DSEF workbook. The list on the right consists of the same names but sorted alphabetically and hyperlinked to the worksheets themselves. Using the control shown in Figure 3 and the hyperlinks shown in Figure 4 enables quick navigation to any worksheet with two simple mouse clicks.

The README worksheet gives a brief overview of DSEF. At the bottom, there is an "Information Flow" description that explains the relationships between many of the worksheets. That part of the README worksheet serves the same purpose as this User Manual, but can be updated more easily when minor modifications and improvements are made to DSEF.

The LISTS worksheet is a tool primarily used by the DSEF Development Team. It is a central location for all drop-down lists and look-up tables used by other worksheets. Some advanced users may choose to view this worksheet to globally see the range of choices in these lists and to recommend additional choices to the DSEF Development Team.

The REV HISTORY worksheet documents the development history of DSEF. Advanced users may choose to view this worksheet to determine comparability of runs with earlier DSEF versions with current runs. 
Figure 4 - The two lists of worksheets in the NAVIGATION worksheet

\begin{tabular}{|l|}
\hline $\begin{array}{c}\text { Worksheets in order } \\
\text { of appearance }\end{array}$ \\
\hline Navigation (this sheet) \\
\hline Readme \\
\hline Inputs \\
\hline Inputs Checklist \\
\hline Case Library \\
\hline Thermal-Interpolate \\
\hline Results \\
\hline Interface Parameters \\
\hline Design Constraints \\
\hline Waste Form \\
\hline Environment \\
\hline Thermal \\
\hline Thermal-Source \\
\hline Thermal-Analytical \\
\hline Thermal-Analytical Output \\
\hline Thermal-FEM \\
\hline Performance Assessment \\
\hline Cost Calculations \\
\hline Cost References \\
\hline Materials \\
\hline Material Data Plotting \\
\hline Materials-Thermal Properties \\
\hline Materials-Transport Properties \\
\hline Materials-Other Properties \\
\hline Materials-References \\
\hline Rev History \\
\hline Lists \\
\hline
\end{tabular}
Hyperlinks to Worksheets in alphabetical order

Case Library

Cost Calculations

Cost References

Design Constraints

Environment

Inputs

Inputs Checklist

Interface Parameters

Lists

Material Data Plotting

Materials

Materials-Other Properties

Materials-References

Materials-Thermal Properties

Materials-Transport Properties

Navigation (this sheet)

Performance Assessment

Readme

Results

Rev History

Thermal

Thermal-Analytical

Thermal-Analytical Output

Thermal-FEM

Thermal-Interpolate

Thermal-Source

Waste Form 


\section{Getting Started - Working with the DSEF Workbook Opening DSEF for the First Time - Enabling the Macros}

DSEF is a Microsoft Excel workbook with macros, and therefore has a file extension of “.xlsm” is used instead of the typical ".xlsx" for a workbook without macros. The macros developed in the built-in Visual Basic for Applications (VBA) programming language allow DSEF to automate a number of process steps coupled with the use of Form controls (such as command buttons and drop-down lists).

The first time that you open the DSEF workbook, you may get a prompt at the top of the workbook (below the Ribbon) notifying you that macros have been disabled for your protection and asking you if you want to enable macros. In order for the Form controls to work, you must enable macros. If you do not see this prompt, and the drop-down lists and other controls do not respond, you must change some settings in Excel. A detailed step-by-step procedure is outlined in Appendix A, complete with screen shots that point out exactly which options to select.

\section{The Color Coding Conventions for Types of Cells and Information in DSEF}

The DSEF file includes a significant amount of error checking and messages, and uses color codes for hyperlinks, errors, and inputs. Color coding conventions to help you recognize where input is needed, and where input is being used from other worksheets are the following:

- Yellow highlighted cells: Input cells or controls that help you select or input data

- White highlighted cells: Normal cells that contain data or formulas

- Cells with a gray background and blue lettering contain hyperlinks to other worksheets

- Light gray highlighting of cells with black text is used to distinguish different subsets of analysis cases for some of the CASE CATALOGs and some of the cases in the CASE LIBRARY. It is also used to distinguish the five cost case example data sets available on the INPUTS worksheet

- Light blue highlighted cells: Cells that retrieve data from other worksheets

- Cross-check / Caution cells:

o White background with black text - Cross-check cells that provide confirmation of valid input

o Light red background with red text - Cross-check cells that caution the user of a potential inconsistency when the cross-check confirmation fails

- Green arrows and text: Point to cells that have special range names used in formulas elsewhere

\section{Working with the Form Controls}

There are several kinds of Form controls used in DSEF, and for the most part, their use is straightforward (such as command buttons and check boxes). Figure 5 and Figure 6 show two examples. 
The Form controls can serve three purposes

- They allow you to select from a pre-defined set of options, or allow you to enter a "user defined" option

- They can automatically run a macro program based on the selection you made. For example the control shown in Figure 5 runs a macro that copies the decay heat data for the selected waste form from a library of decay heat data on the THERMAL-SOURCE worksheet to the named range that defines the decay heat that will be used in the current analysis.

- They can limit the range of values you can use. For example the spinner control shown in Figure 6 only allows values between 5 years and 300 years of surface storage.

Figure 5 - A drop-down list to select the waste form

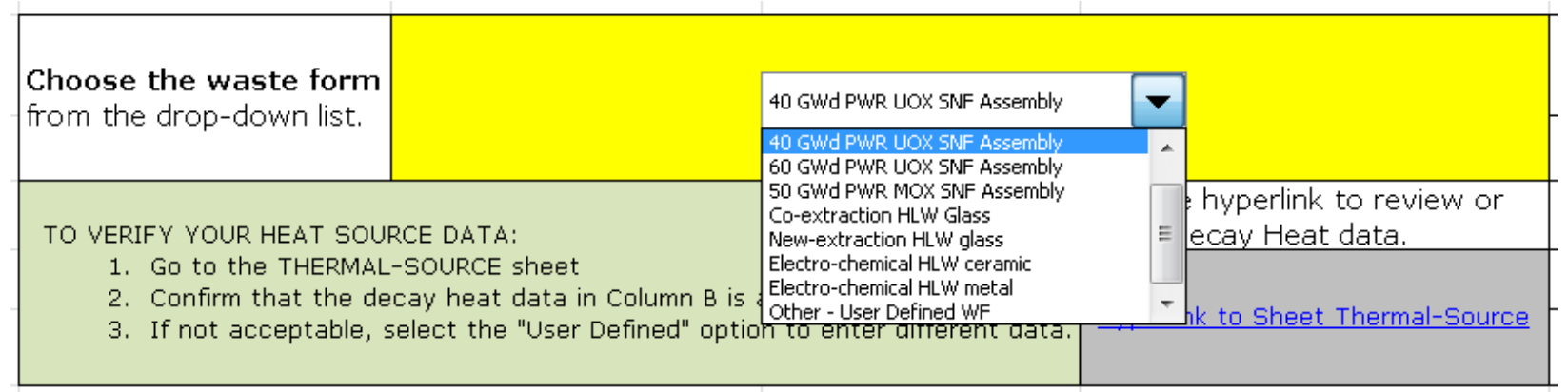

Figure 6-A spinner control to select the number of assemblies in a waste package

\begin{tabular}{|l|l|l|l|}
\hline $\begin{array}{l}\text { For the situation of complete assemblies or standard } \\
\text { canisters, select the number of SNF Assemblies or } \\
\text { HLW canisters. }\end{array}$ & Assembly waste package \\
\hline
\end{tabular}

In a number of cases, the data entry sections of the DSEF worksheet will look different depending on the selections you make using these controls. This is done by using conditional formatting to hide unused data entry cells and to display others, and by running macros that can hide some of the other controls.

\section{Naming and Saving Files}

DSEF is a template and is provided as a read-only, macro-enabled (xlsm), Excel spreadsheet. You must use the SAVE-AS menu command to save a DSEF workbook with your own data in it. The INPUTS worksheet helps you construct a file name with a standard set of information that will be common to all users and has a macro button to save the file (to the current directory) using the file name DSEF itself constructs. It is highly recommended you use this capability, rather than manually using the SAVE-AS Excel command. The name will include the DSEF version, date, your initials, and some information about waste form and medium from other selections you make on the INPUTS worksheet. The name will also include text that you specify after picking from the initial menus, and also a case number if you do multiple runs based on a similar configuration. 


\section{Suggested file name $=$}

\section{DSEF [Version]-[date]-[user's initials]-[waste form \& geologic medium]-[a 4 to 30 character case}

description]-[case number of up to 6 alpha numeric characters].xlsm

After new design cases have been analyzed using DSEF and an external thermal analyzer like Mathcad, the DSEF file will include the results of your analysis on the RESULTS and THERMAL-ANALYTICAL OUTPUT worksheets, and will have a new data record for the analyzed design case on the CASE LIBRARY worksheet (just below the Case Catalog and the list of references).

As described in Section 11 of the User Manual, you can use a macro button on the THERMALANALYTICAL OUTPUT worksheet to format the results written by Mathcad, and after doing that, you need to manually save this file using the FILE SAVE command in Excel. A copy of the completed DSEF file should be sent to LLNL to allow consolidation and augmenting of the master Case Library, thereby allowing updating and sharing of the new information between laboratories via the SNL SharePoint website. 


\section{The Starting Point to Define an Analysis Case - the INPUTS Worksheet}

The central data entry worksheet in DSEF is the INPUTS worksheet. This worksheet builds the analysis case in steps (which are numbered and shown on the left edge). The user can proceed linearly through the worksheet, from top to bottom following the instructions on the worksheet, and completely define the analysis case. DSEF also provides two types of assistance in addition to the linear process:

- Hyperlinks to other worksheets are provided to allow the user to inspect libraries of properties (see Section 12). Some of these worksheets include tools to organize and/or visualize information being considered. The user can then return to the INPUTS worksheet (via another hyperlink, or by manual navigation) and input the parameter.

- Numbered cases in the CASE LIBRARY (see Section 7). The user can select a prior case number in several places on the INPUTS worksheet, resulting in pre-population of some input cells. The user can then overwrite parameters that are different than the "reference" case being used for that set of parameters in the INPUTS worksheet. The user can also use a hyperlink to jump to the THERMAL INTERPOLATE worksheet, which has tools to organize and visualize selected parameters for a selected set of cases (see Figure 22 - Side-by-side case comparison table).

For experienced users, the cells in the linear process that require decisions or inputs are colored, allowing fast input without reading all the instructions for each use of DSEF.

\section{Automatic Entry of Inputs}

The power of DSEF can be used to automatically fill in many of the inputs by simply selecting a CASE LIBRARY case number. Different reference cases can be used for the natural and engineered barrier properties and configurations. Ideally, users can select a common reference case number to set the starting inputs for both NBS and EBS (DSEF won't stop you from using different cases, but it will alert you if you have). An example is shown in Figure 7.

Figure 7 - An example of some of the cross-checks and cautions displayed in the INPUTS worksheet

\begin{tabular}{l} 
Designation of Case from Sheet "Case Library" for Initial EBS parameter data values \\
\hline \multicolumn{3}{|c|}{ Table1: Summary of EBS Component Selection Using CASE: }
\end{tabular}

DSEF has several different constructs to use existing data. Some situations provide drop-down lists of data selections, and others have single data entry value displays and over-ride options. An example of the second approach is shown in Figure 8, in which the yellow override cells change the reference-case- 
populated values to the left. The resulting set of values (some from the pre-population and others from the overrides) are shown to the right of the yellow cells.

Figure 8 - An example of one of the ways DSEF lets you use data from the case library, or override the data with user input

\begin{tabular}{|c|c|c|c|c|c|c|c|}
\hline $\begin{array}{c}\text { Default } \\
\text { EBS Component } \\
\text { Names } \\
\end{array}$ & $\begin{array}{c}\text { User Input Names } \\
\text { for EBS Components }\end{array}$ & $\begin{array}{l}\text { EBS Component } \\
\text { Names } \\
\end{array}$ & \begin{tabular}{|c|} 
Component Radial \\
Thickness, m \\
for Case 229
\end{tabular} & $\begin{array}{c}\text { User Input } \\
\text { Component Radial } \\
\text { Thickness } \\
\end{array}$ & Component Radial Thickness & $\begin{array}{c}\text { Inner Radius } \\
\mathbf{m}\end{array}$ & $\begin{array}{c}\begin{array}{c}\text { Outer Radius } \\
\mathrm{m}\end{array} \\
\end{array}$ \\
\hline Waste Form & & Waste Form & 0.89 & & 0.89 & N/A & 0.89 \\
\hline Canister & & Canister & 0 & & 0 & 0.89 & 0.89 \\
\hline Waste Package & & Waste Package & 0.11 & & 0.11 & 0.89 & 1 \\
\hline Buffer & & Buffer & 0 & 0.1 & 0.1 & 1 & 1.1 \\
\hline Envelope & Buffer Layer 2 & Buffer Layer 2 & 0 & 0.2 & 0.2 & 1.1 & 1.3 \\
\hline Backfill & & Backfill & 1.225 & 0.925 & 0.925 & 1.3 & 2.225 \\
\hline Liner & & Liner & 0.025 & & 0.025 & 2.225 & 2.25 \\
\hline & & & & & Host Rock Inner Radius, $m$...-> & 2.25 & \\
\hline
\end{tabular}

\section{Steps in the INPUTS Worksheet Process}

The INPUTS worksheet is designed to guide the user in developing an analysis case in a structured manner. To assist new or infrequent users, instructions are provided near the entry fields. Color conventions are used to enable frequent users to move through the steps quickly, skipping those instructional fields. For all users, DSEF checks many of the inputs for consistency and provides feedback in cells labeled "Cross-Check".

The user should follow these steps sequentially in the DSEF INPUTS worksheet:

- $\quad$ Step 1 provides the user with the DSEF version number. No action is required, but the user should be aware that DSEF evolution from version to version could compromise comparability of results with earlier runs. The REV HISTORY worksheet documents the changes.

- Step 2 builds the case name and includes a macro for the initial saving of the file using the case name. The user inputs the date, their initials, some descriptive text, and a case number. Because the case name includes the geologic medium and the waste form, the user also selects (from pulldown lists) those parameters in Step 2. Step 2 also includes a macro button that allows the user to "Clear Previous Thermal Output Results" if the same Excel file is being used as a starting point to prepare multiple analysis cases.

- Step 3 selects the waste package capacity, in terms of the number of spent nuclear fuel assemblies or high-level waste canisters. A spinner control enables selection of integer numbers. A check box enables input of a non-integer number (for the situations of rod consolidation or non-standard canister sizes).

- Step 4 selects the storage time, which is the time between removal from the reactor flux to the emplacement in the repository.

- Step 5 selects the repository depth. Three inputs are required: depth, surface temperature, and geothermal gradient. DSEF uses these three inputs to calculate the initial temperature at the 
repository horizon (which is the initial temperature of the infinite medium in the THERMALANALYTICAL worksheet approach). DSEF also uses the depth in the COST CALCULATIONS worksheet.

- Step 6 develops the repository layout. The THERMAL-ANALYTICAL worksheet uses a twodimensional model that calculates thermal response from a central waste package, its axial neighbors, and its lateral neighbors. Thus, axial spacing and lateral spacing are the two inputs. Spacing values are center-to-center. The THERMAL-ANALYTICAL worksheet approach calculates the temperature near a central waste package with four axial (point source) neighbors on each end, and four line-source lateral neighbors on each side. For in-drift emplacement, axial spacing is between waste packages, and lateral spacing is between drifts. For horizontal borehole emplacement, axial spacing is between waste packages, and lateral spacing is between boreholes. For vertical boreholes with one waste package per borehole, the two-dimensional approximation turns each WP to be horizontal, with the axis aligned with the axis of the turned WPs in each neighboring borehole; thus, the axial spacing is the borehole spacing, and the lateral spacing is the drift spacing (the boreholes are drilled in the drift floor). For deep borehole emplacement, the axial spacing is between waste packages, and the lateral spacing is between boreholes (this only calculates one plane of the repository, but lateral spacing is wide enough that the adjacent planes can be ignored).

- $\quad$ Step 7 specifies the natural system material name and properties (thermal conductivity and thermal diffusivity). The user is invited to enter a case number for display of values from that reference case, directly to the left of the yellow input cells. The user may override any or all of these values in the input cells. Directly to the right of the input cells are the values DSEF will use (which are the displayed reference case values if no values are directly input). Hyperlinks to the CASE LIBRARY and the MATERIALS worksheets are provided to enable the user to view available cases and material properties, prior to making their input choices.

- $\quad$ Step 8 specifies the EBS material names, radial thicknesses, thermal conductivities, and thermal diffusivities. EBS layers include the waste form, canister, waste package, buffer, envelope, backfill, and liner. The drift or borehole radius is the outer radius of the liner. The inner three layers are provided for dimensional purposes only; the THERMAL-ANALYTICAL worksheet treats everything inside of the waste package outer radius to be a thermal source with a thermal flux imposed at that location. The outer four layers can be renamed to accommodate a variety of designs. If a layer thickness is zero, it is as if that layer does not exist in the THERMALANALYTICAL worksheet approach. As in Step 7, the user is invited to enter a case number for display of values from that reference case, which may be a different reference case than used in the Step 7. Table 8.B in DSEF, part of which is shown in Figure 8, allows the user to keep the reference case values or override them with user input (where the yellow cells are provided for user input). Table 8.C. displays a summary of the data that will be used, and that is passed to the THERMAL-ANALYTICAL worksheet, which is the interface with the Mathcad component of DSEF. Hyperlinks to the CASE LIBRARY worksheet and the MATERIALS worksheet are provided to enable the user to view prior runs and the assembled set of reference properties, prior to making their input choices. Finally, in Table 8.D, the user specifies a second in-rock 
compliance point. The Mathcad component of DSEF will calculate temperature history (and the value and time of peak temperature) at this location in addition to the outer radius of the waste package, all of the EBS component interfaces, and the drift/borehole radius. The Mathcad component returns the results of the transient temperature calculations to the THERMALANALYTICAL OUTPUT worksheet.

- Step 9 specifies the parameters required to calculate the thermal behavior of an "open mode" repository design concept that includes pre-closure ventilation. These parameters include the ventilation duration and the subsequent unventilated duration during which backfill is emplaced, the ventilation efficiency, the rock wall emissivity, and the waste package emissivity. As in the preceding steps, the user is provided with the reference values from the EBS reference case (from Step 8), and can make their own direct inputs or overrides. The resulting values are shown to the right of the yellow input cells. The step ends with a hyperlink to the THERMAL worksheet which manages the calculation and documentation of the thermal performance. The user should return to this point in the INPUTS worksheet afterward, to address the COST calculation, should it be desired.

- Step 10 specifies the input parameters necessary to generate an approximate cost for the design choices made above. For costing, the entire repository must be specified, rather than the central waste package and neighbors specified above for the thermal performance calculations. Figure 9 shows an example of the repository-level cost input data, where the user enters the repository capacity (MTU) and annual receipt rate (MTU/yr) as well as other variables. The user can also choose one of five example cost calculation cases from the Carter/Hardin model for comparison purposes (see Section 9 on the COST worksheets). Figure 10 shows an example of user data entry for high and low range contingency percentages.

- Step 11 allows the user to input and output constraint data. The user supplies a constraint value for minimum lateral spacing of drifts for drift structural stability that is used to cross-check the repository design concept input data. The other constraint inputs are all related to temperature criteria for maximum waste package surface temperature, and maximum EBS and NBS material thermal constraints. The calculated results are checked against these constraint values, and the RESULTS worksheet displays a color-coded set of temperature compliance results as well as displaying quantitative margins (see Figure 11).

- Step 12 allows the user to document and check the single analysis reference case that was defined in steps 1 to 11 . Step 12 sends the user to the INPUTS CHECKLIST worksheet, which allows the user to track the status of the input data entry, and provides a place to document decisions and data-selection choices, identify references used, and add notes with respect to the data entries. To perform a "one-off" parameter sensitivity study, proceed to Step 13.

- Step 13 allows the user to either select a "single" calculation mode that uses all of the input data for the reference case defined in Steps 1 through 12, or to select a "parametric" study calculation mode. Figure 12 shows the options available for parametric studies, where the basic inputs have been set, but the user can then define up to 10 data values for one of six possible parameters - 
waste package spacing, drift spacing, storage time, ventilation duration, rock thermal conductivity, and backfill thermal conductivity. Caution should be taken because the single value already input will be overwritten for the thermal, but not in the cost calculation. Therefore, the user is encouraged to choose to make one of the parametric values match the "single" value input defined in Steps 1 through12 for easier comparison with the other parametric input results.

- Step 14 sends the user to the RESULTS worksheet, which displays the inputs and results in a reviewable and printable format. 
Figure 9 - Example of repository level cost input data with Carter/Hardin example case data

\begin{tabular}{|c|c|c|c|c|c|}
\hline \multicolumn{2}{|c|}{ 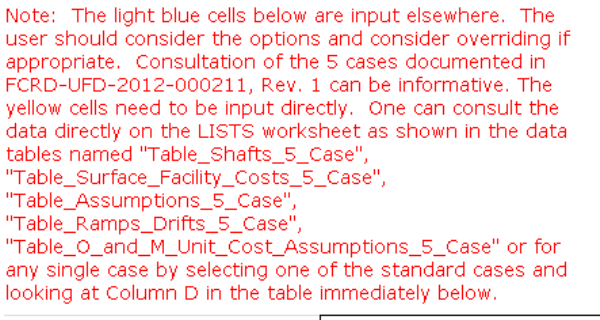 } & $\begin{array}{l}\text { FCRD-UFD-2012- } \\
\text { 000211, Rev } 1 \\
\text { Case description }\end{array}$ & $\begin{array}{l}\text { The cell one row down and one } \\
\text { column to the left is where one } \\
\text { selects "User Defined" or one } \\
\text { of the Carter cases - simply } \\
\text { click on it to show the menu }\end{array}$ & & \\
\hline Repository operations related inputs & $\begin{array}{c}\text { Thermal Calculation Related } \\
\text { Inputs }\end{array}$ & $\begin{array}{l}\text { ROM Cost Case } 4 \text { - } \\
\text { Clay/Shale (open) }\end{array}$ & User Defined Over-ride Inputs & & \\
\hline MTU per Repository & 140,000 & \multirow{4}{*}{\multicolumn{2}{|c|}{$\begin{array}{l}\text { Select Cost Case or User Defined } \\
\text { Select one of the } 5 \text { repository } \\
\text { concept cost cases defined in FCRD- } \\
\text { 3. UFD-2012-000211, Rev } 1 \text { [Generic } \\
\text { Repository ROM Cost Study; Joe T. } \\
\text { Carter, Phillip O. Rodwell, and Mark } \\
2 \text { Dupont (SRNL), Sept. 5, 2012], or } \\
\text { 25 select "User Defined" to input your } \\
\text { own data. }\end{array}$}} & 140000 & $<-$ Repository_MTU \\
\hline $\begin{array}{l}\text { Repositiory Annual Waste } \\
\text { Throughnut (MTLYyr] }\end{array}$ & 3.000 & & & 3000 & $<--$ Repository_MTU_per_year \\
\hline Waste Package Capacity & 21 & & & 21 & <-- WP_capacity_for_cost \\
\hline Ventilation Duration (yr) & 250 & & & 250 & <-- Ventilation_Duration \\
\hline 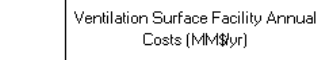 & & 1 & & 1 & <--Vent_Surface_Facility_Annual_Cost \\
\hline $\begin{array}{l}\text { Ventilation Dperations Unit Cost per } \\
\text { Emplacement Drift Length (\$\$rm-yr) }\end{array}$ & & 50 & & 50 & <-- Vent_Operations_per_Drift_Length_Unit_cost \\
\hline Closure Duration [yr] & 10 & 10 & & 10 & |<--Closure_Duration \\
\hline $\begin{array}{l}\text { Closure Facility Annual Cost } \\
\text { [MMSHyr] }\end{array}$ & & 10 & & 10 & <--Closure_Surface_Facility_Annual_cost \\
\hline
\end{tabular}


Figure 10 - Example of cost contingency input data

\begin{tabular}{|c|c|c|c|c|c|}
\hline $\begin{array}{l}\text { For User-Defined Cases, the DSEF te } \\
\text { consult the contingencies for the } 5 \text { Ca } \\
\text { "Table_Contingencies_Carter_5_Cas } \\
\text { selecting one of the standard cases ar } \\
\text { table immediately below. Those value } \\
\text { Column C immediately below. }\end{array}$ & $\begin{array}{l}\text { commends the User } \\
\text { ases. These can be seen in } \\
\text { for any single case by } \\
\text { oking at Column D in the } \\
\text { be "pasted-special" in }\end{array}$ & Case Related Description & & & \\
\hline Contingency Factors & User Defined Inputs & $\begin{array}{c}\text { Rom Cost Case } 4 \text { - Clayl'Shale } \\
\text { (open] }\end{array}$ & User Defined Over-ride Inputs & & \\
\hline $\begin{array}{c}\text { Facility Design \& Startup - } \\
\text { Low }\end{array}$ & $5 \%$ & $5 \%$ & & $5 \%$ & <--Contingenoy__Facility__Design_and_Startup_Low \\
\hline $\begin{array}{c}\text { Facility Design \& Startup - } \\
\text { High }\end{array}$ & $53 \%$ & 53: & & $53 \%$ & <- Contingenoy__Facility__Design_and_Startup_High \\
\hline $\begin{array}{l}\text { Surface Facility Construction } \\
\text { Low }\end{array}$ & $5 \%$ & $5 \%$ & & $5 \%$ & L-Contingency__Surface_Facility_Construction_Low \\
\hline $\begin{array}{l}\text { Surface Facility Construction } \\
\text { Hight }\end{array}$ & $53 \%$ & 53: & & $53 \%$ & \&- Contingency_Surface_Facility_Construction_High \\
\hline $\begin{array}{l}\text { Subsurface Facility } \\
\text { Construction - Low }\end{array}$ & $5 \%$ & $5 \%$ & & $5 \%$ & <--Contingenoy__Subsurface_Facility_Construction_Low \\
\hline \begin{tabular}{c|} 
Subsurface Facility \\
Construction - High \\
\end{tabular} & $53 \%$ & 53\% & & $53 \%$ & <- Contingency_Subsurface_Facility_Construction_High \\
\hline $\begin{array}{c}\text { Ventilation Construction \& } \\
\text { Startup - Low }\end{array}$ & $5 \%$ & $5 \%$ & & $5 \%$ & <--Contingency_Yentilation_Construction_and_Startup_Low \\
\hline $\begin{array}{c}\text { Ventilation Construction \& } \\
\text { Startup }- \text { High }\end{array}$ & $53 \%$ & $53 \%$ & & $53 \%$ & <--Contingency_Ventilation_Construction_and_Startup_High \\
\hline $\begin{array}{l}\text { Operations \& Maintenance - } \\
\text { Low }\end{array}$ & $5 \%$ & $5 \%$ & & $5 \%$ & L--Contingency__Operations_and_Maintenance_Low \\
\hline $\begin{array}{c}\text { Operations \& Maintenance - } \\
\text { High }\end{array}$ & 34\% & 34: & & $34 \%$ & <- Contingency_Operations_and_Maintenance_High \\
\hline Closure Costs - Low & $10 \%$ & $10 \%$ & & $10 \%$ & L-Contingency_Closure_Costs_Low \\
\hline Closure Costs - High & $50 \%$ & $70 \%$ & & $70 \%$ & \&- Contingenoy_Closure_Costs_High \\
\hline Waste Packages - Low & $5 \%$ & $5 \%$ & & $5 \%$ & <--Contingency_Waste_Packages_Low \\
\hline Waste Packages - High & $30 \%$ & $30 \%$ & & $30 \%$ & <--Contingenoy_Waste_Packages_High \\
\hline Regulatory \& Licensing - Low & $5 \%$ & $5 \%$ & & $5 \%$ & <-- Contingency__Regulatory_and_Licensing_Low \\
\hline Regulatory \& Licensing - High & $9 \%$ & $9 \%$ & & $9 \%$ & L--Contingenoy_Riegulatory_and_Licensing_High \\
\hline Monitoring - Low & $10 \%$ & $10 \%$ & & $10 \%$ & <--Contingency__Monitoring_Low \\
\hline Monitoring - High & 50\% & $50 \%$ & & $50 \%$ & <- Contingenoy_Monitoring_High \\
\hline $\begin{array}{c}\text { Performance Confirmation - } \\
\text { Low }\end{array}$ & $5 \%$ & $5 \%$ & & $5 \%$ & <--Contingency__Performance_Confirmation_Low \\
\hline \begin{tabular}{|c|}
$\begin{array}{c}\text { Performance Confirmation - } \\
\text { High }\end{array}$ \\
\end{tabular} & 43\% & 43\% & & $43 \%$ & <--Contingenoy_Performance_Confirmation_High \\
\hline Program Integration - Low & $10 \%$ & $10 \%$ & & $10 \%$ & L--Contingency__Program_Integration_Low \\
\hline Program Integration - High & $50 \%$ & $50 \%$ & & $50 \%$ & _--Contingency__Program_Integration_High \\
\hline
\end{tabular}


Figure 11 - Example of comparison of thermal results against thermal constraints from the RESULTS worksheet

\begin{tabular}{|c|c|c|c|c|c|c|c|}
\hline \multicolumn{8}{|c|}{ Number of parametric sensitivity study cases $=3$} \\
\hline \multicolumn{2}{|c|}{ Summary of Peak Temperatures and Times } & \multicolumn{2}{|c|}{ Ventilation Duration 200, yr } & \multicolumn{2}{|c|}{ Ventilation Duration $250, \mathrm{yr}$} & \multicolumn{2}{|c|}{ Ventilation Duration 300, yr } \\
\hline Location & $\begin{array}{c}\text { Radius, } \\
\mathrm{m}\end{array}$ & Peak Temp, c & $\begin{array}{c}\text { TooR, } \\
\text { yr }\end{array}$ & Peak Temp, c & $\begin{array}{c}\text { TooR, } \\
y r\end{array}$ & Peak Temp, C & $\begin{array}{c}\text { TooR, } \\
y r\end{array}$ \\
\hline Second Compliance Point & 5.25 & 183.58 & 600.00 & 175.39 & 680.00 & 167.86 & 705.00 \\
\hline Peak Rock & 2.25 & 200.19 & 525.00 & 190.62 & 600.00 & 182.25 & 665.00 \\
\hline Liner inner surface & 2.23 & 200.20 & 525.00 & 190.63 & 600.00 & 182.26 & 665.00 \\
\hline Backfill inner surface & 1.00 & 237.70 & 455.00 & 225.19 & 515.00 & 214.34 & 580.00 \\
\hline Envelope inner surface & 1.00 & 237.70 & 455.00 & 225.19 & 515.00 & 214.34 & 580.00 \\
\hline WP surface & 1.00 & 237.70 & 455.00 & 225.19 & 515.00 & 214.34 & 580.00 \\
\hline \multicolumn{8}{|c|}{ Comparison against Thermal Constraints } \\
\hline Location / medium & Thermal Constraint, ${ }^{\circ} \mathrm{C}$ & $\begin{array}{c}\text { Margin } \\
\text { (Constraint - } \\
\text { Peak Temp) }\end{array}$ & & $\begin{array}{c}\text { Margin } \\
\text { (Constraint - Peak } \\
\text { Temp) }\end{array}$ & & $\begin{array}{c}\text { Margin } \\
\text { (Constraint - } \\
\text { Peak Temp) }\end{array}$ & \\
\hline Host rock / Clay & 100 & -100.2 & & -90.6 & & -82.3 & \\
\hline Liner & None & N/A & & $\mathrm{N} / \mathrm{A}$ & & $\mathrm{N} / \mathrm{A}$ & \\
\hline Backfill & 120 & -117.7 & & -105.2 & & -94.3 & \\
\hline Envelope & None & N/A & & $\mathrm{N} / \mathrm{A}$ & & N/A & \\
\hline Buffer & None & N/A & & $\mathrm{N} / \mathrm{A}$ & & N/A & \\
\hline WP surface & 300 & 62.3 & & 74.8 & & 85.7 & \\
\hline
\end{tabular}


Figure 12 - Example of parametric study input data from Step 13 on the INPUTS worksheet

\begin{tabular}{|c|c|c|c|c|c|}
\hline \multicolumn{2}{|c|}{ Single or parametric calculation } & {$\left[\begin{array}{cc}\text { Select Mode } & \\
\text { O Single } & \text { Parametric Options } \\
& \text { O WP Spacing } \\
\text { O Dritt Spacing } \\
\text { O Storage Time } \\
\text { O Ventilation Duration } \\
\text { ORock Conduntivity } \\
\text { O Backfill Conductivity }\end{array}\right.$} & $\begin{array}{c}\text { Base value of Ventilation } \\
\text { Duration }=250\end{array}$ & Ventilation Duration & <-- Calculation_mode \\
\hline \multirow{11}{*}{$\begin{array}{c}\text { Fill in up to } 10 \\
\text { values, starting at } \\
\text { the top (with no } \\
\text { blank rows in the } \\
\text { middle) }\end{array}$} & Value 1 & 200 & & \multicolumn{2}{|l|}{$<--$ Cells reserved for user defined data } \\
\hline & Value 2 & 250 & & \multicolumn{2}{|l|}{$<---$ Cells reserved for user defined data } \\
\hline & Value 3 & 300 & & \multicolumn{2}{|l|}{$<--$ Cells reserved for user defined data } \\
\hline & Value 4 & & & \multicolumn{2}{|l|}{$<---$ Cells reserved for user defined data } \\
\hline & Value 5 & & & \multicolumn{2}{|l|}{$<---$ Cells reserved for user defined data } \\
\hline & Value 6 & & & \multicolumn{2}{|l|}{$<---$ Cells reserved for user defined data } \\
\hline & Value 7 & & & \multicolumn{2}{|l|}{$<---$ Cells reserved for user defined data } \\
\hline & Value 8 & & & \multicolumn{2}{|l|}{$<--$ Cells reserved for user defined data } \\
\hline & Value 9 & & & \multicolumn{2}{|l|}{$<---$ Cells reserved for user defined data } \\
\hline & Value 10 & & & \multicolumn{2}{|l|}{$<--$ Cells reserved for user defined data } \\
\hline & Number of Values Entered & 3 & $\mid \begin{array}{l}<-- \\
\text { Parametric_data_count }\end{array}$ & \multicolumn{2}{|l|}{$<---$ Cells reserved for user defined data } \\
\hline Minimum & Maximum & Average & Single Case Value & Variable Units & \\
\hline 200 & 300 & 250 & 250 & $\mathrm{yr}$ & \\
\hline \multicolumn{4}{|c|}{ CROSS-CHECK: Average of the range equals the single case value } & & \\
\hline $\begin{array}{l}\text { The single case value is } \\
\text { calculations. }\end{array}$ & $\mathrm{n}$ the cost estimate, and $\mathrm{t}$ & e parametric values are & $\mathrm{n}$ the thermal & & \\
\hline
\end{tabular}




\section{The INPUTS CHECKLIST Worksheet}

The INPUTS CHECKLIST worksheet provides a checklist to follow the user's progress in developing an analysis case, and provides documentation for the combination of built-in options chosen versus new user-defined inputs. It also provides a convenient location to document the references and to make explanatory notes to supplement the DSEF data options chosen. Figure 13 shows an example of the checklist style documentation structure of the INPUTS CHECKLIST worksheet. The INPUTS CHECKLIST worksheet also includes a section at the bottom that echoes all of the cross-check and caution warnings that are utilized on the INPUTS worksheet.

If sufficient display monitor space is available, the user can open both the INPUTS and INPUTS CHECKLIST worksheets side-by-side. As decisions are made on the INPUTS worksheet, the cells in the INPUTS CHECKLIST worksheet are automatically populated. The two columns to the right are places the user can document references used and to place notes on the thought process or rationale for the decisions made. The INPUTS CHECKLIST worksheet is narrow enough to be printed for hard-copy retention of case definition.

Figure 13 - Example from a section of the inputs checklist

\begin{tabular}{|c|c|c|c|c|c|}
\hline Category of input & Subcategory & Subcategory & Data from the INPUTS sheet & $\begin{array}{l}\text { References for User defined } \\
\text { inputs }\end{array}$ & Notes \\
\hline \multirow{5}{*}{\multicolumn{2}{|c|}{ Natural Barriers System - Geologic media }} & Media type & Clay & & \\
\hline & & Thermal conductivity & 1.75 & & \\
\hline & & Thermal diffusivity & $6.45 E-07$ & & \\
\hline & & Transport properties & & & \\
\hline & & Constraint temp, ${ }^{\circ} \mathrm{C}$ & 100 & & \\
\hline \multirow{5}{*}{\multicolumn{2}{|c|}{ Waste form properties }} & Mechanical properties & & & \\
\hline & & SNF type & $\begin{array}{c}40 \text { GWdPWR UDX SNF } \\
\text { Assembly }\end{array}$ & & \\
\hline & & SNF burnup & See SNF type & & \\
\hline & & Number of assemblies & 32 & & \\
\hline & & Waste package description & Assembly waste package & & \\
\hline \multirow{6}{*}{\multicolumn{2}{|c|}{ Waste form ' waste package geometry }} & Decay heat source data & & & \\
\hline & & Waste form outer radius, $m$ & 0.89 & & \\
\hline & & Waste package outer radius, m & 1.000 & & \\
\hline & & Waste package length, $\mathrm{m}$ & 5 & & \\
\hline & & Waste package material & Carbon Steel & & \\
\hline & & Waste package wall thickness & 0.11 & & \\
\hline \multirow{22}{*}{$\begin{array}{l}\text { Engineered Barriers } \\
\text { System - Layer data }\end{array}$} & \multirow{6}{*}{$\begin{array}{l}\text { EBS layer } 4 \text { - closest to } \\
\text { waste package }\end{array}$} & Layer descriptive name & Buffer & & \\
\hline & & Layer material & None & & \\
\hline & & Layer thermal kth & NA & & \\
\hline & & Layer thickness, $m$ & 0 & & \\
\hline & & Layer outer radius, $m$ & 1 & & \\
\hline & & Constraint temp, ${ }^{\circ} \mathrm{C}$ & None & & \\
\hline & \multirow{6}{*}{ EBS layer 3 - inner mid-layer } & Layer descriptive name & Envelope & & \\
\hline & & Layer material & None & & \\
\hline & & Layer thermal kth & NA & & \\
\hline & & Layer thickness, $m$ & 0 & & \\
\hline & & Layer outer radius, $m$ & 1 & & \\
\hline & & Constraint temp, ${ }^{\circ} \mathrm{C}$ & None & & \\
\hline & \multirow{6}{*}{ EBS layer 2 - inner mid-layer } & Layer descriptive name & Backfill & & \\
\hline & & Layer material & $70 \%$ Bentonite $30 \%$ Sand & & \\
\hline & & Layer thermal kth & 1.2 & & \\
\hline & & Layer thickness, $\mathrm{m}$ & 1.225 & & \\
\hline & & Layer outer radius, $m$ & 2.225 & & \\
\hline & & Constraint temp, ${ }^{\circ} \mathrm{C}$ & 120 & & \\
\hline & \multirow{4}{*}{$\begin{array}{c}\text { EBS layer } 1 \text { - closest to host } \\
\text { rock }\end{array}$} & Layer descriptive name & Liner & & \\
\hline & & Layer material & Steel & & \\
\hline & & Layer thermal kth & 46 & & \\
\hline & & Layer thickness, $\mathrm{m}$ & 0.025 & & \\
\hline
\end{tabular}




\section{Reviewing Previous Analyses - the CASE LIBRARY and the THERMAL-INTERPOLATE Worksheets}

DSEF provides user-friendly ways to rapidly access and compare a large number of completed thermal analysis cases through the combination of the CASE LIBRARY and the THERMAL-INTERPOLATE worksheets. The CASE LIBRARY is a flat-file database contained in a named range called the Interp_Data_Table. THERMAL INTERPOLATE directly predicts new results by using linear interpolation to get a first-order prediction of the effects of potential changes in a selected set of independent variables.

The database table currently has 721 records (rows) with 56 fields (columns) of data. Figure 14 shows the data fields. DSEF Version 2.1 included 300 analysis cases in the database. DSEF Version 3.0 added cases 301 to 401 from Greenberg 2013a, and cases 402 to 721 from Greenberg 2013b.

The CASE LIBRARY also includes an easy-to-use CASE CATALOG that categorizes the cases in the library and allows the user to quickly jump to a relevant record. Figure 15 through Figure 21 show the CASE CATALOG tables for enclosed mode cases, open mode cases, open mode sensitivity cases, required ventilation calculations, and dual-purpose canister calculations respectively. Each table includes a macro button to jump to the selected case in the CASE LIBRARY.

The "enclosed" mode referred to for Figure 15 means that the space between the waste package and drift or borehole wall is filled with engineered barrier components such as a buffer or backfill. In Figure 15, "Salt 200" is an abbreviation for cases with the thermal properties of salt within the EBS region being evaluated at $200^{\circ} \mathrm{C}$, as opposed to the properties in the host rock which were evaluated at $100^{\circ} \mathrm{C}$. For "Salt 100 " cases, all properties were evaluated at $100^{\circ} \mathrm{C}$.

Follow these steps to use the Case Catalog tables to examine specific case records in the library:

- Examine the Case Catalog tables to select a case of interest

- Click on the catalog case number of interest

- Click on the "Jump to Selected Case" macro button. This utilizes the Excel "freeze panes" feature to place the data field names at the top of the screen, with the first record being the selected case.

- Just above the field names (after the jump), there is another macro button that says "Click Here to Go Back to the Case Library". Clicking on that macro button will put you back at the particular case catalog table you were looking at when you selected the case to review.

- Also above the field names, there is a counter for the "Number of Filtered Rows". When looking at the Case Library the user can click on the Excel menu choice DATA - FILTER to set the autofilter mode on. In this mode, the Case Library data can be filtered to identify specific sets of cases that meet the filter criteria. The number of filtered cases is displayed in the cell with the counter. Note that the DATA - FILTER operation will not work while the normal DSEF worksheet protection is enabled. A password must be used to first "unprotect" the worksheet before filtering. Contact LLNL if you need the password. 
Figure 14 - The data fields used in the CASE LIBRARY

\begin{tabular}{|c|c|}
\hline \multicolumn{2}{|r|}{ Columns in Interp_Data_Table } \\
\hline 1 & Case Number \\
\hline 2 & Case Description \\
\hline 3 & Design Mode \\
\hline 4 & Date of Calc \\
\hline 5 & Reference Document \\
\hline 6 & Author / Org \\
\hline 7 & Geologic Medium \\
\hline 8 & Waste Form \\
\hline 9 & WP Capacity (\# SNFAs or Canisters) \\
\hline 10 & WP Length, m \\
\hline 11 & EBS Components \\
\hline 12 & Waste Form Outer/ Canister Inner Radius, m \\
\hline 13 & Canister Wall Thickness m \\
\hline 14 & WP Wall Thickness m \\
\hline 15 & Buffer Thickness m \\
\hline 16 & Envelope Thickness m \\
\hline 17 & Backfill Thickness m \\
\hline 18 & Liner Thickness m \\
\hline 19 & Calculated Rock Wall Radius, m \\
\hline 20 & Canister Wall Material \\
\hline 21 & WP Wall Material \\
\hline 22 & Buffer Material \\
\hline 23 & Envelope Material \\
\hline 24 & Backfill Material \\
\hline 25 & Liner Material \\
\hline 26 & Canister Wall kth, W/m-K \\
\hline 27 & WP Wall kth, W/m-K \\
\hline 28 & Buffer kth, W/m-K \\
\hline
\end{tabular}

\begin{tabular}{|c|c|}
\hline \multicolumn{2}{|r|}{ Columns in Interp_Data_Table (continued) } \\
\hline 29 & Envelope Wall kth, W/m-K \\
\hline 30 & Backfill kth, W/m-K \\
\hline 31 & Liner kth, W/m-K \\
\hline 32 & Rock k_th, W/m-K \\
\hline 33 & Rock alpha, m2/s \\
\hline 34 & Time Out of Reactor (Storage Time, yr) \\
\hline 35 & Depth of Repository Horizon, m \\
\hline 36 & Ambient $\mathrm{T},{ }^{\circ} \mathrm{C}$ \\
\hline 37 & Center to Center Axial Spacing, $\mathrm{m}$ \\
\hline 38 & Center to Center Lateral Spacing, $\mathrm{m}$ \\
\hline 39 & Time of Peak T at Rock Wall, yr \\
\hline 40 & Peak Rock Wall T, ${ }^{\circ} \mathrm{C}$ \\
\hline 41 & $\begin{array}{l}\text { \% Contribution to Peak Rock Wall T from } \\
\text { Central WP }\end{array}$ \\
\hline 42 & $\begin{array}{l}\text { \% Contribution to Peak from Axial } \\
\text { Neighbor WPs }\end{array}$ \\
\hline 43 & $\begin{array}{l}\text { \% Contribution to Peak from Lateral } \\
\text { Neighbor WP Lines }\end{array}$ \\
\hline 44 & Time of Peak WP T, yr \\
\hline 45 & Peak WP T, ${ }^{\circ} \mathrm{C}$ \\
\hline 46 & Third T Location \\
\hline 47 & Time of T at Third Location (Note 1) \\
\hline 48 & Third Location $\mathrm{T},{ }^{\circ} \mathrm{C}$ (Note 1 ) \\
\hline 49 & Ventilation thermal efficiency \% \\
\hline 50 & Ventilation Period (yr) \\
\hline 51 & Backfill Duration \\
\hline 52 & Time of Operation \\
\hline 53 & Rock Wall Emissivity \\
\hline 54 & Waste Package Emissivity \\
\hline 55 & Single Case or Parameter Studied \\
\hline 56 & Number of Parameter Values in Study \\
\hline
\end{tabular}


Figure 15 - The enclosed mode analysis case catalog

\begin{tabular}{|c|c|c|c|c|c|c|}
\hline \multicolumn{7}{|c|}{ Case Number Cataloq for Enclosed Mode Analysis Cases } \\
\hline \multicolumn{3}{|c|}{ Disposal Scenarios } & \multicolumn{4}{|c|}{ Click Here to Jump to Selected Case } \\
\hline Geology & Haste Form & \begin{tabular}{|c|} 
Assemblies I \\
HP
\end{tabular} & $\begin{array}{l}10 \text { Year } \\
\text { Storaae }\end{array}$ & $\begin{array}{l}\text { 50 Year } \\
\text { Storage }\end{array}$ & $\begin{array}{c}100 \text { Year } \\
\text { Storage }\end{array}$ & $\begin{array}{c}200 \text { Year } \\
\text { Storage }\end{array}$ \\
\hline \multirow{10}{*}{ Grande } & 4-UDX-60-SNFA & 4 & 1 & 55 & 109 & 163 \\
\hline & 4-UDOX-40-SNFA & 4 & 2 & 56 & 110 & 164 \\
\hline & 1-UDX-60-SNFA & -1 & 3 & 57 & 111 & 165 \\
\hline & 1-UOX-40-SNFA & -1 & 4 & 58 & 112 & 166 \\
\hline & 4-MOX-50-SNFA & 4 & 5 & 59 & 113 & 167 \\
\hline & 1-MOX-50-SNFA & 1 & 6 & 60 & 114 & 168 \\
\hline & Co-Extraction & -1 & 7 & 61 & 115 & 169 \\
\hline & New Extraction Glass & -1 & 8 & 62 & 116 & 170 \\
\hline & EC-Ceramic & 1 & 9 & 63 & 117 & 171 \\
\hline & EC-Metal & 1 & 10 & 64 & 118 & 172 \\
\hline \multirow{10}{*}{$\alpha_{\theta, y}$} & 4-UOX-60-SNFA & 4 & 11 & 65 & 119 & 173 \\
\hline & 4-UDX-40-SNFA & 4 & 12 & 66 & 120 & 174 \\
\hline & 1-UDX-60-SNFA & -1 & 13 & 67 & 121 & 175 \\
\hline & 1-UOX-40-SNFA & -1 & 14 & 68 & 122 & 176 \\
\hline & 4-MOX-50-SNFA & 4 & 15 & 69 & 123 & 177 \\
\hline & 1-MOX-50-SNFA & -1 & 16 & 70 & 124 & 178 \\
\hline & Co-Extraction & -1 & 17 & 71 & 125 & 179 \\
\hline & New Extraction Glass & -1 & 18 & 72 & 126 & 180 \\
\hline & EC-Ceramic & 1 & 19 & 73 & 127 & 181 \\
\hline & EC-Metal & 1 & 20 & 74 & 128 & 182 \\
\hline \multirow{8}{*}{$\sin t \infty 0$} & 4-UDX-60-SNFA & 4 & 21 & 75 & 129 & 183 \\
\hline & 1-UOX-60-SNFA & 1 & 24 & 78 & 132 & 186 \\
\hline & 4-MOX-50-SNFA & 4 & 33 & 87 & 141 & 195 \\
\hline & 1-MOX-50-SNFA & 1 & 35 & 89 & 143 & 197 \\
\hline & Co-Extraction & 1 & 40 & 94 & 148 & 202 \\
\hline & New Extraction Glass & -1 & 41 & 95 & 149 & 203 \\
\hline & EC-Ceramic & 1 & 42 & 96 & 150 & 204 \\
\hline & EC-Metal & -1 & 43 & 97 & 151 & 205 \\
\hline \multirow{19}{*}{$S_{3 k} 200$} & 1-UOX-60-SNFA & 1 & 25 & 79 & 133 & 187 \\
\hline & 1-UOX-40-SNFA & -1 & 26 & 80 & 134 & 188 \\
\hline & 2-UDX-60-SNFA & 2 & 27 & 81 & 135 & 189 \\
\hline & 2-UDX-40-SNFA & 2 & 28 & 82 & 136 & 190 \\
\hline & 3-UDX-60-SNFA & 3 & 29 & 83 & 137 & 191 \\
\hline & 3-UDX-40-SNFA & 3 & 30 & 84 & 138 & 192 \\
\hline & 4-UDX-60-SNFA & 4 & 22 & 76 & 130 & 184 \\
\hline & 4-UDX-40-SNFA & 4 & 23 & 77 & 131 & 185 \\
\hline & 12-UOX-60-SNFA & 12 & 31 & 85 & 139 & 193 \\
\hline & 12-UDX-40-SNFA & 12 & 32 & 86 & 140 & 194 \\
\hline & 1-MOX-50-SNFA & -1 & 36 & 90 & 144 & 198 \\
\hline & 2-MOX-50-SNFA & 2 & 37 & 91 & 145 & 199 \\
\hline & 3-MOX-50-SNFA & 3 & 38 & 92 & 146 & 200 \\
\hline & 4-MOX-50-SNFA & 4 & 34 & 88 & 142 & 196 \\
\hline & 12-MOX-50-SNFA & 12 & 39 & 93 & 147 & 201 \\
\hline & Co-Extraction & 1 & 44 & 98 & 152 & 206 \\
\hline & New Extraction Glass & -1 & 45 & 99 & 153 & 207 \\
\hline & EC-Ceramic & 1 & 46 & 100 & 154 & 208 \\
\hline & EC-Metal & 1 & 47 & 101 & 155 & 209 \\
\hline \multirow{7}{*}{$\begin{array}{c}\text { Dosp } \\
\text { Bonoholos }\end{array}$} & 1-UDX-60-SNFA & 1 & 48 & 102 & 156 & 210 \\
\hline & 1-UDX-40-SNFA & 1 & 49 & 103 & 157 & 211 \\
\hline & 1-MOX-50-SNFA & -1 & 50 & 104 & 158 & 212 \\
\hline & Co-Extraction & 0.291 & 51 & 105 & 159 & 213 \\
\hline & New Extraction Glass & 0.291 & 52 & 106 & 160 & 214 \\
\hline & EC-Ceramic & 0.291 & 53 & 107 & 161 & 215 \\
\hline & EC-Metal & 0.291 & 54 & 108 & 162 & 216 \\
\hline
\end{tabular}


Figure 16 - The open mode analysis base case catalog

\begin{tabular}{|c|c|c|c|c|c|}
\hline \multicolumn{6}{|c|}{ Case Number Catalog for Open Mode Analysis Cases } \\
\hline \multirow{2}{*}{\multicolumn{2}{|c|}{$\begin{array}{l}\text { Catalog of Base Cases } \\
\text { Disposal Scenarios }\end{array}$}} & \multicolumn{4}{|c|}{ Click Here to Jump to Selected Case } \\
\hline & & \multicolumn{2}{|c|}{50 Year Storage } & \multicolumn{2}{|c|}{100 Year Storage } \\
\hline Geology & Waste Form & $\begin{array}{l}\text { LLNL-TR- } \\
572252 \\
\text { Case \# }\end{array}$ & $\begin{array}{c}\text { CASE } \\
\text { LIBRARY } \\
\text { Case } \\
\text { Number }\end{array}$ & $\begin{array}{c}\text { LLNL-TR- } \\
572252 \text { Case \# }\end{array}$ & $\begin{array}{c}\text { CASE } \\
\text { LIBRARY } \\
\text { Case Number }\end{array}$ \\
\hline \multirow{8}{*}{ Clay } & 4-UOX 40 & $\# 13$ & 217 & $\# 14$ & 218 \\
\hline & 4-UOX 60 & \#15 & 219 & $\# 16$ & 220 \\
\hline & $12-\mathrm{U} 0 \times 40$ & \#17 & 221 & \#18 & 222 \\
\hline & $12-$ UOX 60 & $\# 19$ & 223 & $\# 20$ & 224 \\
\hline & 21-UOX 40 & \#21 & 225 & \#22 & 226 \\
\hline & 21-UOX 60 & \#23 & 227 & $\# 24$ & 228 \\
\hline & $32-$ UOX 40 & \#25 & 229 & \#26 & 230 \\
\hline & 32-UOX 60 & \#27 & 231 & $\# 28$ & 232 \\
\hline \multirow{8}{*}{ Alluvium } & 4-UOX 40 & $\# 41$ & 233 & $\# 42$ & 234 \\
\hline & 4-UOX 60 & $\# 43$ & 235 & $\# 44$ & 236 \\
\hline & $12-U 0 X 40$ & \#45 & 237 & $\# 46$ & 238 \\
\hline & $12-$ UOX 60 & \#47 & 239 & \#48 & 240 \\
\hline & 21-UOX 40 & $\# 49$ & 241 & \#50 & 242 \\
\hline & 21-UOX 60 & \#51 & 243 & \#52 & 244 \\
\hline & 32-UOX 40 & \#53 & 245 & \#54 & 246 \\
\hline & 32-UOX 60 & \#55 & 247 & \#56 & 248 \\
\hline
\end{tabular}


Figure 17 - The open mode sensitivity studies case catalog

\begin{tabular}{|c|c|c|c|c|c|c|c|c|c|c|c|c|}
\hline \multicolumn{13}{|c|}{ Case Number Catalog for Open Mode Analysis Cases } \\
\hline \multicolumn{2}{|r|}{$\begin{array}{l}\text { Catalog of Dpen Mode } \\
\text { Sensitivity Study Cases }\end{array}$} & \multicolumn{3}{|c|}{ Click Here to Jump to Selected Case } & & & & & & & & \\
\hline Media & Parameter Studied & & & & & & & & & & & \\
\hline \multirow{3}{*}{ Clay } & \multirow{3}{*}{ 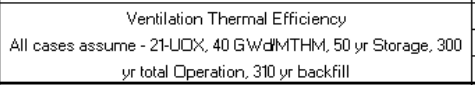 } & Ventilation Efficiency & $50 \%$ & $60 \%$ & $70 \%$ & $75 \%$ & $80 \%$ & $90 \%$ & & & & \\
\hline & & LLNL-TR-572252 Case \# & $\# 21 \mathrm{a}$ & $\# 216$ & $\# 216$ & $\# 21$ & \#21d & \#21e & & & & \\
\hline & & CASE LIBRARY Case \# & 249 & 250 & 251 & 225 & 252 & 253 & & & & \\
\hline \multirow{3}{*}{ Clay } & \multirow{3}{*}{$\begin{array}{l}\text { Ventilation Duration } \\
\text { All cases assume - } 21 \text {-UDX, } 40 \text { GWdMTHMM, } 50 \text { yr Storage, } \\
\text { Ventilation Eff. } 90 \%\end{array}$} & Ventilation Duration & $250 y, D S=30$ & $200 y, D S=30$ & $150 y, D S=30$ & $100 y, D S=30$ & $50 y, D S=30$ & $50 y, D S=40$ & $50 y, D S=50$ & & & \\
\hline & & LLNL-TR-572252 Case \# & \#21e & \#21f & $\# 21 \mathrm{~g}$ & $\# 21 \mathrm{hh}$ & $\# 21 \mathrm{i}$ & $\# 2 i$ & $\# 21 \mathrm{k}$ & & & \\
\hline & & CASE LIBRARYY Case \# & 253 & 254 & 255 & 256 & 257 & 258 & 259 & & & \\
\hline \multirow{3}{*}{ Clay } & \multirow{3}{*}{\begin{tabular}{|c|} 
Drift' Borehole Spacing \\
All cases assume - $21-U 0 X$ or 32 -UDX, 40 GWdMTHM, 50 yr \\
Storage, 300 yr close
\end{tabular}} & Variable Value & $30 \mathrm{~m}, \mathrm{WP}=21$ & $40 \mathrm{~m} W \mathrm{WP}=21$ & $50 \mathrm{~m} W \mathrm{P}=21$ & $60 \mathrm{~m} \mathrm{WP}=21$ & $70 \mathrm{~m} \mathrm{WP}=21$ & $30 \mathrm{~m} \mathrm{WP}=32$ & $40 \mathrm{~m} W P=32$ & $50 \mathrm{~m} W P=32$ & $60 \mathrm{~m} \mathrm{WP}=32$ & $70 \mathrm{~m} W P=32$ \\
\hline & & LLNL-TR-572252 Case \# & \#21 & $\# 21 w_{1}$ & $\# 21 x$ & \#21y & $\# 21 z$ & $\# 25$ & $\# 25 a$ & \#25b & $\# 25 \mathrm{c}$ & $\# 25 \mathrm{~d}$ \\
\hline & & CASE LIBRARYY Case \# & 225 & 260 & 261 & 262 & 263 & 229 & 264 & 265 & 266 & 267 \\
\hline \multirow{3}{*}{ Generic } & \multirow{3}{*}{ 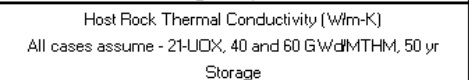 } & Variable Value & $k \mathrm{kth}=1 \mathrm{EU}=40$ & $k \mathrm{kth}=2 \mathrm{BU}=40$ & $\mathrm{kth}=3 \mathrm{BU}=40$ & $\mathrm{kth}=4 \mathrm{EU}=40$ & $k$ th $=5 \mathrm{BU}=40$ & $k \mathrm{kh}=1 \mathrm{EU}=60$ & $\mathrm{kth}=2 \mathrm{BU}=60$ & $\mathrm{kth}=3 \mathrm{BU}=60$ & $\mathrm{kth}=4 \mathrm{BU}=60$ & $k$ th $=5 \mathrm{BU}=60$ \\
\hline & & LLNL-TR-572252 Case\# & \#57 & $\# 58$ & $\# 59$ & $\# 60$ & $\# 61$ & $\# 62$ & $\# 63$ & $\# 64$ & $\# 65$ & $\# 66$ \\
\hline & & CASE LIBRARYY Case \# & 277 & 278 & 279 & 280 & 281 & 282 & 283 & 284 & 285 & 286 \\
\hline \multirow{3}{*}{ Clay } & \multirow{3}{*}{$\begin{array}{c}\text { Backfill Thermal Conductivity } \\
\text { All cases assume - } 21-U 0 X, 40 \text { GWdMMTHM, } 50 \text { yr Storage, } 300 \\
\text { yr close, } 10 \text { yr backfill } \\
\end{array}$} & Variable Value & $k \mathrm{kth}=1 \mathrm{BU}=40$ & $\mathrm{kth}=2 \mathrm{BU}=40$ & $\mathrm{kth}=3 \mathrm{BU}=40$ & $k \mathrm{kth}=4 \mathrm{BU}=40$ & $k \mathrm{kth}=5 \mathrm{BU}=40$ & & & & & \\
\hline & & LLNL-TR-572252 Case\# & $\# 67$ & $\# 68$ & $\# 69$ & $\# 70$ & $\# 71$ & & & & & \\
\hline & & CASE LIBRARY Case \# & 268 & 269 & 270 & 271 & 272 & & & & & \\
\hline \multirow{3}{*}{$\begin{array}{c}\text { Clay \#21's } \\
\text { Alluviumn \#49's }\end{array}$} & \multirow{3}{*}{$\begin{array}{l}\text { Uncertainty in Rock Properties } \\
\text { All cases assume - 21-UOX, } 40 \text { GW'dMTHMM, } 50 \text { yr Storage, } 300 \\
\text { yr close, } 10 \text { yr backfill }\end{array}$} & Variable Value & -2 std. dev. & -1 std. dev. & Mean & +1 std dev. & +2 std. dey. & -2 std. dev. & -1 std. dev. & Mean & +1 std dev. & +2 std. dev. \\
\hline & & LLNL-TR-572252 Case \# & $21 \mathrm{~m}$ & $21 \mathrm{r}$ & 21 & $21 \mathrm{~s}$ & $21 \mathrm{n}$ & $49 a$ & $49 c$ & 49 & 49d & $49 \mathrm{~b}$ \\
\hline & & CASE LIBRARY Case \# & 273 & 287 & 225 & 288 & 274 & 275 & 289 & 241 & 290 & 276 \\
\hline \multirow{3}{*}{ Clay } & \multirow{3}{*}{$\begin{array}{c}\text { Design Test Cases } \\
\text { All cases assume - 21-UDX, 40 GWUMMTHM, cases 72-74, } 50 \text { yr } \\
\text { storage, } \\
\text { cases } 75-77,100 \text { yr storage }\end{array}$} & Variable Value & No backfill & backfill kth=2 & backill kh= 1.2 & backfill kth $=0.6$ & $r D W=5.25 \mathrm{~m}$ & No backill & backfill kth $=2$ & backfill $k$ th $=1.2$ & backfill kth $=0.6$ & $r D W=5.25 \mathrm{~m}$ \\
\hline & & LLNL-TR-572252 Case \# & 72 & 73 & $73 \mathrm{~b}$ & $73 a$ & 74 & 75 & 76 & $76 \mathrm{~b}$ & $76 \mathrm{a}$ & 77 \\
\hline & & CASE LIBRARY Case \# & 291 & 292 & 293 & 294 & 295 & 296 & 297 & 298 & 299 & 300 \\
\hline
\end{tabular}


Figure 18 - Case number catalog for repository layout and required ventilation trade studies in clay/shale (1 of 2)

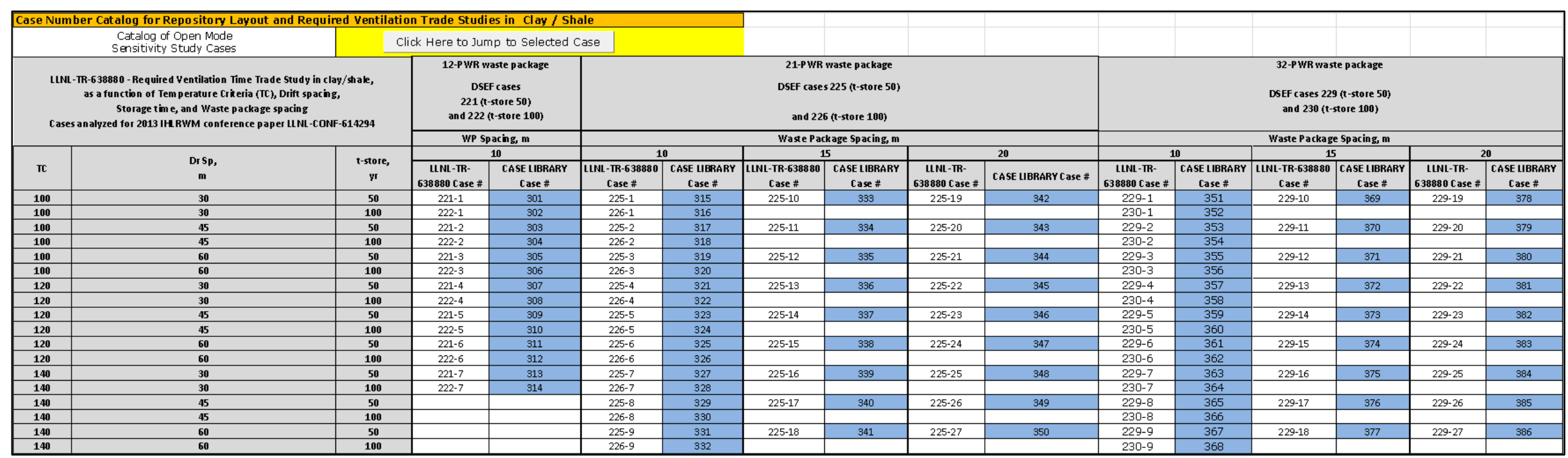


Figure 19 - Case number catalog for repository layout and required ventilation trade studies in clay/shale (2 of 2)

\begin{tabular}{|c|c|c|c|c|c|c|c|c|}
\hline \multicolumn{7}{|c|}{ Case Number Catalog for Repository Layout and Required Ventilation Trade Studies in Clay / Shale } & & \\
\hline \multicolumn{2}{|r|}{$\begin{array}{l}\text { Catalog of Open Mode } \\
\text { Sensitivity Study Cases }\end{array}$} & \multicolumn{5}{|c|}{ Click Here to Jump to Selected Case } & & \\
\hline \multirow{3}{*}{\multicolumn{3}{|c|}{$\begin{array}{l}\text { LLNL-TR- } 638880 \text { - Required Ventilation Time Trade Study in clay/ } \\
\text { as a function of Temperature Criteria (TC), Drift spacing, } \\
\text { Storage time, and Waste package spacing } \\
\text { Additional base cases to extend WP spacing to } 30 \mathrm{~m} \text { and } \\
\text { Drift spacing to } 90 \mathrm{~m}\end{array}$}} & \multicolumn{6}{|c|}{ 32-PWR waste package, $40 \mathrm{GWd} / \mathrm{MT}$ burnup } \\
\hline & & & \multicolumn{6}{|c|}{ Waste Package Spacing } \\
\hline & & & \multicolumn{2}{|c|}{10} & \multicolumn{2}{|c|}{20} & \multicolumn{2}{|c|}{30} \\
\hline \multirow{10}{*}{ Clay/shale } & $\mathrm{TC}$ & Dr Sp & $\begin{array}{c}\text { LLNL-TR- } \\
638880 \text { Case \# }\end{array}$ & $\begin{array}{l}\text { CASE LIBRARY } \\
\text { Case \# }\end{array}$ & $\begin{array}{c}\text { LLNL-TR- } 638880 \\
\text { Ca se \# }\end{array}$ & $\begin{array}{c}\text { CASE LIBRARY } \\
\text { Case \# }\end{array}$ & $\begin{array}{c}\text { LLNL-TR-638880 } \\
\text { Case \# }\end{array}$ & $\begin{array}{c}\text { CASE LIBRARY } \\
\text { Case \# }\end{array}$ \\
\hline & 100 & 30 & $229-1$ & 351 & 229-19 & 378 & $229-67$ & 393 \\
\hline & 100 & 60 & $229-3$ & 355 & $229-21$ & 380 & $229-64$ & 394 \\
\hline & 100 & 90 & $229-37$ & 387 & $229-49$ & 390 & $229-61$ & 395 \\
\hline & 120 & 30 & $229-4$ & 357 & $229-22$ & 381 & $229-68$ & 396 \\
\hline & 120 & 60 & $229-6$ & 361 & $229-24$ & 383 & $229-65$ & 397 \\
\hline & 120 & 90 & $229-38$ & 388 & $229-50$ & 391 & $229-62$ & 398 \\
\hline & 140 & 30 & $229-7$ & 363 & $229-25$ & 384 & $229-69$ & 399 \\
\hline & 140 & 60 & $229-9$ & 367 & $229-27$ & 386 & $229-66$ & 400 \\
\hline & 140 & 90 & 229-39 & 389 & $229-51$ & 392 & $229-63$ & 401 \\
\hline
\end{tabular}


Figure 20 - Case number catalog for scoping thermal analysis of alternative DPC disposal concepts in clay/shale (subset 1)

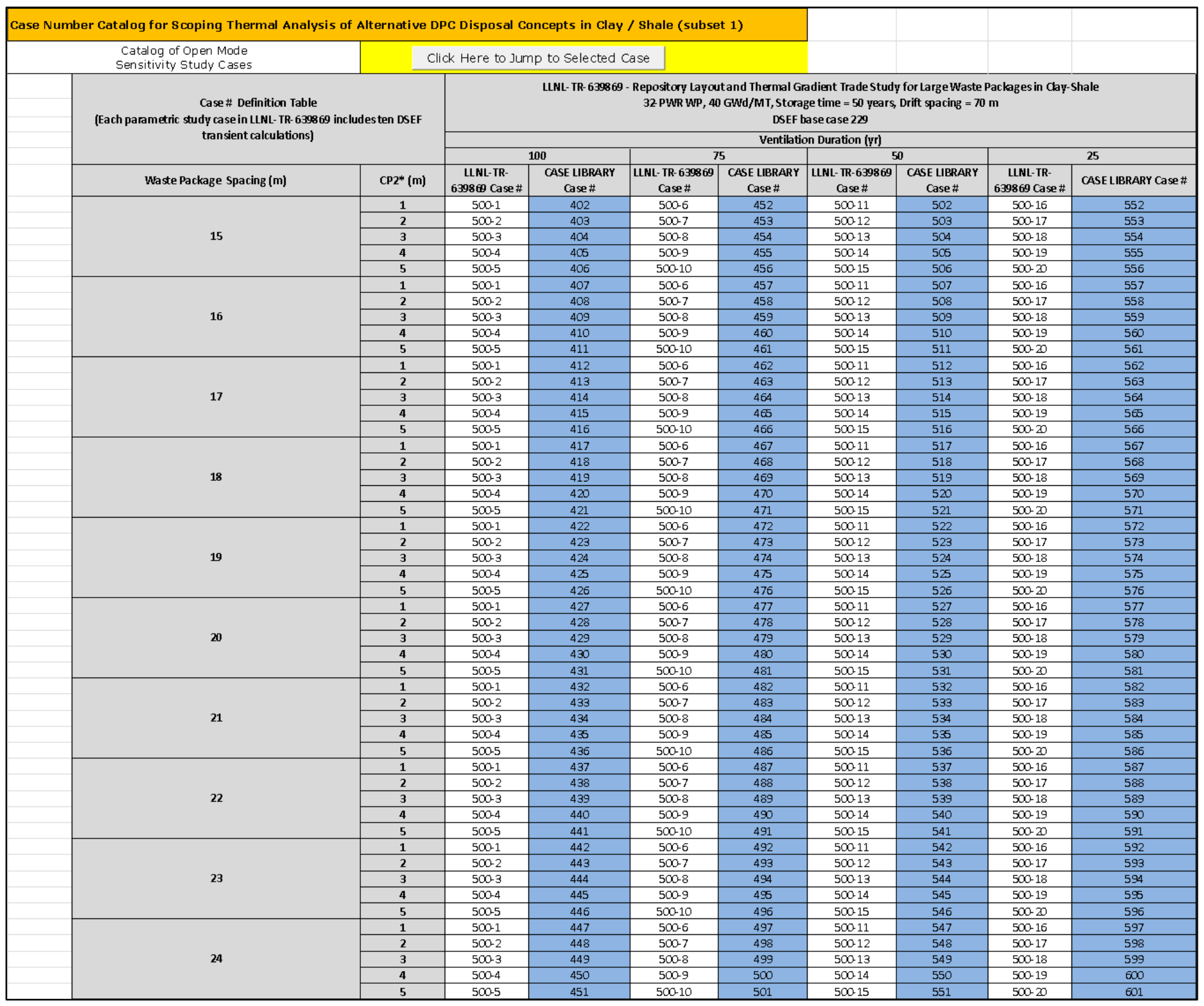


Figure 21 - Case number catalog for scoping thermal analysis of alternative DPC disposal concepts in clay/shale (subset

2)

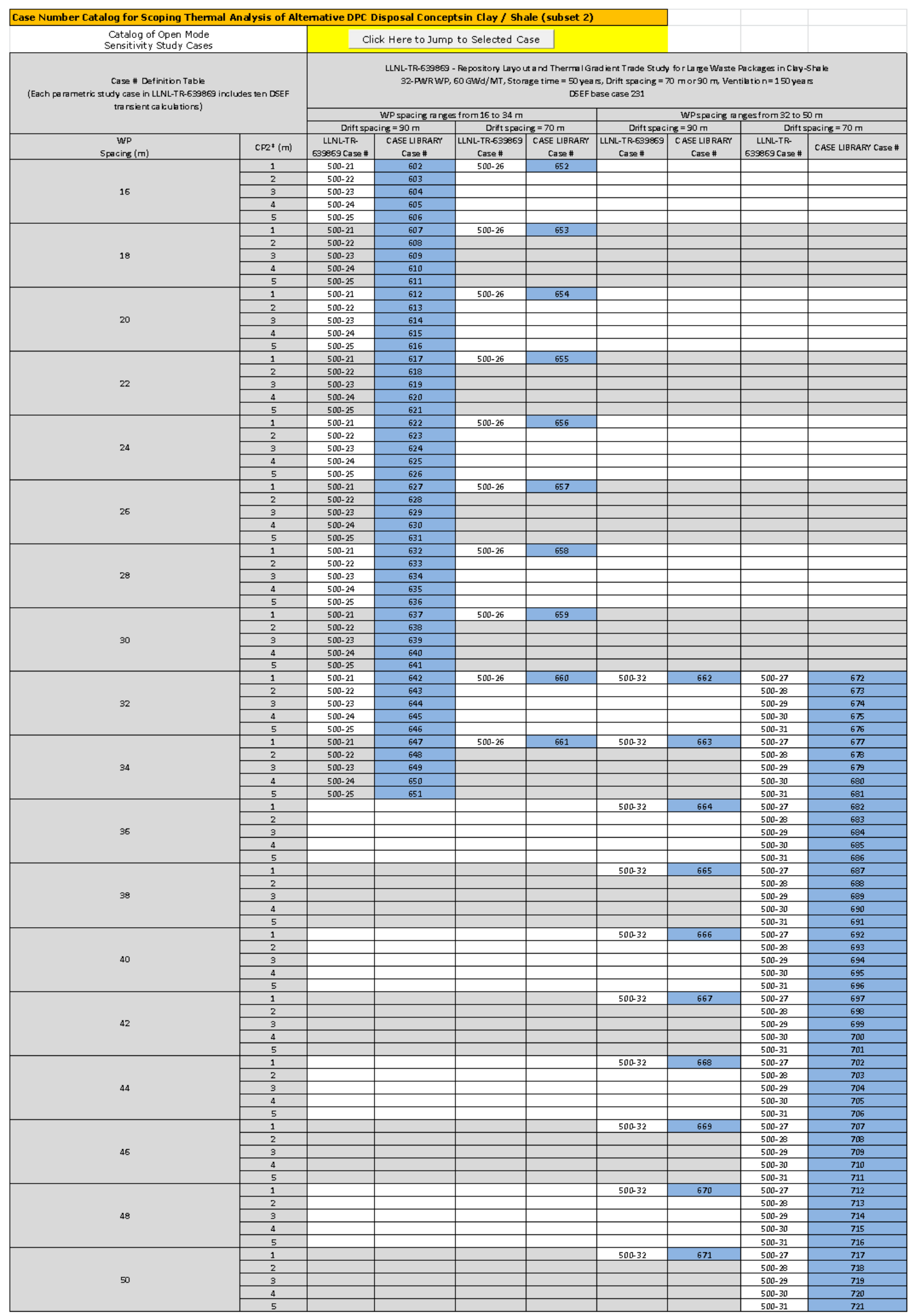


Once the user finds a case of interest that may be used as a starting point for a new variation or analysis, the INPUTS worksheet can automatically populate some of the key data inputs from the selected case, so that the user can either accept it as is, or input their own values. This is discussed in Section 5.

The THERMAL-INTERPOLATE worksheet includes two tools that can be used to develop a new analysis case from the ensemble of existing runs. The first tool allows the user to compare and contrast combinations of cases and data fields from a set of comparison cases, using the worksheet template shown in Figure 22. Following the color conventions introduced in Section 4, the yellow highlighted cells along the left column and in the top row of Figure 22 allow the user to enter case numbers on the left, and selected data fields (from Figure 14) on the top row.

Once the case numbers and selected data fields have been reviewed in the first tool, the user can select two appropriate case numbers for the interpolation. For example, in Figure 23, the Case 225 and 260 rows show results for open mode drift spacing (i.e., lateral spacing) of $30 \mathrm{~m}$ and $40 \mathrm{~m}$. The user is responsible to select cases in which other potential independent variables are identical or at least very similar. In these two cases, the geologic medium, the waste package capacity, the burnup, the waste package spacing (i.e., axial spacing), the surface storage time, and the ventilation duration are identical, as shown in the case description. The user can verify these parameters by inputting their parameter numbers (from the list in Figure 14) on the top row of Figure 22 (the first tool). Other parameters should also be checked using Figure 23 (including thermal conductivities, thermal diffusivities, and EBS dimensions).

Once the two cases are chosen, the user proceeds to the second tool on the THERMAL-INTERPOLATE worksheet, which requires two case numbers, an independent variable, and a dependent variable. Based on the discussion above, lateral spacing could be the independent variable for interpolating between cases 225 and 260 . Consider the case where the waste package peak temperature is the dependent variable, with a desired value of $150^{\circ} \mathrm{C}$, as an example of using the tool. Figure 23, panel (a), displays that example, with a linearly-predicted peak waste package temperature of $154.72^{\circ} \mathrm{C}$ at a lateral spacing of $35 \mathrm{~m}$, obtained from the peak temperatures previously calculated for lateral spacing of 30 and $40 \mathrm{~m}$. The user can simply iterate on the lateral spacing until the interpolated result is as close as desired to the target value. It should be noted that the tool also will extrapolate, but the user should be wary of extrapolating a significant distance.

Figure 23, panel (b), shows the error message if the user inadvertently specifies the same point for each end of the interpolation. Figure 23, panel (c), shows an example of one of the drop-down lists and some of the choices for independent variables. 
Figure 22 - Side-by-side case comparison table

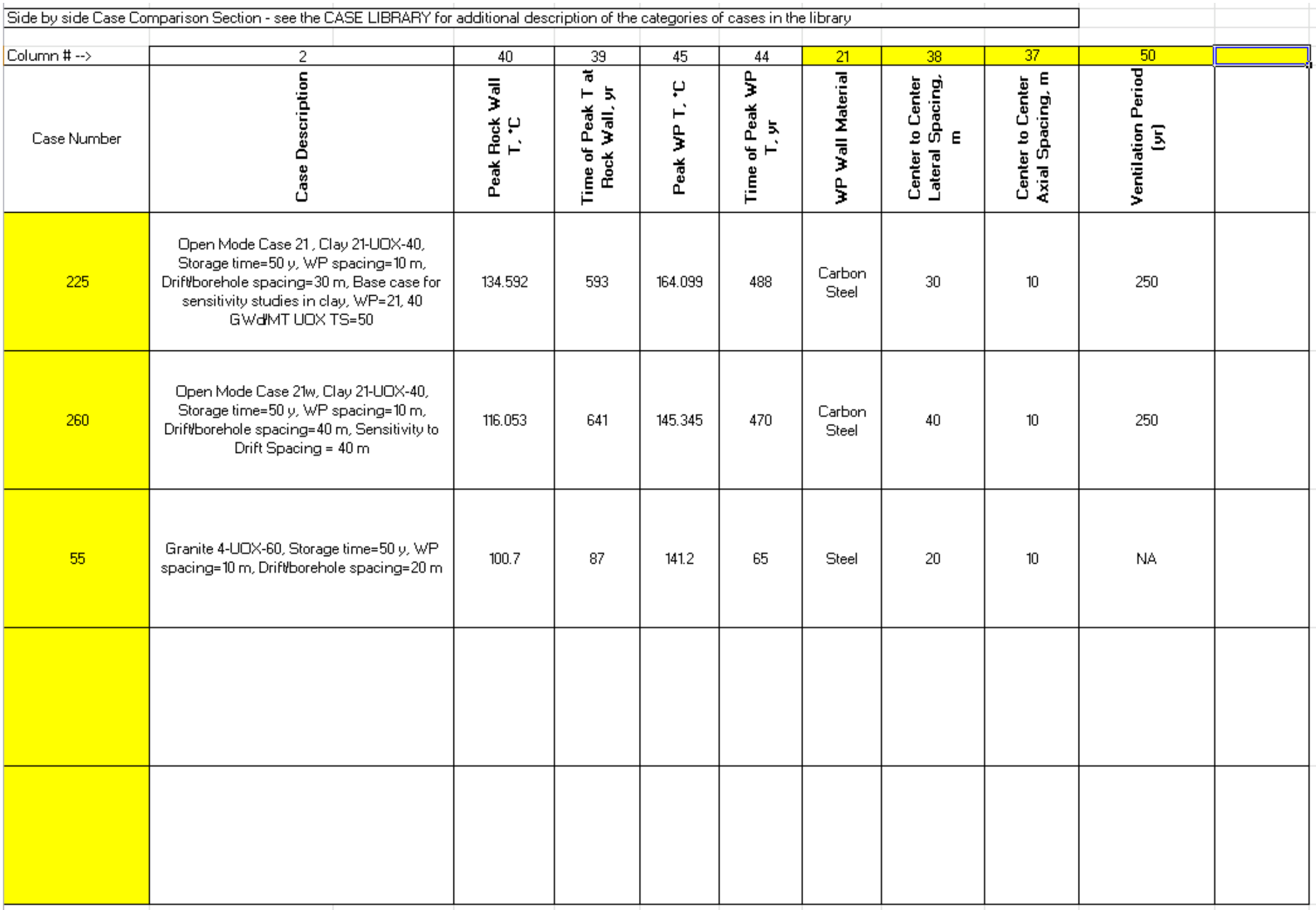


Figure 23 - The template for variable interpolation between relevant cases

(a) - Good selection with no error messages.

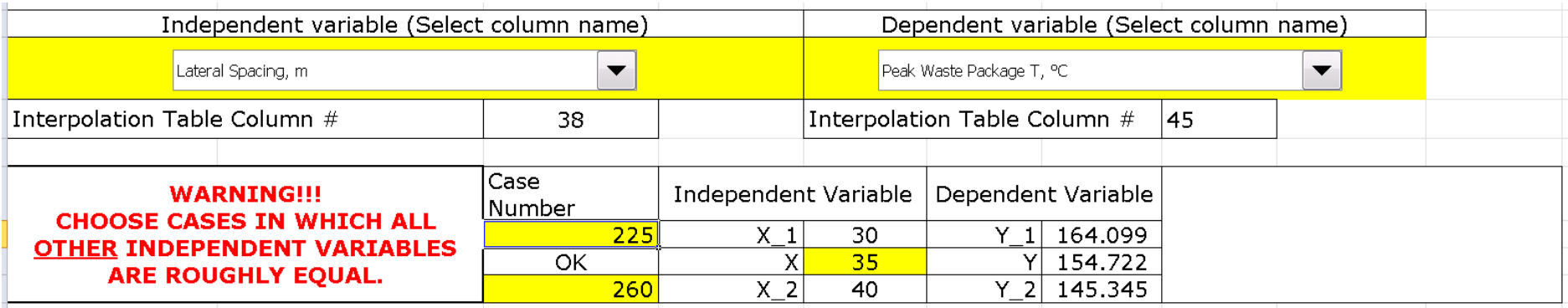

(b) - An example of an error message that helps guide the user

\begin{tabular}{|c|c|c|c|c|c|c|c|c|}
\hline \multicolumn{3}{|c|}{ Independent variable (Select column name) } & \multicolumn{5}{|c|}{ Dependent variable (Select column name) } & \\
\hline Lateral Spacing, m & \multicolumn{2}{|l|}{$\nabla$} & \multicolumn{4}{|c|}{ Peak Waste Package $\mathrm{T},{ }^{\circ} \mathrm{C}$} & $\nabla$ & \\
\hline Interpolation Table Column \# & 38 & & \multicolumn{3}{|c|}{ Interpolation Table Column \# } & 45 & & \\
\hline \multirow{4}{*}{$\begin{array}{c}\text { WARNING!!! } \\
\text { CHOOSE CASES IN WHICH ALL } \\
\text { OTHER INDEPENDENT VARIABLES } \\
\text { ARE ROUGHLY EQUAL. }\end{array}$} & $\begin{array}{l}\text { Case } \\
\text { Number }\end{array}$ & \multicolumn{2}{|c|}{ Independent Variable } & \multicolumn{2}{|c|}{ Dependent Variable } & \multirow{4}{*}{\multicolumn{3}{|c|}{$\begin{array}{l}\text { Select Cases with Different } \\
\text { Independent Variable Values }\end{array}$}} \\
\hline & 225 & X_1 & 30 & $Y \_1$ & 164.099 & & & \\
\hline & Reselect & $\mathrm{X}$ & 35 & $Y$ & \#DIV/O! & & & \\
\hline & 225 & X_2 & 30 & $Y \_2$ & 164.099 & & & \\
\hline
\end{tabular}

(c) - An example of what the drop down lists contain (they scroll to other selections besides the ones shown here)

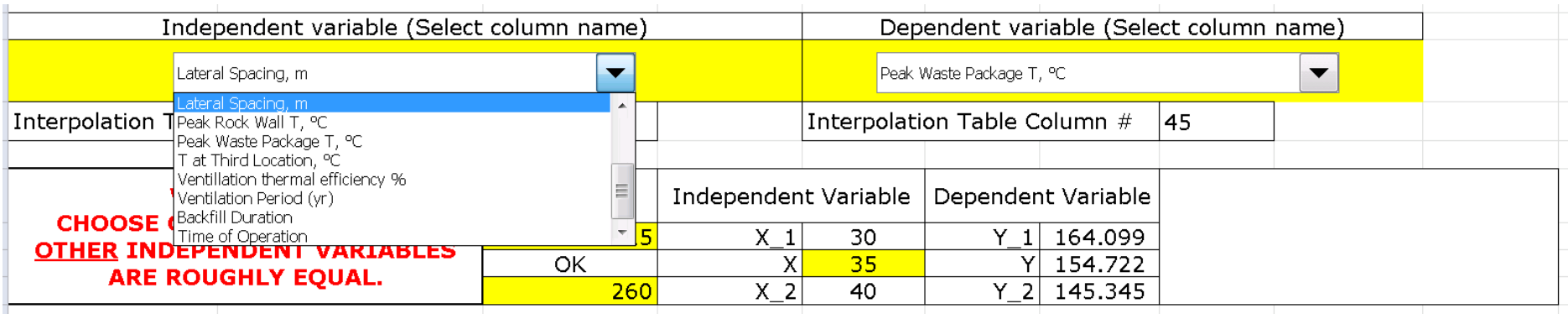




\section{Getting a Quick Overview of the Latest Analysis - the RESULTS and the THERMAL-ANALYTICAL OUTPUT Worksheets}

The RESULTS worksheet contains a concise summary of the input data from both the INPUTS worksheet; the THERMAL-SOURCE worksheets (providing both tabular and graphical summaries of the decay heat data; and results of the COST CALCULATIONS worksheet used in the current analysis case. The output data also includes results from the THERMAL-ANALYTICAL OUTPUT worksheet, including the plots shown later in Section 11 (Figure 36 and Figure 37).

Section 1 of the RESULTS worksheet summarizes the input data as follows:

- 1.A. Case Name and User Information.

- 1.B. Waste Characteristics and Waste Package Capacity.

- 1.C. Repository Design - including layout and ventilation system data.

- 1.D. Host Rock - including geometry, properties, and temperature.

- 1.E. EBS Components - including geometry, material names, and material properties.

- $\quad$ 1.F. Decay Heat - including both tabular and graphical representations.

Section 2 of the RESULTS worksheet summarizes the analysis results as follows:

- 2.A. Peak and Transient Temperature Results - these include peak temperatures and the times of the peaks for the host rock wall, the various EBS component interface locations, and the waste package surface. Figure 11 shows an example of the peak temperature results summary and the results compared to the thermal constraints. When a parametric study is performed in DSEF (as described in Step 12 on the INPUTS sheet), and shown in Figure 12, the full set of peak temperature values and times of the peaks for the parametric study are shown on the RESULTS worksheet, but the graphical results are only shown for the first case of the parametric study, or the single analysis case if no parametric study is performed. The RESULTS worksheet provides a hyperlink to the THERMAL-ANALYTICAL OUTPUT worksheet to allow the user to examine the full set of transient tabular and graphical results when a parametric study is analyzed.

- 2.B. Potential New Case Library Data Entry - this section provides a hyperlink to the CASE LIBRARY, just below the Case Catalog where the current analysis results are displayed in the form of a Case Library record.

- 2.C. Cost Results - this section shows the overall summary of raw, low contingency, and high contingency cost data from the COST CALCULATIONS worksheet (see Figure 28 from Section 9 of this user manual), as well as a short summary of the emplacement drift length calculation based on the thermal analysis model, that is used in the cost calculations.

Note that when the Mathcad component of DSEF returns a table of peak temperatures and times, and one or more sets of transient temperatures (one set for each parametric sensitivity study case) to the THERMAL-ANALYTICAL OUTPUT worksheet, the Excel formatting is lost. There is a macro button on the top of the worksheet which needs to be pressed once to restore the formatting, which makes the results easier to read. There is another macro button which is used to clear all of the transient results in the event the user wishes to use the same Excel file with a few modifications to evaluate another case. 
There is a similar macro button to clear previous transient results provided on the INPUTS worksheet in Step 2.G. 


\section{The COST Worksheets}

As part of the assessment of design concept feasibility, DSEF includes the capability to evaluate the costs of constructing and operating a repository concept that uses the design values from the DSEF INPUTS worksheet. In DSEF Version 2.1, the cost calculations were limited to mining and backfill costs of the repository subsurface only. Version 3.0 extends the cost model to include the total system cost.

Rough order-of-magnitude (ROM) cost data were developed in Carter 2012, and presented in Hardin 2012b, and referred to here as the Carter/Hardin cost model. DSEF Version 3.0 has been revised to address all of the cost categories covered in the Carter/Hardin model. The cost categories have been slightly regrouped to take advantage of repository design details available in DSEF, but are generally comparable to the Carter/Hardin results.

Specifically, the Carter/Hardin model includes two high-level cost categories of "Facility Design, Construction, and Startup”, and “Operations \& Maintenance”. The DSEF calculations use five cost categories whose total is comparable to the total of the two Carter/Hardin categories; the DSEF categories are "Facility Design and Startup”, "Surface Facility Construction”, "Subsurface Facility Construction”, "Ventilation", and "Operations and Maintenance". It should be noted that DSEF construction categories include all such construction, while Carter/Hardin include the first phase of construction in their first category, and subsequent modular construction as part of O\&M. Also, DSEF includes both construction and O\&M for ventilation in the "Ventilation" category. The remaining Carter/Hardin categories are directly comparable to DSEF categories. These are "Closure”, "Waste Package costs”, "Regulatory \& Licensing”, “Monitoring”, "Performance Confirmation”, and "Program Integration”.

The DSEF approach was to match the Carter/Hardin costs for their five base cases, for the sum of the first two Carter/Hardin cost categories, for each of the other six Carter/Hardin cost categories, and for the overall total. This was accomplished by calculating costs as the product of a unit cost times the number of units (meters of excavation, number of waste packages, years of operation, etc.), or as the sum of several of these products. The unit costs were specified to produce agreement with the Carter/Hardin costs and to maintain as much consistency and logic as possible across the five disparate base cases.

The DSEF INPUTS worksheet now includes over 80 new input categories to address these calculations, and includes a set of five example cases that were analyzed in by Hardin and Carter using a drop-down menu to select the example case, and then providing the sample case data for each input so that it can either be used or over-ridden by providing user input for the current analysis case.

Note that the DSEF geologic material selection of "granite" corresponds to the crystalline rock type, and the geologic material selection of "alluvium" corresponds to the sedimentary rock type in the cost cases below.

The five example cost cases are defined in the Carter/Hardin model as follows:

1. Crystalline (enclosed) - Vertical borehole emplacement is used with a copper waste package (e.g., Swedish KBS-3 concept) with a clay buffer installed at emplacement. Access drifts are backfilled with low-permeability clay-based backfill at closure (Hardin 2012b, Section 1.4.5.1). 
2. Generic Salt Repository (enclosed) - A repository in bedded salt in which carbon steel waste packages are placed on the floor in drifts or alcoves, and immediately covered (backfilled) with run-of-mine salt (Hardin 2012b, Section 1.4.5.2).

3. Clay/Shale (enclosed) - SNF or HLW is emplaced in blind, steel-lined horizontal borings constructed from access drifts. SNF is emplaced in carbon steel packages with a clay buffer. HLW glass is emplaced in stainless steel pour canisters, within a steel liner (Hardin 2012b, Section 1.4.5.3).

4. Shale Unbackfilled (open) - A repository in a thick shale formation constructed so that ventilation is maintained for at least 50 to 100 years after waste emplacement. Emplacement drifts are not backfilled at closure, but all other openings are backfilled to provide waste isolation (Hardin 2012b, Section 1.5.1).

5. Sedimentary Backfilled (open) - Constructed in sedimentary rock so that ventilation is maintained for at least 50 to 100 years after waste emplacement. All waste emplacement and other openings are backfilled with low-permeability clay-based backfill prior to repository closure (Hardin 2012b, Section 1.5.2).

The specific data for these cases is captured in a set of Excel lookup tables on the DSEF LISTS worksheet, and then used as described above on the INPUTS worksheet. DSEF provides a hyperlink to the relevant section of the LISTS worksheet that allows the user to examine the cost data summary tables if desired. The user can also see all the inputs for a single Carter/Hardin base case by simply selecting it. Then, the user can copy the values desired for a user design case, row by row, as appropriate, and then change to User-Defined in the case selection menu. The unit cost data were extracted from both Carter 2012 and Hardin 2012b, or were back calculated to match the Carter results in each category listed above. A number of the key reference tables from Hardin 2012b are included on the COST REFERENCES worksheet.

Error! Reference source not found.Error! Reference source not found.Figure 24, Figure 25, and Figure 26summarize the five example cases from the Carter/Hardin model, and Figure 27 is an example of the detailed cost data for one of the examples (where the details for all of them are shown on the COST REFERENCES worksheet). 
Figure 24 - Summary of waste package numbers for the 5 example cost cases

(From Hardin 2012b Tables 2.1-1 and 4-1)

Table 2.1-1 -Numbers of Different Size Waste Packages for a 140,000 MT SNF Repository

\begin{tabular}{|l|c|c|c|}
\hline & 4-PWR/9-BWR & 12-PWR/24-BWR & 21-PWR/44-BWR \\
\hline PWR & 52,250 & 17,417 & 9,952 \\
\hline BWR & 30,333 & 11,375 & 6,205 \\
\hline Total & 82,583 & 28,792 & 16,157 \\
\hline
\end{tabular}

Table 4-1 - Summary of Waste Package Numbers for 5 Disposal Concepts

\begin{tabular}{|l|c|c|c|c|}
\hline & \multirow{2}{*}{$\begin{array}{c}\text { Package } \\
\text { Capacity }\end{array}$} & \multicolumn{2}{|c|}{$\mathbf{1 4 0 , 0 0 0}$ MT Repository } & $\begin{array}{c}\text { Disposal } \\
\text { Overpack }\end{array}$ \\
\cline { 3 - 5 } & (PWR/BWR) & $\begin{array}{c}\text { Total Waste } \\
\text { Packages }\end{array}$ & $\begin{array}{c}\text { Annual } \\
\text { Waste } \\
\text { Packages }\end{array}$ & Material \\
\hline Crystalline (enclosed) & $4 / 9$ & 82,583 & 1,757 & Copper \\
\hline Generic Salt Repository (enclosed) & $12 / 24$ & 28,792 & 616 & Carbon Steel \\
\hline Clay/Shale (enclosed) & $4 / 9$ & 82,583 & 1,757 & Carbon Steel \\
\hline Shale Unbackfilled (open) & $21 / 44$ & 16,157 & 344 & Carbon Steel \\
\hline Sedimentary Backfilled (open) & $21 / 44$ & 16,157 & 344 & Carbon Steel \\
\hline
\end{tabular}


Figure 25 - Summary of mined opening length and volume for the 5 example cost cases

(From Hardin 2012b Table 4-2)

Table 4-2 - Summary of Mined Opening Length and Volume for 5 Disposal Concepts

\begin{tabular}{|l|c|c|c|c|c|c|c|c|}
\hline \multirow{2}{*}{} & \multicolumn{2}{|c|}{ Access Drift } & \multicolumn{2}{c|}{$\begin{array}{c}\text { Disposal Drifts/ } \\
\text { Borings }\end{array}$} & \multicolumn{2}{c|}{ Service Drift } & \multicolumn{2}{c|}{ Repository Total } \\
\cline { 2 - 10 } & $\begin{array}{c}\text { Length } \\
(\mathbf{m})\end{array}$ & $\begin{array}{c}\text { Volume } \\
\mathbf{( m}^{\mathbf{3}} \mathbf{)}\end{array}$ & $\begin{array}{c}\text { Length } \\
\mathbf{( m )}\end{array}$ & $\begin{array}{c}\text { Volume } \\
\mathbf{( m}^{\mathbf{3}} \mathbf{)}\end{array}$ & $\begin{array}{c}\text { Length } \\
\mathbf{( m )}\end{array}$ & $\begin{array}{c}\text { Volume } \\
\mathbf{( m}^{3} \mathbf{)}\end{array}$ & $\begin{array}{c}\text { Length } \\
(\mathbf{m})\end{array}$ & $\begin{array}{c}\text { Volume } \\
\left.\mathbf{( m}^{3}\right)\end{array}$ \\
\hline Crystalline (enclosed) & $8.3 \mathrm{E} 5$ & $2.7 \mathrm{E} 7$ & $8.3 \mathrm{E} 5$ & $1.8 \mathrm{E} 6$ & $2.3 \mathrm{E} 5$ & $7.7 \mathrm{E} 6$ & $1.9 \mathrm{E} 6$ & $3.7 \mathrm{E} 7$ \\
\hline $\begin{array}{l}\text { Generic Salt Repository } \\
\text { (enclosed) }\end{array}$ & $3.1 \mathrm{E} 5$ & $1.7 \mathrm{E} 7$ & $3.5 \mathrm{E} 5$ & $4.4 \mathrm{E} 6$ & $1.3 \mathrm{E} 5$ & $7.2 \mathrm{E} 6$ & $7.9 \mathrm{E} 5$ & $2.9 \mathrm{E} 7$ \\
\hline Clay/Shale (enclosed) & $3.9 \mathrm{E} 5$ & $9.2 \mathrm{E} 6$ & $8.3 \mathrm{E} 5$ & $4.6 \mathrm{E} 6$ & $3.7 \mathrm{E} 5$ & $8.7 \mathrm{E} 6$ & $1.6 \mathrm{E} 6$ & $2.3 \mathrm{E} 7$ \\
\hline Shale Unbackfilled (open) & $7.7 \mathrm{E} 4$ & $2.2 \mathrm{E} 6$ & $1.4 \mathrm{E} 5$ & $2.3 \mathrm{E} 6$ & $9.3 \mathrm{E} 4$ & $2.2 \mathrm{E} 6$ & $3.1 \mathrm{E} 5$ & $6.7 \mathrm{E} 6$ \\
\hline Sedimentary Backfilled (open) & $8.5 \mathrm{E} 4$ & $2.0 \mathrm{E} 6$ & $2.2 \mathrm{E} 5$ & $3.5 \mathrm{E} 6$ & $5.8 \mathrm{E} 4$ & $1.4 \mathrm{E} 6$ & $3.6 \mathrm{E} 5$ & $6.9 \mathrm{E} 6$ \\
\hline
\end{tabular}

Figure 26 - Summary of shaft and ramp quantities for the 5 example cost cases

(From Hardin 2012b Table 4-3)

Table 4-3 - Summary of Shaft and Ramp Quantities for a 140,000 MT SNF Repository

\begin{tabular}{|l|c|c|c|c|c|}
\hline & \multirow{2}{*}{ Air Intake } & \multirow{2}{*}{ Rock Waste } & \multirow{2}{*}{$\begin{array}{c}\text { Ventilation } \\
\text { Exhaust }\end{array}$} & \multicolumn{2}{|c|}{ Waste Emplacement } \\
\cline { 5 - 6 } & & & 2 & 1 & 0 \\
\hline Crystalline (enclosed) & 1 & 1 & 2 & 1 & 0 \\
\hline Generic Salt Repository (enclosed) & 1 & 1 & 2 & 0 & 1 \\
\hline Clay/Shale (enclosed) & 1 & 1 & 4 & 0 & 1 \\
\hline Shale Unbackfilled (open) & 8 & 1 & 5 & 0 & 1 \\
\hline Sedimentary Backfilled (open) & 10 & 1 & & 2 & 1 \\
\hline
\end{tabular}


Figure 27 - Cost example case 1 - crystalline (enclosed) repository drift panel detail summary

(From Hardin 2012b Table 4.1-1 and 4.1-2)

Table 4.1-1 - Crystalline (enclosed) Repository Drift Panel Detail Summary

\begin{tabular}{|c|c|c|c|c|c|c|}
\hline Drift/Boring Function & $\begin{array}{c}\text { Diameter } \\
\text { (m) }\end{array}$ & $\begin{array}{c}\text { Length } \\
\text { (m) }\end{array}$ & $\begin{array}{l}\text { Number (per } \\
\text { panel) }\end{array}$ & $\begin{array}{c}\text { Total Length } \\
\text { (m) }\end{array}$ & $\begin{array}{c}\text { Spacing } \\
\text { (m) }\end{array}$ & Closure \\
\hline Waste Emplacement & 1.66 & 10 & 1,200 & 12,000 & 10 & $\begin{array}{l}\text { Bentonite clay } \\
\text { backfilled at } \\
\text { emplacement and shield } \\
\text { plug installed }\end{array}$ \\
\hline Access Drifts & 6.5 & 1000 & 12 & 12,000 & 20 & $\begin{array}{l}\text { Backfilled with } 30 \% \\
\text { bentonite clay and } 70 \% \\
\text { crushed rock }\end{array}$ \\
\hline Service Drifts & 5.5 & $\begin{array}{c}326 \\
1100\end{array}$ & $\begin{array}{l}4 \\
2\end{array}$ & 3,352 & N/A & $\begin{array}{l}\text { Backfilled with } 30 \% \\
\text { bentonite clay and } 70 \% \\
\text { crushed rock }\end{array}$ \\
\hline Panel Total & & & & 27,352 & & \\
\hline
\end{tabular}

Table 4.1-2 - Crystalline (enclosed) Concept Repository Waste Emplacement Details

\begin{tabular}{|c|c|c|c|c|c|}
\hline $\begin{array}{c}\text { Emplacement } \\
\text { Mode }\end{array}$ & $\begin{array}{c}\text { PWR/BWR } \\
\text { Package } \\
\text { Size }\end{array}$ & $\begin{array}{c}\text { Waste } \\
\text { Package } \\
\text { Spacing (m) }\end{array}$ & $\begin{array}{c}\text { Waste Packages per } \\
\text { Emplacement Drift }\end{array}$ & $\begin{array}{c}\text { Waste } \\
\text { Packages } \\
\text { Per Panel }\end{array}$ & $\begin{array}{c}\text { Waste Package } \\
\text { Description }\end{array}$ \\
\hline Vertical Borehole & $4 / 9$ & 10 & $\begin{array}{c}100 \mathrm{WP} \text { per } \\
1,000 \mathrm{~m} \text { segment }\end{array}$ & 1200 & $\begin{array}{l}\text { Stainless steel SNF } \\
\text { canister with } 5 \mathrm{~cm} \text { thick } \\
\text { copper overpack }\end{array}$ \\
\hline
\end{tabular}


As shown on the NAVIGATION worksheet in Figure 4, there are two cost-related worksheets

\section{- COST CALCULATIONS}

- COST REFERENCES

The COST CALCULATIONS worksheet (below the summary information described in the next two paragraphs) follows the Carter/Hardin model cost categories with the changes described above. Depending on the availability of source data, the calculations can be done at three increasing levels of detail. In some cases, there are detailed data on unit costs, and a specific measure of the number of units is available, such as cost per unit volume to excavate emplacement drifts, and emplacement drift lengths. In this case, the calculation could start at level 3 (the most detailed) and build up the costs of subsurface construction to be added together at level 2 or level 1 . In other cases, the detailed information may not be available, so the user can put data in at level 2 for several cost components to be summed up at level 1. If there isn't enough detail to break the calculation down further, such as for regulatory \& licensing, then the user may enter the data at level 1. As on the INPUTS worksheet, data transferred from other worksheets or data areas in DSEF is shown in light blue, and cells that allow the user to override or directly input data are highlighted in yellow. It is recommended that the user do the overrides in the INPUTS worksheet. Overrides in the COST CALCULATIONS worksheet persist even if the user makes changes in INPUTS, so the user should scan the COST CALCULATIONS override columns to avoid inadvertent overrides for subsequent cases.

The top-left section of the COST CALCULATION worksheet summarizes the raw costs in each category as well as the low and high contingency values. Figure 28 shows an example of the top-left section. The low contingency values are copied from the three-level detailed table below it (as described in the preceding paragraph), and the raw and high contingency values are calculated in the summary table, using the contingencies selected in the INPUTS worksheet. As detailed in the Carter/Hardin model documentation, the values applied for low and high contingency adjustment vary by the cost calculation category. The lookup tables in the LISTS worksheet (which supply contingency values to the INPUTS sheet for the five Carter/Hardin examples) assume the low contingency value is $5 \%$ in most cases (except where it is given explicitly by Carter). These lookup tables also include high contingency values that were derived from the summary low and high contingency cost results in Carter/Hardin. This approach yielded good agreement with the five example cases, as shown below. Since the DSEF modeling was based on matching the low contingency values, the raw cost values were obtained by dividing the low contingency calculated values by 1 plus the low contingency, and the high contingency values were then calculated by multiplying the raw cost values by 1 plus the high contingency.. A table showing the general rules for applying contingency factors that were used in the Carter/Hardin model is included in the COST REFERENCES worksheet. The user can override the recommended contingency values in INPUTS. 
Figure 28 - Cost summary table example as shown on the RESULTS worksheet

\begin{tabular}{|l|r|r|r|}
\hline \multirow{2}{*}{ Cost in MM\$ } & \multicolumn{3}{|c|}{ Current Case } \\
\cline { 2 - 4 } & \multicolumn{3}{|c|}{ Case evaluation below is ROM cost study case: ROM Cost } \\
Case 4 - Clay/Shale (open)
\end{tabular}


The five Carter/Hardin cost cases (that had detailed costing in unreleased documentation) were used to construct the DSEF cost model, using cost results summarized by Carter and Hardin at the category level. That comparison is documented on the top-right section of the COST CALCULATIONS worksheet, where the DSEF calculated numbers are compared to the "Low and High Contingency" numbers from Carter/Hardin. The comparisons are shown in Figure 29 through Figure 33, and are generally within 5\% of the total costs. In a number of cases, the DSEF modeling was based on estimating some scaling factors, such as scaling backfill costs for emplacement drifts per unit volume or length while accounting for a volume reduction fraction due to drift inverts. The Carter/Hardin unit costs were shifted slightly to allow for this kind of user input, while still calculating a reasonable total backfill cost.

Figure 29 - Cost summary table comparing Carter/Hardin Case 1 (Crystalline Enclosed) results with DSEF results

\begin{tabular}{|l|c|c|c|c|c|c|}
\hline \multicolumn{1}{|c|}{ Costs in MM\$ } & DSEF & Carter & $\begin{array}{c}\text { DSEF/ } \\
\text { Carter }\end{array}$ & DSEF & Carter & $\begin{array}{c}\text { DSEF/ } \\
\text { Carter }\end{array}$ \\
\hline Cost Category & Low & Low & Low $\%$ & High & High & High $\%$ \\
\hline Facility DC\&S & & $\$ 3,754$ & & & $\$ 5,495$ & \\
\hline Facility D\&S & $\$ 1,026$ & & & $\$ 1,498$ & & \\
\hline Surface & $\$ 1,368$ & & & $\$ 1,997$ & & \\
\hline Subsurface & $\$ 12,484$ & & & $\$ 18,227$ & & \\
\hline Ventilation & $\$ 0$ & & & $\$ 0$ & & \\
\hline O\&M (incl some constr) & & $\$ 17,545$ & & & $\$ 22,475$ & \\
\hline O\&M (n/i ventilation) & $\$ 7,050$ & & & $\$ 9,024$ & & \\
\hline Upper Half Subtotal & $\$ 21,928$ & $\$ 21,299$ & $103 \%$ & $\$ 30,746$ & $\$ 27,970$ & $110 \%$ \\
\hline Closure & $\$ 9,698$ & $\$ 9,563$ & $101 \%$ & $\$ 13,224$ & $\$ 13,704$ & $96 \%$ \\
\hline WPs & $\$ 16,682$ & $\$ 17,489$ & $95 \%$ & $\$ 20,685$ & $\$ 21,647$ & $96 \%$ \\
\hline Regulatory \& Licensing & $\$ 424$ & $\$ 424$ & $100 \%$ & $\$ 441$ & $\$ 441$ & $100 \%$ \\
\hline Monitoring & $\$ 10,436$ & $\$ 10,685$ & $98 \%$ & $\$ 14,231$ & $\$ 14,571$ & $98 \%$ \\
\hline PC & $\$ 420$ & $\$ 411$ & $102 \%$ & $\$ 571$ & $\$ 561$ & $102 \%$ \\
\hline Integration & $\$ 1,575$ & $\$ 1,575$ & $100 \%$ & $\$ 2,148$ & $\$ 2,142$ & $100 \%$ \\
\hline Lower Half Subtotal & $\$ 39,235$ & $\$ 40,147$ & $98 \%$ & $\$ 51,300$ & $\$ 53,066$ & $97 \%$ \\
\hline Total & $\$ 61,163$ & $\$ 61,446$ & $100 \%$ & $\$ 82,046$ & $\$ 81,036$ & $101 \%$ \\
\hline
\end{tabular}


Figure 30 - Cost summary table comparing Carter/Hardin Case 2 (Salt Enclosed) results with DSEF results

\begin{tabular}{|l|c|c|c|c|c|c|}
\hline \multicolumn{1}{|c|}{ Costs in MM\$ } & DSEF & Carter & $\begin{array}{c}\text { DSEF/ } \\
\text { Carter }\end{array}$ & DSEF & Carter & $\begin{array}{c}\text { DSEF/ } \\
\text { Carter }\end{array}$ \\
\hline Cost Category & Low & Low & Low $\%$ & High & High & High $\%$ \\
\hline Facility DC\&S & & $\$ 3,896$ & & & $\$ 5,595$ & \\
\hline Facility D\&S & $\$ 1,015$ & & & $\$ 1,482$ & & \\
\hline Surface & $\$ 1,368$ & & & $\$ 1,997$ & & \\
\hline Subsurface & $\$ 2,893$ & & & $\$ 4,224$ & & \\
\hline Ventilation & $\$ 0$ & & & $\$ 0$ & & \\
\hline O\&M (incl some constr) & & $\$ 7,947$ & & & $\$ 10,259$ & \\
\hline O\&M (n/i ventilation) & $\$ 7,050$ & & & $\$ 9,024$ & & \\
\hline Upper Half Subtotal & $\$ 12,326$ & $\$ 11,843$ & $104 \%$ & $\$ 16,727$ & $\$ 15,854$ & $106 \%$ \\
\hline Closure & $\$ 855$ & $\$ 832$ & $103 \%$ & $\$ 1,322$ & $\$ 1,363$ & $97 \%$ \\
\hline WPs & $\$ 3,801$ & $\$ 3,998$ & $95 \%$ & $\$ 4,713$ & $\$ 4,950$ & $95 \%$ \\
\hline Regulatory \& Licensing & $\$ 368$ & $\$ 368$ & $100 \%$ & $\$ 383$ & $\$ 379$ & $101 \%$ \\
\hline Monitoring & $\$ 4,646$ & $\$ 4,580$ & $101 \%$ & $\$ 6,336$ & $\$ 6,246$ & $101 \%$ \\
\hline PC & $\$ 560$ & $\$ 567$ & $99 \%$ & $\$ 762$ & $\$ 773$ & $99 \%$ \\
\hline Integration & $\$ 2,136$ & $\$ 2,136$ & $100 \%$ & $\$ 2,913$ & $\$ 2,907$ & $100 \%$ \\
\hline Lower Half Subtotal & $\$ 12,366$ & $\$ 12,481$ & $99 \%$ & $\$ 16,428$ & $\$ 16,618$ & $99 \%$ \\
\hline Total & $\$ 24,692$ & $\$ 24,324$ & $102 \%$ & $\$ 33,155$ & $\$ 32,472$ & $102 \%$ \\
\hline
\end{tabular}


Figure 31 - Cost summary table comparing Carter/Hardin Case 3 (Clay/Shale Enclosed) results with DSEF results

\begin{tabular}{|l|c|c|c|c|c|c|}
\hline \multicolumn{1}{|c|}{ Costs in MM\$ } & DSEF & Carter & $\begin{array}{c}\text { DSEF/ } \\
\text { Carter }\end{array}$ & DSEF & Carter & $\begin{array}{c}\text { DSEF/ } \\
\text { Carter }\end{array}$ \\
\hline Cost Category & Low & Low & Low $\%$ & High & High & High $\%$ \\
\hline Facility DC\&S & & 6,872 & & & 10,064 & \\
\hline Facility D\&S & 1,547 & & & 2,259 & & \\
\hline Surface & 1,368 & & & 1,997 & & \\
\hline Subsurface & 22,949 & & & 33,506 & & \\
\hline Ventilation & 0 & & & 0 & & \\
\hline O\&M (incl some constr) & & 26,884 & & & 34,525 & \\
\hline O\&M (n/i ventilation) & 7,050 & & & 9,024 & & \\
\hline Upper Half Subtotal & $\$ 32,914$ & $\$ 33,756$ & $98 \%$ & $\$ 46,786$ & $\$ 44,589$ & $105 \%$ \\
\hline Closure & 5,199 & 5,556 & $94 \%$ & 8,035 & 8,334 & $96 \%$ \\
\hline WPs & 7,185 & 7,542 & $95 \%$ & 8,909 & 9,337 & $95 \%$ \\
\hline Regulatory \& Licensing & 414 & 414 & $100 \%$ & 431 & 429 & $100 \%$ \\
\hline Monitoring & 9,028 & 9,021 & $100 \%$ & 12,311 & 12,302 & $100 \%$ \\
\hline PC & 756 & 758 & $100 \%$ & 1,028 & 1,034 & $99 \%$ \\
\hline Integration & 2914 & 2,914 & $100 \%$ & 3,974 & 3,965 & $100 \%$ \\
\hline Lower Half Subtotal & $\$ 25,496$ & $\$ 26,205$ & $97 \%$ & $\$ 34,688$ & $\$ 35,401$ & $98 \%$ \\
\hline Total & $\$ 58,410$ & $\$ 59,961$ & $97 \%$ & $\$ 81,474$ & $\$ 79,990$ & $102 \%$ \\
\hline
\end{tabular}


Figure 32 - Cost summary table comparing Carter/Hardin Case 4 (Clay/Shale Open) results with DSEF results

\begin{tabular}{|l|c|c|c|c|c|c|}
\hline \multicolumn{1}{|c|}{ Costs in MM\$ } & DSEF & Carter & $\begin{array}{c}\text { DSEF/ } \\
\text { Carter }\end{array}$ & DSEF & Carter & $\begin{array}{c}\text { DSEF/ } \\
\text { Carter }\end{array}$ \\
\hline Cost Category & Low & Low & Low $\%$ & High & High & High $\%$ \\
\hline Facility DC\&S & & 3,303 & & & 4,711 & \\
\hline Facility D\&S & 740 & & & 1,080 & & \\
\hline Surface & 1,368 & & & 1,997 & & \\
\hline Subsurface & 1,831 & & & 2,674 & & \\
\hline Ventilation & 2,035 & & & 2,971 & & \\
\hline O\&M (incl some constr) & & 9,702 & & & 12,408 & \\
\hline O\&M (n/i ventilation) & 7,050 & & & 9,024 & & \\
\hline Upper Half Subtotal & $\$ 13,024$ & $\$ 13,005$ & $100 \%$ & $\$ 17,746$ & $\$ 17,119$ & $104 \%$ \\
\hline Closure & 1,425 & 1,622 & $88 \%$ & 2,203 & 2,515 & $88 \%$ \\
\hline WPs & 2,747 & 2,882 & $95 \%$ & 3,406 & 3,569 & $95 \%$ \\
\hline Regulatory \& Licensing & 417 & 417 & $100 \%$ & 434 & 421 & $103 \%$ \\
\hline Monitoring & 3,320 & 3,395 & $98 \%$ & 4,528 & 4,629 & $98 \%$ \\
\hline PC & 420 & 423 & $99 \%$ & 571 & 576 & $99 \%$ \\
\hline Integration & 3732 & 3,732 & $100 \%$ & 5,089 & 5,084 & $100 \%$ \\
\hline Lower Half Subtotal & $\$ 12,061$ & $\$ 12,471$ & $97 \%$ & $\$ 16,231$ & $\$ 16,794$ & $97 \%$ \\
\hline Total & $\$ 25,085$ & $\$ 25,476$ & $98 \%$ & $\$ 33,977$ & $\$ 33,913$ & $100 \%$ \\
\hline
\end{tabular}


Figure 33 - Cost summary table comparing Carter/Hardin Case 5 (Sedimentary Open) results with DSEF results

\begin{tabular}{|l|c|c|c|c|c|c|}
\hline \multicolumn{1}{|c|}{ Costs in MM\$ } & DSEF & Carter & $\begin{array}{c}\text { DSEF/ } \\
\text { Carter }\end{array}$ & DSEF & Carter & $\begin{array}{c}\text { DSEF/ } \\
\text { Carter }\end{array}$ \\
\hline Cost Category & Low & Low & Low $\%$ & High & High & High $\%$ \\
\hline Facility DC\&S & & 5,410 & & & 7,599 & \\
\hline Facility D\&S & 1,282 & & & 1,872 & & \\
\hline Surface & 1,368 & & & 1,997 & & \\
\hline Subsurface & 1,923 & & & 2,807 & & \\
\hline Ventilation & 3,010 & & & 4,395 & & \\
\hline O\&M (incl some constr) & & 9,614 & & & 12,264 & \\
\hline O\&M (n/i ventilation) & 7,050 & & & 9,024 & & \\
\hline Upper Half Subtotal & $\$ 14,633$ & $\$ 15,024$ & $97 \%$ & $\$ 20,095$ & $\$ 19,863$ & $101 \%$ \\
\hline Closure & 2,075 & 2,263 & $92 \%$ & 3,207 & 3,558 & $90 \%$ \\
\hline WPs & 2,747 & 2,882 & $95 \%$ & 3,406 & 3,569 & $95 \%$ \\
\hline Regulatory \& Licensing & 668 & 668 & $100 \%$ & 695 & 679 & $102 \%$ \\
\hline Monitoring & 3,780 & 3,775 & $100 \%$ & 5,155 & 5,148 & $100 \%$ \\
\hline PC & 798 & 798 & $100 \%$ & 1,085 & 1,088 & $100 \%$ \\
\hline Integration & 6878 & 6,878 & $100 \%$ & 9,379 & 9,370 & $100 \%$ \\
\hline Lower Half Subtotal & $\$ 16,946$ & $\$ 17,264$ & $98 \%$ & $\$ 22,927$ & $\$ 23,412$ & $98 \%$ \\
\hline Total & $\$ 31,579$ & $\$ 32,288$ & $98 \%$ & $\$ 43,022$ & $\$ 43,275$ & $99 \%$ \\
\hline
\end{tabular}

The bottom section of the COST CALCULATION worksheet retains some of the emplacement drift mining calculations that were performed in DSEF Version 2.1, summarizing required drift length based on waste package capacity, drift dimensions, and waste package spacing information. In the future, this section could be expanded to calculate lengths of access drifts and service drifts for various layouts, as well as shaft and ramp counts and lengths.

The top section of the COST-REFERENCES worksheet includes tables extracted from Hardin 2012b summarizing the data and assumptions for the five example cases that DSEF displays on the cost section of the INPUTS worksheet. The bottom section of the COST-REFERENCES worksheet provides a number of web pages for current data related to backfill material properties and costs. However, this is neither an endorsement nor a recommendation for using these particular web pages, which were chosen as examples for a ballpark estimate as a starting point for the user. 


\section{The WASTE FORM Worksheet}

The WASTE FORM worksheet summarizes the waste form and waste package dimensions assumed for all of the enclosed mode and open mode cases. Currently there is a limited set of sizes that have been considered. Figure 34 shows the tables of data from the enclosed mode and open mode repository design cases analyzed in FY11 and FY12 included on the WASTE FORM worksheet. The enclosed mode waste package dimensions were based on the reference international repository design concepts (see Hardin 2011).

Figure 35 shows is a lookup table for PWR waste form outer radius (waste package inner radius), and the geometric figures that form the basis for the development of the lookup table. The WASTE FORM worksheet also includes data on PWR and BWR fuel basket designs from storage cask vendor designs. This data was used to define the unit cell dimensions used in the PWR waste form radius lookup table. As shown on the WASTE FORM worksheet, a cross-check of the calculation methodology used to construct the table for the 21-PWR waste package inner radius agrees closely with the value assumed in the open mode thermal analysis for that waste package size.

Although not currently planned, other potential developments of this worksheet might be used to define an equivalent internal thermal conductivity for waste packages for the purpose of determining peak cladding or HLW glass temperatures during thermal transients. This has not been investigated until now since the waste package surface temperature results have been low enough that this does not appear to be an issue. 
Figure 34 - Tables from the WASTE FORM worksheet

\begin{tabular}{|c|c|c|}
\hline \multirow{2}{*}{ Enclosed Mode Cases } \\
\hline \multirow{4}{*}{ Waste Form } & $\begin{array}{c}\text { Geologic } \\
\text { Medium }\end{array}$ & $\begin{array}{c}\text { Waste } \\
\text { Package } \\
\text { Wall } \\
\text { thickness } \\
(\mathrm{m})\end{array}$ \\
\hline \multirow{4}{*}{ SNF (UOX and MOX) } & 0.1 \\
\cline { 2 - 3 } & Granite & 0.11 \\
\cline { 2 - 3 } & Clay & 0.11 \\
\cline { 2 - 3 } & Salt & 0.03 \\
\hline \multirow{3}{*}{ HLW (Co-X, New-X,,$\quad$ borehole } & 0.011 \\
\cline { 2 - 3 } EC-C, and EC-M) & Granite & 0.01 \\
\cline { 2 - 3 } & Clay & 0.01 \\
\cline { 2 - 3 } & Salt & 0.01 \\
\hline
\end{tabular}

\begin{tabular}{|c|c|c|}
\hline \multicolumn{3}{|c|}{ Open Mode Cases } \\
\hline \multirow{4}{*}{ Waste Form } & Geologic & $\begin{array}{c}\text { Waste } \\
\text { Package } \\
\text { Wall } \\
\text { Medium } \\
\text { thickness } \\
(\mathrm{m})\end{array}$ \\
\hline \multirow{2}{*}{ SNF (UOX) } & Clay & 0.11 \\
\cline { 2 - 3 } & Alluvium & 0.11 \\
\hline
\end{tabular}

\begin{tabular}{|c|c|}
\hline \multicolumn{2}{|c|}{ Open Mode Cases } \\
\hline Waste Form & $\begin{array}{c}\text { Waste Package } \\
\text { Length }(\mathrm{m})\end{array}$ \\
\hline SNF (UOX) & 5 \\
\hline
\end{tabular}

\begin{tabular}{|c|c|}
\hline \multicolumn{2}{|c|}{ Enclosed Mode Cases } \\
\hline Waste Form & $\begin{array}{c}\text { Waste Package } \\
\text { Length }(\mathrm{m})\end{array}$ \\
\hline SNF (UOX and MOX) & 5 \\
\hline $\begin{array}{c}\mathrm{HLW}(\mathrm{Co}-\mathrm{X}, \mathrm{NeW}-\mathrm{X} \\
\text { and } \mathrm{EC}-\mathrm{C})\end{array}$ & $\begin{array}{l}4.572 \\
(15 \mathrm{ft})\end{array}$ \\
\hline HWL (EC-M) & $\begin{array}{l}3.048 \\
(10 \mathrm{ft})\end{array}$ \\
\hline
\end{tabular}

\begin{tabular}{|c|c|c|}
\hline \multicolumn{3}{|c|}{ Open Mode Cases } \\
\hline $\begin{array}{c}\text { Number of SNF } \\
\text { Assemblies }\end{array}$ & $\begin{array}{c}\text { Waste Package } \\
\text { Inner Radius } \\
\text { (m) }\end{array}$ & $\begin{array}{c}\text { Waste } \\
\text { Package } \\
\text { Outer Radius } \\
\text { (m) }\end{array}$ \\
\hline 4 & 0.3 & 0.41 \\
\hline 12 & 0.535 & 0.645 \\
\hline 21 & 0.69 & 0.8 \\
\hline 32 & 0.89 & 1 \\
\hline
\end{tabular}

\begin{tabular}{|c|c|c|c|c|c|c|}
\hline \multicolumn{7}{|c|}{ Enclosed Mode Cases } \\
\hline $\begin{array}{l}\text { Number of } \\
\text { Assemblies or } \\
\text { Canisters }\end{array}$ & $\begin{array}{l}\text { Geologic } \\
\text { Medium }\end{array}$ & $\begin{array}{c}\text { Waste } \\
\text { Package } \\
\text { Inner Radius } \\
\text { (m) }\end{array}$ & $\begin{array}{c}\text { Waste } \\
\text { Package } \\
\text { Outer Radius } \\
\text { Granite }(\mathrm{m})\end{array}$ & $\begin{array}{c}\text { Waste Package } \\
\text { Outer Radius } \\
\text { Clay }(\mathrm{m})\end{array}$ & $\begin{array}{c}\text { Waste } \\
\text { Package } \\
\text { Outer Radius } \\
\text { Salt }(\mathrm{m})\end{array}$ & $\begin{array}{c}\text { Waste } \\
\text { Package } \\
\text { Outer Radius } \\
\text { Deep } \\
\text { Borehole } \\
\text { (m) }\end{array}$ \\
\hline 1 SNF assembly & \multirow{6}{*}{$\begin{array}{c}\text { All Except } \\
\text { Deep Borehole }\end{array}$} & 0.19 & 0.29 & 0.3 & 0.22 & \\
\hline 2 SNF assemblies & & 0.38 & 0.48 & 0.49 & 0.41 & \\
\hline 3 SNF assemblies & & 0.38 & 0.48 & 0.49 & 0.41 & \\
\hline 4 SNF assemblies & & 0.38 & 0.48 & 0.49 & 0.41 & \\
\hline 12 SNF assemblies & & 0.555 & 0.655 & 0.665 & 0.585 & \\
\hline $1 \mathrm{HLW}$ canister & & 0.295 & 0.305 & 0.305 & 0.305 & \\
\hline $\begin{array}{c}1 \text { assembly (with rod } \\
\text { consolidation) }\end{array}$ & \multirow[b]{2}{*}{ Deep Borehole } & 0.159 & & & & 0.17 \\
\hline $\begin{array}{c}0.291 \text { canisters } \\
\text { (modified smaller } \\
\text { radius HLW canister) }\end{array}$ & & 0.159 & & & & 0.17 \\
\hline
\end{tabular}


Figure 35 - WASTE FORM worksheet - calculated waste form outer radius lookup table

\begin{tabular}{|c|c|}
\hline $\begin{array}{l}\text { Number of } \\
\text { Assemblies }\end{array}$ & $\begin{array}{l}\text { PWR Waste } \\
\text { Form Outer } \\
\text { Radius }(m)\end{array}$ \\
\hline 1 & 0.168 \\
\hline 2 & 0.335 \\
\hline 3 & 0.335 \\
\hline 4 & 0.335 \\
\hline 5 & 0.375 \\
\hline 6 & 0.427 \\
\hline 7 & 0.427 \\
\hline 8 & 0.503 \\
\hline 9 & 0.503 \\
\hline 10 & 0.503 \\
\hline 11 & 0.530 \\
\hline 12 & 0.530 \\
\hline 13 & 0.593 \\
\hline 14 & 0.593 \\
\hline 15 & 0.691 \\
\hline 16 & 0.691 \\
\hline 17 & 0.691 \\
\hline 18 & 0.691 \\
\hline 19 & 0.691 \\
\hline 20 & 0.691 \\
\hline 21 & 0.691 \\
\hline 22 & 0.749 \\
\hline 23 & 0.749 \\
\hline 24 & 0.749 \\
\hline 25 & 0.855 \\
\hline 26 & 0.855 \\
\hline 27 & 0.855 \\
\hline 28 & 0.855 \\
\hline 29 & 0.855 \\
\hline 30 & 0.855 \\
\hline 31 & 0.855 \\
\hline 32 & 0.855 \\
\hline
\end{tabular}
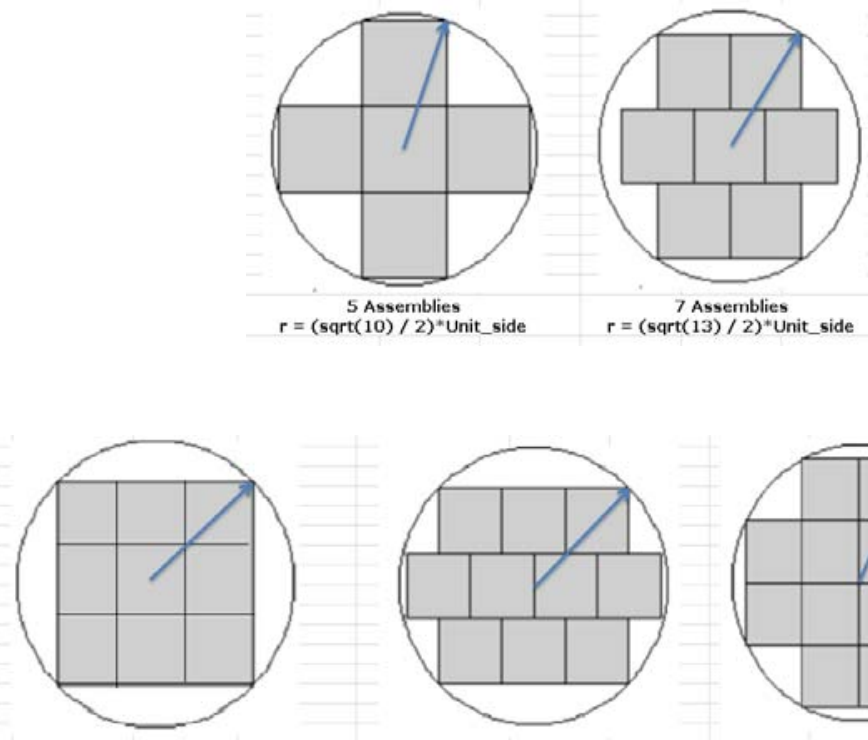
9 Assemblies
$r=\left(3^{*}\right.$ sqrt $\left.\left.(2)\right) / 2\right)^{*}$ Unit_side

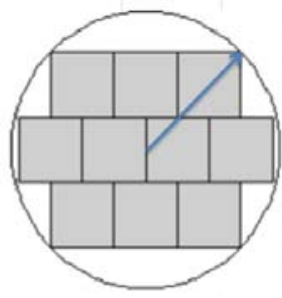

10 Assemblies $r=\left(3^{*}\right.$ sqrt $\left.\left.(2)\right) / 2\right)^{*}$ Unit_side
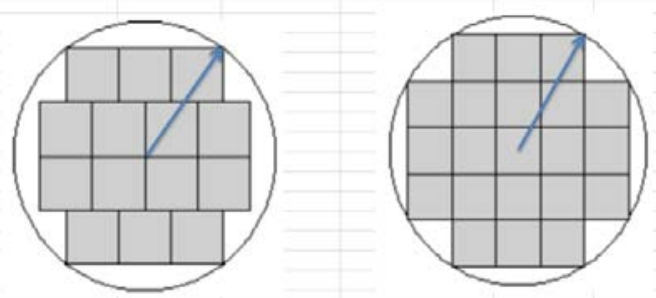
14 Assemblies
$r=2.5^{*}$ Unit_side

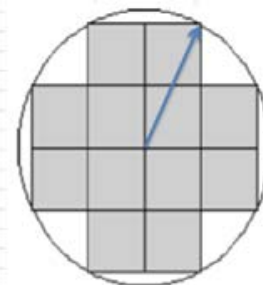

$\begin{aligned} & 12 \text { Assemblies } \\ = & \text { sqrt }(5)^{*} \text { Unit_sid }\end{aligned}$

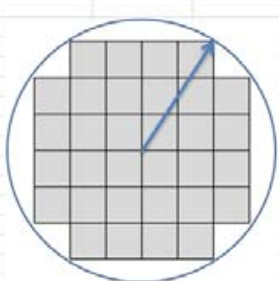

32 Assemblies $=\operatorname{sqrt}(13) *$ Unit_side 


\section{Defining Thermal Data Inputs and Outputs -the THERMAL Worksheets}

As shown on the NAVIGATION worksheet in Figure 4, there are a series of thermal worksheets

- THERMAL

- THERMAL-ANALYTICAL

- THERMAL-ANALYTICAL OUTPUT

- THERMAL-FEM (see Section 13)

- THERMAL-INTERPOLATE (discussed in Section 7 with the CASE LIBRARY)

- THERMAL-SOURCE

These worksheets are all linked together by the main THERMAL worksheet. Besides including hyperlinks to the other worksheets, the THERMAL worksheet also displays plots of the decay heat chosen for the current analysis case on the THERMAL-SOURCE worksheet. The following describes the use of these other worksheets.

The THERMAL-ANALYTICAL Worksheet - Passing Input Data to Mathcad

The THERMAL-ANALYTICAL worksheet is the interface for passing data to the Mathcad thermal analytical component of DSEF. No numerical calculations are performed in this worksheet, but the formulas in the worksheet cells pull data from the INPUTS and THERMAL-SOURCE worksheets to a standard location cited in the Mathcad file.

The Mathcad file and the DSEF Excel file need to be in the same directory to facilitate the data transfer. As described in Appendix B, the Excel file name is entered in the Mathcad variable "file". Before Mathcad can read the Excel file, the Excel file must be closed. By default the Mathcad DSEF file has the calculation mode set to manual, and the variable "Write_OK" is set to "No". This allows the user to make adjustments and look at results prior to writing them back to the DSEF Excel file. To calculate a screen at a time as the user pages through the Mathcad file, press F9 or use the Mathcad TOOLS CALCULATE menu to select CALCULATE NOW, alternatively the user can calculate the entire document by pressing CTRL-F9 or selecting the menu option TOOLS - CALCULATE - CALCULATE WORKSHEET. After reviewing the results in MathCad, set the variable "Write_OK" to "Yes" and recalculate the Mathcad document to write the results back to the Excel file in the THERMALANALYTICAL OUTPUT worksheet. To preserve a record of the full Mathcad calculation, the user should print the file to a PDF file for future reference.

The THERMAL-ANALYTICAL OUTPUT Worksheet - Getting Results Back from Mathcad

After running an analysis case in Mathcad the summary of peak temperatures and times, and the full transient outputs are passed back to the THERMAL-ANALYTICAL OUTPUT worksheet, which in turn passes this data to the RESULTS worksheet of DSEF.

The THERMAL-ANALYTICAL OUTPUT worksheet also creates several kinds of plots. There are two plots that are specifically related to parametric studies, as shown in Figure 36. In addition to those plots, for each case in the parametric study two additional plots are provided. One showing the temperature 
transients at various locations within the EBS and at a second compliance point within the host rock, and another showing the contributions to the rock wall surface temperature are shown in Figure 37.

Figure 36- Example of parametric study plots on the THERMAL-ANALYTICAL OUTPUT worksheet
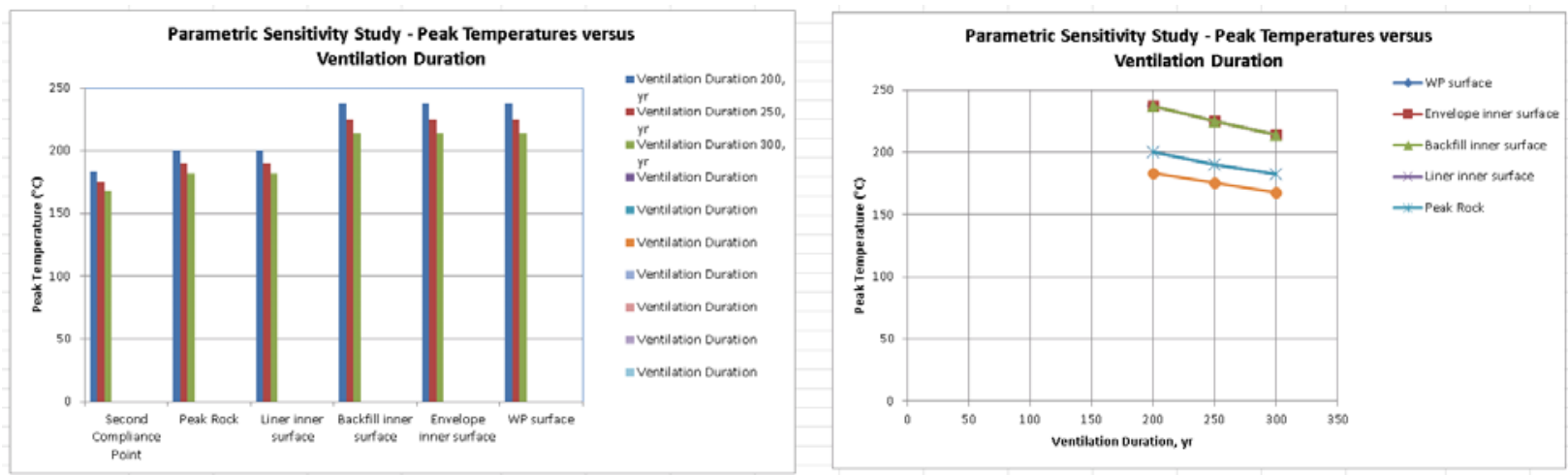

Figure 37 - Example transient output data plotted in the THERMAL-ANALYTICAL OUTPUT worksheet

Temperature Transients for Clay_UOX-40_QC-V2.0-B6-parametric_Case-229, for Parameter Value: Ventilation Duration 200, yr

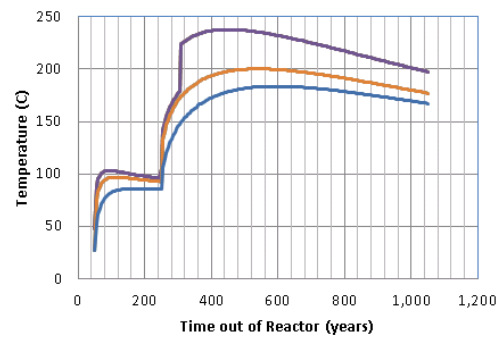

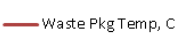

- EBS 3 inner Temp, C

-EBS 2 inner Temp, C

-EBS 1 inner Temp, C

- Rock Wall Temp, C

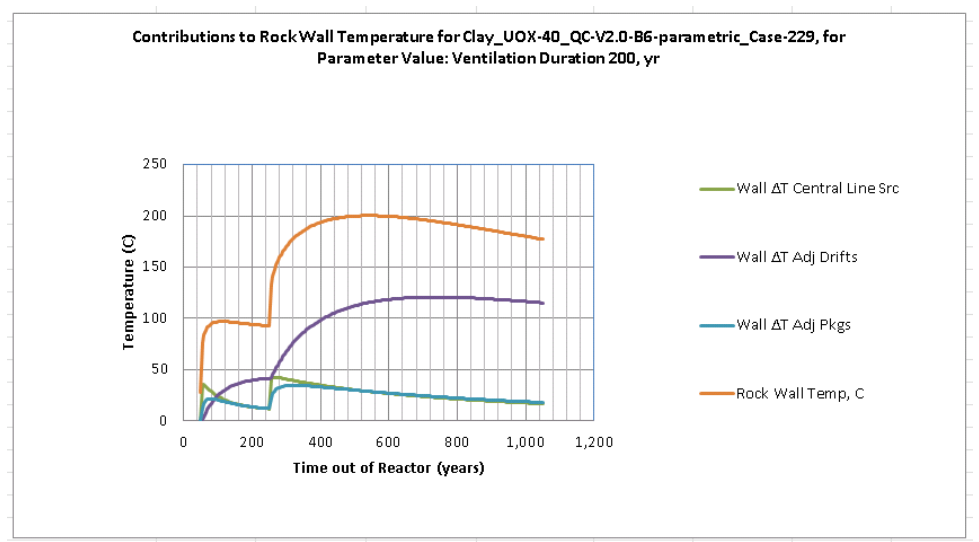

The THERMAL SOURCE Worksheet - Defining the Waste Form Decay Heat

The THERMAL SOURCE worksheet includes a fully documented set of decay heat curves for a set of seven waste forms previously analyzed from three potential fuel cycles

- A once-through LWR fuel cycle with UOX SNF of either $40 \mathrm{GWd} / \mathrm{MTU}$ or $60 \mathrm{GWd} / \mathrm{MTU}$ burnup

- A partial recycle fuel cycle with MOX SNF of $50 \mathrm{GWd} / \mathrm{MTU}$ burnup, and co-extraction glass HLW waste forms (COEX)

- A full recycle based on an Advanced Burner Reactor (ABR) with three HLW waste forms - newextraction glass (NUEX), Electro-chemical ceramic (E-Chem Ceramic), and Electro-chemical metal (E-Chem Metal).

In addition to these options there is a user-defined option for input from another fuel cycle or modifications to any of the pre-defined cases. Figure 38 shows a plot of the pre-defined waste form decay heat data available for selection on the THERMAL-SOURCE worksheet (Greenberg 2012a). 
Figure 38 - Decay heat data built-in to the THERMAL-SOURCE worksheet

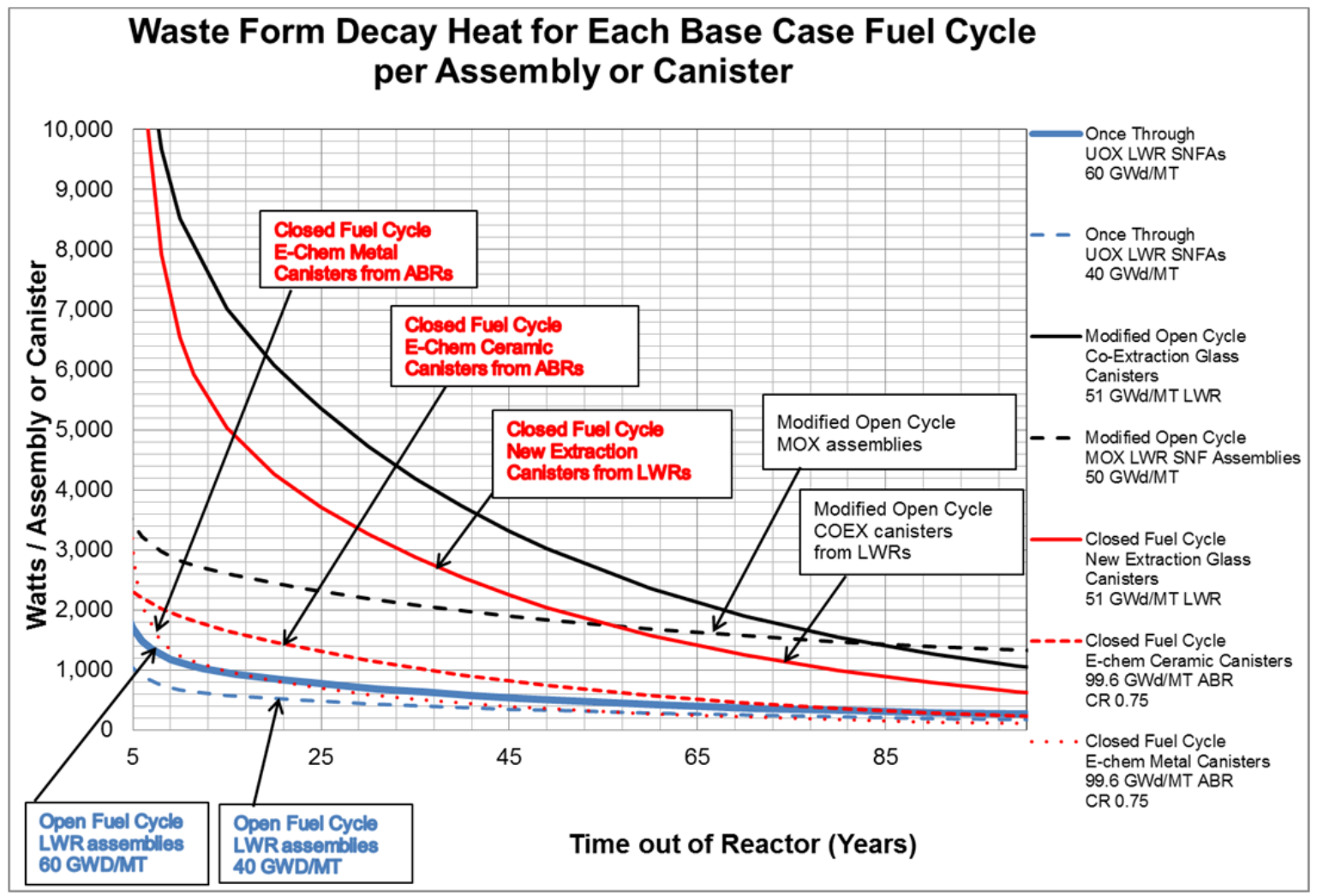

A drop-down list on the INPUTS worksheet allows the user to select one of these data sets, or choose to enter their own data. A prompt and a hyperlink are provided to go the THERMAL-SOURCE worksheet to examine the data, and to click on a macro button to update the decay heat input curve if necessary. Figure 39 shows an example of the "Update Decay Heat" macro button and the two types of prompts.

Figure 39 - Examples of decay heat update caution and confirmation prompts

The caution prompt:

\begin{tabular}{|c|}
\hline Update Decay Heat \\
\hline CAUTION - User Defined Decay Heat Data \\
Changed - Needs to be Updated
\end{tabular}

The confirmation prompt:

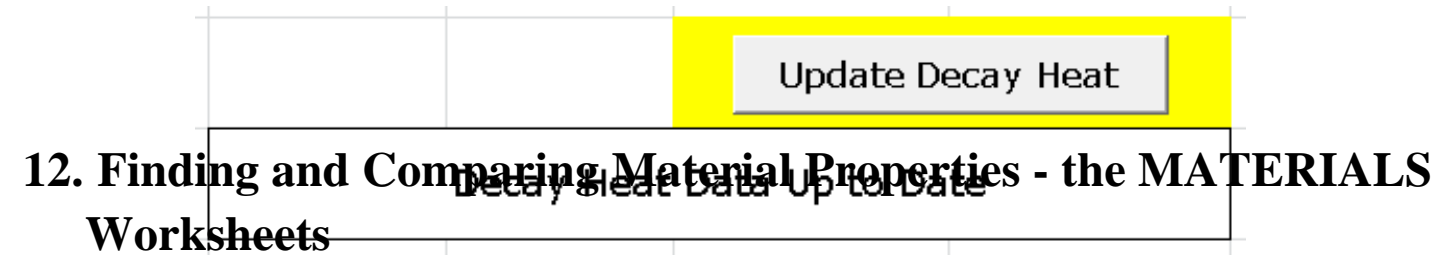

As shown on the NAVIGATION worksheet in Figure 4, there are a series of material worksheets 
- MATERIAL DATA PLOTTING

- MATERIALS

- MATERIALS-OTHER PROPERTIES (discussed in Section 13)

- MATERIALS-REFERENCES

- MATERIALS-THERMAL PROPERTIES

- MATERIALS-TRANSPORT PROPERTIES

These worksheets are all linked together by the main MATERIALS worksheet, which includes hyperlinks to the other materials worksheets, and then back to the INPUTS worksheet where the derived material properties will be used.

\section{The MATERIAL DATA PLOTTING Worksheet}

The MATERIAL DATA PLOTTING worksheet only contains a short list of instructions and a Click here to plot data distribution macro button. After clicking on that macro button a Select a Range user input box appears, as shown in Figure 40. At this point the user is free to navigate between material data worksheets by clicking on their tabs at the bottom of the screen, and then scrolling with the mouse to any set of data on those worksheets. The only restriction is that the range of data must be restricted to two yellow-highlighted columns, representing the high and low values of a single data parameter.

The range of data selected can be a continuous block of data values or a separate collection of different data sets (use the CTRL key with the mouse to select non-contiguous sets of data). Any blank rows in the middle of a range of data will be ignored. After clicking OK on the range selection box the user is returned to the MATERIAL DATA PLOTTING worksheet where they pick a location to place the statistical data and the plot, as shown in Figure 41 and Figure 41. However, the user is not restricted to placing the output data and plot on this worksheet. It can be placed on any other worksheet by navigating to the new location before clicking OK to insert the plot. 
Figure 40 - The first step - selecting the materials data to plot

\begin{tabular}{|c|c|c|c|c|c|c|}
\hline TH-N-9 & Clay & Opalinus clay & & & 0 & \\
\hline $\mathrm{TH}-\mathrm{N}-10$ & Clay & Opalinus clay & 1.38 & 1.24 & 1.31 & $\begin{array}{l}\text { Ref. C-27, citing Ref. C- } \\
31 \text {, assumed to be } \\
\text { isotropic }\end{array}$ \\
\hline \multirow[b]{2}{*}{$\mathrm{TH}-\mathrm{N}-11$} & \multirow[b]{2}{*}{ Clay } & \multirow[b]{2}{*}{ Opalinus clay } & \multirow{2}{*}{\multicolumn{2}{|c|}{ 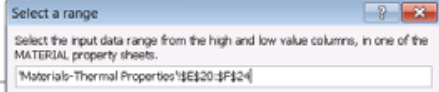 }} & \multirow[b]{2}{*}{0.81} & \multirow{2}{*}{$\begin{array}{l}\text { Ref. C-27, (by inverse } \\
\text { modeling, two } \\
\text { boreholes) - } \\
\text { perpendicular to } \\
\text { bedding }\end{array}$} \\
\hline & & & & & & \\
\hline $\mathrm{TH}-\mathrm{N}-12$ & Clay & Opalinus clay & \multicolumn{2}{|c|}{\begin{tabular}{|l|l|} 
a & cornol \\
\end{tabular}} & \multirow[t]{2}{*}{1.87} & \multirow{2}{*}{$\begin{array}{l}\text { Ref. C-27, (by inverse } \\
\text { modeling, two } \\
\text { boreholes) - parallel to } \\
\text { bedding }\end{array}$} \\
\hline & & & & & & \\
\hline TH-N-13 & Clay & Opalinus clay & 1.49 & 1.20 & 1.345 & $\begin{array}{l}\text { Ref. C-27, (by inverse } \\
\text { modeling, two } \\
\text { boreholes) - mean } \\
\text { (assuming isotropic) }\end{array}$ \\
\hline $\mathrm{TH}-\mathrm{N}-14$ & Clay & Opalinus clay & 1.136 & 0.916 & 1.026 & $\begin{array}{l}\text { Ref. C-27, citing C- } 32 \text {, } \\
\text { for perpendicular to } \\
\text { bedding }\end{array}$ \\
\hline TH-N-15 & Clay & Opalinus clay & 2.27 & 1.81 & 2.04 & $\begin{array}{l}\text { Ref. C-27, citing C-32 } \\
\text { for parallel to bedding }\end{array}$ \\
\hline $\mathrm{TH}-\mathrm{N}-16$ & Clay & Opalinus clay & 2.5 & & 2.5 & Ref. C-18 \\
\hline $\mathrm{TH}-\mathrm{N}-17$ & Clay & Opalinus clay & 2.2 & & 2.2 & $\begin{array}{l}\text { Ref. C-18, citing Ref. C- } \\
12\end{array}$ \\
\hline $\mathrm{TH}-\mathrm{N}-18$ & Clay & Opalinus clay & 2.5 & & 2.5 & $\begin{array}{l}\text { Ref. C-18, citing Ref. C- } \\
33\end{array}$ \\
\hline
\end{tabular}

Figure 41 - Example output of the materials data plotting macro

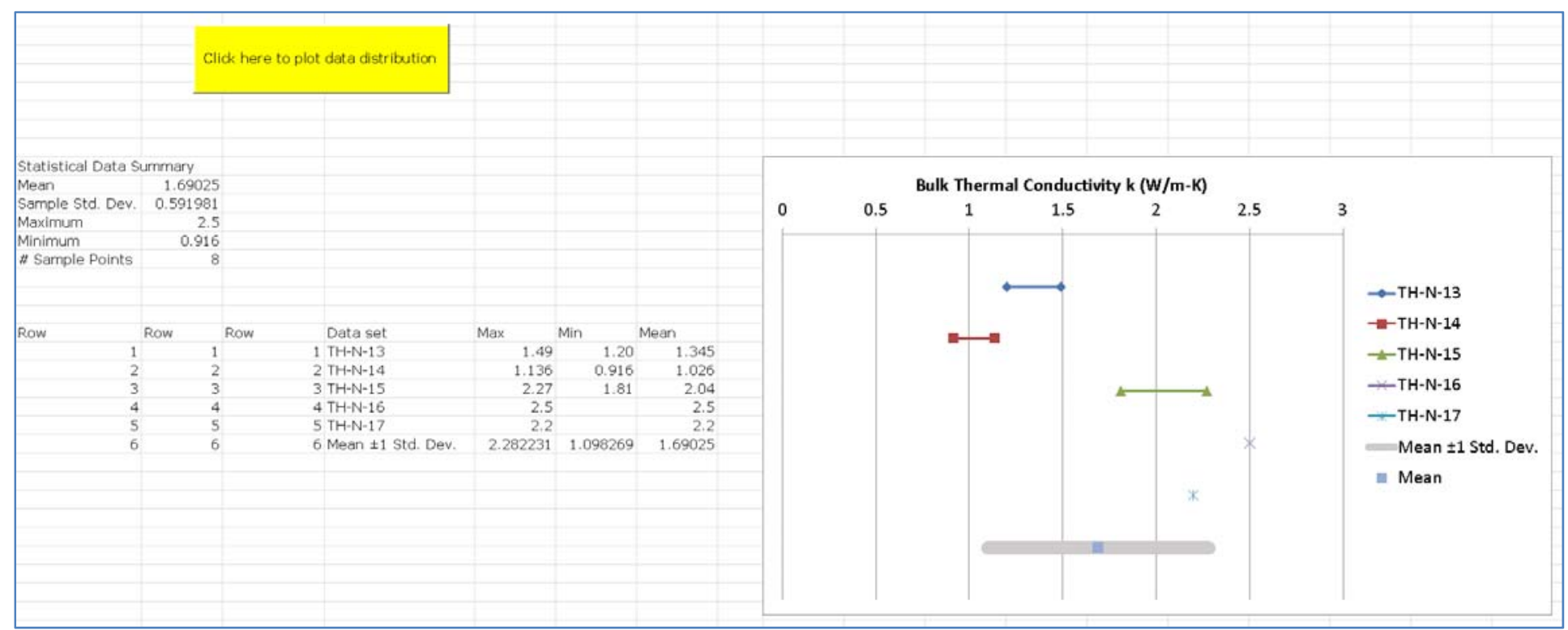

The MATERIALS-THERMAL PROPERTIES Worksheet

The data records on the MATERIALS-THERMAL PROPERTIES worksheet are identified with a sequential data set number starting with TH-N (for natural material properties) or TH-E for engineered material properties. The natural property data is grouped into major categories of rock, and then subcategories, as shown in Figure 42.

Figure 42 - Example of data structure in the MATERIALS-THERMAL PROPERTIES worksheet

\begin{tabular}{|c|c|c|c|c|c|c|c|}
\hline \multirow[b]{2}{*}{$\begin{array}{l}\text { Data Set } \\
\text { Number }\end{array}$} & \multirow{2}{*}{\begin{tabular}{|c|} 
Host Rock \\
$\begin{array}{c}\text { General Material } \\
\text { Category }\end{array}$ \\
\end{tabular}} & \multirow[b]{2}{*}{ Specific Material Data Source } & \multirow[b]{2}{*}{$\begin{array}{c}\text { Source Organization / } \\
\text { Reference }\end{array}$} & \multicolumn{2}{|c|}{ Range } & \multirow{2}{*}{\begin{tabular}{|c|} 
Mean \\
$\begin{array}{c}\text { Bulk Thermal } \\
\text { Conductivity k } \\
(\mathrm{W} / \mathrm{m}-\mathrm{K})\end{array}$ \\
\end{tabular}} & \multirow[b]{2}{*}{$\begin{array}{c}\text { Bulk } \\
\text { Thermal } \\
\text { Conductivity } \\
\text { Comments }\end{array}$} \\
\hline & & & & $\begin{array}{l}\text { High Bulk } \\
\text { Thermal } \\
\text { Conductivity } \\
\mathrm{k}(\mathrm{W} / \mathrm{m}-\mathrm{K})\end{array}$ & $\begin{array}{c}\text { Low Bulk } \\
\text { Thermal } \\
\text { Conductivity } \\
k(W / m-K)\end{array}$ & & \\
\hline $\mathrm{TH}-\mathrm{N}-1$ & Clay & Boom Clay & $\begin{array}{l}\text { NIRAS/ONDRAF, Belgium } \\
\text { Ref. C-01 }\end{array}$ & 1.69 & & 1.69 & Ref. C-01 \\
\hline $\mathrm{TH}-\mathrm{N}-2$ & Clay & Clay - non-specific & $\begin{array}{l}\text { Handbook of Heat Transfer, R- } \\
03\end{array}$ & 1.3 & & 1.3 & $\begin{array}{l}\text { Ref. R-03, Table } 2.35 \text { - } \\
\text { Thermophysical } \\
\text { Properties of } \\
\text { Miscellaneous Materials }\end{array}$ \\
\hline
\end{tabular}


The MATERIALS-TRANSPORT PROPERTIES Worksheet

The data records on the MATERIALS-TRANSPORT PROPERTIES worksheet are identified with a sequential data set number starting with TP-N (for natural material properties) or TP-E for engineered material properties. The natural property data is grouped into major categories of rock, and then subcategories, as shown in Figure 43.

Figure 43 - Example of data structure in the MATERIALS-TRANSPORT PROPERTIES worksheet

\begin{tabular}{|c|c|c|c|c|c|c|c|}
\hline & Host Rock & & & Rar & nge & Mean & \\
\hline $\begin{array}{l}\text { Data Set } \\
\text { Number }\end{array}$ & $\begin{array}{l}\text { General Material } \\
\text { Category }\end{array}$ & Specific Material Subcategory & $\begin{array}{c}\text { Source Organization / } \\
\text { Reference }\end{array}$ & $\begin{array}{c}\text { High } \\
\text { Permeability } \\
\left(\mathrm{m}^{2}\right)\end{array}$ & $\begin{array}{c}\text { Low } \\
\text { Permeability } \\
\left(\mathrm{m}^{2}\right)\end{array}$ & $\begin{array}{c}\text { Permeability } \\
\left(\mathrm{m}^{2}\right)\end{array}$ & $\begin{array}{l}\text { Permeability } \\
\text { Comments }\end{array}$ \\
\hline TP-N-1 & Granite & $\begin{array}{l}\text { Canadian Shield granite, measured } \\
\text { values }\end{array}$ & & $1.00 \mathrm{E}-17$ & $1.00 \mathrm{E}-19$ & $5.05 \mathrm{E}-18$ & Ref. G-06 \\
\hline TP-N-2 & Granite & Äspö diorite & & $1.00 \mathrm{E}-19$ & $1.00 \mathrm{E}-20$ & $5.5 E-20$ & $\begin{array}{l}\text { Ref. G-08 - for } \\
\text { undisturbed rock }\end{array}$ \\
\hline
\end{tabular}

The MATERIALS-REFERENCES Worksheet

The MATERIALS-REFERENCES worksheet contains around 100 references that include both primary and secondary reference citations. These references are listed in groups with category letters as follows:

- A - alluvium

- C - clay

- $\quad$ EBS - engineered barrier materials

- $\mathrm{G}$ - granite

- $\mathrm{R}$ - general reference documents like handbooks or textbooks

- $\mathrm{S}$ - salt

- $\mathrm{T}-$ tuff

At LLNL a large number of these references are hyperlinked to the source documents on the network drive, but the distribution copy of DSEF Version 3.0 has all of these hyperlinks removed. 


\section{Placeholder worksheets for future development}

No work is currently planned to develop these placeholder worksheets; however, their potential use is described below:

The INTERFACE PARAMETERS Worksheet

This worksheet has limited current operability, with the capability to read and write "comma delimited files”, which are universally accepted by most computer codes.

\section{The DESIGN CONSTRAINTS Worksheet}

This worksheet currently documents existing calculations and other references that formed the basis for assumed design constraints in previous calculations, and provides background information for the users. Design constraint data are currently entered in Step 11 of the INPUTS worksheet. However, the DESIGN CONSTRAINTS worksheet could also allow documentation of experimental results and other information currently being developed that might form the basis for design constraints.

The ENVIRONMENT Worksheet

This worksheet is only a placeholder with no detailed description. This worksheet could be used to interface repository design an analysis to NEPA type of environmental impact statement related data such as passing the data on the volume of excavated muck, required concrete, and electricity / diesel fuel requirements - derived from the COST worksheets (for example).

\section{The PERFORMANCE ASSESSMENT Worksheet}

This worksheet is a placeholder intended to pass repository design data - repository layout and dimensions, material quantities and properties, and thermal transient data input to performance assessment external programs.

\section{The MATERIALS-OTHER PROPERTIES Worksheet}

This worksheet is a placeholder intended to gather property data and references for properties other than thermal or transport properties that already have data worksheets in DSEF. One example would be to have a worksheet for mechanical properties such as Young's Modulus, compressive strength, thermal expansion coefficients, etc. The data from such a worksheet could then be passed to ARIA or DIABLO to run thermal-mechanical analysis.

\section{The THERMAL-FEM Worksheet}

The THERMAL-FEM worksheet is a placeholder to interface with other Finite Element Model (FEM) thermal analysis codes, such as TOPAZ or DIABLO from LLNL, ARIA from SNL, SINDAG from ANL, etc. It is meant to be able to pass required inputs for those codes by pulling the problem/case definition information from other worksheets in DSEF.

This worksheet could function the way that the THERMAL-ANALYTICAL worksheet does to pass information to an external FEM code. It is expected that use of such codes would also include some postprocessing of data to write the results back to the THERMAL-ANALYTICAL OUTPUT worksheet 


\section{References}

(Carter 2012). Joe T. Carter, Phillip O. Rodwell, Mark DuPont, Generic Repository ROM Cost Study, FCRD-UFD-2012-000211 Rev 1, September 5, 2012

(Greenberg 2012a). Harris R. Greenberg, Montu Sharma, Mark Sutton, and Alethia V. Barnwell, Repository Near-Field Thermal Modeling Update Including Analysis of Open Mode Design Concepts, LLNL-TR-572252, Aug 2012

(Greenberg 2012b). Harris R. Greenberg, Montu Sharma and Mark Sutton, Investigations on Repository Near-Field Thermal Modeling, LLNL-TR-491099-Rev-2, November 2012

(Greenberg 2013a). H.R. Greenberg, J. A. Blink, and T. A. Buscheck, Repository Layout and Required Ventilation Trade Studies in Clay/Shale using the DSEF Thermal Analytical Model, LLNL-TR-638880, June 12, 2013.

(Greenberg 2013b). H. R. Greenberg, J. Wen, and T. A. Buscheck, Scoping Thermal Analysis of Alternative Dual-Purpose Canister Disposal Concepts, June 26, 2013

(Hardin 2011). Hardin, E., J. Blink, H. Greenberg, M. Sutton, M. Fratoni, J. Carter, M. DuPont and R. Howard 2011, Generic Repository Design Concepts and Thermal Analysis (FY11). FCRD-USED-2011000143 Rev. 2. December, 2011

(Hardin 2012a). E. Hardin, T. Hadgu, D. Clayton; R. Howard; H. R. Greenberg, J. Blink, M. Sharma, M. Sutton, J. Carter, M. DuPont and P. Rodwell, Design Concepts/Thermal Load Management (FY11/12) Summary Report, FCRD-UFD-2012-00219, August 2012

(Hardin 2012b). E. Hardin, T. Hadgu, D. Clayton; R. Howard; H. R. Greenberg, J. Blink, M. Sharma, M. Sutton, J. Carter, M. DuPont and P. Rodwell, Repository Reference Disposal Concepts and Thermal Load Management Analysis, FCRD-UFD-2012-00219, Rev. 2, November 2012

(Sutton 2011). Mark Sutton, James A. Blink, Massimiliano Fratoni, Harris R. Greenberg, William G. Halsey and Thomas J. Wolery, Disposal Systems Evaluation Framework Version 1.0 Progress Report, June 2011. 


\section{Appendix A - Setting up Excel to Allow the DSEF Macros to Work}

In order for the Form controls in DSEF to work you must enable macros. If you weren't prompted to ENABLE MACROS when you first started DSEF, and the Form controls do not appear to be working, the steps outlined in this Appendix should resolve the problem.

Please follow Figures A.1 through A.7 and the steps outlined below:

Figure A-1- The FILE menu choices

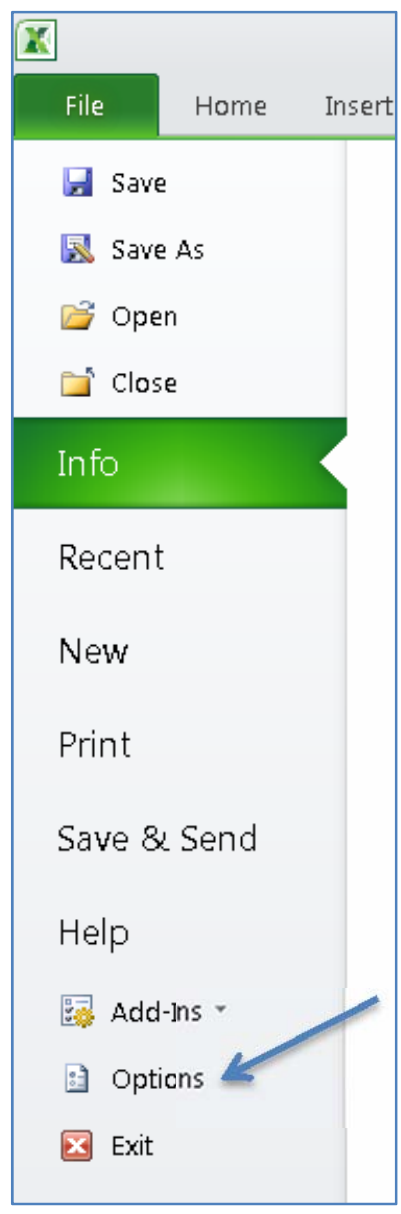

- Figure A.1 - Click on the FILE menu

- Under HELP, select OPTIONS

- Figure A.2 shows the OPTIONS menu,

- Select the TRUST CENTER option

- Figure A.3 shows the TRUST CENTER button

- Click on the TRUST CENTER SETTINGS button

- Figure A.4 shows the TRUST CENTER options

- You need to select settings for
o Macros
o Message bar

- Suggested settings are shown in Figures A.5 - A.7 
Figure A-2 - The OPTIONS menu choices

\begin{tabular}{|c|c|}
\hline Excel Options & \\
\hline General & \multirow{6}{*}{ 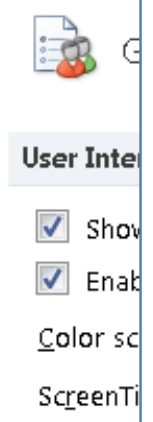 } \\
\hline Formulas & \\
\hline Proofing & \\
\hline Save & \\
\hline Language & \\
\hline Advanced & \\
\hline Customize Ribbon & \multirow{4}{*}{$\begin{array}{l}\text { When cre } \\
\text { Use this } \\
\text { Font size } \\
\text { Default }\end{array}$} \\
\hline Quick Access Toolbar & \\
\hline Add-Ins & \\
\hline & \\
\hline
\end{tabular}

Figure A-3 - Select Trust Center Settings

\section{Microsoft Excel Trust Center}

The Trust Center contains security and privacy settings. These settings help keep your computer secure. We recommend that you do not change these settings.

reenT

cre

\section{Figure A-4 - Trust Center Settings}

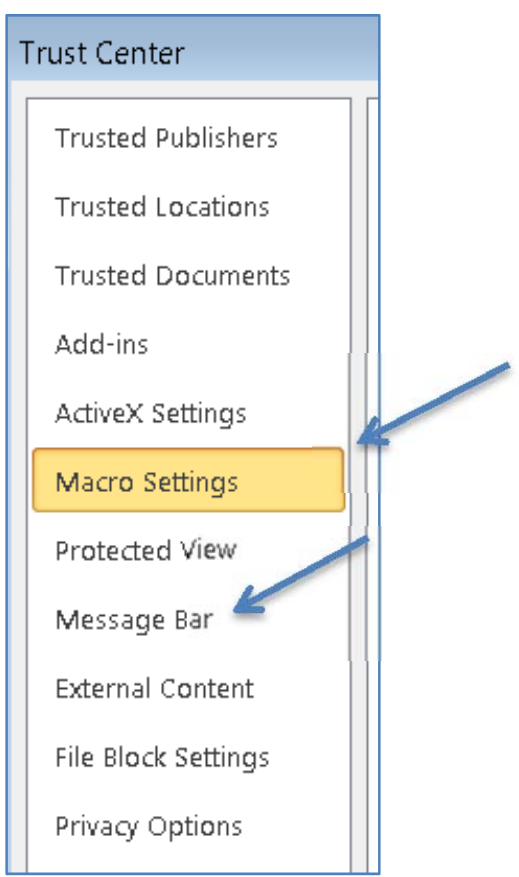




\section{Appendix A}

Figure A-5 - Prompt before enabling all controls with minimal restrictions

ActiveX Settings for all Office Applications

Disable all controls without notification

(1) Prompt me before enabling Unsafe for Initialization (UFI) controls with additional restrictions and Safe for Initialization (SFI) controls with minimal restrictions

(2) Prompt me before enabling all controls with minimal restrictions

(Enable all controls without restrictions and without prompting (not recommended; potentially dangerous controls can run)

Safe mode (helps limit the control's access to your computer)

Figure A-6 - Macro settings

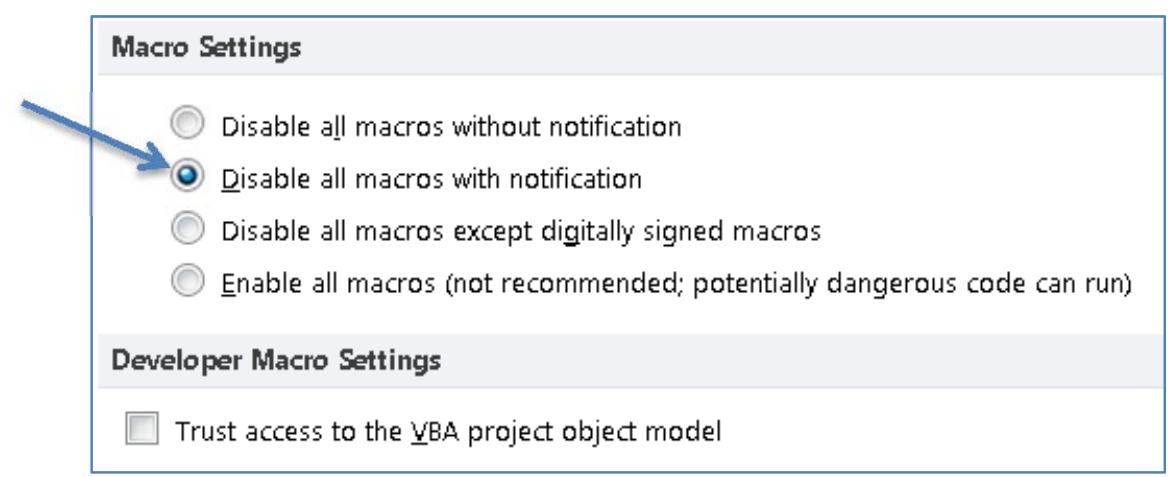

Figure A-7 - Message bar settings

Message Bar Settings for all Office Applications

Showing the Message Bar

( Show the Message Bar in all applications when active content, such as ActiveX controls and macros, has been blocked

Never show information about blocked content 


\section{Appendix B - The Mathcad Thermal-Analytical Component of DSEF}

This appendix contains PDF pages of the two DSEF Version 3.0 Mathcad thermal-analytical models that receive input from the THERMAL-ANALYTICAL worksheet, and return transient and peak summary data to the THERMAL-ANALYTICAL OUTPUT worksheet in DSEF. The basic Mathcad thermal-analytical model was benchmarked against two different finite-element model (FEM) computer codes by ANL and by SNL. The benchmarking analyses are documented in Sections G.6.1 and G.6.2 of Greenberg 2012b respectively.

Section B.1 describes the use of the Mathcad thermal-analytical models, and their interface with the DSEF Excel spreadsheet.

Section B.2 documents the update to the parametric study analysis model documented in the DSEF Version 2.1 User Manual to add the capability to perform iterative analyses to determine required ventilation time. This one model can perform either parametric study case analyses when the input data sets the mode to "Parametric", or individual case and iterative convergence modeling when the mode is set to "Single". Section B.2 shows an example of a parametric study set of analysis cases.

Section B.3 documents the additional programming added to the parametric study analysis model to perform iterative analysis to determine required ventilation time necessary to meet input temperature constraint values for the drift wall (which is easily modified to apply the temperature constraint at other locations as well). This model was used to perform the analyses documented in Greenberg 2012a.

Section B.4 documents a new DSEF Version 3.0 Mathcad model that allows temperature and time-dependent thermal properties within the EBS layers of the model. The particular PDF file and Mathcad document example applies these to salt for temperature-dependent thermal conductivity and time-dependent crushed salt porosity to model consolidation of the crushed salt layer with time and heat. The data for the time-dependent crushed salt consolidation comes from a finite element model in Hardin 2012b (Figure C-5). This model provides proof-of-principle that the thermal-analytical model can accommodate more complex thermal property modeling than the constant properties assumed in models and analysis using earlier versions of DSEF. The thermal results of this new model have a better fit to the FEM model results for the 12-PWR 40GWd/MT burnup waste stream with 50 years of surface storage documented in Hardin 2012b than was possible with previous analyses using constant salt properties in the EBS (see Greenberg 2012b, Section G.6.2).

With different temperature or time-depending functions, this methodology could be used to model moisture dependent properties covering dryout or re-wetting effects in other media. This would require other data or analysis to set the basic input functions, but then the benefits of the analytical-model approach could be applied to a broader class of problems. 


\section{B.1 Using the Mathcad models in conjunction with the DSEF Excel file}

The Mathcad file and the DSEF Excel file need to be in the same directory to facilitate the data transfer. Before Mathcad can read the Excel file, the Excel file must be closed. By default the Mathcad DSEF file has the calculation mode set to manual, and the variable "Write_OK" is set to "No". This allows the user to make adjustments and look at results prior to writing them back to the DSEF Excel file. To calculate a screen at a time as the user pages through the Mathcad file, press F9 or use the Mathcad TOOLS - CALCULATE menu to select CALCULATE NOW, alternatively the user can calculate the entire document by pressing CTRL-F9 or selecting the menu option TOOLS - CALCULATE - CALCULATE WORKSHEET. After reviewing the results in MathCad, set the variable "Write_OK" to "Yes" and recalculate the Mathcad document to write the results back to the Excel file in the THERMAL-ANALYTICAL OUTPUT worksheet. To preserve a record of the full Mathcad calculation, the user should print the file to a PDF file for future reference.

Working with the Mathcad component of DSEF - here are some key pointers for using the Mathcad file:

- $\quad$ Connecting to the DSEF Excel component - on the first page (page 1 of 21 of the PDF listing) assign the file name of the Excel file you want to work with to the variable "file".

- $\quad$ The calculation mode setting in Mathcad - the calculation mode setting in the Mathcad component is set to "Manual” (under the Mathcad TOOLS menu selection). This gives the user more control when working with a large model, and also allows you to set variables that will turn on or delay writing back to the DSEF Excel file until you are ready. Pressing the F9 key, or using the Mathcad menu to select "Calculate Now" will process only the currently visible screen and variables, so you can work your way slowly through the file and see the data, section-by-section as it is being read in from the THERMAL-ANALYTICAL worksheet. Either pressing CTRL-F9, or using the menu to select "Calculate Worksheet” will initiate a complete calculation of the entire file.

- Writing the results back to the THERMAL-ANALYTICAL OUTPUT worksheet - on the first page of the PDF listing, use the variable "Write_OK" to "Yes" if you are ready to immediately write your calculated results back to the Excel file, or to "No" if you want to examine the results first. Setting the variable to "No" allows you to make changes in Mathcad to some of the input variables if you want to make adjustments to refine your design case to reach some desired goal. For example, if you wanted to find the required ventilation time to meet a given design constraint, you might want to adjust the ventilation time until the goal was met, and then go back and set "Write_OK" to "Yes".

- $\quad$ Speeding up the calculations - on the bottom of page 11 of 21 in the PDF file, there are two variables "Counter" and "Step". These variables set the number of time-steps and the size of the time-step in the main calculation loop for the transient calculations. If you are doing a large number of parametric study cases, or covering a long time period, you may first want to set a large time-step to quickly get a ball-park answer, and then later 
rerun the case with a smaller time-step after you have adjusted some variables in your design case to try to optimize your results.

- $\quad$ Additional graphics in the Mathcad file - the Mathcad file includes a number of plots for working with the analysis that are not currently returned to the DSEF Excel component. These include a plot of the thermal resistance versus radius of the EBS layers before and after backfill is installed (see pages 5 and 6 of the PDF file), and a plot of the thermal gradients within the EBS at the time of the waste package peak temperature and the drift wall peak temperature (see page 19 of 21 in the PDF file).

- $\quad$ Selectively overriding input variables - After a variable has been assigned a value, either by reading it in from the DSEF Excel component or within the Mathcad component itself, the user can override the value and provide a new assignment. Mathcad notes the reassignment by underlining the variable and displaying a message on mouse-over of the variable as you work. Care should be taken when re-assigning variables. The user is advised to make any re-assignments at the point where the variable is first assigned, so that the changes are easily identified. The notes section of the INPUTS CHECKLIST in the DSEF Excel component is the place to note any such changes that remain in effect when the final analysis results are returned to the Excel file.

- $\quad$ Printing the Mathcad Output - it should be noted that saving the Mathcad file after an analysis does not save the results, it just saves the problem setup and variables. To see the results again the Mathcad worksheet must be completely recalculated. This is not a problem for short calculations. However, for longer more complex calculations, or if you want to keep a record of intermediate design "test cases", it is recommended that the user print the fully evaluated results to a PDF file or to a printer for traceability, and to create records for QA/QC purposes. The current Mathcad component has a header that lists the Mathcad file name. 


\section{B.2 The Mathcad parametric analysis and iterative convergence model - parametric study example}

Step 13 on the DSEF INPUTS worksheet allows the user to either select a "single" calculation mode that uses all of the input data for the reference case defined in Steps 1 through 12, or to select a "parametric" study calculation mode. Figure 12 shows the options available for parametric studies, where the basic inputs have been set, but the user can then define up to 10 data values for one of six possible parameters - waste package spacing, drift spacing, storage time, ventilation duration, rock thermal conductivity, and backfill thermal conductivity. The Mathcad model documented in this section is essentially the same as that documented in the Version 2.1 User Manual for running parametric study cases when "parametric" is selected as the study mode. The model looks slightly different because of the additional capabilities discussed in Section B.3, and because "collapsible" regions have been added to the Mathcad document to speed up review of results when using the iterative model discussed in Section B.3. The collapsible region boundaries appear as lines going across the entire page, with a drop-down arrow at the left-hand edge of the line.

The specific parametric study example case was taken from Greenberg 2012b, and is Case 500-1 in that report, which corresponds to DSEF Case Library case number 427. It is a parametric study of waste package spacing (with 10 values ranging from 15 to $24 \mathrm{~m}$ ) for a large 32-PWR waste package having 40-GWd/MT burnup, with a drift spacing of $70 \mathrm{~m}$, surface storage of 50 years, and 100 years of ventilation in a clay/shale repository design. As the last figure in the analysis shows, a waste package spacing of $23 \mathrm{~m}$ is required to achieve a maximum drift wall temperature of $100^{\circ} \mathrm{C}$. Greenberg $2012 \mathrm{~b}$ included analysis of thermal gradients into the host rock outside the drift wall by varying the depth of Compliance Point 2 (CP2), and in this example run $\mathrm{CP} 2=1 \mathrm{~m}$.

The program loop for the iterative convergence model appears on page 19 of 23 of the example output, but there are no results shown on pages 20 and 21 of 23, since the variable Iterate_OK = "No", and thus the iterative model was not used. 
DSEF R3.0 parametric and iterative model with collapsable areas - for rapid iteration.

Values over-written from DSEF Excel file to create case include: Drift_spacing, TC and tvent.

Variables for repository symmetry and extent:

Allow output transients to be written back to DSEF FILE

Write_OK := "YES"

Case_name := "500-1"

$\mathrm{N}_{\text {drifts }}:=4 \quad \mathrm{~N}_{\text {adj }}:=4$

REQUIRED REPOSITORY INPUT DATA (from DSEF):

file := "DSEF R3.0_2013Aug12_HRG-Clay_UOX-40_CP2=1m,DS70,Vent100,WP param_Case-500-1.xlsm"

sheet := "Thermal-Analytical!"

DATA FOR ITERATION ON TEMPERATURE ACCEPTACE CRITERIAA:

READ DSEF INPUT FILE

Input 1 = Operating Mode (enclosed or open)

Input_1 := READEXCEL(file, concat(sheet, "A5:B5"))

Input 1 = ("MODE = Open or Enclosed:" - "Open" )

Mode := Input $11,2=$ "Open"

TC $:=100 \quad \mathrm{~T}_{\text {criteria }}:=(\mathrm{TC}+273.15) \cdot \mathrm{K}=373.15 \mathrm{~K} \quad \mathrm{~T}_{\text {criteria }}=100 \cdot{ }^{\circ} \mathrm{C}$

\section{Convergence $:=1 \cdot y$ Pr}

SET THE VARIABLE ITERATE_OK TO "NO" TO

TURN OFF THE AUTOMATIC CONVERGENCE

"YES" IFYOU WANT TO FUALTUESET TO

Input_2 := READEXCEL(file, concat(sheet, "A7:B16")) Input 2 = Case Definitions

Input_2 $=\left(\begin{array}{cc}\text { "Host Media" } & \text { "Clay" } \\ \text { "Rock thermal conductivity, W/m-K" } & 1.75 \\ \text { "Rock thermal diffusivity, m2/sec" } & 6.45 \times 10^{-7} \\ \text { "Repository Depth, m" } & 500 \\ \text { "Surface temperature, }{ }^{\circ} \mathrm{C} " & 15 \\ \text { "Geothermal gradient, }{ }^{\circ} \mathrm{C} / \mathrm{km} " & 25 \\ \text { "Ambient temperature at depth, }{ }^{\circ} \mathrm{C} " & 27.5 \\ \text { "Waste Package (axial) spacing, } \mathrm{m} " & 20 \\ \text { "Drift / Borehole (lateral) spacing, m" } & 70 \\ \text { "Surface storage time, } \mathrm{y"} & 50\end{array}\right)$

Input 3 = Ventilation Parameters (for Open Modes)

Input_3 := READEXCEL(file, concat(sheet, "e7:f11"))

Input_3 = $\left.\begin{array}{cc}\text { "Ventilation Duration, yr" } & 100 \\ \text { "Unventilated Closure Duration (Backfill Installation), yr" } & 10 \\ \text { "Ventilation Thermal Efficiency, \%" } & 0.75 \\ \text { "Rock Wall Emissivity" } & 0.9 \\ \text { "Waste Package Emissivity" } & 0.6\end{array}\right)$

RT_name := Input_21,2 = "Clay"

Kth := Input_22,2 $\frac{\mathrm{W}}{\mathrm{m} \cdot \mathrm{K}}=1.75 \frac{\mathrm{m} \cdot \mathrm{kg}}{\mathrm{K} \cdot \mathrm{s}^{3}}$

$\mathrm{t}_{\text {vent }}:=\mathrm{if}[($ Mode $=$ "Enclosed" $), 0$, Input_31,2] $]$ yr $=100 \cdot$ yr

$\alpha:=$ Input_23,2 $2 \cdot \frac{\mathrm{m}^{2}}{\mathrm{~s}}=6.45 \times 10^{-7} \frac{\mathrm{m}^{2}}{\mathrm{~s}}$

tbackfill $:=$ if $[$ (Mode $=$ "Enclosed" $), 0$, Input_32, 2$] \cdot y r=10 \cdot y r$

$\mathrm{V}_{\text {eff }}:=$ if $[($ Mode $=$ "Enclosed" $), 0$, Input_33,2 $]=0.75$

$\varepsilon_{\text {wall }}:=$ if $[$ (Mode $=$ "Enclosed" $), 9$, ,Input_34,2 $]=0.9$ 
WP_depth $:=$ Input_24,2·m $=500 \mathrm{~m}$

$\mathrm{T}_{\text {surface }}:=($ Input_ $25,2+273.15) \cdot \mathrm{K}=288.15 \mathrm{~K}$

geothermal_gradient := Input_26,2 $\frac{\mathrm{K}}{\mathrm{km}}=0.025 \frac{\mathrm{K}}{\mathrm{m}}$

$\mathrm{T}_{\text {ambient }}:=($ Input_27, $2+273.15) \cdot \mathrm{K}=300.65 \mathrm{~K}$

WP_spacing $:=$ Input_ $28,2 \cdot \mathrm{m}=20 \mathrm{~m}$

Drift_spacing $:=$ Input_29,2$\cdot \mathrm{m}=70 \mathrm{~m}$

$\mathrm{t}_{\text {store }}:=$ Input $\_210,2 \cdot \mathrm{yr}=50 \cdot \mathrm{yr}$
$\varepsilon_{\mathrm{WP}}:=$ if $[($ Mode $=$ "Enclosed" $), .6$, Input_35,2] $]=0.6$

OVER-RIDE VENTILATION DURATION

OVER-RIDE DRIFT AND/OR WASTE PACKAGE SPACING

\title{
$\mathrm{t}_{\text {operate }}:=\left(\mathrm{t}_{\text {store }}+\mathrm{t}_{\text {vent }}\right)=150 \cdot \mathrm{yr}$
}

\section{T_OPERATE $=$ T STORE + T_VENTILATE} ${ }^{\text {closure }}:=\mathrm{t}_{\text {operate }}+\mathrm{t}_{\text {backfill }}=160 \cdot \mathrm{yr}$

\section{TCLOSURE = TOPERATE + TIME TO BACKFILL}

\section{Input 4 = ENGINEERED BARRIER SYSTEM DATA}

Input_4 := READEXCEL(file, concat(sheet, "A20:F27"))

\section{Input $\mathbf{5}$ = COMPLIANCE POINT $\mathbf{2}$ INPUT DATA}

Input_5 := READEXCEL(file, concat(sheet, "C32"))

Input_4 = $\left.\begin{array}{cccccc}\text { "Waste Form Outer Radius, m" } & 0.535 & \text { "N/A" } & 0.535 & \text { "UOX-40" } & \text { "N/A" } \\ \text { "Canister" } & 0 & 0.535 & 0.535 & \text { "None" } & \text { "N/A" } \\ \text { "Waste Package" } & 0.11 & 0.535 & 0.645 & \text { "Carbon Steel" } & \text { "N/A" } \\ \text { "Buffer" } & 0 & 0.645 & 0.645 & \text { "None" } & \text { "N/A" } \\ \text { "Envelope" } & 0 & 0.645 & 0.645 & \text { "None" } & \text { "N/A" } \\ \text { "Backfill" } & 1.58 & 0.645 & 2.225 & \text { "70\% Bentonite 30\% Sand" } & 1.2 \\ \text { "Liner" } & 0.025 & 2.225 & 2.25 & \text { "Steel" } & 46 \\ \text { "Host } & & & & \end{array}\right)$

\begin{abstract}
${ }^{\mathrm{r}} \mathrm{DW}:=$ Input_4 $48,3 \cdot \mathrm{m}=2.25 \mathrm{~m}$
\end{abstract}
$\mathrm{r}_{\mathrm{WP}}:=$ Input_43,4$\cdot \mathrm{m}=0.645 \mathrm{~m}$

EBS_name $_{1}:=$ Input_4 $4,1=$ "Liner"

thickness $1:=$ Input_47, $2 \cdot \mathrm{m}=0.025 \mathrm{~m}$

$\mathrm{k} 1:=$ Input $47,6=46$
EBS_material $1:=$ Input_47,5 = "Steel"

$\mathrm{r}_{1}:=$ Input_47, $4 \cdot \mathrm{m}=2.25 \mathrm{~m}$

$\mathrm{k}_{1}:=$ if $[(\mathrm{k} 1=\mathrm{N} / \mathrm{A} "), 0, \mathrm{k} 1] \cdot \frac{\mathrm{W}}{\mathrm{m} \cdot \mathrm{K}}=46 \cdot \frac{\mathrm{W}}{\mathrm{m} \cdot \mathrm{K}}$
Input $5=(3.25)$

${ }_{\mathrm{C}} \mathrm{CP} 2:=$ Input_ $51 \cdot \mathrm{m}=3.25 \mathrm{~m}$ 
EBS_name $_{2}:=$ Input_46,1 = "Backfill"

thickness $2:=$ Input_ $46,2 \cdot \mathrm{m}=1.58 \mathrm{~m}$

k2 := Input_46,6 $=1.2$

EBS_material $_{2}:=$ Input_46,5 = "70\% Bentonite 30\% Sand"

$\mathrm{r}_{2}:=$ Input_ $46,4 \cdot \mathrm{m}=2.225 \mathrm{~m}$

$\mathrm{k}_{2}:=$ if $[(\mathrm{k} 2=$ "N/A" $), 0, \mathrm{k} 2] \cdot \frac{\mathrm{W}}{\mathrm{m} \cdot \mathrm{K}}=1.2 \cdot \frac{\mathrm{W}}{\mathrm{m} \cdot \mathrm{K}}$

$\mathrm{k}_{\text {radiation }}:=\operatorname{if}\left[(\right.$ Mode $=$ "Enclosed" $\left.), \mathrm{k}_{2}, 0\right]=0 \cdot \frac{\mathrm{W}}{\mathrm{m} \cdot \mathrm{K}}$

EBS_name $_{3}:=$ Input_45,1 = "Envelope"

thickness $_{3}:=$ Input_ $45,2 \cdot \mathrm{m}=0 \mathrm{~m}$

$\mathrm{k} 3:=$ Input_45,6 = "N/A"

EBS_name $_{4}:=$ Input_ $44,1=$ "Buffer"

thickness $4:=$ Input_44,2$\cdot \mathbf{m}=0 \mathrm{~m}$

$\mathrm{k} 4:=$ Input_44,6 $=$ "N/A"
EBS_material $3:=$ Input_45, $5=$ "None"

$\mathrm{r}_{3}:=$ Input_45,4$\cdot \mathrm{m}=0.645 \mathrm{~m}$

$\mathrm{k}_{3}:=$ if $[(\mathrm{k} 3=" \mathrm{~N} / \mathrm{A} "), 0, \mathrm{k} 3] \cdot \frac{\mathrm{W}}{\mathrm{m} \cdot \mathrm{K}}=0 \cdot \frac{\mathrm{W}}{\mathrm{m} \cdot \mathrm{K}}$

EBS_material $4:=$ Input_ $44,5=$ "None"

$\mathrm{r}_{4}:=$ Input $44,4 \cdot \mathrm{m}=0.645 \mathrm{~m}$

$\mathrm{k}_{4}:=\operatorname{if}[(\mathrm{k} 4=\mathrm{N} / \mathrm{A} "), 0, \mathrm{k} 4] \cdot \frac{\mathrm{W}}{\mathrm{m} \cdot \mathrm{K}}=0 \cdot \frac{\mathrm{W}}{\mathrm{m} \cdot \mathrm{K}}$

Define the total thermal resistance between the rock wall and the waste package surface

based on a heat flux per unit area, it is then applied to a heat flux is per unit length adjusting to

area per unit length and $\mathrm{q}_{\mathrm{L}}(\mathrm{W} / \mathrm{m})$ :

$\mathrm{r}_{\mathrm{WP}}=0.645 \mathrm{~m}$

$\mathrm{r}_{4}=0.645 \mathrm{~m}$

$r_{3}=0.645 \mathrm{~m}$

$\mathrm{r}_{2}=2.225 \mathrm{~m}$

$\mathrm{r}_{1}=2.25 \mathrm{~m}$

$\mathrm{r}_{\mathrm{DW}}=2.25 \mathrm{~m}$

$\mathrm{R}_{1}\left(\mathrm{k}_{1}\right):=$ if $\left[\right.$ thickness $\left.\left.1=0 \vee\left(\mathrm{k} 1=" \mathrm{~N} / \mathrm{A}^{n}\right)\right], 0, \frac{\mathrm{r}^{\mathrm{DW}}}{\mathrm{k}_{1}} \cdot \ln \left(\frac{\mathrm{r}_{1}}{\mathrm{r}_{2}}\right)\right] \quad \mathrm{R}_{1}\left(\mathrm{k}_{1}\right)=5.465 \times 10^{-4} \cdot \frac{\mathrm{m}^{2} \cdot \mathrm{K}}{\mathrm{W}}$

Thermal resistance

EBS_name $_{1}=$ "Liner" $\quad$ EBS_material $_{1}=$ "Steel"

ADDED CORRECTION FOR PARAMETRIC $\mathrm{t}_{\text {closure }}$ Revised $\mathrm{R}_{2}$ to make it an explicit function of $\mathrm{t}_{\text {operate }}$ and $\mathrm{t}_{\text {backfifl }}$

eplaced $\mathrm{t}_{\text {closure }}$ with $\left(\mathrm{t}_{\text {operate }}+\mathrm{t}_{\text {backfill }}\right)$

$$
\frac{\mathrm{r}_{\mathrm{DW}}}{\mathrm{k}_{2}} \cdot \ln \left(\frac{\mathrm{r}_{2}}{\mathrm{r}_{3}}\right)=2.322 \cdot \frac{\mathrm{m}^{2} \cdot \mathrm{K}}{\mathrm{W}}
$$


EBS_name $_{2}=$ "Backfill" $\quad$ EBS_material ${ }_{2}=$ "70\% Bentonite 30\% Sand"

$$
\mathrm{R}_{2}\left(\mathrm{k}_{2}, 5 \cdot \mathrm{yr}, 300 \cdot \mathrm{yr}, 10 \cdot \mathrm{yr}\right)=0 \cdot \frac{\mathrm{m}^{2} \cdot \mathrm{K}}{\mathrm{W}}
$$

$\mathrm{R}_{2}\left(\mathrm{k}_{2}, 1000 \cdot \mathrm{yr}, 300 \cdot \mathrm{yr}, 10 \cdot \mathrm{yr}\right)=2.321741 \cdot \frac{\mathrm{m}^{2} \cdot \mathrm{K}}{\mathrm{W}}$

$\mathrm{R}_{3}\left(\mathrm{k}_{3}\right):=$ if $\left[\left[\right.\right.$ thickness $\left.\left._{3}=0 \vee(\mathrm{k} 3=\mathrm{N} / \mathrm{A} ")\right], 0, \frac{\mathrm{r}_{\mathrm{DW}}}{\mathrm{k}_{3}} \cdot \ln \left(\frac{\mathrm{r}_{3}}{\mathrm{r}_{4}}\right)\right] \quad \mathrm{R}_{3}\left(\mathrm{k}_{3}\right)=0 \cdot \frac{\mathrm{m}^{2} \cdot \mathrm{K}}{\mathrm{W}}$

EBS_name $_{3}=$ "Envelope" $\quad$ EBS_material $3=$ "None"

$\mathrm{R}_{4}\left(\mathrm{k}_{4}\right):=\operatorname{if}\left[\left[\right.\right.$ thickness $\left.\left._{4}=0 \vee(\mathrm{k} 4=" \mathrm{~N} / \mathrm{A} ")\right], 0, \frac{\mathrm{r}_{\mathrm{DW}}}{\mathrm{k}_{4}} \cdot \ln \left(\frac{\mathrm{r}_{4}}{\mathrm{r}_{\mathrm{WP}}}\right)\right] \quad \mathrm{R}_{4}\left(\mathrm{k}_{4}\right)=0 \cdot \frac{\mathrm{m}^{2} \cdot \mathrm{K}}{\mathrm{W}}$

EBS_name $_{4}=$ "Buffer"

EBS_material $_{4}=$ "None"

$\mathrm{R}_{\text {Total }}\left(\mathrm{t}, \mathrm{k}_{1}, \mathrm{k}_{2}, \mathrm{k}_{3}, \mathrm{k}_{4}\right):=\mathrm{R}_{1}\left(\mathrm{k}_{1}\right)+\mathrm{R}_{2}\left(\mathrm{k}_{2}, \mathrm{t}, \mathrm{t}_{\text {operate }}, \mathrm{t}_{\text {backfill }}\right)+\mathrm{R}_{3}\left(\mathrm{k}_{3}\right)+\mathrm{R}_{4}\left(\mathrm{k}_{4}\right) \quad$ Total thermal resistance between wall and waste package $\mathrm{t}_{\text {backfill }}=10 \cdot \mathrm{yr} \quad \mathrm{t}_{\text {operate }}=150 \cdot \mathrm{yr}$

$\mathrm{R}_{\text {continuous }}\left(\mathrm{t}, \mathrm{r}, \mathrm{k}_{1}, \mathrm{k}_{2}, \mathrm{k}_{3}, \mathrm{k}_{4}\right):=\mid \mathrm{kk}_{2} \leftarrow \mathrm{k}_{\text {radiation }} \cdot\left[\mathrm{t}<\left(\mathrm{t}_{\text {operate }}+\mathrm{t}_{\text {backfill }}\right)\right]+\mathrm{k}_{2} \cdot\left[\mathrm{t} \geq\left(\mathrm{t}_{\text {operate }}+\mathrm{t}_{\text {backfill }}\right)\right]$

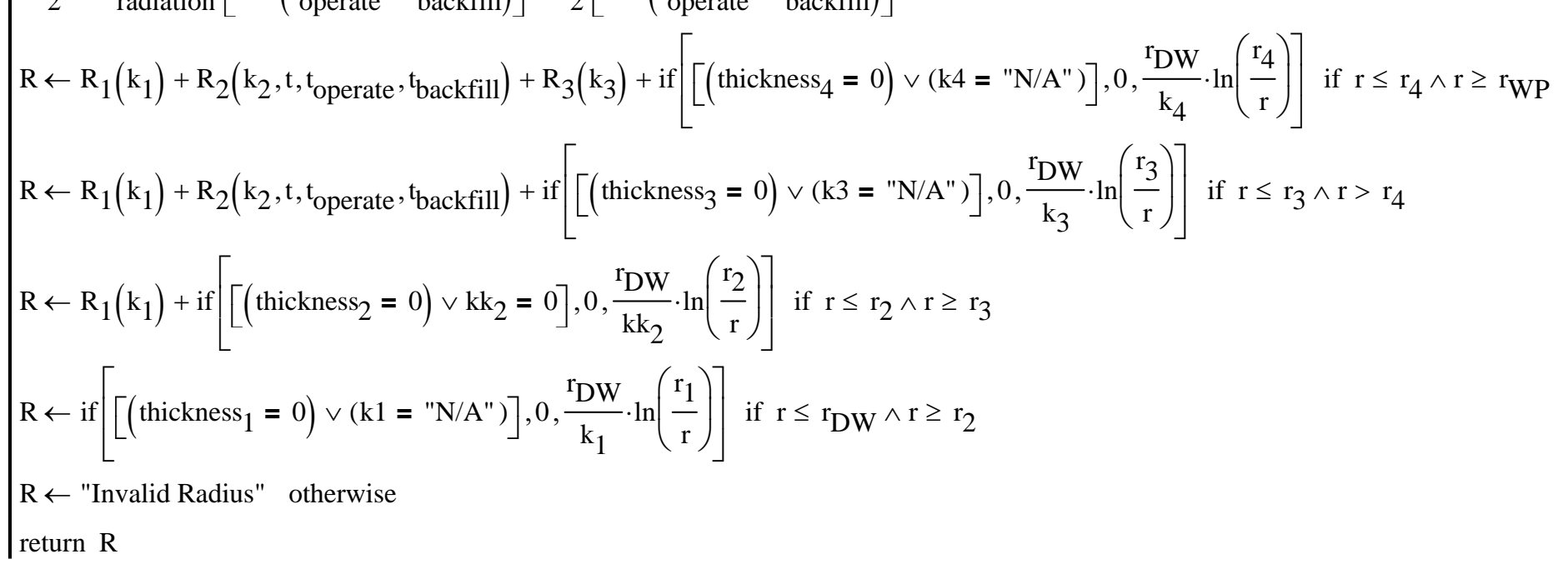

$\mathrm{R}_{\text {continuous }}\left(5 \cdot \mathrm{yr}, \mathrm{r}_{\mathrm{WP}}, \mathrm{k}_{1}, \mathrm{k}_{2}, \mathrm{k}_{3}, \mathrm{k}_{4}\right)=5.465 \times 10^{-4} \frac{\mathrm{K} \cdot \mathrm{s}^{3}}{\mathrm{~kg}} \quad \mathrm{R}_{\text {continuous }}\left(1000 \cdot \mathrm{yr}, \mathrm{r}_{\mathrm{WP}}, \mathrm{k}_{1}, \mathrm{k}_{2}, \mathrm{k}_{3}, \mathrm{k}_{4}\right)=2.322288 \frac{\mathrm{K} \cdot \mathrm{s}^{3}}{\mathrm{~kg}}$ 


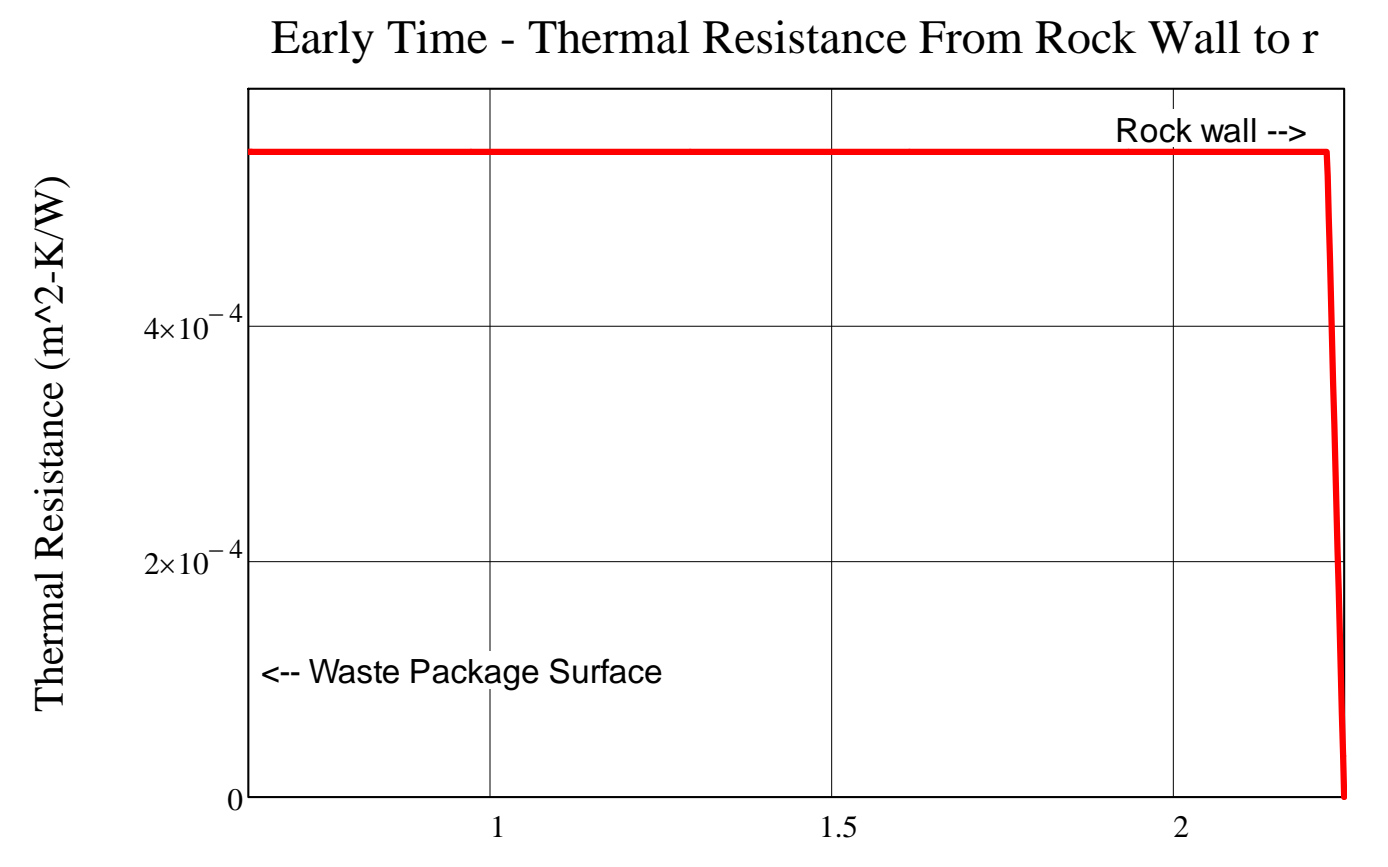

Radial Location Within the EBS (m)

— Thermal resistance prior to closure

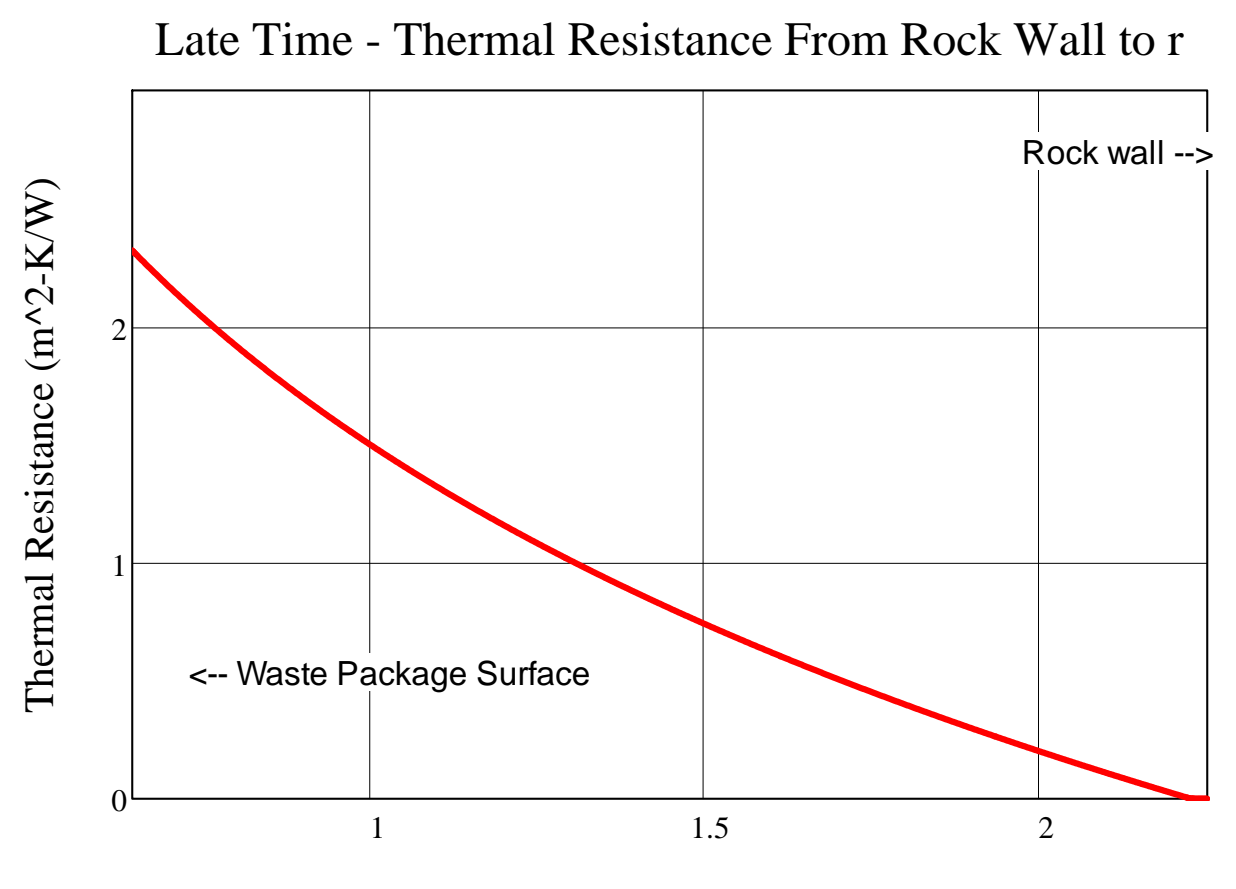

Radial Location Within the EBS (m)

— Thermal resistance prior to closure
$\mathrm{r}_{\mathrm{DW}}=2.25 \mathrm{~m}$

$\mathrm{r}_{1}=2.25 \mathrm{~m} \quad$ EBS_name $1=$ "Liner" $\quad$ EBS_material $_{1}=$ "Steel"

$\mathrm{r}_{2}=2.225 \mathrm{~m} \quad$ Note that for "open modes", the

backfill hasn't been emplaced at

$\mathrm{r}_{3}=0.645 \mathrm{~m} \quad \begin{aligned} & \text { early time } \\ & \text { EBS_name }_{3}=\text { "Envelope" }\end{aligned}$ ก. EBS_material $_{3}=$ "None"

$\mathrm{r}_{4}=0.645 \mathrm{~m} \quad$ EBS_name $_{4}=$ "Buffer" $\quad$ EBS_material $4=$ "None"

$\mathrm{r}_{\mathrm{WP}}=0.645 \mathrm{~m}$

$\mathrm{R}_{1}\left(\mathrm{k}_{1}\right)=5.465 \times 10^{-4} \cdot \frac{\mathrm{m}^{2} \cdot \mathrm{K}}{\mathrm{W}} \quad \mathrm{R}_{2}\left(\mathrm{k}_{2}, 5 \cdot \mathrm{yr}, \mathrm{t}_{\text {operate }}, \mathrm{t}_{\text {backfill }}\right)=0 \cdot \frac{\mathrm{m}^{2} \cdot \mathrm{K}}{\mathrm{W}} \quad \mathrm{R}_{3}\left(\mathrm{k}_{3}\right)=0 \cdot \frac{\mathrm{m}^{2} \cdot \mathrm{K}}{\mathrm{W}} \quad \mathrm{R}_{4}\left(\mathrm{k}_{4}\right)=0 \cdot \frac{\mathrm{m}^{2} \cdot \mathrm{K}}{\mathrm{W}}$

$\mathrm{R}_{\text {Total }}\left(50 \mathrm{yr}, \mathrm{k}_{1}, \mathrm{k}_{2}, \mathrm{k}_{3}, \mathrm{k}_{4}\right)=5.465 \times 10^{-4} \cdot \frac{\mathrm{m}^{2} \cdot \mathrm{K}}{\mathrm{W}}$

$\mathrm{r}_{\mathrm{DW}}=2.25 \mathrm{~m}$

$\mathrm{r}_{1}=2.25 \mathrm{~m} \quad$ EBS_name $_{1}=$ "Liner" $\quad$ EBS_material $_{1}=$ "Steel"

$\mathrm{r}_{2}=2.225 \mathrm{~m} \quad$ EBS_name $2=$ "Backfill" $\quad$ EBS_material ${ }_{2}=$ "70\% Bentonite $30 \%$ Sand"

$\mathrm{r}_{3}=0.645 \mathrm{~m} \quad$ EBS_name $_{3}=$ "Envelope" $\quad$ EBS_material $_{3}=$ "None"

$\mathrm{r}_{4}=0.645 \mathrm{~m} \quad$ EBS_name $_{4}=$ "Buffer" $\quad$ EBS_material ${ }_{4}=$ "None"

$\mathrm{r}_{\mathrm{WP}}=0.645 \mathrm{~m}$

$\mathrm{R}_{1}\left(\mathrm{k}_{1}\right)=5.465 \times 10^{-4} \cdot \frac{\mathrm{m}^{2} \cdot \mathrm{K}}{\mathrm{W}} \quad \mathrm{R}_{2}\left(\mathrm{k}_{2}, \mathrm{t}_{\text {closure }}, \mathrm{t}_{\text {operate }}, \mathrm{t}_{\text {backfill }}\right)=2.322 \cdot \frac{\mathrm{m}^{2} \cdot \mathrm{K}}{\mathrm{W}} \quad \mathrm{R}_{3}\left(\mathrm{k}_{3}\right)=0 \cdot \frac{\mathrm{m}^{2} \cdot \mathrm{K}}{\mathrm{W}}$

$\mathrm{R}_{\text {Total }}\left(1000 \mathrm{yr}, \mathrm{k}_{1}, \mathrm{k}_{2}, \mathrm{k}_{3}, \mathrm{k}_{4}\right)=2.322 \cdot \frac{\mathrm{m}^{2} \cdot \mathrm{K}}{\mathrm{W}}$ 


\section{INPUT $6=$ WASTE FORM DATA}

Input_6 := READEXCEL(file, concat(sheet, "A35:B38"))

Input_6 = $\left(\begin{array}{cc}\text { "Waste form short name" } & \text { "UOX-40" } \\ \text { "Waste form type" } & \text { "Assembly" } \\ \text { "Waste package capacity" } & 32 \\ \text { "Waste package length, m" } & 5\end{array}\right)$

WF_name := Input_61,2 = "UOX-40"

WF_type $:=$ Input_62,2 = "Assembly"

WP_cap := Input_63,2 $=32$

WP_length := Input_64,2·m $=5 \mathrm{~m}$

\section{Outside of the liner}

$\mathrm{A}_{1}:=2 \cdot \pi \cdot \mathrm{r}_{1} \cdot \mathrm{WP} \_$length $=70.69 \mathrm{~m}^{2}$

$\mathrm{A}_{\mathrm{DW}}:=2 \cdot \pi \cdot \mathrm{r}_{\mathrm{DW}} \cdot \mathrm{WP} \_$length $=70.686 \mathrm{~m}^{2}$
Outside of the backfil

$\mathrm{A}_{2}:=2 \cdot \pi \cdot \mathrm{r}_{2} \cdot \mathrm{WP} \_$length $=69.9 \mathrm{~m}^{2}$

$A_{3}:=2 \cdot \pi \cdot r_{3} \cdot$ WP_length $=20.26 \mathrm{~m}^{2}$
Outside of the buffer

$\mathrm{A}_{4}:=2 \cdot \pi \cdot r_{4} \cdot \mathrm{WP} \_$length $=20.26 \mathrm{~m}^{2}$

$A_{W P}:=2 \cdot \pi \cdot r_{W P} \cdot$ WP_length $=20.263 \mathrm{~m}^{2}$

CONSIDER THE ALTERNATE DESIGN CASE OF AN "OPEN MODE" DESIGN, WITH A CEMENTITIOUS LINER, BUT ONLY AIR BETWEEN THE LINER AND THE WASTE PACKAGE FOR THE FIRST 300 YEARS. ASSUME NO VENTILATION FOR 300 YEARS, AND THEN BACKFILL AT CLOSURE.

CALCULATE THE EQUIVALENT THERMAL RESISTANCE OF THE AIR GAP USING A LINEARIZED RADIATION HEAT TRANSFER COEFFICIENT. BASE THE COEFFICIENT

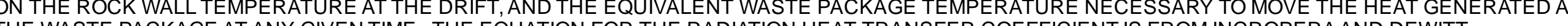

$\mathrm{A}_{\text {wall }}:=$ WP_length $\cdot 2 \cdot \pi \cdot \mathrm{r}_{\mathrm{DW}}=70.686 \mathrm{~m}^{2}$

Stefan Boltzmann constant $\quad \sigma:=5.670 \cdot 10^{-8} \cdot \frac{\mathrm{W}}{\mathrm{m}^{2} \cdot \mathrm{K}^{4}}$

Waste Package emissivity $\quad \varepsilon_{\mathrm{WP}}=0.6$

\section{Rock wall or cementious liner emissivity}

$\varepsilon_{\text {wall }}=0.9$
The basis for the rock and waste package emissivity assumed is F. P. Incropera and D.P. DeWitt, Fundamentals of Heat and Mass Transfer, 4th Edition, 1996, Table A-11, which shows a range of 0.88 to 0.93 is adapted from hemispherical emissivity of rock at around $300 \mathrm{~K}$. This range is corroborated by the "Heat Transmission" section of Perry's Chemical Engineers Handbook, 6th Edition, 1984 (Table 10-17, pages 10-51 to 10-52) for normal emissivity of rough silica and rough fused quartz, ranging from 0.8 to 0.93 . The waste package surface is assumed to be covered with dust and dirt. The emissivity values to the left were specified in DSEF, and should be changed there if necessary.

Reference for radiation heat transfer coefficient, $h_{\text {rad }}$, is from Incropera and DeWitt, Table 13.3 for concentric infinite cylinders (based on the inner surface as the heat source), and is also referenced in the YMP Ventilation Model and Analysis Report, ANL-EBS-MD-000030 REV 04, Oct. 2004, page 6-8.

$\mathrm{h}_{\text {rad_infinite }}\left(\mathrm{r}_{\mathrm{i}}, \mathrm{r}_{\mathrm{O}}, \varepsilon_{\mathrm{i}}, \varepsilon_{\mathrm{O}}\right):=\frac{\sigma}{\frac{1}{\varepsilon_{\mathrm{i}}}+\left(\frac{1-\varepsilon_{\mathrm{o}}}{\varepsilon_{\mathrm{o}}}\right) \cdot \frac{\mathrm{r}_{\mathrm{i}}}{\mathrm{r}_{\mathrm{O}}}}$ $\mathrm{h}_{\text {rad_infinite }}\left({ }_{\mathrm{WP}}, \mathrm{r}_{\mathrm{DW}}, \varepsilon_{\mathrm{WP}}, \varepsilon_{\mathrm{wall}}\right)=3.338 \times 10^{-8} \cdot \frac{\mathrm{W}}{\mathrm{m}^{2} \mathrm{~K}^{4}}$ Usage is $Q$ in watts $=h^{\star} A_{i}^{*}\left(T_{i}^{\wedge} 4-T_{0}^{\wedge} 4\right)$
For radiation betwen the liner and the envelope (both metal surfaces) use $r_{2}$ and $r_{3}$, and assume the same emissivity for both surfaces. 
$\mathrm{Q}_{\text {rad_infinite }}\left(\mathrm{r}_{\mathrm{i}}, \mathrm{r}_{\mathrm{O}}, \varepsilon_{\mathrm{i}}, \varepsilon_{\mathrm{O}}, \mathrm{L}, \mathrm{T}_{\text {cold }}, \mathrm{T}_{\text {hot }}\right):=\mathrm{h}_{\text {rad_infinite }}\left(\mathrm{r}_{\mathrm{i}}, \mathrm{r}_{\mathrm{O}}, \varepsilon_{\mathrm{i}}, \varepsilon_{\mathrm{O}}\right) \cdot\left(2 \cdot \pi \cdot \mathrm{r}_{\mathrm{i}} \mathrm{L}\right)\left(\mathrm{T}_{\text {hot }} \stackrel{4}{4}-\mathrm{T}_{\text {cold }} 4\right)$

$\mathrm{Q}_{\mathrm{L}_{\_} \text {rad_infinite }}\left(\mathrm{r}_{\mathrm{i}}, \mathrm{r}_{\mathrm{O}}, \varepsilon_{\mathrm{i}}, \varepsilon_{\mathrm{O}}, \mathrm{T}_{\text {cold }}, \mathrm{T}_{\text {hot }}\right):=\mathrm{h}_{\text {rad_infinite }}\left(\mathrm{r}_{\mathrm{i}}, \mathrm{r}_{\mathrm{O}}, \varepsilon_{\mathrm{i}}, \varepsilon_{\mathrm{o}}\right) \cdot\left(2 \cdot \pi \cdot \mathrm{r}_{\mathrm{i}}\right)\left(\mathrm{T}_{\text {hot }}{ }^{4}-\mathrm{T}_{\text {cold }}{ }^{4}\right)$

Heat transfer by radiation from NIRAS/ONDRAF December 2005 Report: Eef Weetjens and Xavier Sillen; Thermal analysis of the Supercontainer concept 2D

axisymmetric heat transport calculations, Section 6.4.3. Pg 34, equation 29.

$\mathrm{Q}_{\mathrm{L}_{-} \text {infinite }}\left(\mathrm{r}_{\mathrm{i}}, \mathrm{r}_{\mathrm{O}}, \varepsilon_{\mathrm{i}}, \varepsilon_{\mathrm{O}}, \mathrm{T}_{\text {cold }}, \mathrm{T}_{\text {hot }}\right):=\frac{2 \pi \sigma \cdot\left(\mathrm{T}_{\text {hot }}{ }^{4}-\mathrm{T}_{\text {cold }}{ }^{4}\right)}{\frac{1-\varepsilon_{\mathrm{i}}}{\varepsilon_{\mathrm{i}} \mathrm{r}_{\mathrm{i}}}+\frac{1}{\mathrm{r}_{\mathrm{i}}}+\frac{1-\varepsilon_{\mathrm{o}}}{\varepsilon_{0} \cdot \mathrm{r}_{\mathrm{O}}}}$

$\mathrm{Q}_{\mathrm{L} \_ \text {infinite }}\left(\mathrm{r}_{3}, \mathrm{r}_{2}, \varepsilon_{\mathrm{WP}}, \varepsilon_{\mathrm{wall}}, 300 \cdot \mathrm{K}, 600 \cdot \mathrm{K}\right)=1.643 \times 10^{4} \cdot \frac{\mathrm{W}}{\mathrm{m}}$

\section{Comparision of thermal radiation across a gap to conduction after the gap has been filled with backfill material.}

$\mathrm{Q}_{\mathrm{L} \_ \text {conduction_comparison }}\left(\mathrm{r}_{\mathrm{i}}, \mathrm{r}_{\mathrm{O}}, \mathrm{T}_{\text {cold }}, \mathrm{T}_{\text {hot }}\right):=\frac{2 \cdot \pi \cdot \mathrm{r}_{\mathrm{o}}}{\frac{\mathrm{r}_{\mathrm{DW}}}{\mathrm{k}_{2}} \cdot \ln \left(\frac{\mathrm{r}_{\mathrm{o}}}{\mathrm{r}_{\mathrm{i}}}\right)} \cdot\left(\mathrm{T}_{\text {hot }}-\mathrm{T}_{\text {cold }}\right) \quad \mathrm{Q}_{\mathrm{L}_{-} \text {conduction_comparison }}\left(\mathrm{r}_{3}, \mathrm{r}_{2}, 300 \cdot \mathrm{K}, 600 \cdot \mathrm{K}\right)=1.806 \times 10^{3} \cdot \frac{\mathrm{W}}{\mathrm{m}}$

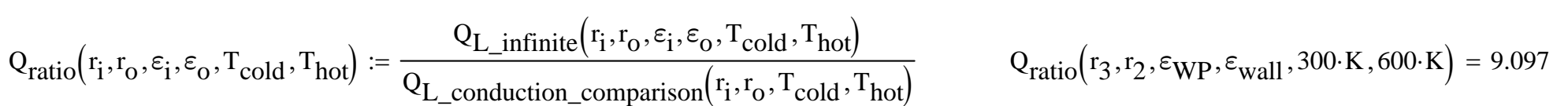

\section{INPUT 7 = PARAMETRIC STUDY VARIABLE INPUT DATA}

Input_7 := READEXCEL(file, concat(sheet, "F29:F41"))

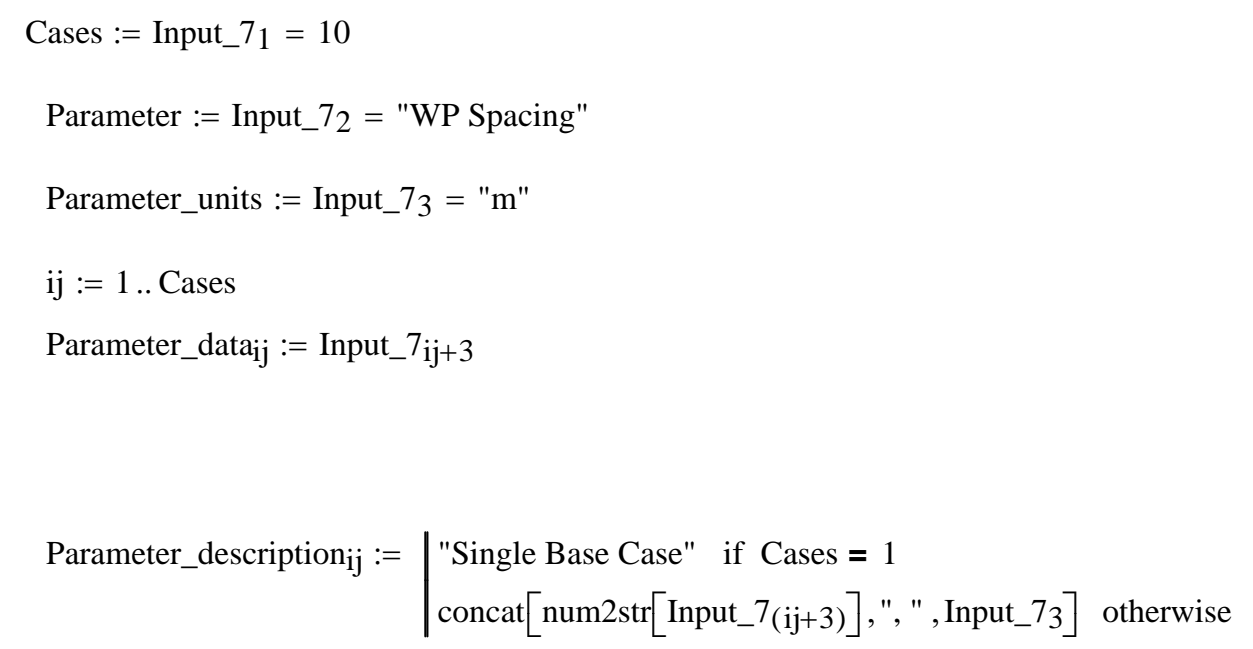

Parameter_data

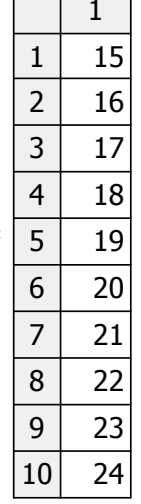

Input_ $7=$

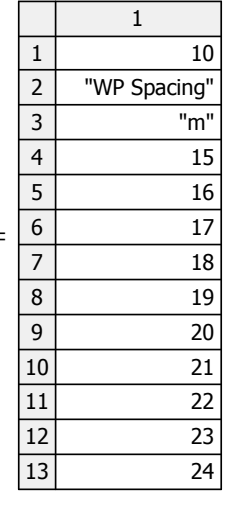

Mathcad Component of DSEF 3.0 
INPUT 8 = DECAY HEAT INPUT DATA PER UNIT SOURCE (ASSEMBLY OR CANISTER):

Input_8_size := READEXCEL(file, concat(sheet, "C43")) Input_8_size $1=$

Decay_heat_range := concat["A43:B" ,num2str((Input_8_size $1+42))]$ = "A43:B100"

Input_8 := READEXCEL(file, concat(sheet,Decay_heat_range))

Time_out_of_Reactor := Input__ ${ }^{\langle 1\rangle} \cdot$ yr

Decay_Heat_per_Cnt $:=$ Input_8 ${ }^{\langle 2\rangle}$.W

Input_8

\begin{tabular}{|r|r|r|}
\hline & 1 & \multicolumn{1}{|c|}{2} \\
\hline 1 & 5 & $1.028 \cdot 10^{3}$ \\
\hline 2 & 5.1 & $1.011 \cdot 10^{3}$ \\
\hline 3 & 5.5 & 949.125 \\
\hline 4 & 5.75 & 916.671 \\
\hline 5 & 6 & 887.984 \\
\hline 6 & 8 & 742.948 \\
\hline 7 & 10 & 670.028 \\
\hline 8 & 11.5 & 634.239 \\
\hline 9 & 15 & 576.929 \\
\hline 10 & 20 &.. \\
\hline
\end{tabular}

Time_out_of_Reactor

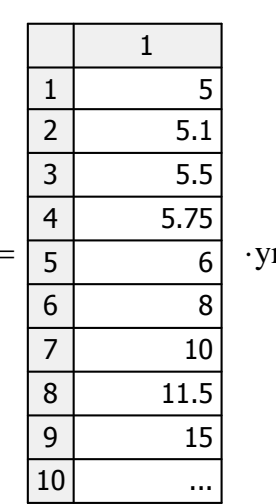

Decay_Heat_per_Cnt $=$

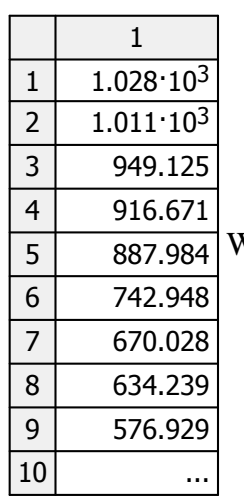

$\mathrm{Q}(\mathrm{t})$ := interp(cspline(Time_out_of_Reactor,Decay_Heat_per_Cnt),Time_out_of_Reactor,Decay_Heat_per_Cnt,t)

Ventilation efficiency for open systems is $\quad \mathrm{V}_{\text {eff }}=0.75$ between $\mathrm{t}_{\text {store }}$ and $\mathrm{t}_{\text {operate }}$

FUNCTION DEFINITION FOR ONE OUTPUT FILE

\section{FORMULAS FOR CALCULATING THE TRANSIENT DRIFT WALL TEMPERATURE:}

Central waste package:

$\mathrm{Q}_{\mathrm{L} \_ \text {wp }}\left(\mathrm{t}, \mathrm{t}_{\text {store }}, \mathrm{t}_{\text {operate }}, \mathrm{WP} \_\right.$cap $):=\frac{\mathrm{Q}(\mathrm{t}) \cdot \mathrm{WP} \_ \text {cap }}{\text { WP_length }} \cdot\left[1-1 \cdot\left(\mathrm{t} \leq \mathrm{t}_{\text {store }}\right)\right] \cdot\left[1-\mathrm{V}_{\text {eff }} \cdot\left(\mathrm{t} \leq \mathrm{t}_{\text {operate }}\right)\right]$

$$
\mathrm{Q}_{\mathrm{L}_{\_} \mathrm{wP}}\left(55 \cdot \mathrm{yr}, \mathrm{t}_{\text {store }}, \mathrm{t}_{\text {operate }}, 12\right)=177.365 \cdot \frac{\mathrm{W}}{\mathrm{m}}
$$




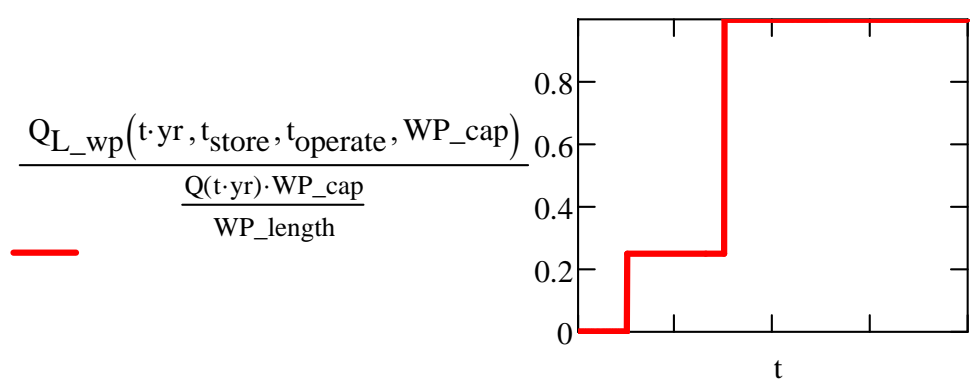

\section{Note - added $\mathrm{r}_{\mathrm{DW}}$ as a function parameter to allow calculations at additional compliance points inside the rock, where $\mathrm{r}_{\mathrm{DW}}$ would be replaced with new radius value.}

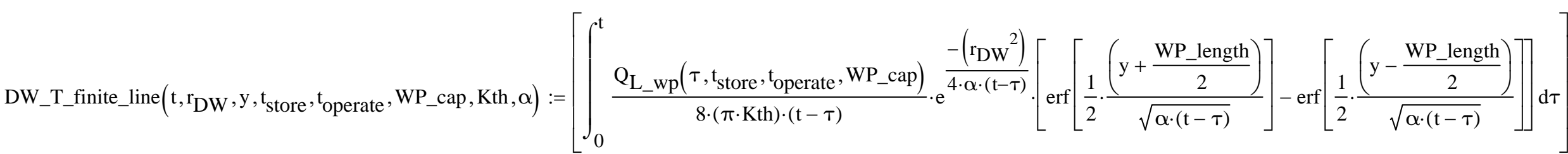

Adjacent drifts:

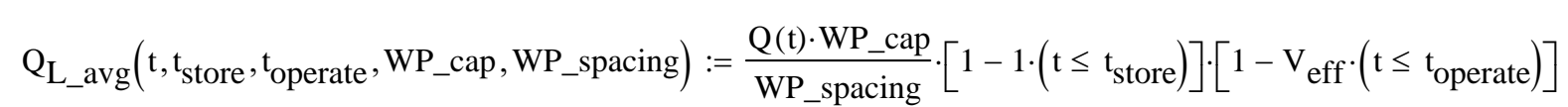

Note - added $\mathrm{r}_{\mathrm{DW}}$ as a function parameter to allow calculations at additional compliance points inside the rock, where $\mathrm{r}_{\mathrm{DW}}$ would be replaced with new radius value.

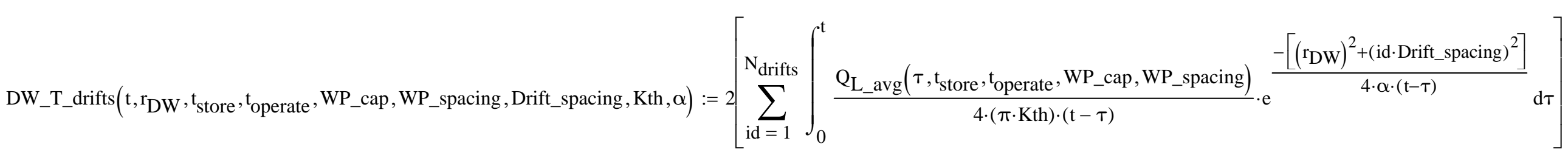

Adjacent waste packages:

$\mathrm{Q}_{\mathrm{wp}}\left(\mathrm{t}, \mathrm{t}_{\text {store }}, \mathrm{t}_{\text {operate }}, \mathrm{WP} \_\right.$cap $):=\mathrm{Q}(\mathrm{t}) \mathrm{WP} \_$cap $\cdot\left[1-1 \cdot\left(\mathrm{t} \leq \mathrm{t}_{\text {store }}\right)\right] \cdot\left[1-\mathrm{V}_{\text {eff }} \cdot\left(\mathrm{t} \leq \mathrm{t}_{\text {operate }}\right)\right]$

Note - added $\mathrm{r}_{\mathrm{DW}}$ as a function parameter to allow calculations at additional compliance points inside the rock, where $\mathrm{r}_{\mathrm{DW}}$ would be replaced with new radius value.

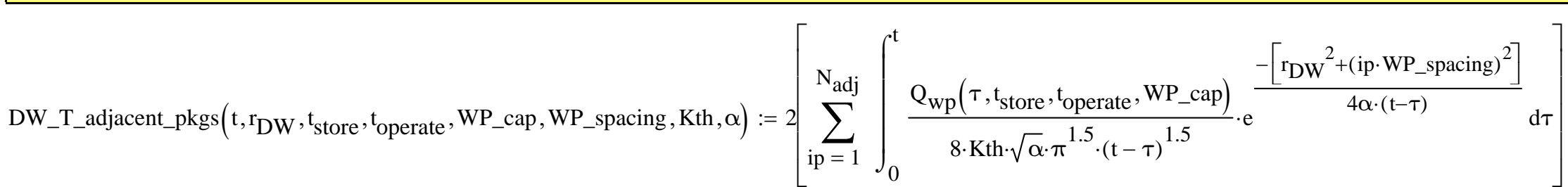




\section{This command specifies two rows of column headings for output paramenter sensitivity runs}

OutfileName := file = "DSEF R3.0_2013Aug12_HRG-Clay_UOX-40_CP2=1m,DS70,Vent100,WP param_Case-500-1.xlsm" Out_sheet := "Thermal-Analytical Output!"

This section specifies the column headings for output sensitivity studies

Cases $=10 \quad$ Read in from Thermal-Analytical sheet in DSEF (Inputs_7)

$i:=1$.. Cases

Parameter_vectori := $\mid$ "Base Case" if Cases $=1$

concat(Parameter, " ", Parameter_descriptioni) otherwise
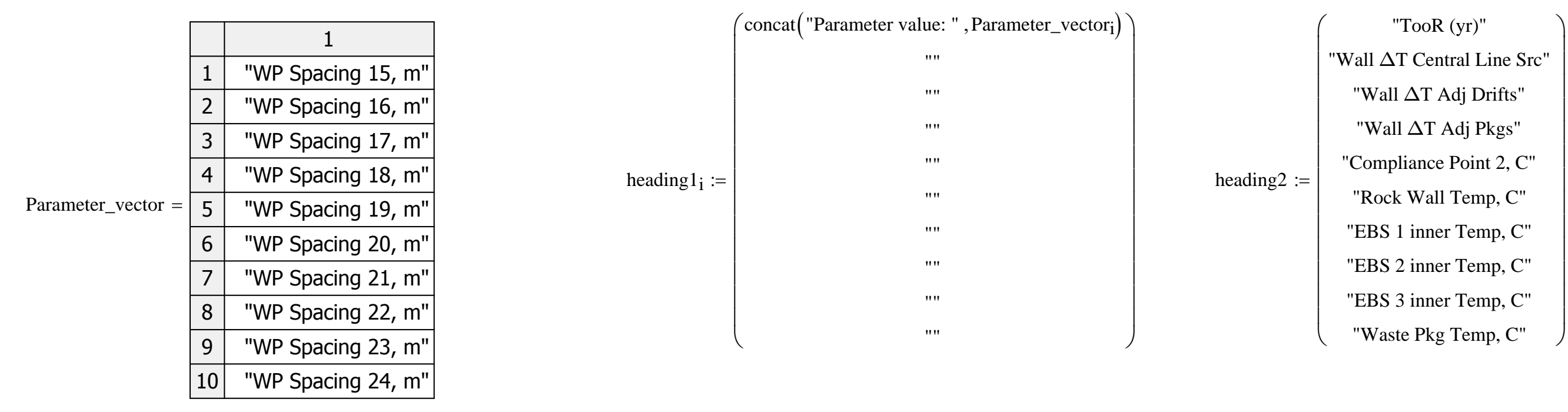

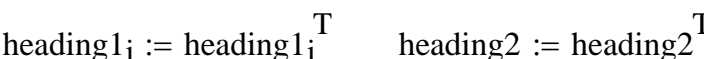

Title_arrayi := stack(heading1 1 , heading2

Title_array2 $=$

\begin{tabular}{|r|r|}
\hline & \multicolumn{1}{|c|}{1} \\
\hline 1 & ter value: WP Spacing $16, \mathrm{~m} "$ \\
\hline 2 & "TooR $(\mathrm{yr}) "$ \\
\hline
\end{tabular}

2 "Wall $\Delta \mathrm{T}$ Central Line Src"

\begin{tabular}{|r|r|rr|}
3 & 4 & 5 \\
\hline "'" & "'" & & "'" \\
\hline "Wall $\Delta$ T Adj Drifts" & "Wall $\Delta$ T Adj Pkgs" & & $\ldots$ \\
\hline
\end{tabular}

For-Loop analysis returning the output time, three temperature contribution terms, and six temperatures

length(Parameter_data) $=10$

$$
\begin{aligned}
{ }^{\mathrm{r}} \mathrm{DW} & =2.25 \mathrm{~m} \\
{ }^{\mathrm{r}} \mathrm{CP2} & =3.25 \mathrm{~m}
\end{aligned}
$$

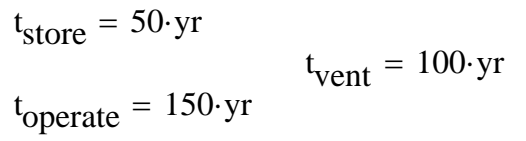$$
\mathrm{t}_{\text {closure }}=160 \cdot \mathrm{yr}
$$

Removed loop on "j", added r r into DW _T functions.

$\mathrm{t}_{\text {closure }}=160 \cdot \mathrm{yr}$
Changed j vector to Parameter data, Inserted row 2

Cow 5 changed to $\mathrm{k}_{\text {radi }}$ and $\mathrm{k}_{2}$ from $\mathrm{k}_{2}$ and $\mathrm{k}_{\text {backill }}$

row 8 changed WP spacej to WP_spacing

Page 10 of 23

Note for enclosed modes $\mathrm{k}_{\text {radiation }}=\mathrm{k}_{2}$ 
outdata $\left(\mathrm{r}_{\mathrm{DW}}, \mathrm{r}_{\mathrm{CP} 2}, \mathrm{t}_{\text {store }}, \mathrm{t}_{\text {operate }}\right.$, WP_cap, WP_spacing, Drift_spacing, Kth, $\left.\alpha, \mathrm{k}_{1}, \mathrm{k}_{2}, \mathrm{k}_{3}, \mathrm{k}_{4}\right):=\mid$ for $\mathrm{i} \in 1$... Counter +1

$\mathrm{tt}_{\mathrm{i}} \leftarrow$ Step. $\cdot \mathrm{i} \cdot \mathrm{yr}+\mathrm{t}_{\text {store }}-$ Step $\cdot 1 \mathrm{yr}$

$\mathrm{kk}_{2} \leftarrow \mathrm{k}_{\text {radiation }} \cdot\left[\mathrm{ti}_{\mathrm{i}}<\left(\mathrm{t}_{\text {operate }}+\mathrm{t}_{\text {backfill }}\right)\right]+\mathrm{k}_{2} \cdot\left[\mathrm{tt}_{\mathrm{i}} \geq\left(\mathrm{t}_{\text {operate }}+\mathrm{t}_{\text {backfill }}\right)\right]$

Wall_deltaT_finite_line ${ }_{i} \leftarrow$ DW_T_finite_line $\left(\mathrm{tti}_{\mathrm{i}}, \mathrm{r} \mathrm{DW}, 0, \mathrm{t}_{\text {store }}, \mathrm{t}_{\text {operate }}, \mathrm{WP}\right.$ _cap, Kth, $\left.\alpha\right)$

Wall_deltaT_drifts $\leftarrow$ DW_T_drifts $\left(\mathrm{tt}_{\mathrm{i}}, \mathrm{r}\right.$ DW $, \mathrm{t}_{\text {store }}, \mathrm{t}_{\text {operate }}$, WP_cap, WP_spacing, Driff_spacing, Kth, $\left.\alpha\right)$

Wall_deltaT_adj_pkgsi $\leftarrow$ DW_T_adjacent_pkgs $\left(\mathrm{tti}_{\mathrm{i}}, \mathrm{r}_{\mathrm{DW}}, \mathrm{t}_{\text {store }}, \mathrm{t}_{\text {operate }}, \mathrm{WP}\right.$ _cap, WP_spacing, Kth, $\left.\alpha\right)$

Wall_ $T_{i} \leftarrow T_{\text {ambient }}+$ Wall_deltaT_finite_line + Wall_deltaT_driftsi + Wall_deltaT_adj_pkgsi

CP2_deltaT_finite_line $\leftarrow$ $\leftarrow$ DW_T_finite_line $\left(\mathrm{tt}_{\mathrm{i}}, \mathrm{r}_{\mathrm{CP}}, 0, \mathrm{t}_{\text {store }}, \mathrm{t}_{\text {operate }}\right.$, WP_cap, Kth,$\left.\alpha\right)$

CP2_deltaT_driftsi $\leftarrow$ DW_T_drifts $\left(\mathrm{tt}_{\mathrm{t}},{ }_{\mathrm{C}} \mathrm{CP2}, \mathrm{t}_{\text {store }}, \mathrm{t}_{\text {operate }}, \mathrm{WP}\right.$ _cap, WP_spacing, Drift_spacing, Kth , $\left.\alpha\right)$

CP2_deltaT_adj_pkgsi $\leftarrow$ DW_T_adjacent_pkgs $\left(\mathrm{tt}_{\mathrm{i}}, \mathrm{r}\right.$ CP2 $, \mathrm{t}_{\text {store }}, \mathrm{t}_{\text {operate }}$, WP_cap, WP_spacing, Kth, $\left.\alpha\right)$

$\mathrm{CP2} \mathrm{T}_{\mathrm{i}} \leftarrow \mathrm{T}_{\text {ambient }}+\mathrm{CP2}$ _deltaT_finite_line $\mathrm{i}_{\mathrm{i}}+\mathrm{CP2} \_$deltaT_drifts + CP2_deltaT_adj_pkgsi

$\mathrm{Q}_{\mathrm{i}} \leftarrow \mathrm{Q}_{\mathrm{L} \_w p}\left(\mathrm{tti}_{\mathrm{i}}, \mathrm{t}_{\text {store }}, \mathrm{t}_{\text {operate }}, \mathrm{WP} \mathrm{W}_{-} \mathrm{cap}\right)$

EBS_ $1_{i} \leftarrow$ Wall_ $T_{i}+\frac{Q_{i}}{2 \cdot \pi \cdot r_{D W}} \cdot R_{1}\left(k_{1}\right)$

EBS_2 $2_{i} \leftarrow \mid$ EBS_ $1_{i}+\frac{Q_{i}}{2 \cdot \pi \cdot r_{D W}} \cdot R_{2}\left(k_{2}, t_{1}, t_{\text {operate }}, t_{\text {backfill }}\right)$ if $\mathrm{kk}_{2} \neq 0 \cdot \frac{\mathrm{W}}{\mathrm{m} \cdot \mathrm{K}}$

$$
\left[\left[\frac{\mathrm{Q}_{\mathrm{i}}}{\mathrm{h}_{\text {rad_infinite }}\left(\mathrm{r}_{3}, \mathrm{r}_{2}, \varepsilon_{\mathrm{WP}}, \varepsilon_{\mathrm{wall}}\right) \cdot 2 \cdot \pi \cdot \mathrm{r}_{3}}+\left(\text { EBS_1 } 1_{\mathrm{i}}\right)^{4}\right]^{\frac{1}{4}}\right] \text { otherwise }
$$

EBS_3 3 $\leftarrow$ EBS_2 $2 \mathrm{i}+\frac{\mathrm{Q}_{\mathrm{i}}}{2 \cdot \pi \cdot \mathrm{r}_{\mathrm{DW}}} \cdot \mathrm{R}_{3}\left(\mathrm{k}_{3}\right)$

WP_ $\mathrm{T}_{\mathrm{i}} \leftarrow$ EBS_ $3_{\mathrm{i}}+\frac{\mathrm{Q}_{\mathrm{i}}}{2 \cdot \pi \cdot \mathrm{r} \mathrm{DW}} \cdot \mathrm{R}_{4}\left(\mathrm{k}_{4}\right)$

$\mathrm{T} 1_{\mathrm{i}} \leftarrow \mathrm{CP} 2 \mathrm{~T}_{\mathrm{i}}-273.15 \mathrm{~K}$

$\mathrm{T} 2 \mathrm{i} \leftarrow$ Wall $\_\mathrm{T}_{\mathrm{i}}-273.15 \mathrm{~K}$

T3 $3_{\mathrm{i}} \leftarrow$ EBS $\_11_{\mathrm{i}}-273.15 \mathrm{~K}$

T4 $4_{\mathrm{i}} \leftarrow$ EBS_2 $2 \mathrm{i}-273.15 \mathrm{~K}$

T5 $5_{\mathrm{i}} \leftarrow$ EBS_ $33_{\mathrm{i}}-273.15 \mathrm{~K}$

$\mathrm{T} 6_{\mathrm{i}} \leftarrow$ WP_T $\mathrm{T}_{\mathrm{i}}-273.15 \mathrm{~K}$

Data_array $\leftarrow$ augment $\left(\mathrm{tt} \cdot \frac{1}{\mathrm{yr}}\right.$, Wall_deltaT_finite_line $\cdot \frac{1}{\mathrm{~K}}$,Wall_deltaT_drifts $\cdot \frac{1}{\mathrm{~K}}$,Wall_deltaT_adj_pkgs $\left.\cdot \frac{1}{\mathrm{~K}}, \mathrm{~T} 1 \cdot \frac{1}{\mathrm{~K}}, \mathrm{~T} 2 \cdot \frac{1}{\mathrm{~K}}, \mathrm{~T} 3 \cdot \frac{1}{\mathrm{~K}}, \mathrm{~T} 4 \cdot \frac{1}{\mathrm{~K}}, \mathrm{~T} 5 \cdot \frac{1}{\mathrm{~K}}, \mathrm{~T} 6 \cdot \frac{1}{\mathrm{~K}}\right)$ 


\section{$\mathrm{jjj}:=1 .$. Cases $\quad$ Cases $=10$}

$\mathrm{X}_{\mathrm{jjj}}:=$ Parameter_datajjj $\quad$ Parameter $=$ "WP Spacing"

Temp_array $\mathrm{jjj}:=\mid$ outdata $\left(\mathrm{r}_{\mathrm{DW}},{ }_{\mathrm{CP}}\right.$, ${ }_{\text {store }}, \mathrm{t}_{\text {operate }}$, WP_cap, WP_spacing, Drift_spacing, $\left.\mathrm{Kth}, \alpha, \mathrm{k}_{1}, \mathrm{k}_{2}, \mathrm{k}_{3}, \mathrm{k}_{4}\right)$ if Parameter $=$ "Single" outdata $\left({ }_{\mathrm{DW}},{ }_{\mathrm{C}} \mathrm{CP} 2, \mathrm{t}_{\text {store }}, \mathrm{t}_{\text {operate }}, \mathrm{WP}_{-}\right.$cap, WP_spacing, $\left.\mathrm{X}_{\mathrm{jjj}} \cdot \mathrm{m}, \mathrm{Kth}, \alpha, \mathrm{k}_{1}, \mathrm{k}_{2}, \mathrm{k}_{3}, \mathrm{k}_{4}\right)$ if Parameter $=$ "Drift Spacing" outdata $\left({ }_{\mathrm{DW}}, \mathrm{r}_{\mathrm{CP} 2}, \mathrm{t}_{\text {store }}, \mathrm{t}_{\text {operate }}, \mathrm{WP} \mathrm{W}_{-} \mathrm{cap}, \mathrm{X}_{\mathrm{jjj}}\right.$, $\mathrm{m}$, Drift_spacing, $\left.\mathrm{Kth}, \alpha, \mathrm{k}_{1}, \mathrm{k}_{2}, \mathrm{k}_{3}, \mathrm{k}_{4}\right)$ if Parameter $=$ "WP Spacing" outdata $\left({ }_{\mathrm{DW}}, \mathrm{r}_{\mathrm{CP}}, \mathrm{X}_{\mathrm{jjj}} \cdot \mathrm{yr}, \mathrm{t}_{\text {operate }}\right.$, WP_cap, WP_spacing, Drift_spacing, Kth, $\left.\alpha, \mathrm{k}_{1}, \mathrm{k}_{2}, \mathrm{k}_{3}, \mathrm{k}_{4}\right)$ if Parameter $=$ "Storage Time" outdata $\left({ }_{\mathrm{DW}},{ }_{\mathrm{C} P 2}, \mathrm{t}_{\text {store }}, \mathrm{t}_{\text {store }}+\mathrm{X}_{\mathrm{jjj}} \cdot \mathrm{yr}\right.$,WP_cap, WP_spacing, Drift_spacing, Kth, $\left.\alpha, \mathrm{k}_{1}, \mathrm{k}_{2}, \mathrm{k}_{3}, \mathrm{k}_{4}\right)$ if Parameter $=$ "Ventilation Duration" outdata $\left({ }_{\mathrm{DW}},{ }_{\mathrm{CP} 2}, \mathrm{t}_{\text {store }}, \mathrm{t}_{\text {operate }}, \mathrm{WP}_{-}\right.$cap, WP_spacing, Drift_spacing, $\left.\mathrm{X}_{\mathrm{jjj}} \cdot \frac{\mathrm{W}}{\mathrm{m} \cdot \mathrm{K}}, \alpha, \mathrm{k}_{1}, \mathrm{k}_{2}, \mathrm{k}_{3}, \mathrm{k}_{4}\right)$ if Parameter $=$ "Rock Conductivity" outdata $\left(\mathrm{r}_{\mathrm{DW}}, \mathrm{r}_{\mathrm{CP}}, \mathrm{r}_{\text {store }}, \mathrm{t}_{\text {operate }}\right.$, WP_cap, WP_spacing, Drift_spacing, Kth, $\left.\alpha, \mathrm{k}_{1}, \mathrm{X}_{\mathrm{jjj}} \cdot \frac{\mathrm{W}}{\mathrm{m} \cdot \mathrm{K}}, \mathrm{k}_{3}, \mathrm{k}_{4}\right)$ if Parameter $=$ "Backfill Conductivity" "Undefined" otherwise

File_array $\mathrm{jjj}$ := stack(Title_arrayjjj, Temp_array $\mathrm{jjj})$

\begin{tabular}{|c|c|c|c|c|c|c|}
\hline & 1 & 2 & 3 & 4 & 5 & 6 \\
\hline 1 & "Parameter value: WP Spacing 15, m" & "n' & "'"' & "m" & "'"' & "'m \\
\hline 2 & "TooR (yr)" & "Wall $\Delta \mathrm{T}$ Central Line Src" & "Wall $\Delta T$ Adj Drifts" & "Wall $\Delta \mathrm{T}$ Adj Pkgs" & "Compliance Point 2, C" & "Rock Wall Temp, C" \\
\hline 3 & 50 & 0 & 0 & 0 & 27.5 & 27.5 \\
\hline 4 & 55 & 35.579 & $6.058^{\circ} \cdot 10^{-6}$ & 4.514 & 56.729 & 67.593 \\
\hline 5 & 60 & 34.943 & $5.304 \cdot 10^{-3}$ & 7.492 & 59.778 & 69.94 \\
\hline 6 & 65 & 33.507 & 0.055 & 9.174 & 60.687 & 70.236 \\
\hline 7 & 70 & 31.898 & 0.188 & 10.203 & 60.822 & 69.789 \\
\hline 8 & 75 & 30.316 & 0.402 & 10.841 & 60.618 & 69.059 \\
\hline 9 & 80 & 28.814 & 0.677 & 11.225 & 60.25 & 68.216 \\
\hline 10 & 85 & 27.416 & 0.992 & 11.436 & 59.808 & 67.344 \\
\hline 11 & 90 & 26.118 & 1.328 & 11.527 & 59.325 & 66.473 \\
\hline 12 & 95 & 24.936 & 1.671 & 11.531 & 58.841 & 65.638 \\
\hline 13 & 100 & 23.83 & 2.016 & 11.479 & 58.349 & 64.826 \\
\hline 14 & 105 & 22.827 & 2.354 & 11.387 & 57.878 & 64.068 \\
\hline 15 & 110 & 21.9 & 2.682 & 11.252 & 57.41 & 63.334 \\
\hline 16 & 115 & 21.059 & 2.999 & 11.117 & 56.99 & \\
\hline
\end{tabular}


iii $:=1 . .10$

Peak_array ${ }_{j \mathrm{jj}}$, iii : $=\max \left[\left[\left(\text { Temp_array }_{\mathrm{jjj}}\right)^{\langle\text {iiii }}\right\rangle\right]$

Peak_array $1,2=59.322$

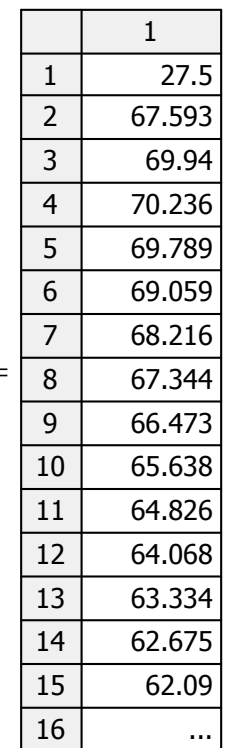

Time_array := (Temp_array 1$)^{\langle 1\rangle}$

Peak_T $(m, n):=\max \left[(\text { Temp_arraym })^{\langle\mathrm{n}\rangle}\right]$

Peak_T $T(1,5)=102.266$

Peak_time $(\mathrm{m}, \mathrm{n}):=$ lookup $\left[\right.$ Peak_T $(\mathrm{m}, \mathrm{n}),(\text { Temp_arraym })^{\langle\mathrm{n}\rangle}$,Time_array $]$

Peak_time $(1,5)=(315)$

Time_array

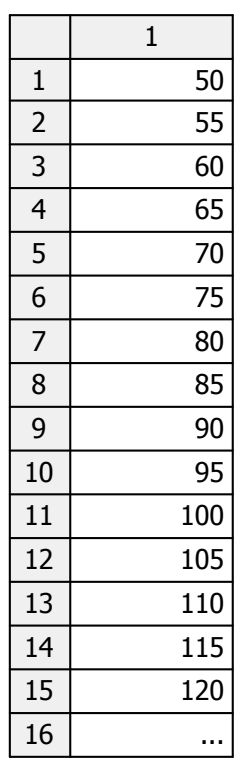

Initialize the peak value data array:

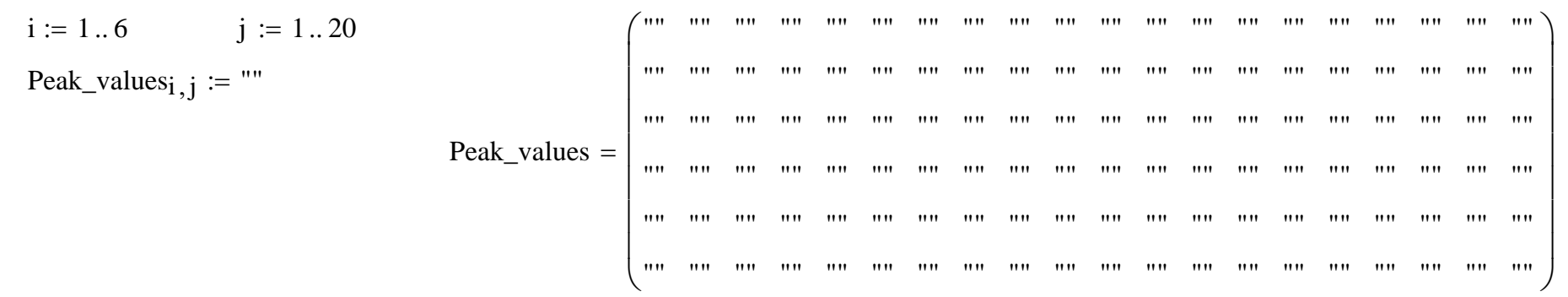

Fill in the peak temperatures and times:

$\mathrm{mj}:=1 .$. Cases $\quad \mathrm{nn}:=1 . .6$

Peak_valuesnn,mj.2-1 := Peak_T $(m j, n n+4)$

Peak_valuesnn,mj.2 := Peak_time $(m j, n n+4)_{1}$

$\mathrm{t}_{\text {vent }}=100 \cdot \mathrm{yr}$

Parameter_vector $^{\mathrm{T}}=$\begin{tabular}{|c|c|c|}
\hline & 1 & 2 \\
\hline 1 & "WP Spacing 15, m" &
\end{tabular} 
Peak_values $=\left(\begin{array}{cccccccccccccccccccc}102.266 & 315 & 99.137 & 285 & 96.413 & 285 & 93.988 & 285 & 91.828 & 260 & 89.914 & 250 & 88.231 & 235 & 86.66 & 235 & 85.276 & 230 & 84.019 & 230 \\ 115.262 & 210 & 112.287 & 205 & 109.734 & 190 & 107.536 & 190 & 105.602 & 185 & 103.927 & 185 & 102.391 & 185 & 101.064 & 180 & 99.912 & 175 & 98.88 & 175 \\ 115.285 & 210 & 112.311 & 205 & 109.759 & 190 & 107.561 & 190 & 105.628 & 185 & 103.952 & 185 & 102.417 & 185 & 101.09 & 180 & 99.939 & 175 & 98.907 & 175 \\ 231.735 & 160 & 229.391 & 160 & 227.373 & 160 & 225.623 & 160 & 224.095 & 160 & 222.753 & 160 & 221.567 & 160 & 220.514 & 160 & 219.576 & 160 & 218.736 & 160 \\ 231.735 & 160 & 229.391 & 160 & 227.373 & 160 & 225.623 & 160 & 224.095 & 160 & 222.753 & 160 & 221.567 & 160 & 220.514 & 160 & 219.576 & 160 & 218.736 & 160 \\ 231.735 & 160 & 229.391 & 160 & 227.373 & 160 & 225.623 & 160 & 224.095 & 160 & 222.753 & 160 & 221.567 & 160 & 220.514 & 160 & 219.576 & 160 & 218.736 & 160\end{array}\right)$

Peak_Wall_T := $\left(\right.$ Peak_values $\left\langle{ }^{\langle 1\rangle}\right)_{2}=115.262$

outsheet := "Thermal-Analytical Output!"

$\operatorname{rows}($ Temp_array 1$)=201 \quad$ rows $($ File_array 1$)=203$

Transient output starting row in DSEF on the Thermal-= 60

start_row $:=100$ end_row $:=$ start_row + rows $($ Temp_array 1$)-1=300$

\section{NOTE - USE File array to write to stand-alone Excel files, and Temp array to write back to the DSEF Excel file.}

transient_case_cols := $\left(\begin{array}{cc}\text { "A" } & \text { "J" } \\ \text { "L" } & \text { "U" } \\ \text { "W" } & \text { "AF" } \\ \text { "AH" } & \text { "AQ" } \\ \text { "AS" } & \text { "BB" } \\ \text { "BD" } & \text { "BM" } \\ \text { "BO" } & \text { "BX" } \\ \text { "BZ" } & \text { "CI" } \\ \text { "CK" } & \text { "CT" } \\ \text { "CV" } & \text { "DE" }\end{array}\right)$

To write the transients for each case horizontally instead of vertically, the following location array ncludes 10 columns for each case with one column separating the cases.

iw $:=1$.. Cases

start_row $=100$

end_row $=300$

transient_write_rangeiw $:=$ concat $\left[\right.$ outsheet, $\left(\text { transient_case_cols }{ }^{\langle 1\rangle}\right)_{\text {iw }}$, num2str(start_row), $": ",\left(\text { transient_case_cols }{ }^{\langle 2\rangle}\right)_{\text {iw }}$, num2str(end_row) 
transient_write_range2 = "Thermal-Analytical Output!L100:U300"

transient_write_range $=\left(\begin{array}{c}\text { "Thermal-Analytical Output!A100:J300" } \\ \text { "Thermal-Analytical Output!L100:U300" } \\ \text { "Thermal-Analytical Output!W100:AF300" } \\ \text { "Thermal-Analytical Output!AH100:AQ300" } \\ \text { "Thermal-Analytical Output!AS100:BB300" } \\ \text { "Thermal-Analytical Output!BD100:BM300" } \\ \text { "Thermal-Analytical Output!BO100:BX300" } \\ \text { "Thermal-Analytical Output!BZ100:CI300" } \\ \text { "Thermal-Analytical Output!CK100:CT300" } \\ \text { "Thermal-Analytical Output!CV100:DE300" }\end{array}\right.$
Transient_size $=\left(\begin{array}{ll}200 & 5\end{array}\right)$

Make writing an output file optional

Write_file := Write_OK = "YES" write_the_peaks(Write_file) := $\mid$ write_it $\mid$\begin{tabular}{l|l} 
write_it $\leftarrow$ & WRITEEXCE \\
"File written"
\end{tabular}

write_the_peaks(Write_file) $=$ "File written"

write_the_transient_size(Write_file) $:=\mid$ write_it $\leftarrow$ WRITEEXCEL(Transient_size,OutfileName,Transient_size_range) $\quad$ if (Write_file $=$ "Yes") $\vee($ Write_file = "YES")

$$
\mid \begin{aligned}
& \text { write_it } \leftarrow \\
& \text { write_it } \leftarrow \text { "No file written" otherwise } \\
& \text { "File written" }
\end{aligned}
$$

write_the_transient_size(Write_file) $=$ "File written"

Write file: := Write_OK = "YES"

Cases $=10$

$\mathrm{iww}:=1 .$. Cases

NOTE - USE File array to write to stand-alone Excel files, and Temp array to write back to the DSEF Excel file.

write_the_transients(jj) := $\mid$ write_array $\leftarrow$ Temp_arrayj

write_it $\leftarrow \mid$ WRITEEXCEL(write_array, OutfileName,transient_write_rangejij) $\quad$ if $($ Write_file = "Yes" $) \vee($ Write_file = "YES")

"File written"

write_it $\leftarrow$ "No file written" otherwis 


write_the_transients(iww) $=\left(\begin{array}{l}\text { "File written" } \\ \text { "File written" } \\ \text { "File written" } \\ \text { "File written" } \\ \text { "File written" } \\ \text { "File written" } \\ \text { "File written" } \\ \text { "File written" } \\ \text { "File written" } \\ \text { "File written" }\end{array}\right)$

Plot_case $:=6$

Select parametric study case to plot (default plot is for case 1)

WP_plot :=[(Temp_arrayPlot_case $\left.)^{\langle 10\rangle}\right] \quad$ EBS3_T_plot :=[(Temp_arrayPlot_case $\left.)^{\langle 9\rangle}\right] \quad$ EBS2_T_plot :=[(Temp_arrayPlot_case $\left.)^{\langle 8\rangle}\right] \quad$ EBS1_T_plot := $\left[(\text { Temp_arrayPlot_case })^{\langle 7\rangle}\right] \quad$ Wall_T_plot :=[(Temp_arrayPlot_case $\left.)^{\langle 6\rangle}\right]$

CP2_plot := $\left[\left(\right.\right.$ Temp_arrayPlot_case $\left.^{\langle(5)}\right] \quad$ Delta_WPs_T_plot := $\left.\left[\left(\text { Temp_arrayPlot_case }^{\langle 4\rangle}\right] \quad \text { Delta_drifts_T_plot :=[(Temp_arrayPlot_case }\right)^{\langle 3\rangle}\right] \quad$ Delta_central_T_plot :=[(Temp_arrayPlot_case $\left.)^{\langle 2\rangle}\right]$ 
Temperature Transients

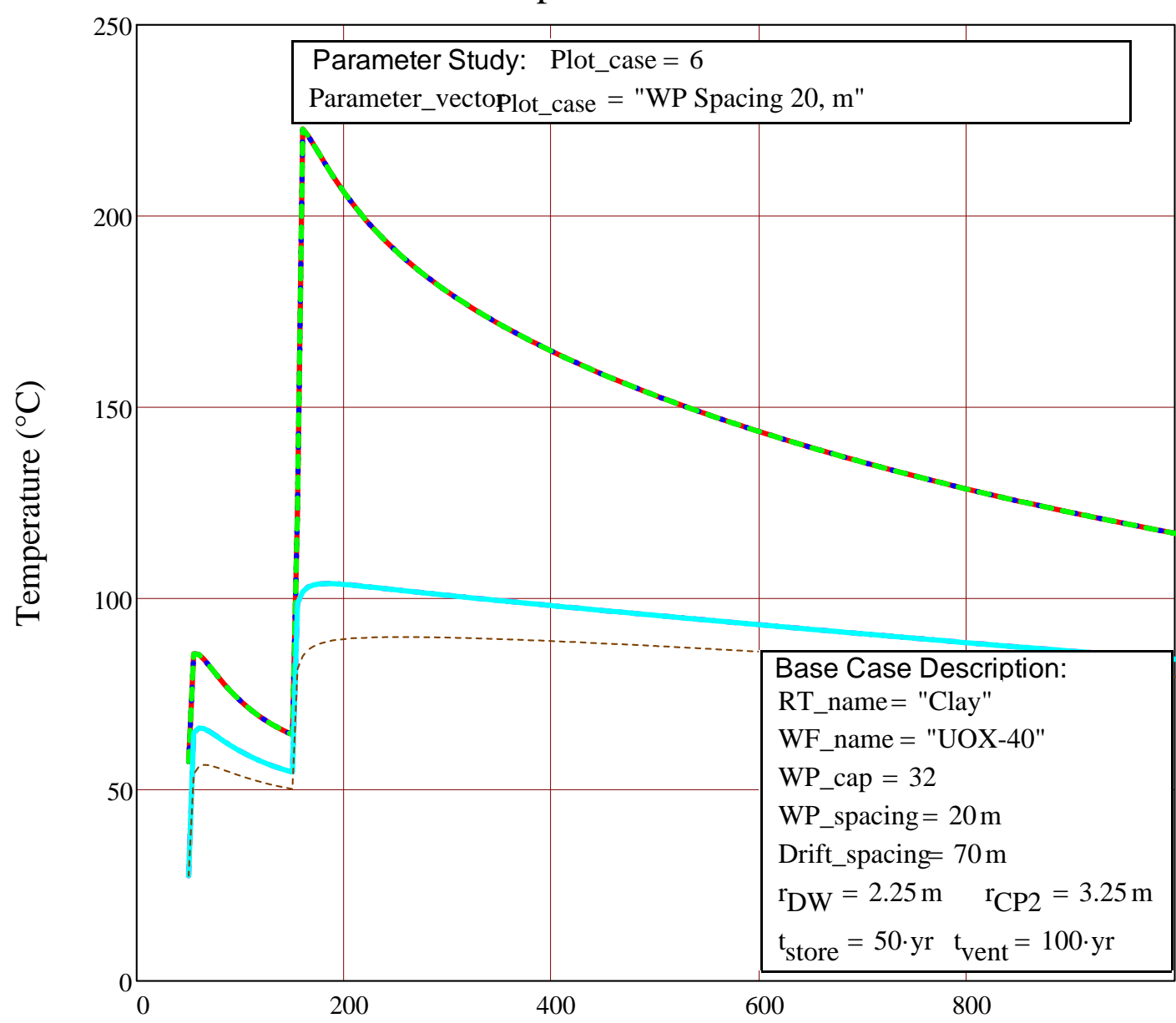

Time out of Reactor (yr)

- Waste Package Surface Temperature

..... EBS3 Temperature

-- EBS2 Temperature

-... EBS1 Temperature

- Drift Wall Temperature

-.... Compliance point 2 Temperature

\footnotetext{
$\mathrm{T}_{\text {EBS }}\left(\mathrm{r}, \mathrm{t}, \mathrm{Wall} \_\mathrm{T}, \mathrm{k}_{1}, \mathrm{k}_{2}, \mathrm{k}_{3}, \mathrm{k}_{4}\right):=$ Wall_T$\cdot \mathrm{K}+\frac{\mathrm{Q}_{\mathrm{L}_{-} w \mathrm{wp}}\left(\mathrm{t}, \mathrm{t}_{\text {store }}, \mathrm{t}_{\text {operate }}, \mathrm{WP} \_\mathrm{cap}\right)}{2 \cdot \pi \cdot \mathrm{r}_{\mathrm{DW}}} \cdot \mathrm{R}_{\text {continuous }}\left(\mathrm{t}, \mathrm{r}, \mathrm{k}_{1}, \mathrm{k}_{2}, \mathrm{k}_{3}, \mathrm{k}_{4}\right)$
}

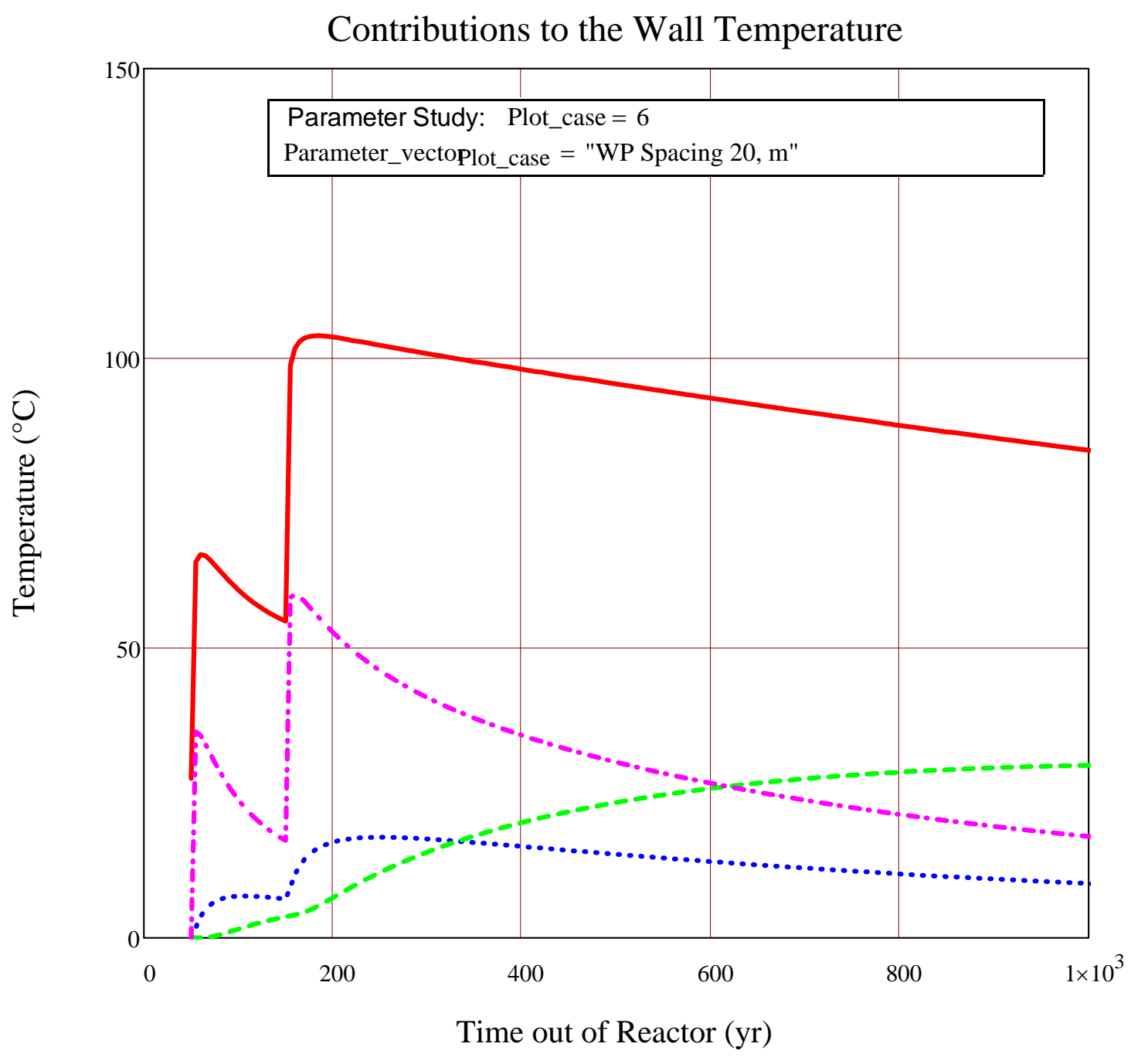

- Rock Wall Temperature (total)

.... Adjacent Waste Packages

-- Adjacent Drifts / Boreholes

... Central Line Source 


$$
\begin{aligned}
& \left.\left.\mathrm{tt} \_r w:=[\text { (Peak_values })^{\langle\text {Plot_case-2 }\rangle}\right]_{2}=185 \text { Wall_T_at_tt_rw :=[(Peak_values) }{ }^{\langle\text {Plot_case } \cdot 2-1\rangle}\right]_{2}=103.927
\end{aligned}
$$

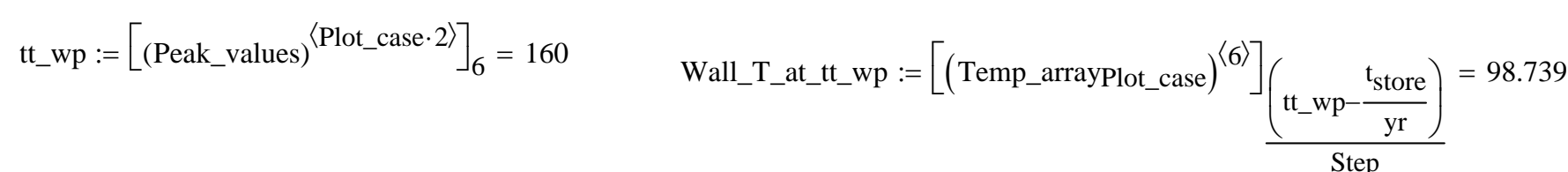

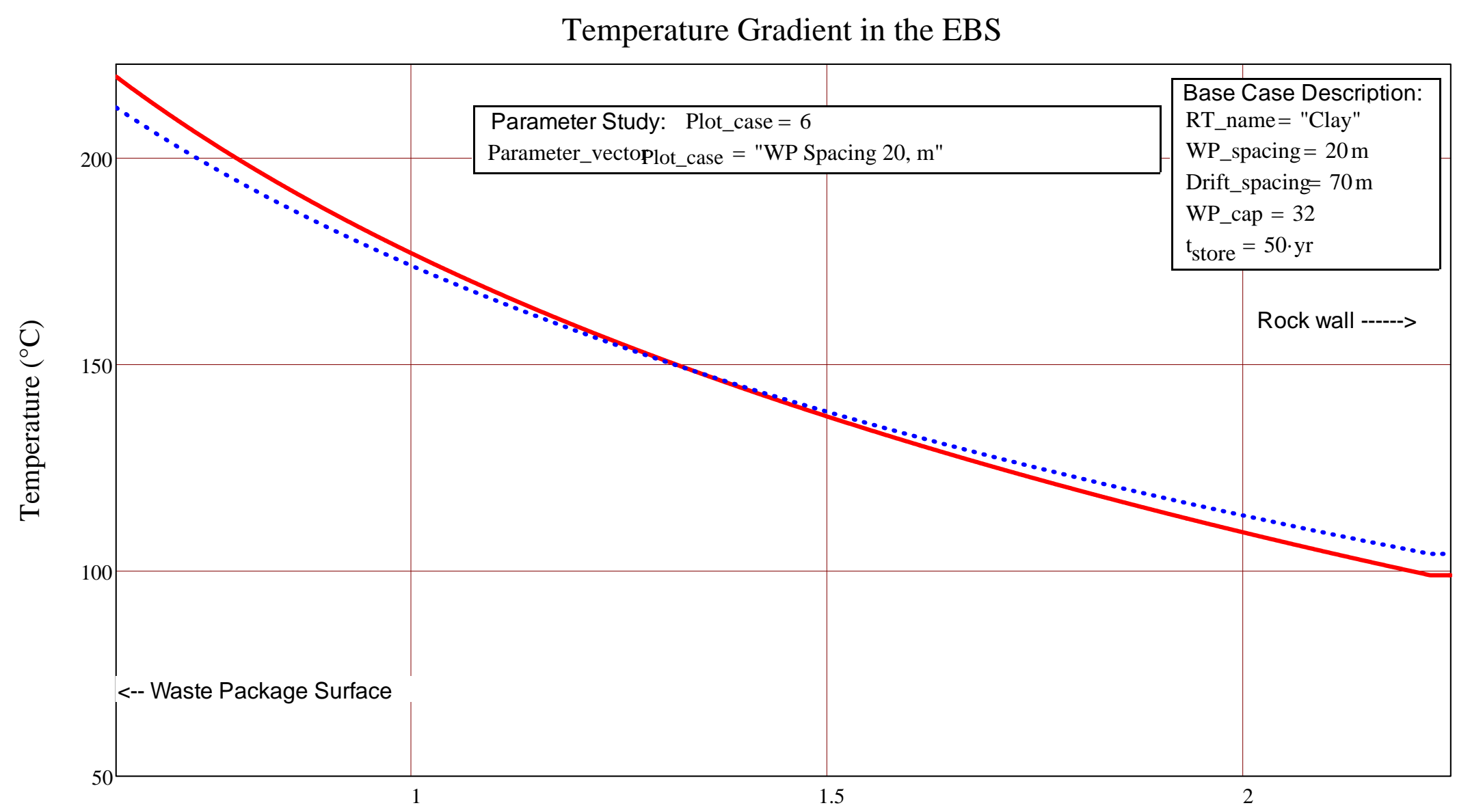

Radial Location in the EBS (m)

- Gradient at the time of the Waste Package Peak T

.... Gradient at the time of the Rock Wall Peak T

\section{OVERRIDE COUNTER AND STEP SIZE TO GET FINER CONVERGENCE ON THE ANSWER}


$\mathrm{t}_{\text {vent }}=100 \cdot \mathrm{yr} \quad$ OPTIONALLY OVERRIDE VENTILATION TIME TO SHORTEN ITERATION CONVERGENCE
ITERATE OK: = "No"
$\mathrm{t}_{\text {convergence }}=1 \cdot \mathrm{yr}$

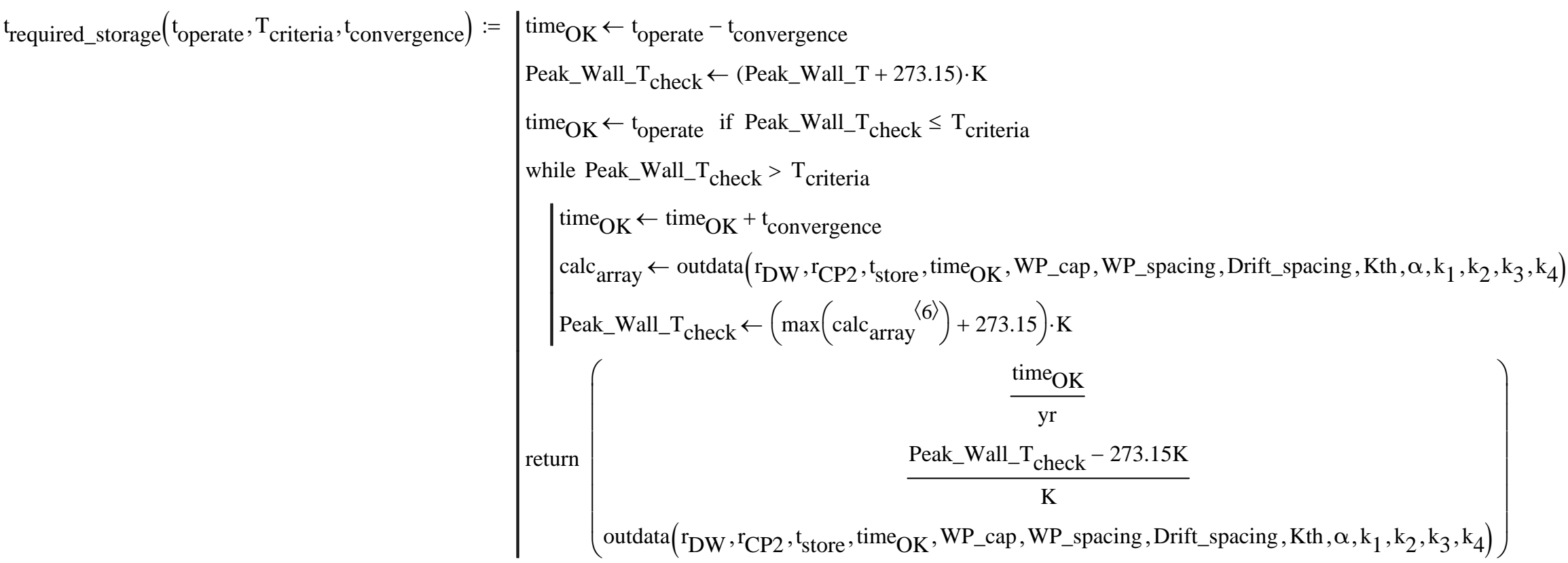

Final_array := $\mid$ trequired_storage $\left(\mathrm{t}_{\text {operate }}, \mathrm{T}_{\text {criteria }}, \mathrm{t}_{\text {convergence }}\right)$ if ITERATE_OK = "YES"

"No Iteration Performed" otherwise

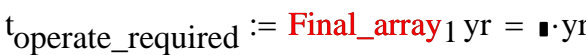

vent_required $:=t_{\text {operate_required }}{ }^{-} \mathrm{t}_{\text {store }}=\boldsymbol{\bullet} \cdot \mathrm{yr} \quad$ REQUIRED VENTILATION TIME NEEDED TO MEET $\mathrm{T}_{\text {criteria }}=100 \cdot{ }^{\circ} \mathrm{C}$

Peak_Wall_T $\mathrm{T}_{\text {check }}:=($ Final_array $2+273.15) \cdot \mathrm{K}=\mathbf{\mathbf { l }}{ }^{\circ} \mathrm{C}$ 
Time_array := (Final_array3 $)^{\langle 1\rangle}$

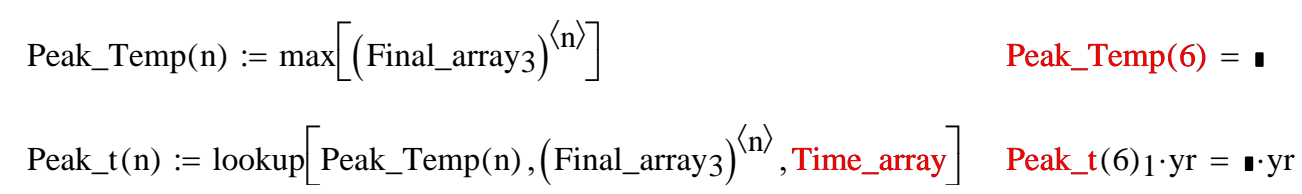

$\mathrm{nn}:=5 . .10 \quad$ Peak_resultsnn-4,1 $:=$ Peak_Temp(nn) Peak_resultsnn-4,2 $:=$ Peak_t(nn) 1

CP2 time of peak

Peak Wall $T$, time of peak

Peak EBS 1, time of peak

Peak EBS 2, time of peak

Peak EBS 3, time of peak

Waste Pkg T, time of peak
Array_row_at_Wall_T_peak := match $\left.[\text { Peak_Temp(6),(Final_array3) })^{\langle 6\rangle}\right] 1=$ ・

CP2_at_Wall_T_pk_t :=[(Final_array 3$\left.)^{\langle 5\rangle}\right]_{\text {Array_row_at_Wall_T_peak }}=$

Ceintral_WP_delta := $\left[(\text { Final_array3 })^{\langle 2\rangle}\right]_{\text {Array_row_at_Wall_T_peak }}=$

Adj_Drift_delta := $\left[\left({\text { Final_array } 3)^{\langle 3\rangle}}^{\langle\text {Array_row_at_Wall_T_peak }}=\right.\right.$ 
Adj_WP_delta :=[(Final_array3 $\left.)^{\langle 4\rangle}\right]_{\text {Array_row_at_Wall_T_peak }}=\mathbf{~}$

Result_Vector : $=\left(\frac{\text { WP_spacing }}{\mathrm{m}}\right.$ TC $\frac{\text { Drift_spacing }}{\mathrm{m}}$ Peak_results6,1 Peak_results6,2 Peak_results2,1 Peak_results2,2 CP2_at_Wall_T_pk_t $\frac{\text { tvent_required }}{\text { yr }}$ Ceintral_WP_delta Adj_Drift_delta Adj_WP_delta $)$

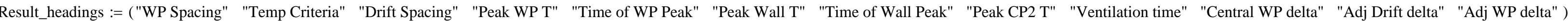

Result_Vector $=\boldsymbol{~}$

This is the result vector for transcription to the Excel case results tracking file

$\mathrm{RV}:=$ augment $\left(\right.$ Result_headings ${ }^{\mathrm{T}}$, Result_Vector $\left.^{\mathrm{T}}\right) \quad \mathrm{T}_{\text {ambient }}=27.5{ }^{\circ} \mathrm{C} \quad$ Contribution percentages at time of peak wall temperature

$$
\begin{aligned}
& \text { Percent_central_WP_delta }:=\frac{\text { Ceintral_WP_delta }}{\text { Peak_Temp(6) }-\frac{\left(\mathrm{T}_{\text {ambient }}-273.15 \cdot \mathrm{K}\right)}{\mathrm{K}}} \cdot 100=\mathbf{\bullet} \\
& \text { Percent_adj_Drift_delta }:=\frac{\text { Adj_Drift_delta }}{\text { Peak_Temp(6) }-\frac{\left(\mathrm{T}_{\text {ambient }}-273.15 \cdot \mathrm{K}\right)}{\mathrm{K}}} \cdot 100=\mathbf{~}
\end{aligned}
$$

Percent_adj_WP_delta $:=\frac{\text { Adj_WP_delta }}{\text { Peak_Temp(6) }-\frac{\left(\mathrm{T}_{\text {ambient }}-273.15 \cdot \mathrm{K}\right)}{\mathrm{K}}} \cdot 100=$,

Percent_central_WP_delta + Percent_adj_WP_delta + Percent_adj_Drift_delta = 


\section{Plot temperature results as a function of parameter dat}

\section{ip := 1 .. Cases}

Peak_WP_Tip := $\left(\text { Peak_values }^{\langle\text {ip.2-1〉}}\right)_{6}$

Peak_WP_T $=\left(\begin{array}{c}231.735 \\ 229.391 \\ 227.373 \\ 225.623 \\ 224.095 \\ 222.753 \\ 221.567 \\ 220.514 \\ 219.576 \\ 218.736\end{array}\right)$

Peak Wall Tip $_{\text {ip }}:=\left(\right.$ Peak_values $^{\langle\text {ip } \cdot 2-1\rangle)}$

Peak_Wall_T $=\left(\begin{array}{c}115.262 \\ 112.287 \\ 109.734 \\ 107.536 \\ 105.602 \\ 103.927 \\ 102.391 \\ 101.064 \\ 99.912 \\ 98.88\end{array}\right)$

Peak_EBS3_Tip :=(Peak_values $\left.{ }^{\langle i p \cdot 2-1\rangle}\right)_{5}$

Peak_EBS3_T $=\left(\begin{array}{c}231.735 \\ 229.391 \\ 227.373 \\ 225.623 \\ 224.095 \\ 222.753 \\ 221.567 \\ 220.514 \\ 219.576 \\ 218.736\end{array}\right)$

Peak_CP2_Tip :=(Peak_values $\left.{ }^{\langle i p \cdot 2-1\rangle}\right)$

Peak_CP2_T $=\left(\begin{array}{c}102.266 \\ 99.137 \\ 96.413 \\ 93.988 \\ 91.828 \\ 89.914 \\ 88.231 \\ 86.66 \\ 85.276 \\ 84.019\end{array}\right)$

Peak_EBS2_Tip := $\left(\text { Peak_values }^{\langle\text {ip. } \cdot 2-1\rangle}\right)_{4}$

Peak_EBS1_Tip :=(Peak_values $\left.{ }^{\langle\text {ip } \cdot 2-1\rangle}\right)_{3}$

Peak_EBS2_T $=\left(\begin{array}{c}231.735 \\ 229.391 \\ 227.373 \\ 225.623 \\ 224.095 \\ 222.753 \\ 221.567 \\ 220.514 \\ 219.576 \\ 218.736\end{array}\right)$

Parameter_data $=\left(\begin{array}{l}15 \\ 16 \\ 17 \\ 18 \\ 19 \\ 20 \\ 21 \\ 22 \\ 23 \\ 24\end{array}\right)$

Peak_EBS1_T $=\left(\begin{array}{c}115.285 \\ 112.311 \\ 109.759 \\ 107.561 \\ 105.628 \\ 103.952 \\ 102.417 \\ 101.09 \\ 99.939 \\ 98.907\end{array}\right)$

Parameter_vector $=\left(\begin{array}{l}\text { "WP Spacing 15, m" } \\ \text { "WP Spacing 16, m" } \\ \text { "WP Spacing 17, m" } \\ \text { "WP Spacing 18, m" } \\ \text { "WP Spacing 19, m" } \\ \text { "WP Spacing 20, m" } \\ \text { "WP Spacing 21, m" } \\ \text { "WP Spacing 22, m" } \\ \text { "WP Spacing 23, m" } \\ \text { "WP Spacing 24, m" }\end{array}\right)$


Peak Temperatures versus Parameter Study Data

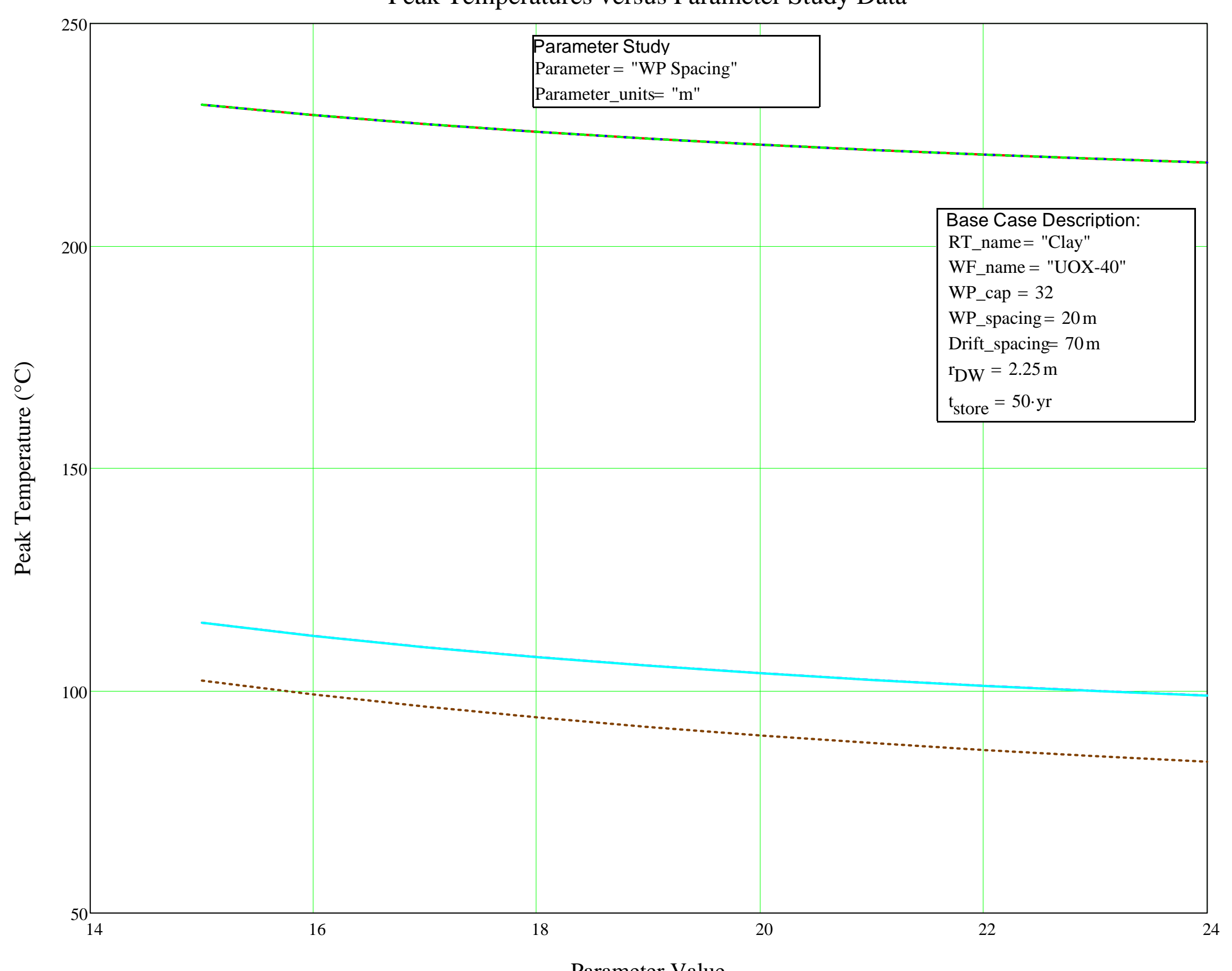

Parameter Value

- Waste Package Surface Temperaturee

…. EBS_3 Temperature

--- EBS 2 Temperature

-...- EBS_1 Temperature

- Rock Wall Temperature

.... Compliance Point 2 Temperature 


\section{B.3 The Mathcad parametric analysis and iterative convergence model - iterative convergence example}

As noted in Section B.2, the iterative convergence programming loop started on page 19 of 23 of the Mathcad document. However, to perform an iterative convergence analysis to determine required ventilation time, a number of input variables must be set. First, the "Parameter" variable passed from the DSEF Excel file must be set to "Single". Then the two critical variables of the iterative convergence study - the initial guess for required ventilation time ( $\mathrm{t}_{\mathrm{vent}}$ ), and the target temperature criterion (TC) are set locally in the Mathcad document itself.

The next variable to be set turns the iterative loop on or keeps it off, and it is recommended to keep it initially off (Iterate_OK = "No") unless, based on previous analysis in the Case Library, you already have a reasonable guess for the required ventilation time. This is recommended since a single non-iterative analysis with the Mathcad thermal-analytical model should take around 15 to 30 seconds. If the initial guess is a poor one and if the step size is small and close convergence is being required, then the iterative mode could take a long time to run. Before setting Iterate_OK to "Yes", make sure the starting ventilation time results in a temperature that is above the temperature acceptance value. If you start with a ventilation time that already meets the acceptance criterion, then the convergence loop will just return the same starting ventilation time since it is already acceptable.

The example PDF file in this appendix set the temperature acceptance criterion at the drift wall of a clay/shale repository analysis at $\mathrm{TC}=100^{\circ} \mathrm{C}$. To speed up the iterative calculation process there are also three new input variables "Counter”, "Step”, and “Convergence” that allow initially larger and few calculation steps to quickly converge an analysis, and then optionally to make more smaller steps to cover the same time span but a more detailed transient if desired.

This specific example is from Greenberg 2013a, and is report case 225-19 (DSEF Case Library case number 342) and represents a required ventilation time calculation for a 21-PWR waste package with $40 \mathrm{GWd} / \mathrm{MT}$ burnup in a clay/shale repository, with a layout design of $30 \mathrm{~m}$ drift spacing and $20 \mathrm{~m}$ waste package spacing, to meet a temperature acceptance criterion of $100^{\circ} \mathrm{C}$ at the drift wall. The result presented originally was taken within 0.5 degrees and gave $100.1^{\circ} \mathrm{C}$ with 125 years of ventilation. To check more accurately and assure the temperature is below $100^{\circ} \mathrm{C}$, the iterative convergence was turned on using Iterate_OK:=”YES”. In this case, we knew the answer, but just to demonstrate the convergence loop, we started the case off with a guess of $\mathrm{t}_{\mathrm{vent}}=120$ years. The result showed that with 127 years of ventilation, we get a drift wall temperature of $99.93^{\circ} \mathrm{C}$ (shown on page 19 of 23 in the PDF printout).

Note that the last figure on page 23 of 23 is blank, since it is reserved to show parametric study results and this was a "Single" analysis. 
DSEF R3.0 parametric and iterative model with collapsed areas - for rapid iteration.

Allow output transients to be written back to DSEF FILE

Write_OK := "YES"

Variables for repository symmetry and extent:

$$
\mathrm{N}_{\mathrm{adj}}:=4
$$

REQUIRED REPOSITORY INPUT DATA (from DSEF):

file := "DSEF R3.0_2013Aug12_HRG-Clay_UOX-40_Iterative convergence example_Case-225-19.xlsm"

sheet := "Thermal-Analytical!"

\section{READ DSEF INPUT FILE}

Input 1 = Operating Mode (enclosed or open)

Input_1 := READEXCEL(file, concat(sheet, "A5:B5"))

Input_1 = ("MODE = Open or Enclosed:" "Open" )

Mode := Input $11,2=$ "Open"

Input_2 := READEXCEL(file, concat(sheet, "A7:B16")) Input 2 = Case Definitions

Input_2 $=\left(\begin{array}{cc}\text { "Host Media" } & \text { "Clay" } \\ \text { "Rock thermal conductivity, W/m-K" } & 1.75 \\ \text { "Rock thermal diffusivity, m2/sec" } & 6.45 \times 10^{-7} \\ \text { "Repository Depth, } \mathrm{m} " & 500 \\ \text { "Surface temperature, }{ }^{\mathrm{C}} \mathrm{C} & 15 \\ \text { "Geothermal gradient, }{ }^{\circ} \mathrm{C} / \mathrm{km} " & 25 \\ \text { "Ambient temperature at depth, }{ }^{\circ} \mathrm{C} " & 27.5 \\ \text { "Waste Package (axial) spacing, m" } & 20 \\ \text { "Drift / Borehole (lateral) spacing, m" } & 30 \\ \text { "Surface storage time, y" } & 50\end{array}\right)$

\section{DATA FOR ITERATION ON TEMPERATURE ACCEPTACE CRITERIAA:}

$\mathrm{TC}:=100 \quad \mathrm{~T}_{\text {criteria }}:=(\mathrm{TC}+273.15) \cdot \mathrm{K}=373.15 \mathrm{~K} \quad \mathrm{~T}_{\text {criteria }}=100 \cdot{ }^{\circ} \mathrm{C}$

\section{Convergence $:=1 \cdot y$ PI CONVERGE CRITERIA FOR REQUIRED VENTILATION TIME IN YEARS}

SET THE VARIABLE ITERATE_OK TO "NO" TO

TURN OFF THE AUTOMATIC CONVERGENCE

"YES" IFYOU, WANDT TO FILT TUNEYOUR$$
\text { ITERATE_OK := "YES"'" }
$$

Input 3 = Ventilation Parameters (for Open Modes)

Input_3 := READEXCEL(file, concat(sheet, "e7:f11"))

Input_3 = $\left(\begin{array}{cc}\text { "Ventilation Duration, yr" } & 125 \\ \text { "Unventilated Closure Duration (Backfill Installation), yr" } & 10 \\ \text { "Ventilation Thermal Efficiency, \%" } & 0.75 \\ \text { "Rock Wall Emissivity" } & 0.9 \\ \text { "Waste Package Emissivity" } & 0.6\end{array}\right)$

RT_name := Input_21,2 = "Clay"

Kth := Input_22,2 $\frac{\mathrm{W}}{\mathrm{m} \cdot \mathrm{K}}=1.75 \frac{\mathrm{m} \cdot \mathrm{kg}}{\mathrm{K} \cdot \mathrm{s}^{3}}$

$\alpha:=$ Input_23,2 $2 \cdot \frac{\mathrm{m}^{2}}{\mathrm{~s}}=6.45 \times 10^{-7} \frac{\mathrm{m}^{2}}{\mathrm{~s}}$

$\mathrm{t}_{\text {vent }}:=\operatorname{if}[($ Mode $=$ "Enclosed" $), 0$, Input_31,2]·yr $=125 \cdot \mathrm{yr}$

$t_{\text {backfill }}:=\operatorname{if}[($ Mode $=$ "Enclosed" $), 0$, Input_32,2] $]$ yr $=10 \cdot y r$

$\mathrm{V}_{\text {eff }}:=$ if $[($ Mode $=$ "Enclosed" $), 0$, Input_33,2 $]=0.75$

$\varepsilon_{\text {wall }}:=$ if $[$ (Mode $=$ "Enclosed" $), 9$, ,Input_34,2 $]=0.9$ 
WP_depth $:=$ Input_24,2·m $=500 \mathrm{~m}$

$\mathrm{T}_{\text {surface }}:=($ Input_ $25,2+273.15) \cdot \mathrm{K}=288.15 \mathrm{~K}$

geothermal_gradient := Input_26,2 $\frac{\mathrm{K}}{\mathrm{km}}=0.025 \frac{\mathrm{K}}{\mathrm{m}}$

$\mathrm{T}_{\text {ambient }}:=\left(\right.$ Input $\left.\_27,2+273.15\right) \cdot \mathrm{K}=300.65 \mathrm{~K}$

WP_spacing $:=$ Input_ $28,2 \cdot \mathrm{m}=20 \mathrm{~m}$

Drift_spacing $:=$ Input_29,2$\cdot \mathrm{m}=30 \mathrm{~m}$

$\mathrm{t}_{\text {store }}:=$ Input $\_210,2 \cdot \mathrm{yr}=50 \cdot \mathrm{yr}$
$\varepsilon_{\mathrm{WP}}:=$ if $[($ Mode $=$ "Enclosed" $), .6$, Input_35,2] $=0.6$

\section{OVER-RIDE VENTILATION DURATION}

twent: $:=120 \cdot \mathrm{y}$ :

OVER-RIDE DRIFT AND/OR WASTE PACKAGE SPACING

\section{Input 4 = ENGINEERED BARRIER SYSTEM DATA}

Input_4 := READEXCEL(file, concat(sheet, "A20:F27"))

\section{T_OPERATE $=$ T $\_$STORE + T_VENTILATE}

\section{TCLOSURE = TOPERATE + TIME TO BACKFILL}

\section{Input 5 = COMPLIANCE POINT 2 INPUT DATA}

Input_ 5 := READEXCEL(file, concat(sheet, "C32"))

Input_4 = $\left.\begin{array}{cccccc}\text { "Waste Form Outer Radius, m" } & 0.535 & \text { "N/A" } & 0.535 & \text { "UOX-40" } & \text { "N/A" } \\ \text { "Canister" } & 0 & 0.535 & 0.535 & \text { "None" } & \text { "N/A" } \\ \text { "Waste Package" } & 0.11 & 0.535 & 0.645 & \text { "Carbon Steel" } & \text { "N/A" } \\ \text { "Buffer" } & 0 & 0.645 & 0.645 & \text { "None" } & \text { "N/A" } \\ \text { "Envelope" } & 0 & 0.645 & 0.645 & \text { "None" } & \text { "N/A" } \\ \text { "Backfill" } & 1.58 & 0.645 & 2.225 & \text { "70\% Bentonite 30\% Sand" } & 1.2 \\ \text { "Liner" } & 0.025 & 2.225 & 2.25 & \text { "Steel" } & 46 \\ \text { "Host } & & & & \end{array}\right)$

$\mathrm{r}_{\text {DW }}:=$ Input_ $48,3 \cdot \mathrm{m}=2.25 \mathrm{~m}$

$\mathrm{r}_{\mathrm{WP}}:=$ Input_43,4 $4 \mathrm{~m}=0.645 \mathrm{~m}$

EBS_name $1:=$ Input_47, $1=$ "Liner"

thickness $1:=$ Input_ $47,2 \cdot \mathrm{m}=0.025 \mathrm{~m}$

$\mathrm{k} 1:=$ Input $47,6=46$

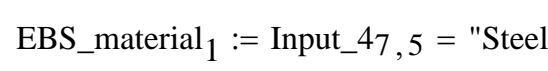

$\mathrm{r}_{1}:=$ Input_47, $4 \cdot \mathrm{m}=2.25 \mathrm{~m}$

$\mathrm{k}_{1}:=$ if $[(\mathrm{k} 1=\mathrm{N} / \mathrm{A} "), 0, \mathrm{k} 1] \cdot \frac{\mathrm{W}}{\mathrm{m} \cdot \mathrm{K}}=46 \cdot \frac{\mathrm{W}}{\mathrm{m} \cdot \mathrm{K}}$ 
EBS name $2:=$ Input $46,1=$ "Backfill"

thickness ${ }_{2}:=$ Input_ $46,2 \cdot \mathrm{m}=1.58 \mathrm{~m}$

k2 := Input_46,6 $=1.2$

EBS_material $2:=$ Input_46,5 $=$ "70\% Bentonite 30\% Sand"

$\mathrm{r}_{2}:=$ Input $46,4 \cdot \mathrm{m}=2.225 \mathrm{~m}$

$\mathrm{k}_{2}:=$ if $[(\mathrm{k} 2=\mathrm{N} / \mathrm{A} "), 0, \mathrm{k} 2] \cdot \frac{\mathrm{W}}{\mathrm{m} \cdot \mathrm{K}}=1.2 \cdot \frac{\mathrm{W}}{\mathrm{m} \cdot \mathrm{K}}$

$\mathrm{k}_{\text {radiation }}:=\operatorname{if}\left[(\right.$ Mode $=$ "Enclosed" $\left.), \mathrm{k}_{2}, 0\right]=0 \cdot \frac{\mathrm{W}}{\mathrm{m} \cdot \mathrm{K}}$

EBS_name $_{3}:=$ Input_45,1 = "Envelope"

thickness $3:=$ Input_45,2·m $=0 \mathrm{~m}$

k3 := Input_45,6 = "N/A"

EBS_name $_{4}:=$ Input_4 $4,1=$ "Buffer"

thickness $4:=$ Input_ $44,2 \cdot \mathrm{m}=0 \mathrm{~m}$

$\mathrm{k} 4:=$ Input_44,6 $=$ "N/A"
EBS_material $3:=$ Input_45, $5=$ "None"

$\mathrm{r}_{3}:=$ Input_45,4$\cdot \mathrm{m}=0.645 \mathrm{~m}$

$\mathrm{k}_{3}:=$ if $[(\mathrm{k} 3=" \mathrm{~N} / \mathrm{A} "), 0, \mathrm{k} 3] \cdot \frac{\mathrm{W}}{\mathrm{m} \cdot \mathrm{K}}=0 \cdot \frac{\mathrm{W}}{\mathrm{m} \cdot \mathrm{K}}$

EBS_material $4:=$ Input_44,5 $=$ "None"

$\mathrm{r}_{4}:=$ Input $44,4 \cdot \mathrm{m}=0.645 \mathrm{~m}$

$\mathrm{k}_{4}:=\operatorname{if}[(\mathrm{k} 4=\mathrm{N} / \mathrm{A} "), 0, \mathrm{k} 4] \cdot \frac{\mathrm{W}}{\mathrm{m} \cdot \mathrm{K}}=0 \cdot \frac{\mathrm{W}}{\mathrm{m} \cdot \mathrm{K}}$

Define the total thermal resistance between the rock wall and the waste package surface

based on a heat flux per unit area, it is then applied to a heat flux is per unit length adjusting to

area per unit length and $\mathrm{q}_{\mathrm{L}}(\mathrm{W} / \mathrm{m})$ :

$\mathrm{r}_{4}=0.645 \mathrm{~m}$

$r_{3}=0.645 \mathrm{~m}$

$\mathrm{r}_{2}=2.225 \mathrm{~m}$

$\mathrm{r}_{1}=2.25 \mathrm{~m}$

$\mathrm{r}_{\mathrm{DW}}=2.25 \mathrm{~m}$

$\mathrm{R}_{1}\left(\mathrm{k}_{1}\right):=$ if $\left[\right.$ thickness $\left.\left.1=0 \vee\left(\mathrm{k} 1=" \mathrm{~N} / \mathrm{A}^{\prime \prime}\right)\right], 0, \frac{\mathrm{r}^{\mathrm{DW}}}{\mathrm{k}_{1}} \cdot \ln \left(\frac{\mathrm{r}_{1}}{\mathrm{r}_{2}}\right)\right] \quad \mathrm{R}_{1}\left(\mathrm{k}_{1}\right)=5.465 \times 10^{-4} \cdot \frac{\mathrm{m}^{2} \cdot \mathrm{K}}{\mathrm{W}}$

Thermal resistance

EBS_name $_{1}=$ "Liner" $\quad$ EBS_material $_{1}=$ "Steel"

\section{ADDED CORRECTION FOR PARAMETRIC $t_{\text {closur }}$ Revised $R_{2}$ to make it an explicit function of $t_{\text {operate }}$ and $t_{\text {backfill }}$}

eplaced $t_{\text {closure }}$ with $\left(t_{\text {operate }}+t_{\text {backfill }}\right)$

$$
\frac{\mathrm{r}_{\mathrm{DW}}}{\mathrm{k}_{2}} \cdot \ln \left(\frac{\mathrm{r}_{2}}{\mathrm{r}_{3}}\right)=2.322 \cdot \frac{\mathrm{m}^{2} \cdot \mathrm{K}}{\mathrm{W}}
$$


EBS_name $_{2}=$ "Backfill" $\quad$ EBS_material ${ }_{2}=$ "70\% Bentonite 30\% Sand"

$$
\mathrm{R}_{2}\left(\mathrm{k}_{2}, 5 \cdot \mathrm{yr}, 300 \cdot \mathrm{yr}, 10 \cdot \mathrm{yr}\right)=0 \cdot \frac{\mathrm{m}^{2} \cdot \mathrm{K}}{\mathrm{W}}
$$

$\mathrm{R}_{2}\left(\mathrm{k}_{2}, 1000 \cdot \mathrm{yr}, 300 \cdot \mathrm{yr}, 10 \cdot \mathrm{yr}\right)=2.321741 \cdot \frac{\mathrm{m}^{2} \cdot \mathrm{K}}{\mathrm{W}}$

$\mathrm{R}_{3}\left(\mathrm{k}_{3}\right):=$ if $\left[\right.$ thickness $\left.\left.3=0 \vee\left(\mathrm{k} 3=" \mathrm{~N} / \mathrm{A}^{\mathrm{N}}\right)\right], 0, \frac{\mathrm{r}^{\mathrm{DW}}}{\mathrm{k}_{3}} \cdot \ln \left(\frac{\mathrm{r}_{3}}{\mathrm{r}_{4}}\right)\right] \quad \mathrm{R}_{3}\left(\mathrm{k}_{3}\right)=0 \cdot \frac{\mathrm{m}^{2} \cdot \mathrm{K}}{\mathrm{W}}$

EBS_name $_{3}=$ "Envelope" $\quad$ EBS_material ${ }_{3}=$ "None"

$\mathrm{R}_{4}\left(\mathrm{k}_{4}\right):=$ if $[$ thickness $\left.4=0 \vee(\mathrm{k} 4=" \mathrm{~N} / \mathrm{A} ")], 0, \frac{\mathrm{r}^{\mathrm{DW}}}{\mathrm{k}_{4}} \cdot \ln \left(\frac{\mathrm{r}_{4}}{\mathrm{r}_{\mathrm{WP}}}\right)\right] \quad \mathrm{R}_{4}\left(\mathrm{k}_{4}\right)=0 \cdot \frac{\mathrm{m}^{2} \cdot \mathrm{K}}{\mathrm{W}}$

EBS_name $_{4}=$ "Buffer"

EBS_material $_{4}=$ "None"

$\mathrm{R}_{\text {Total }}\left(\mathrm{t}, \mathrm{k}_{1}, \mathrm{k}_{2}, \mathrm{k}_{3}, \mathrm{k}_{4}\right):=\mathrm{R}_{1}\left(\mathrm{k}_{1}\right)+\mathrm{R}_{2}\left(\mathrm{k}_{2}, \mathrm{t}, \mathrm{t}_{\text {operate }}, \mathrm{t}_{\text {backfill }}\right)+\mathrm{R}_{3}\left(\mathrm{k}_{3}\right)+\mathrm{R}_{4}\left(\mathrm{k}_{4}\right) \quad$ Total thermal resistance between wall and waste package $\mathrm{t}_{\text {backfill }}=10 \cdot \mathrm{yr} \quad \mathrm{t}_{\text {operate }}=170 \cdot \mathrm{yr}$

$\mathrm{R}_{\text {continuous }}\left(\mathrm{t}, \mathrm{r}, \mathrm{k}_{1}, \mathrm{k}_{2}, \mathrm{k}_{3}, \mathrm{k}_{4}\right):=\mid \mathrm{kk}_{2} \leftarrow \mathrm{k}_{\text {radiation }} \cdot\left[\mathrm{t}<\left(\mathrm{t}_{\text {operate }}+\mathrm{t}_{\text {backfill }}\right)\right]+\mathrm{k}_{2} \cdot\left[\mathrm{t} \geq\left(\mathrm{t}_{\text {operate }}+\mathrm{t}_{\text {backfill }}\right)\right]$

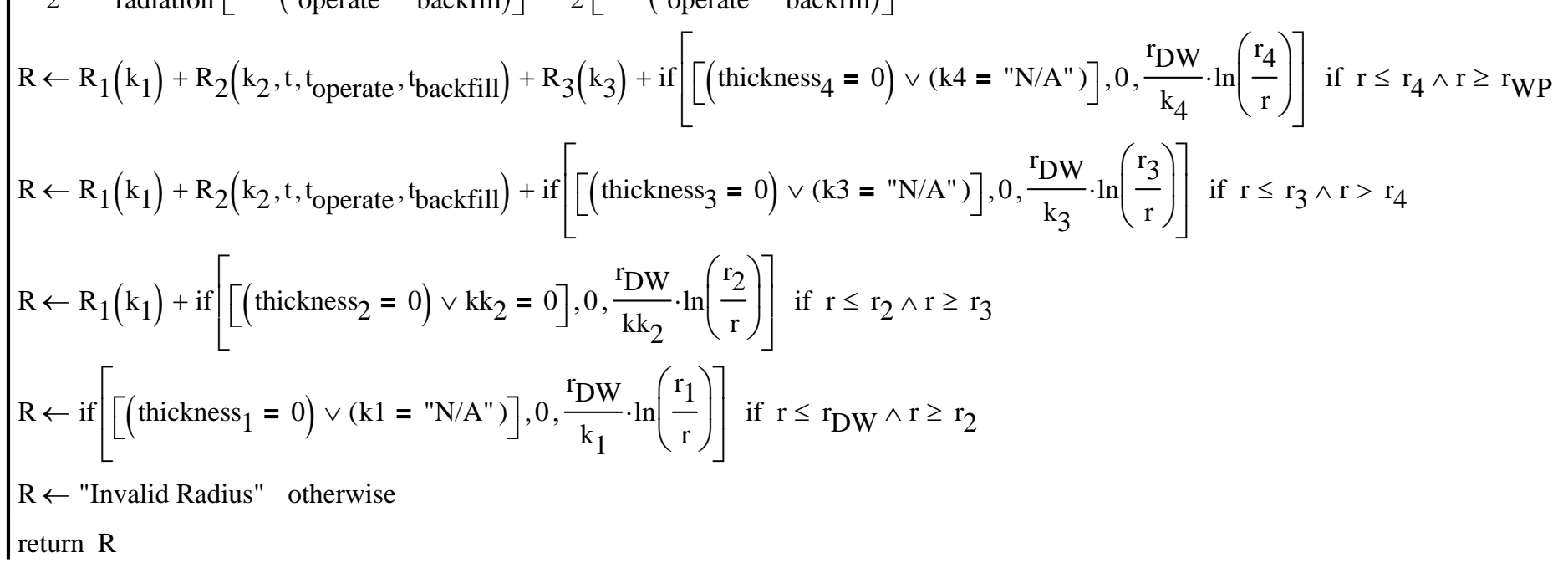

$\mathrm{R}_{\text {continuous }}\left(5 \cdot \mathrm{yr}, \mathrm{r}_{\mathrm{WP}}, \mathrm{k}_{1}, \mathrm{k}_{2}, \mathrm{k}_{3}, \mathrm{k}_{4}\right)=5.465 \times 10^{-4} \frac{\mathrm{K} \cdot \mathrm{s}^{3}}{\mathrm{~kg}} \quad \mathrm{R}_{\text {continuous }}\left(1000 \cdot \mathrm{yr}, \mathrm{r}_{\mathrm{WP}}, \mathrm{k}_{1}, \mathrm{k}_{2}, \mathrm{k}_{3}, \mathrm{k}_{4}\right)=2.322288 \frac{\mathrm{K} \cdot \mathrm{s}^{3}}{\mathrm{~kg}}$ 


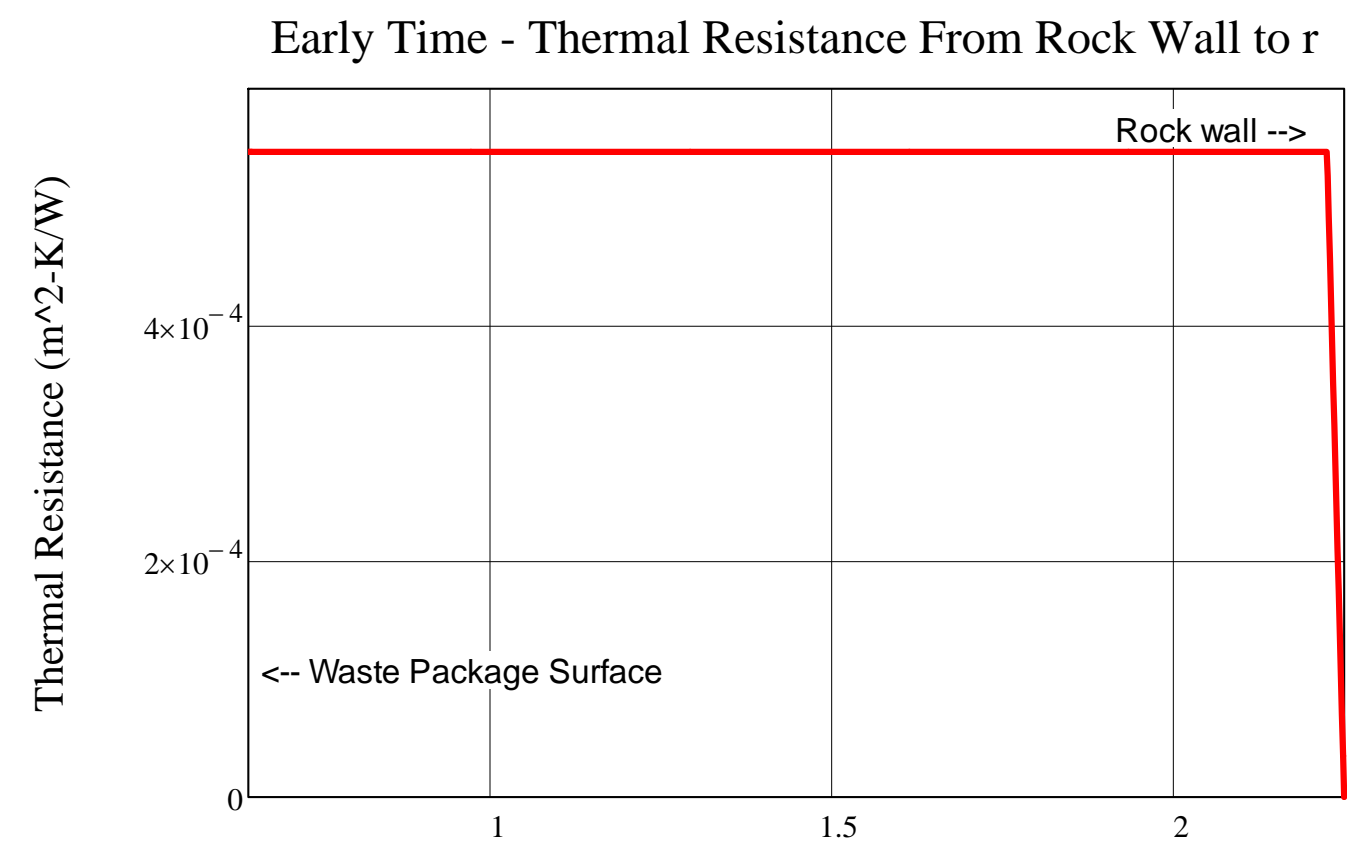

Radial Location Within the EBS (m)

— Thermal resistance prior to closure

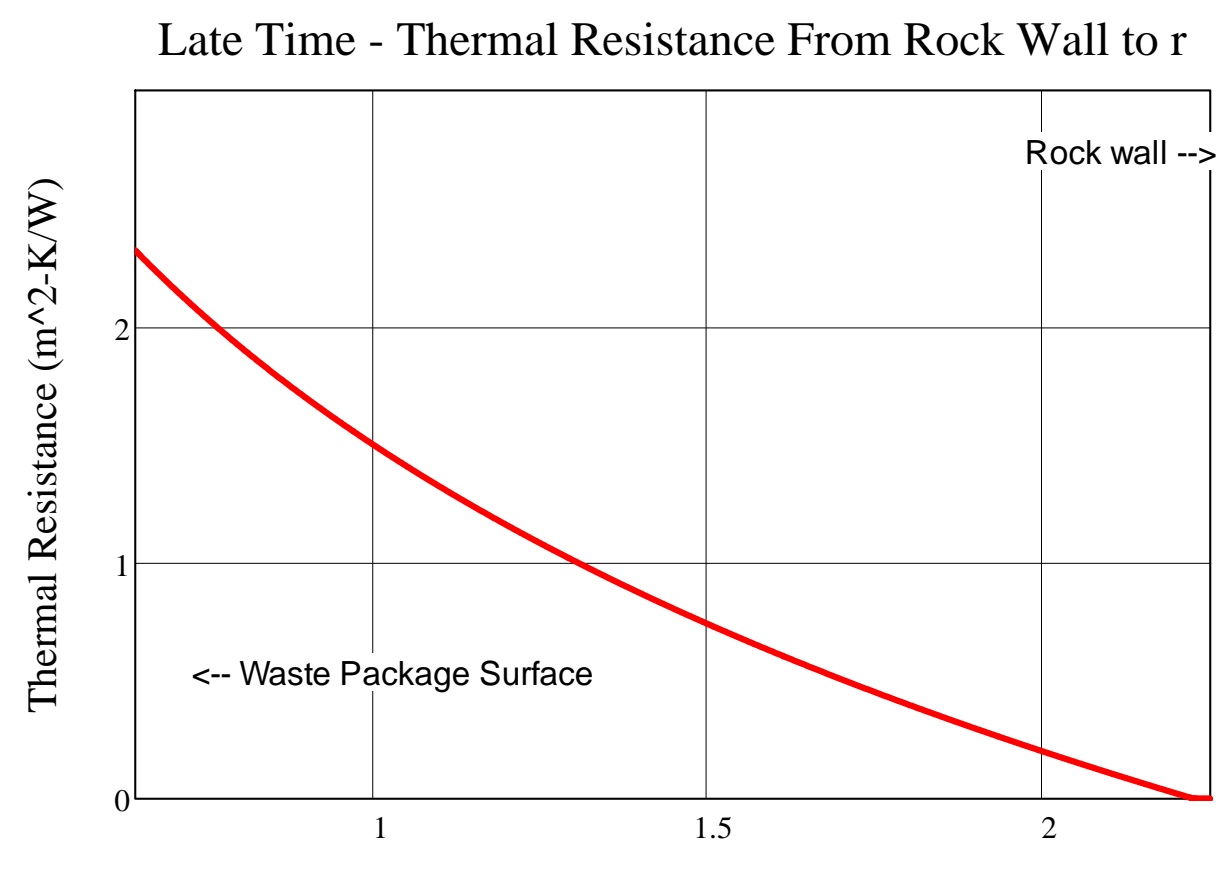

Radial Location Within the EBS (m)

— Thermal resistance prior to closure
$\mathrm{r}_{\mathrm{DW}}=2.25 \mathrm{~m}$

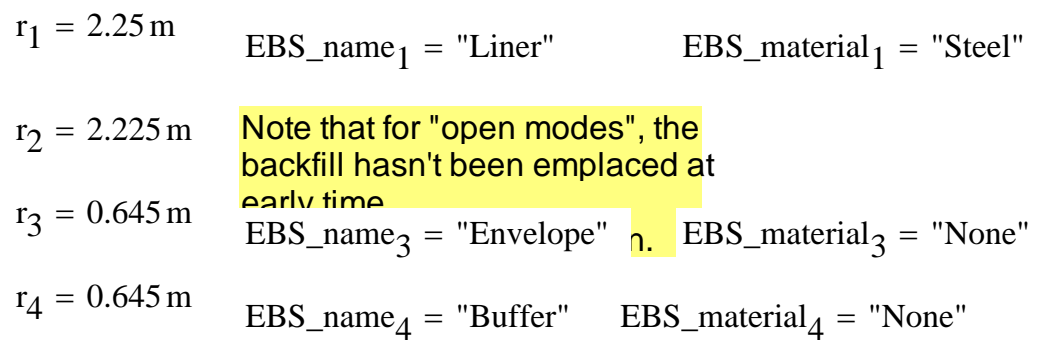

$\mathrm{r}_{\mathrm{WP}}=0.645 \mathrm{~m}$

$\mathrm{R}_{1}\left(\mathrm{k}_{1}\right)=5.465 \times 10^{-4} \cdot \frac{\mathrm{m}^{2} \cdot \mathrm{K}}{\mathrm{W}} \quad \mathrm{R}_{2}\left(\mathrm{k}_{2}, 5 \cdot \mathrm{yr}, \mathrm{t}_{\text {operate }}, \mathrm{t}_{\text {backfill }}\right)=0 \cdot \frac{\mathrm{m}^{2} \cdot \mathrm{K}}{\mathrm{W}} \quad \mathrm{R}_{3}\left(\mathrm{k}_{3}\right)=0 \cdot \frac{\mathrm{m}^{2} \cdot \mathrm{K}}{\mathrm{W}} \quad \mathrm{R}_{4}\left(\mathrm{k}_{4}\right)=0 \cdot \frac{\mathrm{m}^{2} \cdot \mathrm{K}}{\mathrm{W}}$

$\mathrm{R}_{\text {Total }}\left(50 \mathrm{yr}, \mathrm{k}_{1}, \mathrm{k}_{2}, \mathrm{k}_{3}, \mathrm{k}_{4}\right)=5.465 \times 10^{-4} \cdot \frac{\mathrm{m}^{2} \cdot \mathrm{K}}{\mathrm{W}}$

$\mathrm{r}_{\mathrm{DW}}=2.25 \mathrm{~m}$

$\mathrm{r}_{1}=2.25 \mathrm{~m} \quad$ EBS_name $_{1}=$ "Liner" $\quad$ EBS_material $_{1}=$ "Steel"

$\mathrm{r}_{2}=2.225 \mathrm{~m} \quad$ EBS_name $2=$ "Backfill" $\quad$ EBS_material ${ }_{2}=$ "70\% Bentonite $30 \%$ Sand"

$\mathrm{r}_{3}=0.645 \mathrm{~m} \quad$ EBS_name $_{3}=$ "Envelope" $\quad$ EBS_material $_{3}=$ "None"

$\mathrm{r}_{4}=0.645 \mathrm{~m} \quad$ EBS_name $_{4}=$ "Buffer" $\quad$ EBS_material $4=$ "None"

$r_{\mathrm{WP}}=0.645 \mathrm{~m}$

$\mathrm{R}_{1}\left(\mathrm{k}_{1}\right)=5.465 \times 10^{-4} \cdot \frac{\mathrm{m}^{2} \cdot \mathrm{K}}{\mathrm{W}} \quad \mathrm{R}_{2}\left(\mathrm{k}_{2}, \mathrm{t}_{\text {closure }}, \mathrm{t}_{\text {operate }}, \mathrm{t}_{\text {backfill }}\right)=2.322 \cdot \frac{\mathrm{m}^{2} \cdot \mathrm{K}}{\mathrm{W}} \quad \mathrm{R}_{3}\left(\mathrm{k}_{3}\right)=0 \cdot \frac{\mathrm{m}^{2} \cdot \mathrm{K}}{\mathrm{W}}$

$\mathrm{R}_{\text {Total }}\left(1000 \mathrm{yr}, \mathrm{k}_{1}, \mathrm{k}_{2}, \mathrm{k}_{3}, \mathrm{k}_{4}\right)=2.322 \cdot \frac{\mathrm{m}^{2} \cdot \mathrm{K}}{\mathrm{W}}$ 


\section{INPUT $6=$ WASTE FORM DATA}

Input_6 := READEXCEL(file, concat(sheet, "A35:B38"))

Input_6 = $\left(\begin{array}{cc}\text { "Waste form short name" } & \text { "UOX-40" } \\ \text { "Waste form type" } & \text { "Assembly" } \\ \text { "Waste package capacity" } & 21 \\ \text { "Waste package length, m" } & 5\end{array}\right)$

WF_name := Input_61,2 = "UOX-40"

WF_type $:=$ Input_62,2 = "Assembly"

WP_cap := Input_63,2 $=21$

WP_length := Input_64,2·m $=5 \mathrm{~m}$

\section{Outside of the liner}

$\mathrm{A}_{1}:=2 \cdot \pi \cdot \mathrm{r}_{1} \cdot \mathrm{WP} \_$length $=70.69 \mathrm{~m}^{2}$

$\mathrm{A}_{\mathrm{DW}}:=2 \cdot \pi \cdot \mathrm{r}_{\mathrm{DW}} \cdot \mathrm{WP} \_$length $=70.686 \mathrm{~m}^{2}$
Outside of the backfill_- Outside of the envelope

$\mathrm{A}_{2}:=2 \cdot \pi \cdot \mathrm{r}_{2} \cdot \mathrm{WP} \_$length $=69.9 \mathrm{~m}^{2} \quad \mathrm{~A}_{3}:=2 \cdot \pi \cdot \mathrm{r}_{3} \cdot \mathrm{WP} \_$length $=20.26 \mathrm{~m}^{2}$
Outside of the buffer

$\mathrm{A}_{4}:=2 \cdot \pi \cdot \mathrm{r}_{4} \cdot \mathrm{WP} \_$length $=20.26 \mathrm{~m}^{2}$

$A_{W P}:=2 \cdot \pi \cdot r_{W P} \cdot$ WP_length $=20.263 \mathrm{~m}^{2}$

CONSIDER THE ALTERNATE DESIGN CASE OF AN "OPEN MODE" DESIGN, WITH A CEMENTITIOUS LINER, BUT ONLY AIR BETWEEN THE LINER AND THE WASTE PACKAGE FOR THE FIRST 300 YEARS. ASSUME NO VENTILATION FOR 300 YEARS, AND THEN BACKFILL AT CLOSURE.

CALCULATE THE EQUIVALENT THERMAL RESISTANCE OF THE AIR GAP USING A LINEARIZED RADIATION HEAT TRANSFER COEFFICIENT. BASE THE COEFFICIENT ON THE ROCK WALL TEMPERATURE AT THE DRIFT, AND THE EQUIVALENT WASTE PACKAGE TEMPERATURE NECESSARY TO MOVE THE HEAT GENERATED AT

$\mathrm{A}_{\text {wall }}:=$ WP_length $\cdot 2 \cdot \pi \cdot \mathrm{r}_{\mathrm{DW}}=70.686 \mathrm{~m}^{2}$

Stefan Boltzmann constant $\quad \sigma:=5.670 \cdot 10^{-8} \cdot \frac{\mathrm{W}}{\mathrm{m}^{2} \cdot \mathrm{K}^{4}}$

Waste Package emissivity $\quad \varepsilon_{\mathrm{WP}}=0.6$

Rock wall or cementitious liner emissivity $\quad \varepsilon_{\text {wall }}=0.9$
The basis for the rock and waste package emissivity assumed is F. P. Incropera and D.P. DeWitt, Fundamentals of Heat and Mass

Transfer, 4th Edition, 1996, Table A-11, which shows a range of 0.88 to 0.93 is adapted from hemispherical emissivity of rock at around $300 \mathrm{~K}$.

This range is corroborated by the "Heat Transmission" section of Perry's Chemical Engineers Handbook, 6th Edition, 1984 (Table 10-17, pages 10-51 to 10-52) for normal emissivity of rough silica and rough fused quartz, ranging from 0.8 to 0.93 . The waste package surface is assumed to be covered with dust and dirt. The emissivity values to the left were specified in DSEF, and should be changed there if necessary.

Reference for radiation heat transfer coefficient, $h_{\text {rad, }}$ is from Incropera and DeWitt, Table 13.3 for concentric infinite cylinders (based on the inner surface as the heat source), and is also referenced in the YMP Ventilation Model and Analysis Report, ANL-EBS-MD-000030 REV 04, Oct. 2004, page 6-8.

$\mathrm{h}_{\text {rad_infinite }}\left(\mathrm{r}_{\mathrm{i}}, \mathrm{r}_{\mathrm{o}}, \varepsilon_{\mathrm{i}}, \varepsilon_{\mathrm{o}}\right):=\frac{\sigma}{\frac{1}{\varepsilon_{\mathrm{i}}}+\left(\frac{1-\varepsilon_{\mathrm{o}}}{\varepsilon_{\mathrm{o}}}\right) \cdot \frac{\mathrm{r}_{\mathrm{i}}}{\mathrm{r}_{\mathrm{o}}}}$ $\mathrm{h}_{\text {rad_infinite }}\left({ }_{\mathrm{WP}}, \mathrm{r}_{\mathrm{DW}}, \varepsilon_{\mathrm{WP}}, \varepsilon_{\mathrm{wall}}\right)=3.338 \times 10^{-8} \cdot \frac{\mathrm{W}}{\mathrm{m}^{2} \mathrm{~K}^{4}}$ Usage is $Q$ in watts $=h^{*} A_{i}^{*}\left(T_{i}^{\wedge} 4-T_{0}^{\wedge} 4\right)$
For radiation betwen the liner and the envelope (both metal

surfaces) use $r_{2}$ and $r_{3}$, and assume the same

emissivity for both surfaces. 
$\mathrm{Q}_{\text {rad_infinite }}\left(\mathrm{r}_{\mathrm{i}}, \mathrm{r}_{\mathrm{O}}, \varepsilon_{\mathrm{i}}, \varepsilon_{\mathrm{o}}, \mathrm{L}, \mathrm{T}_{\text {cold }}, \mathrm{T}_{\text {hot }}\right):=\mathrm{h}_{\text {rad_infinite }}\left(\mathrm{r}_{\mathrm{i}}, \mathrm{r}_{\mathrm{O}}, \varepsilon_{\mathrm{i}}, \varepsilon_{\mathrm{o}}\right) \cdot\left(2 \cdot \pi \cdot \mathrm{r}_{\mathrm{i}} \cdot \mathrm{L}\right)\left(\mathrm{T}_{\text {hot }}{ }^{4}-\mathrm{T}_{\text {cold }}{ }^{4}\right)$

$\mathrm{Q}_{\mathrm{L}_{\_} \text {rad_infinite }}\left(\mathrm{r}_{\mathrm{i}}, \mathrm{r}_{\mathrm{O}}, \varepsilon_{\mathrm{i}}, \varepsilon_{\mathrm{O}}, \mathrm{T}_{\text {cold }}, \mathrm{T}_{\text {hot }}\right):=\mathrm{h}_{\text {rad_infinite }}\left(\mathrm{r}_{\mathrm{i}}, \mathrm{r}_{\mathrm{O}}, \varepsilon_{\mathrm{i}}, \varepsilon_{\mathrm{o}}\right) \cdot\left(2 \cdot \pi \cdot \mathrm{r}_{\mathrm{i}}\right)\left(\mathrm{T}_{\text {hot }}{ }^{4}-\mathrm{T}_{\text {cold }}{ }^{4}\right)$

Heat transfer by radiation from NIRAS/ONDRAF December 2005 Report: Eef Weetjens and Xavier Sillen; Thermal analysis of the Supercontainer concept 2D

axisymmetric heat transport calculations, Section 6.4.3. Pg 34, equation 29.

$\mathrm{Q}_{\mathrm{L}_{-} \text {infinite }}\left(\mathrm{r}_{\mathrm{i}}, \mathrm{r}_{\mathrm{O}}, \varepsilon_{\mathrm{i}}, \varepsilon_{\mathrm{O}}, \mathrm{T}_{\text {cold }}, \mathrm{T}_{\text {hot }}\right):=\frac{2 \pi \sigma \cdot\left(\mathrm{T}_{\text {hot }}{ }^{4}-\mathrm{T}_{\text {cold }}{ }^{4}\right)}{\frac{1-\varepsilon_{\mathrm{i}}}{\varepsilon_{\mathrm{i}} \mathrm{r}_{\mathrm{i}}}+\frac{1}{\mathrm{r}_{\mathrm{i}}}+\frac{1-\varepsilon_{\mathrm{o}}}{\varepsilon_{0} \cdot \mathrm{r}_{\mathrm{O}}}}$

$\mathrm{Q}_{\mathrm{L} \_ \text {infinite }}\left(\mathrm{r}_{3}, \mathrm{r}_{2}, \varepsilon_{\mathrm{WP}}, \varepsilon_{\mathrm{wall}}, 300 \cdot \mathrm{K}, 600 \cdot \mathrm{K}\right)=1.643 \times 10^{4} \cdot \frac{\mathrm{W}}{\mathrm{m}}$

\section{Comparision of thermal radiation across a gap to conduction after the gap has been filled with backfill material.}

$\mathrm{Q}_{\mathrm{L} \_ \text {conduction_comparison }}\left(\mathrm{r}_{\mathrm{i}}, \mathrm{r}_{\mathrm{O}}, \mathrm{T}_{\text {cold }}, \mathrm{T}_{\text {hot }}\right):=\frac{2 \cdot \pi \cdot \mathrm{r}_{\mathrm{o}}}{\frac{\mathrm{r}_{\mathrm{DW}}}{\mathrm{k}_{2}} \cdot \ln \left(\frac{\mathrm{r}_{\mathrm{o}}}{\mathrm{r}_{\mathrm{i}}}\right)} \cdot\left(\mathrm{T}_{\text {hot }}-\mathrm{T}_{\text {cold }}\right) \quad \mathrm{Q}_{\mathrm{L}_{-} \text {conduction_comparison }}\left(\mathrm{r}_{3}, \mathrm{r}_{2}, 300 \cdot \mathrm{K}, 600 \cdot \mathrm{K}\right)=1.806 \times 10^{3} \cdot \frac{\mathrm{W}}{\mathrm{m}}$

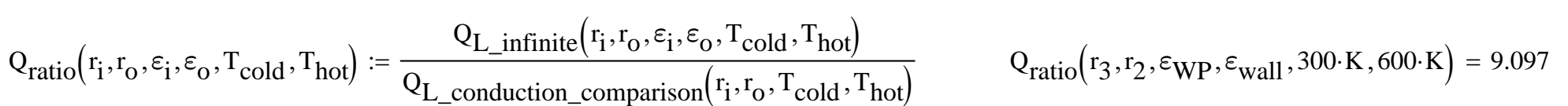

\section{INPUT 7 = PARAMETRIC STUDY VARIABLE INPUT DATA}

Input_7 := READEXCEL(file, concat(sheet, "F29:F41"))

$$
\begin{aligned}
& \text { Cases := Input_71 = } 1 \\
& \text { Parameter }:=\text { Input_72 = "Single" }
\end{aligned}
$$

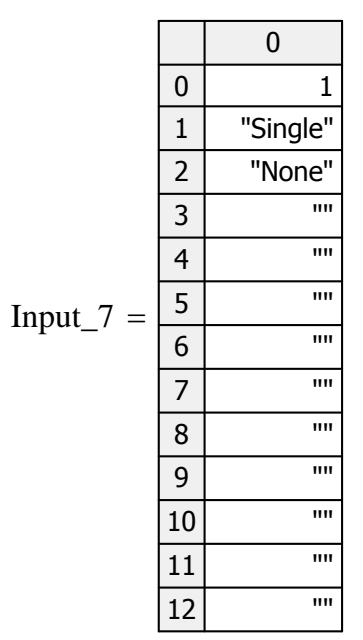

Parameter_units := Input_73 = "None"

ij $:=1$.. Cases

Parameter_dataij := Input_ $7 \mathrm{ij}+3$

Parameter_data $=(" ' ")$

Parameter_description $_{i j}:=\mid \begin{aligned} & \text { "Single Base Case" if Cases }=1 \\ & \text { concat[num2str[Input_7(ij+3)], ", ", Input_73] }\end{aligned}$ otherwise 
INPUT 8 = DECAY HEAT INPUT DATA PER UNIT SOURCE (ASSEMBLY OR CANISTER):

Input_8_size $:=$ READEXCEL(file, concat (sheet, "C43")) Input_8_size $1=58$

Decay_heat_range := concat["A43:B" ,num2str((Input_8_size $1+42))]$ = "A43:B100"

Input_8 := READEXCEL(file, concat(sheet,Decay_heat_range))

Time_out_of_Reactor := Input__ ${ }^{\langle 1\rangle} \cdot$ yr

Decay_Heat_per_Cnt $:=$ Input_8 ${ }^{\langle 2\rangle}$.W

Input 8 8 $=$

\begin{tabular}{|l|r|r|}
\hline & 0 & \multicolumn{1}{|c|}{1} \\
\hline 0 & 5 & $1.028 \cdot 10^{3}$ \\
\hline 1 & 5.1 & $1.011 \cdot 10^{3}$ \\
\hline 2 & 5.5 & 949.125 \\
\hline 3 & 5.75 & 916.671 \\
\hline 4 & 6 & 887.984 \\
\hline 5 & 8 & 742.948 \\
\hline 6 & 10 & 670.028 \\
\hline 7 & 11.5 & 634.239 \\
\hline 8 & 15 & 576.929 \\
\hline 9 & 20 &.. \\
\hline
\end{tabular}

Time_out_of_Reactor

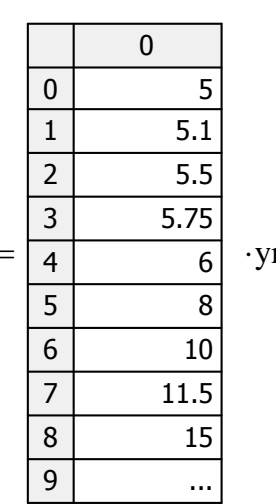

Decay_Heat_per_Cnt $=$

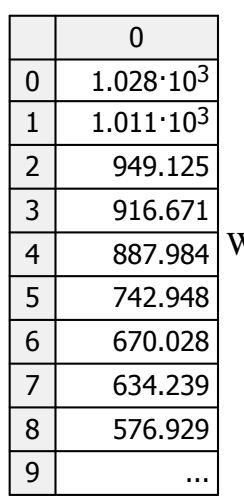

$\mathrm{Q}(\mathrm{t})$ := interp(cspline(Time_out_of_Reactor,Decay_Heat_per_Cnt),Time_out_of_Reactor,Decay_Heat_per_Cnt,t)

Ventilation efficiency for open systems is $\quad \mathrm{V}_{\text {eff }}=0.75$ between $\mathrm{t}_{\text {store }}$ and $\mathrm{t}_{\text {operate }}$

FUNCTION DEFINITION FOR ONE OUTPUT FILE

\section{FORMULAS FOR CALCULATING THE TRANSIENT DRIFT WALL TEMPERATURE:}

Central waste package:

$\mathrm{Q}_{\mathrm{L} \_ \text {wp }}\left(\mathrm{t}, \mathrm{t}_{\text {store }}, \mathrm{t}_{\text {operate }}, \mathrm{WP} \_\right.$cap $):=\frac{\mathrm{Q}(\mathrm{t}) \cdot \mathrm{WP} \_ \text {cap }}{\text { WP_length }} \cdot\left[1-1 \cdot\left(\mathrm{t} \leq \mathrm{t}_{\text {store }}\right)\right] \cdot\left[1-\mathrm{V}_{\text {eff }} \cdot\left(\mathrm{t} \leq \mathrm{t}_{\text {operate }}\right)\right]$

$$
\mathrm{Q}_{\mathrm{L}_{\_} \mathrm{wP}}\left(55 \cdot \mathrm{yr}, \mathrm{t}_{\text {store }}, \mathrm{t}_{\text {operate }}, 12\right)=177.365 \cdot \frac{\mathrm{W}}{\mathrm{m}}
$$




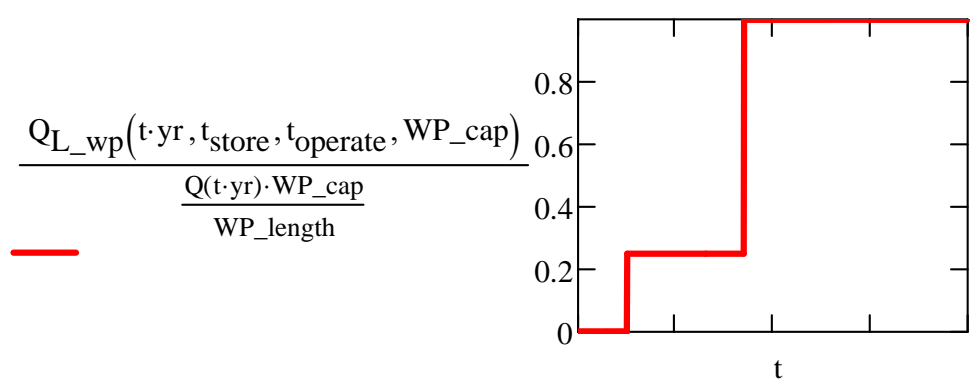

\section{Note - added $\mathrm{r}_{\mathrm{DW}}$ as a function parameter to allow calculations at additional compliance points inside the rock, where $\mathrm{r}_{\mathrm{DW}}$ would be replaced with new radius value.}

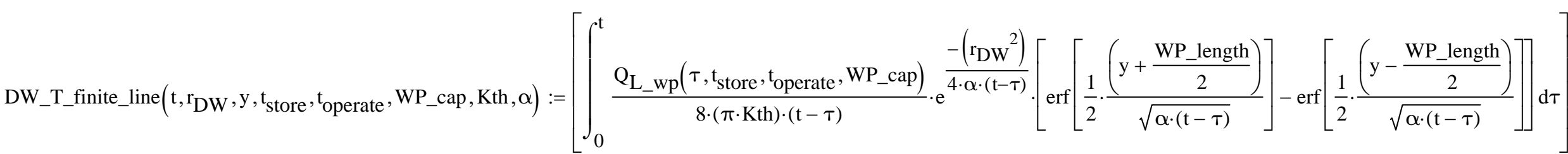

Adjacent drifts:

$\mathrm{Q}_{\mathrm{L} \_ \text {avg }}\left(\mathrm{t}, \mathrm{t}_{\text {store }}, \mathrm{t}_{\text {operate }}, \mathrm{WP} \_\right.$cap, WP_spacing $):=\frac{\mathrm{Q}(\mathrm{t}) \cdot \mathrm{WP}_{\text {_cap }}}{\mathrm{WP} \_ \text {spacing }} \cdot\left[1-1 \cdot\left(\mathrm{t} \leq \mathrm{t}_{\text {store }}\right)\right] \cdot\left[1-\mathrm{V}_{\text {eff }} \cdot\left(\mathrm{t} \leq \mathrm{t}_{\text {operate }}\right)\right]$

Note - added $\mathrm{r}_{\mathrm{DW}}$ as a function parameter to allow calculations at additional compliance points inside the rock, where $\mathrm{r}_{\mathrm{DW}}$ would be replaced with new radius value.

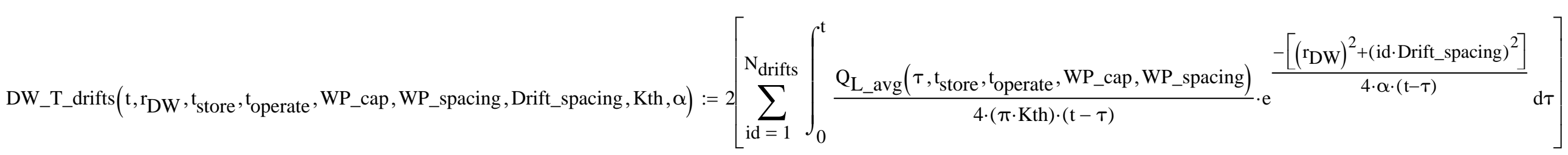

Adjacent waste packages:

$\mathrm{Q}_{\mathrm{wp}}\left(\mathrm{t}, \mathrm{t}_{\text {store }}, \mathrm{t}_{\text {operate }}, \mathrm{WP} \_\right.$cap $):=\mathrm{Q}(\mathrm{t}) \mathrm{WP} \_$cap $\cdot\left[1-1 \cdot\left(\mathrm{t} \leq \mathrm{t}_{\text {store }}\right)\right] \cdot\left[1-\mathrm{V}_{\text {eff }} \cdot\left(\mathrm{t} \leq \mathrm{t}_{\text {operate }}\right)\right]$

Note - added $\mathrm{r}_{\mathrm{DW}}$ as a function parameter to allow calculations at additional compliance points inside the rock, where $\mathrm{r}_{\mathrm{DW}}$ would be replaced with new radius value.

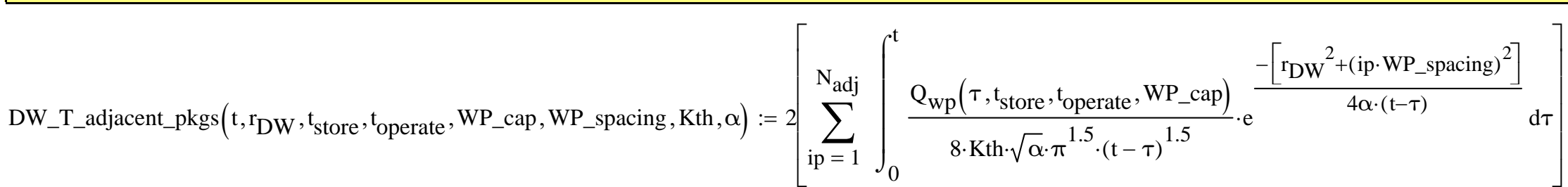




\section{This command specifies two rows of column headings for output paramenter sensitivity runs}

OutfileName := file = "DSEF R3.0_2013Aug12_HRG-Clay_UOX-40_Iterative convergence example_Case-225-19.xlsm"

Out_sheet := "Thermal-Analytical Output!"

This section specifies the column headings for output sensitivity studies

Cases $=1 \quad$ Read in from Thermal-Analytical sheet in DSEF (Inputs_7)

$:=1 .$. Cases

Parameter_vectori := $\mid$ "Base Case" if Cases $=1$

concat(Parameter, " ",Parameter_descriptioni) otherwise

Parameter_vector $=($ "Base Case" $)$

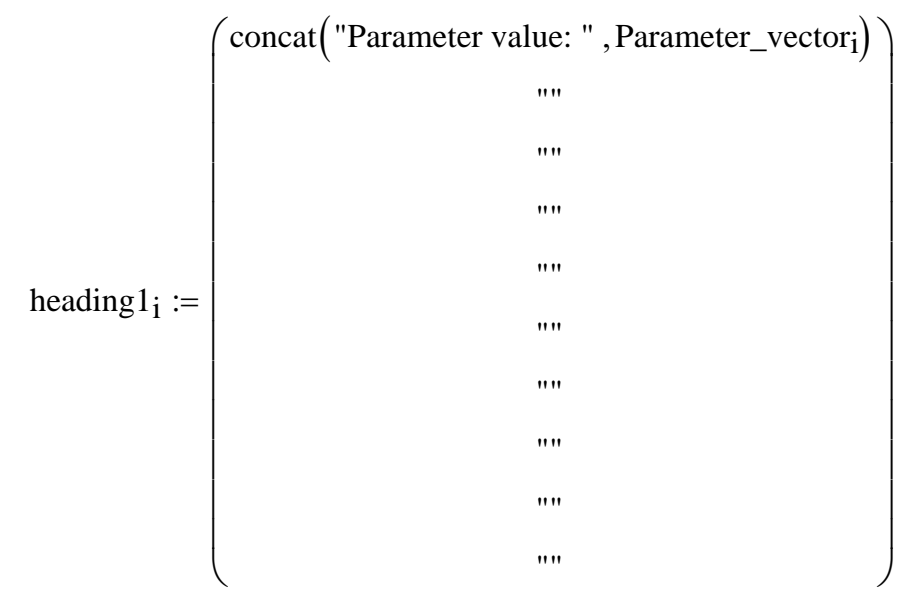

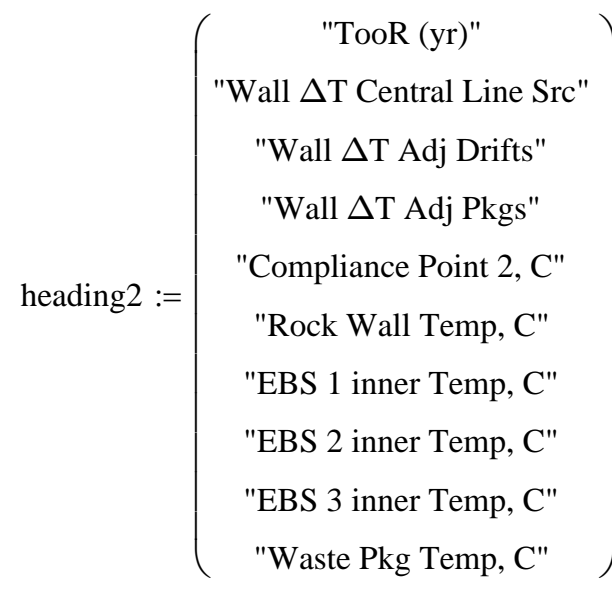

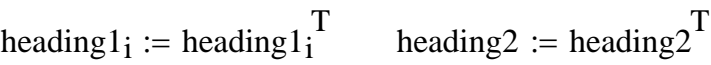

Title_arrayi := stack(heading1 1 , heading2)

Title_array $2=$,

For-Loop analysis returning the output time, three temperature contribution terms, and six temperatures

\begin{tabular}{|c|c|c|c|}
\hline length $($ Parameter_data) $=1$ & $\begin{array}{l}{ }^{\mathrm{r}} \mathrm{DW}=2.25 \mathrm{~m} \\
{ }_{\mathrm{C}}{ }_{\mathrm{CP} 2}=5.25 \mathrm{~m}\end{array}$ & $\begin{array}{l}\mathrm{t}_{\text {store }}=50 \cdot \mathrm{yr} \\
\mathrm{t}_{\text {operate }}=170 \cdot \mathrm{yr}\end{array}$ & $\begin{array}{l}\text { Changed j vector to Parameter_data, Inserted row } 2 \\
\text { in row } 5 \text { changed to } k_{\text {radiation }} \text { and } k_{2} \text { from } k_{2} \text { and } k_{\text {backfill }}\end{array}$ \\
\hline
\end{tabular}

$\mathrm{t}_{\text {closure }}=180 \cdot \mathrm{yr}$ 


\section{DEFINE STEP SIZE FOR OUTDATA Counter $:=200 \quad$ Step $:=5 \quad$ time_after_emplacement_analzyed $:=($ Counter $\cdot$ Step $\cdot y r)+\mathrm{t}_{\text {store }}=1050 \cdot \mathrm{yr}$}

ADDED CORRECTION FOR PARAMETRIC $t_{\text {closure }}$ eplaced $t_{\text {closure }}$ with $\left(t_{\text {operate }}+t_{\text {backfill }}\right.$ )

outdata $\left({ }_{\mathrm{DW}}, \mathrm{r}_{\mathrm{CP}},_{\text {store }},{ }_{\text {operate }}\right.$,WP_cap, WP_spacing, Drift_spacing, Kth, $\left.\alpha, \mathrm{k}_{1}, \mathrm{k}_{2}, \mathrm{k}_{3}, \mathrm{k}_{4}\right):=\mid$ for $\mathrm{i} \in 1$... Counter +1

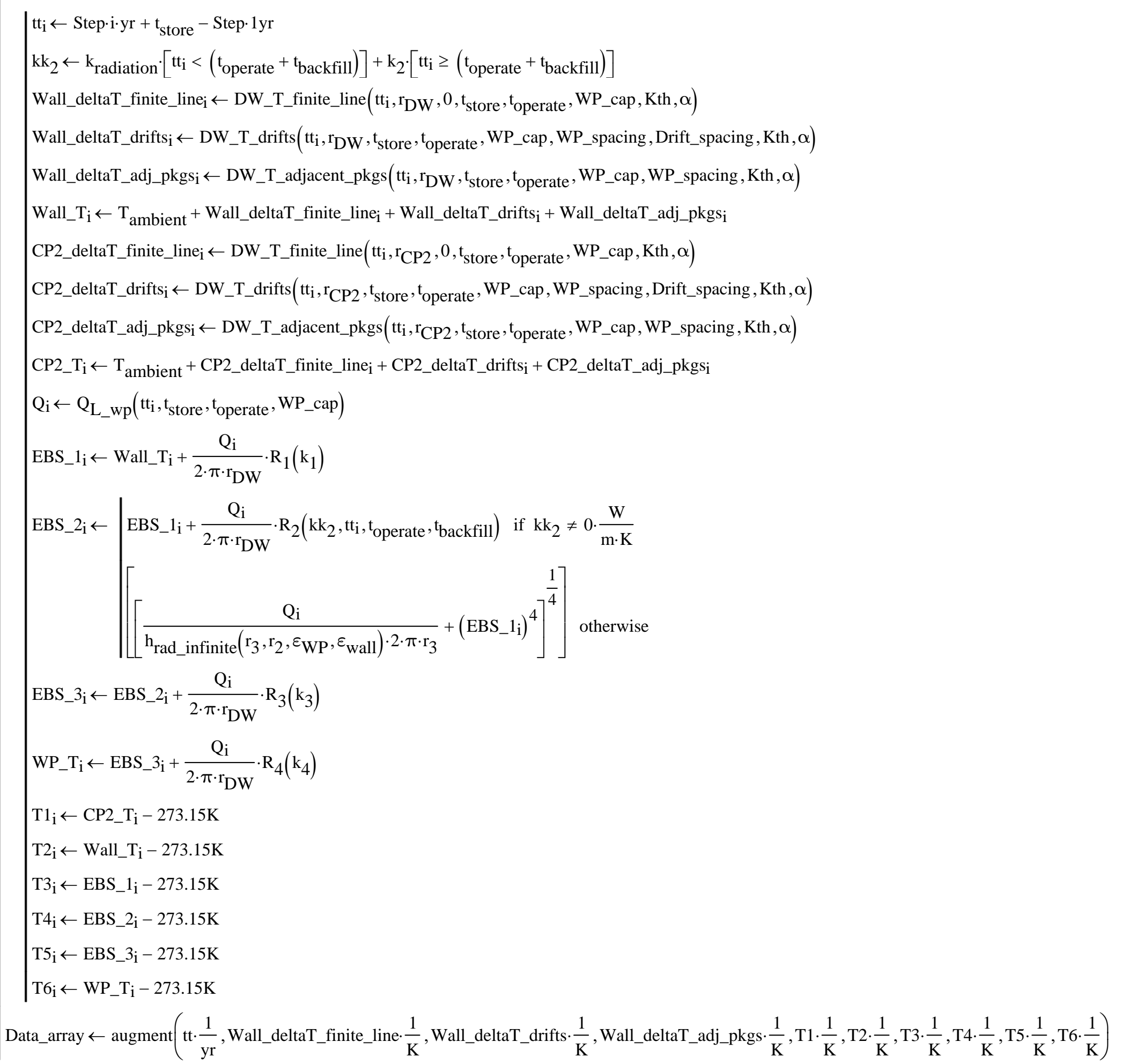


$\mathrm{jjj}:=1 .$. Cases $\quad$ Cases $=1$

$\mathrm{X}_{\mathrm{jjj}}:=$ Parameter_datajjj $\quad$ Parameter $=$ "Single"

Temp_array jjj := outdata $\left({ }_{\mathrm{DW}},{ }_{\mathrm{C}} \mathrm{CP} 2, \mathrm{t}_{\mathrm{store}}, \mathrm{t}_{\text {operate }}, \mathrm{WP}_{-} \mathrm{Cap}, \mathrm{WP} \_\right.$spacing, $\left.\mathrm{X}_{\mathrm{jjj}} \cdot \mathrm{m}, \mathrm{Kth}, \alpha, \mathrm{k}_{1}, \mathrm{k}_{2}, \mathrm{k}_{3}, \mathrm{k}_{4}\right)$ if Parameter $=$ "Drift Spacing" outdata $\left({ }_{\mathrm{DW}}, \mathrm{r}_{\mathrm{CP}}, \mathrm{r}_{\text {store }}, \mathrm{t}_{\text {operate }}, \mathrm{WP} \_\mathrm{Cap}, \mathrm{X}_{\mathrm{jjj}} \cdot \mathrm{m}\right.$, Drift_spacing, Kth, $\left.\alpha, \mathrm{k}_{1}, \mathrm{k}_{2}, \mathrm{k}_{3}, \mathrm{k}_{4}\right)$ if Parameter $=$ "WP Spacing" outdata $\left({ }_{\mathrm{DW}},{ }_{\mathrm{C} P 2}, \mathrm{X}_{\mathrm{jjj}} \cdot \mathrm{yr}, \mathrm{t}_{\text {operate }}, \mathrm{WP}_{-} \mathrm{Cap}, \mathrm{WP} \_\right.$spacing, Drift_spacing, Kth, $\left.\alpha, \mathrm{k}_{1}, \mathrm{k}_{2}, \mathrm{k}_{3}, \mathrm{k}_{4}\right)$ if Parameter $=$ "Storage Time" outdata $\left(\mathrm{r}_{\mathrm{DW}},{ }_{\mathrm{C}} \mathrm{CP}\right.$, $\mathrm{t}_{\text {store }}, \mathrm{t}_{\text {store }}+\mathrm{X}_{\mathrm{jjj}}$. yr, WP_cap, WP_spacing, Drift_spacing, Kth, $\left.\alpha, \mathrm{k}_{1}, \mathrm{k}_{2}, \mathrm{k}_{3}, \mathrm{k}_{4}\right)$ if Parameter $=$ "Ventilation Duration" outdata $\left({ }_{\mathrm{DW}},{ }_{\mathrm{CP} 2}, \mathrm{t}_{\text {store }}, \mathrm{t}_{\text {operate }}, \mathrm{WP} \_\right.$cap, WP_spacing, Drift_spacing, $\left.\mathrm{X}_{\mathrm{jjj}} \cdot \frac{\mathrm{W}}{\mathrm{m} \cdot \mathrm{K}}, \alpha, \mathrm{k}_{1}, \mathrm{k}_{2}, \mathrm{k}_{3}, \mathrm{k}_{4}\right)$ if Parameter $=$ "Rock Conductivity"

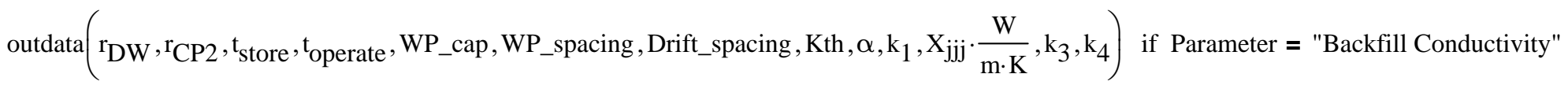
"Undefined" otherwise

File_arrayjjj := stack(Title_arrayjjj, Temp_array,jj)

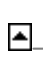

File_array 1

\begin{tabular}{|c|c|c|c|c|c|c|}
\hline & 0 & 1 & 2 & 3 & 4 & 5 \\
\hline 0 & "Parameter value: Base Case" & "'"' & "'"' & "'"' & "I"' & \\
\hline 1 & "TOoR (yr)" & "Wall $\Delta T$ Central Line Src" & "Wall $\Delta T$ Adj Drifts" & "Wall $\Delta$ T Adj Pkgs" & "Compliance Point 2, C" & "Rock Wall Temp, C" \\
\hline 2 & 50 & 0 & 0 & 0 & 27.5 & 27.5 \\
\hline 3 & 55 & 23.349 & 0.269 & 1.181 & 38.116 & 52.299 \\
\hline 4 & 60 & 22.931 & 1.341 & 2.422 & 40.833 & 54.195 \\
\hline 5 & 65 & 21.989 & 2.532 & 3.206 & 42.678 & 55.227 \\
\hline 6 & 70 & 20.933 & 3.643 & 3.728 & 43.983 & 55.804 \\
\hline 7 & 75 & 19.895 & 4.644 & 4.085 & 44.978 & 56.124 \\
\hline 8 & 80 & 18.909 & 5.536 & 4.332 & 45.748 & 56.278 \\
\hline 9 & 85 & 17.992 & 6.332 & 4.501 & 46.352 & 56.325 \\
\hline 10 & 90 & 17.14 & 7.042 & 4.612 & 46.831 & 56.294 \\
\hline 11 & 95 & 16.364 & 7.675 & 4.681 & 47.21 & 56.22 \\
\hline 12 & 100 & 15.639 & 8.245 & 4.719 & 47.518 & 56.103 \\
\hline 13 & 105 & 14.98 & 8.756 & 4.735 & 47.767 & 55.972 \\
\hline 14 & $\overline{110}$ & 14.372 & 9.214 & 4.728 & 47.957 & 55.814 \\
\hline 15 & 115 & 13.82 & 9.628 & 4.71 & 48.116 & \\
\hline
\end{tabular}


iii := $1 . .10$

Peak_array ${ }_{j j j}$, iii : $\left.=\max \left[\left[\left(\text { Temp_array }_{\mathrm{jjj}}\right)^{\langle\mathrm{iii}}\right\rangle\right]\right]$

Peak_array $1,2=35.526$

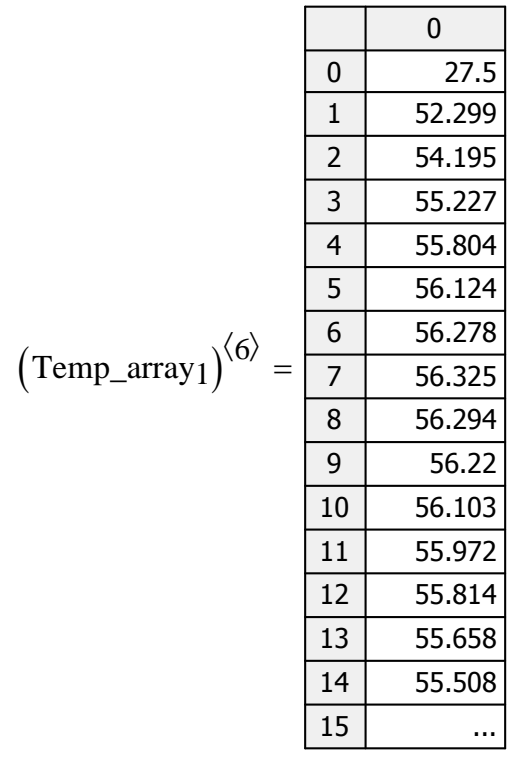

Time_array := (Temp_array 1$)^{\langle 1\rangle}$

Peak_T $(\mathrm{m}, \mathrm{n}):=\max \left[(\text { Temp_array } m)^{\langle\mathrm{n}\rangle}\right]$

Peak $\mathrm{T}(1,5)=88.663$

Peak_time $(m, n):=$ lookup[Peak_T(m,n), (Temp_array $\left.\_\right)^{\langle n\rangle}$,Time_array $]$

Peak_time $(1,5)=(475$

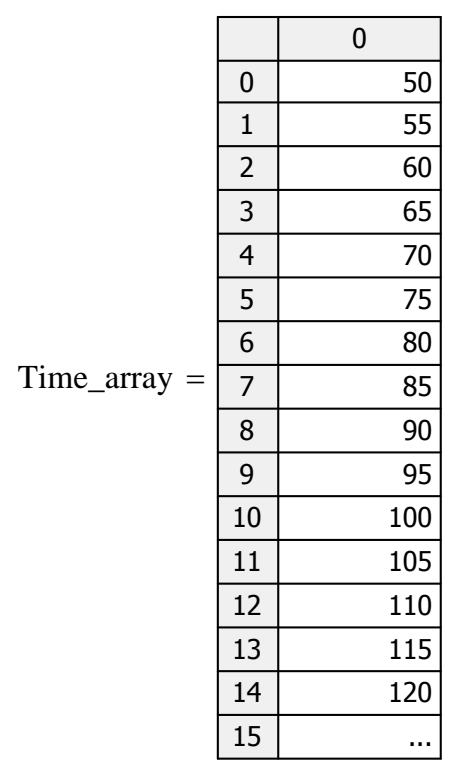

Initialize the peak value data array:

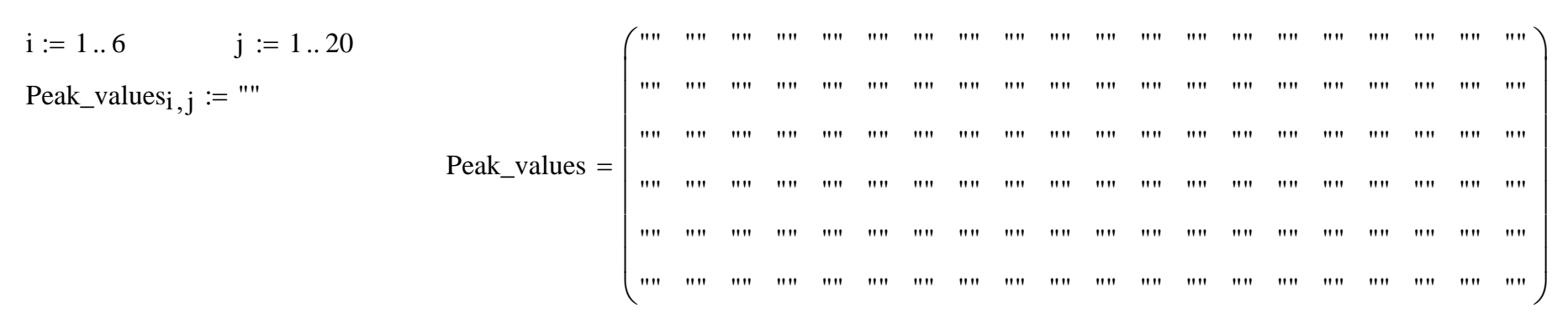

Fill in the peak temperatures and times:

$\mathrm{mj}:=1$.. Cases $\quad \mathrm{nn}:=1 . .6$

Peak_valuesnn,mj·2-1 := Peak_T(mj, nn + 4)

Peak_values $n n$, mj.2 $:=$ Peak_time $(m j, n n+4) 1$

$\mathrm{t}_{\mathrm{vent}}=120 \cdot \mathrm{yr}$

Parameter_vector ${ }^{\mathrm{T}}=($ "Base Case" $)$ 


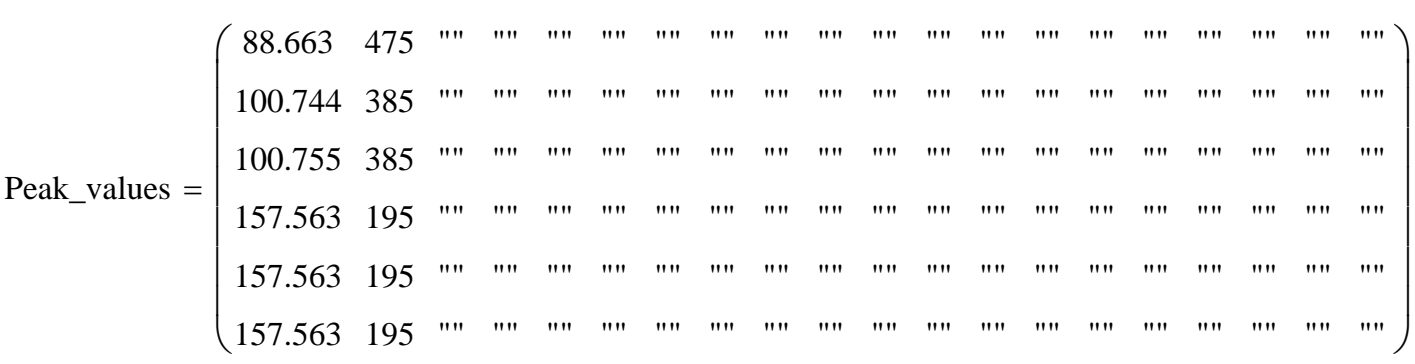

Peak_Wall_T := $(\text { Peak_values }\langle 1\rangle)_{2}=100.744$

outsheet := "Thermal-Analytical Output!"

rows $($ Temp_array 1$)=201 \quad$ rows $($ File_array 1$)=203$

Transient output starting row in DSEF on the Thermal-= 60

start row $:=100$ end_row $:=$ start_row + rows $($ Temp_array 1$)-1=300$

NOTE - USE File array to write to stand -alone Excel files and Temp array to write back to the DSEF Excel file.

transient_case_cols := $\left(\begin{array}{cc}\text { "A" } & \text { "J" } \\ \text { "L" } & \text { "U" } \\ \text { "W" } & \text { "AF" } \\ \text { "AH" } & \text { "AQ" } \\ \text { "AS" } & \text { "BB" } \\ \text { "BD" } & \text { "BM" } \\ \text { "BO" } & \text { "BX" } \\ \text { "BZ" } & \text { "CI" } \\ \text { "CK" } & \text { "CT" } \\ \text { "CV" } & \text { "DE" }\end{array}\right)$

To write the transients for each case horizontally instead of vertically, the following location array includes 10 columns for each case with one column separating the cases.

iw := 1 .. Cases

start_row $=100 \quad$ end_row $=300$

transient_write_rangeiw $:=$ concat $\left[\right.$ outsheet, $\left(\right.$ transient_case_cols $\left\langle\langle)_{\text {iw }} \text {,num2str(start_row), ":" , (transient_case_cols }{ }^{\langle 2\rangle}\right)_{\text {iw }}$, num2str(end_row) 
transient_write_range $=($ "Thermal-Analytical Output!A100:J300" $)$

Transient_size $:=($ Counter Step $)$

Transient_size $=\left(\begin{array}{ll}200 & 5\end{array}\right)$

Transient_size_range := concat(outsheet, "B92:C92" ) = "Thermal-Analytical Output!B92:C92"

\section{Make writing an output file optional}

$\mathrm{t}_{\text {vent }}=120 \cdot \mathrm{yr}$

Write_file := Write_OK = "YES"

OutfileName = "DSEF R3.0_2013Aug12_HRG-Clay_UOX-40_Iterative convergence example_Case-225-19.xlsm" write_the_peaks(Write_file) $:=\mid \begin{aligned} & \text { write_it } \leftarrow \\ & \text { "File written" }\end{aligned}$

write_it $\leftarrow$ "No file written" otherwise

write_the_peaks(Write_file) $=$ "File written"

write_the_transient_size(Write_file) $:=\mid$ write_it $\leftarrow \mid$ WRITEEXCEL(Transient_size,OutfileName,Transient_size_range) $\quad$ if (Write_file $=$ "Yes") $\vee($ Write_file = "YES")

$$
\mid \begin{array}{l|l}
\text { write_it } \leftarrow & \begin{array}{l}
\text { WRITEEXCEL_Transient_ } \\
\text { "File written" }
\end{array} \\
\text { write_it } \leftarrow \text { "No file written" otherwise }
\end{array}
$$

write_the_transient_size(Write_file) = "File written"

Write file: := Write_OK = "YES"

Cases $=1$

iww $:=1$.. Cases

NOTE - USE File array to write to stand-alone Excel files, and Temp array to write back to the DSEF Excel file.

write_the_transients(jj) := $\mid$ write_array $\leftarrow$ Temp_arrayj

write_it $\leftarrow \mid$ WRITEEXCEL(write_array, OutfileName, transient_write_rangejj) $\quad$ if (Write_file = "Yes") $\vee($ Write_file $=$ "YES")

"File written"

write_it $\leftarrow$ "No file written" otherwis

write_the_transients(iww) $=($ "File written" $)$ 
Plot_case := 1

WP_plot :=[(Temp_arrayplot_case $\left.)^{\langle 10\rangle}\right]$

CP2 plot : $=\left[\left(\right.\right.$ Temp_arrayplo_cs) $\left.{ }^{\langle 5\rangle}\right]$

\section{Select parametric study case to plot (default plot is for case 1)}

SS3_T_plot :=[(Temp_arrayPlot_case $\left.)^{\langle 9\rangle}\right] \quad$ EBS2_T_plot := $\left.\left[\left(\text { Temp_arrayPlot_case }^{\langle 8\rangle}\right] \quad \text { EBS1_T_plot :=[(Temp_arrayPlot_case }\right)^{\langle 7\rangle}\right] \quad$ Wall_T_plot :=[(Temp_arrayPlot_case $\left.)^{\langle 6\rangle}\right]$ Delta_WPs_T_plot := $\left.\left[\left(\text { Temp_arrayPlot_case }^{\langle 4\rangle}\right] \quad \text { Delta_drifts_T_plot := }\left[(\text { Temp_arrayPlot_case })^{\langle 3\rangle}\right] \quad \text { Delta_central_T_plot :=[(Temp_arrayPlot_case }\right)^{\langle 2\rangle}\right]$ 


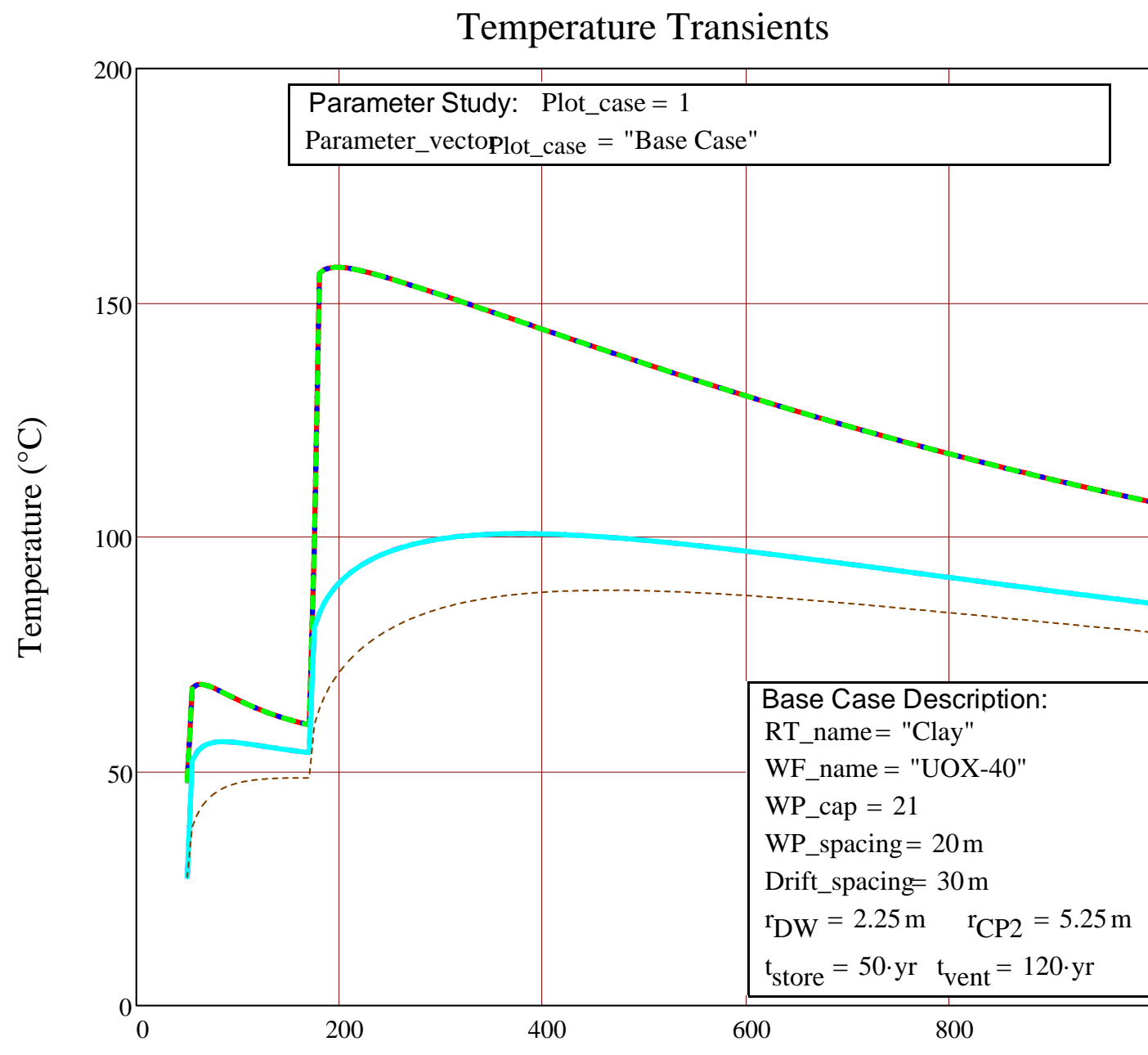

Time out of Reactor (yr)

- Waste Package Surface Temperature

.... EBS3 Temperature

-- EBS2 Temperature

-... EBS1 Temperature

- Drift Wall Temperature

Compliance point 2 Temperature

\footnotetext{
$\mathrm{T}_{\text {EBS }}\left(\mathrm{r}, \mathrm{t}, \mathrm{Wall} \_\mathrm{T}, \mathrm{k}_{1}, \mathrm{k}_{2}, \mathrm{k}_{3}, \mathrm{k}_{4}\right):=$ Wall_T$\cdot \mathrm{K}+\frac{\mathrm{Q}_{\mathrm{L} \_ \text {wp }}\left(\mathrm{t}, \mathrm{t}_{\text {store }}, \mathrm{t}_{\text {operate }}, \mathrm{WP} \_ \text {cap }\right)}{2 \cdot \pi \cdot \mathrm{r}_{\mathrm{DW}}} \cdot \mathrm{R}_{\text {continuous }}\left(\mathrm{t}, \mathrm{r}, \mathrm{k}_{1}, \mathrm{k}_{2}, \mathrm{k}_{3}, \mathrm{k}_{4}\right)$
}

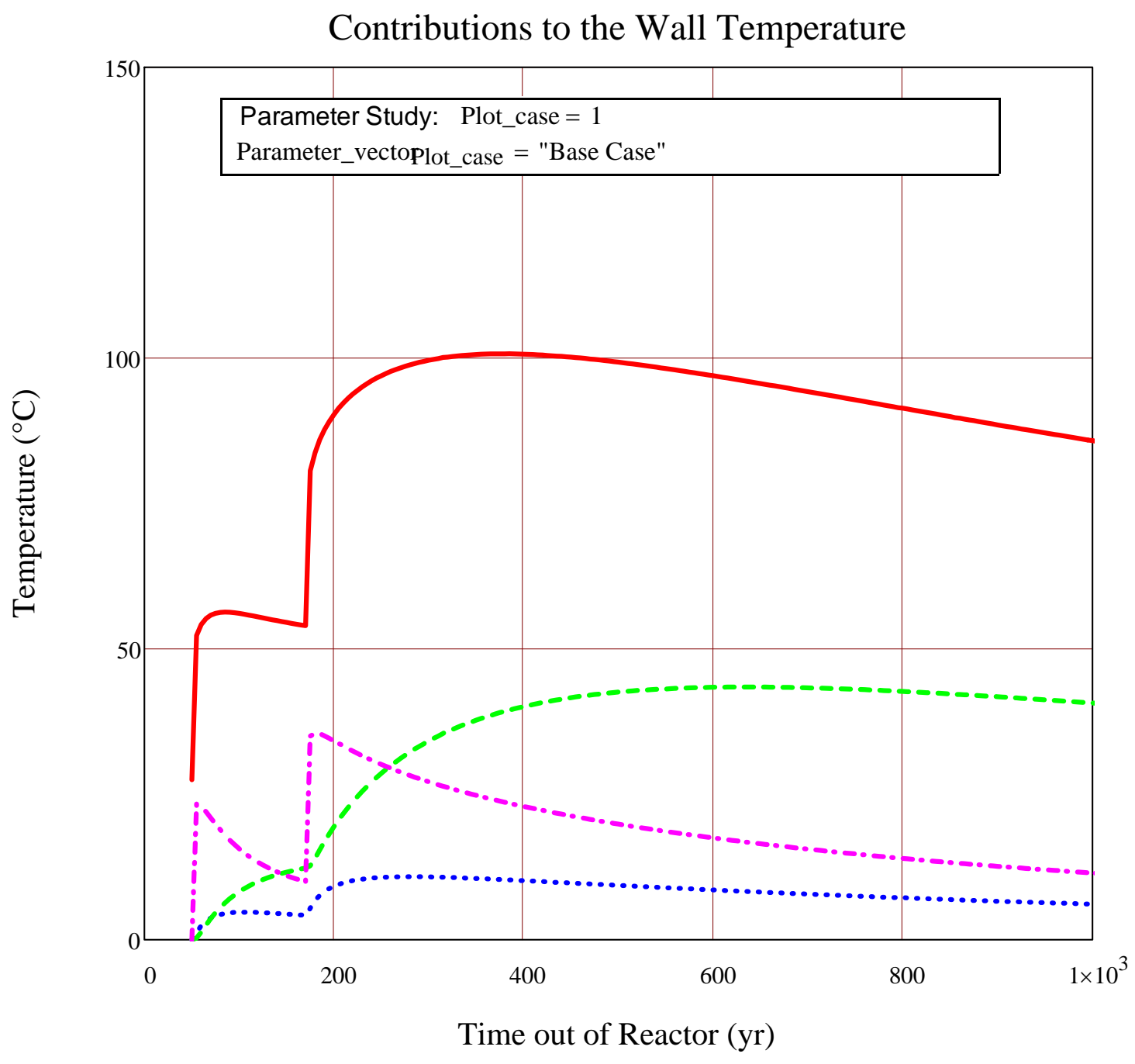

— Rock Wall Temperature (total)

.... Adjacent Waste Packages

- - Adjacent Drifts / Boreholes

-... Central Line Source 


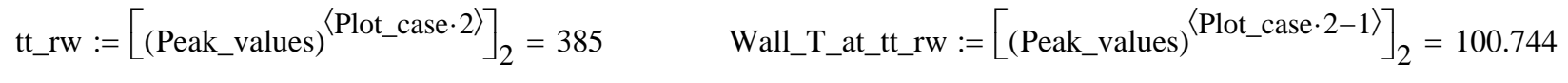

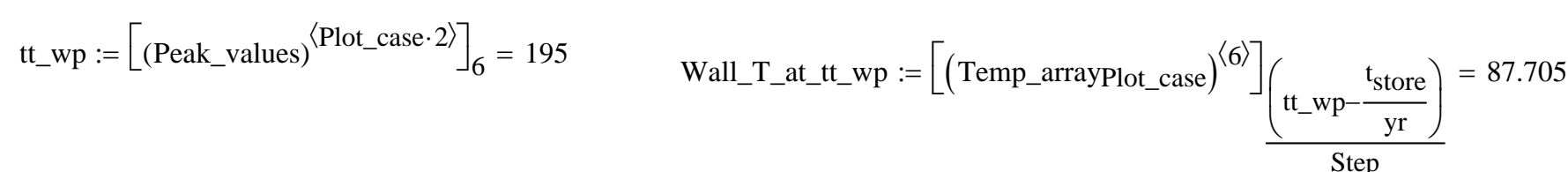

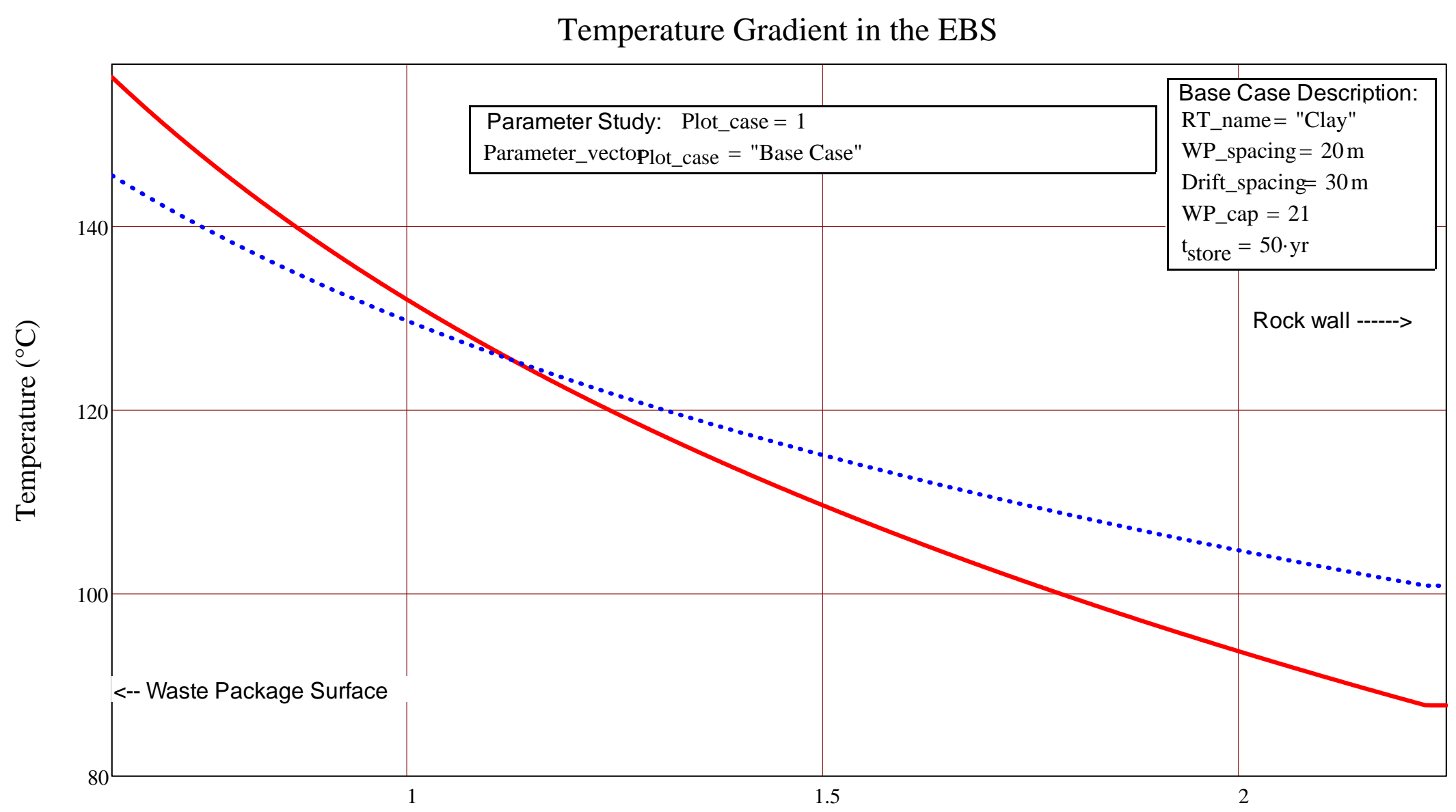

Radial Location in the EBS (m)

- Gradient at the time of the Waste Package Peak T

.... Gradient at the time of the Rock Wall Peak T

\section{OVERRIDE COUNTER AND STEP SIZE TO GET FINER CONVERGENCE ON THE ANSWER}




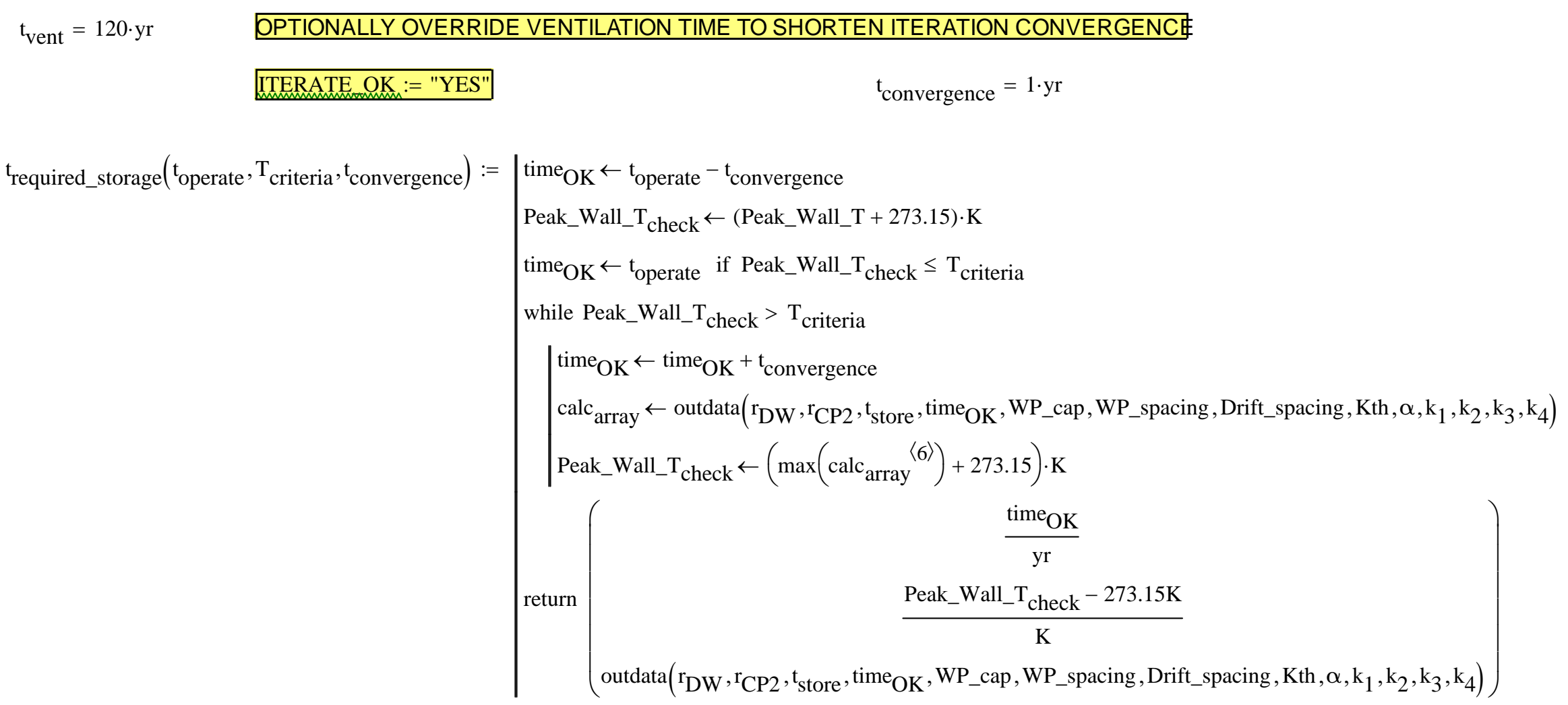

Final_array := trequired_storage $\left._{\text {toperate }}, \mathrm{T}_{\text {criteria }}, \mathrm{t}_{\text {convergence }}\right)$ if ITERATE_OK = "YES" "No Iteration Performed" otherwise

$\mathrm{t}_{\text {operate_required }}:=$ Final_array $1 \mathrm{yr}=177 \cdot \mathrm{yr}$

$t_{\text {vent_required }}:=\mathrm{t}_{\text {operate_required }}{ }^{-\mathrm{t}_{\text {store }}}=127 \cdot \mathrm{yr} \quad$ REQUIRED VENTILATION TIME NEEDED TO MEET $\mathrm{T}_{\text {criteria }}=100 \cdot{ }^{\circ} \mathrm{C}$

Peak_Wall_T $\mathrm{T}_{\text {check }}:=($ Final_array $2+273.15) \cdot \mathrm{K}=99.931{ }^{\circ} \mathrm{C}$ 
Result $:=$ stack(Title_array1, Final_array3) $\quad$ NOTE THAT THIS SECTION WILL BE BLANK IF NO ITERATIVE ANALYSIS IS PERFORMED (Iterate_OK ="NNo"

\begin{tabular}{|c|c|c|c|c|c|c|c|}
\hline & 1 & 2 & 3 & 4 & 5 & 6 & 7 \\
\hline 1 & "Parameter value: Base Case" & "'"' & "'"' & "'"' & "'"' & "'"' & "'"' \\
\hline 2 & "TooR (yr)" & "Wall $\Delta \mathrm{T}$ Central Line Src" & "Wall $\Delta \mathrm{T}$ Adj Drifts" & "Wall $\Delta \mathrm{T}$ Adj Pkgs" & "Compliance Point 2, C" & "Rock Wall Temp, C" & "EBS 1 inner Temp, C" \\
\hline 3 & 50 & 0 & 0 & 0 & 27.5 & 27.5 & 27.513 \\
\hline 4 & 55 & 23.349 & 0.269 & 1.181 & 38.116 & 52.299 & 52.311 \\
\hline 5 & 60 & 22.931 & 1.341 & 2.422 & 40.833 & 54.195 & 54.206 \\
\hline 6 & 65 & 21.989 & 2.532 & 3.206 & 42.678 & 55.227 & 55.238 \\
\hline 7 & 70 & 20.933 & 3.643 & 3.728 & 43.983 & 55.804 & 55.814 \\
\hline 8 & 75 & 19.895 & 4.644 & 4.085 & 44.978 & 56.124 & 56.133 \\
\hline 9 & 80 & \begin{tabular}{ll|}
18.909 \\
\end{tabular} & 5.536 & 4.332 & 45.748 & 56.278 & 56.287 \\
\hline 10 & 85 & \begin{tabular}{ll|}
17.992 \\
\end{tabular} & 6.332 & 4.501 & 46.352 & 56.325 & 56.333 \\
\hline 11 & 90 & 17.14 & 7.042 & 4.612 & 46.831 & 56.294 & 56.302 \\
\hline 12 & 95 & \begin{tabular}{c|c|}
16.364 \\
\end{tabular} & 7.675 & 4.681 & 47.21 & 56.22 & 56.227 \\
\hline 13 & 100 & 15.639 & 8.245 & 4.719 & 47.518 & 56.103 & 56.111 \\
\hline 14 & 105 & 14.98 & 8.756 & 4.735 & 47.767 & 55.972 & 55.979 \\
\hline 15 & 110 & 14.372 & 9.214 & 4.728 & 47.957 & 55.814 & 55.82 \\
\hline 16 & 115 & 13.82 & 9.628 & 4.71 & 48.116 & 55.658 & 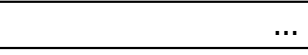 \\
\hline
\end{tabular}

Time_array :=(Final_array 3$)^{\langle 1\rangle}$

Peak_Temp(n) := max $\left[(\text { Final_array3 })^{\langle\mathrm{n}\rangle}\right]$

Peak_Temp(6) $=99.931$

Peak_t(n) := lookup[Peak_Temp(n),(Final_array 3$)^{\langle\mathrm{n}\rangle}$,Time_array $] \quad$ Peak_t(6)1.yr $=380 \cdot \mathrm{yr}$

$\mathrm{nn}:=5 . .10 \quad$ Peak_resultsnn-4,1 $:=$ Peak_Temp(nn) Peak_resultsnn-4,2 $:=$ Peak_t $(\mathrm{nn})_{1}$

Peak_results $=\left(\begin{array}{ll}88.045 & 470 \\ 99.931 & 380 \\ 99.941 & 380 \\ 154.961 & 210 \\ 154.961 & 210 \\ 154.961 & 210\end{array}\right) \quad \begin{aligned} & \text { CP2 } \\ & \text { Peak Wall T, time of peak } \\ & \text { Peak EBS 1, time of peak } \\ & \text { Peak EBS 2, time of peak } \\ & \text { Peak EBS 3, time of peak } \\ & \text { Waste Pkg T, time of peak }\end{aligned}$
Array_row_at_Wall_T_peak := match[Peak_Temp(6),(Final_array3 $\left.)^{\langle 6\rangle}\right] 1=67$

CP2_at_Wall_T_pk_t := $\left[(\text { Final_array3 })^{\langle 5\rangle}\right]_{\text {Array_row_at_Wall_T_peak }}=87.069$

Ceintral_WP_delta :=[(Final_array3 $\left.)^{\langle 2\rangle}\right]_{\text {Array_row_at_Wall_T_peak }}=23.638$

Adj_Drift_delta := $\left[(\text { Final_array3 } 3)^{\langle 3\rangle}\right]_{\text {Array_row_at_Wall_T_peak }}=38.538$ 
Adj_WP_delta := $\left[(\text { Final_array } 3)^{\langle 4\rangle}\right]_{\text {Array_row_at_Wall_T_peak }}=10.254$

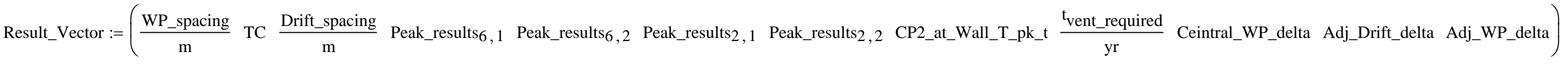

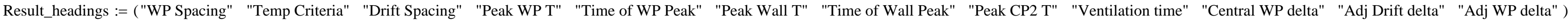

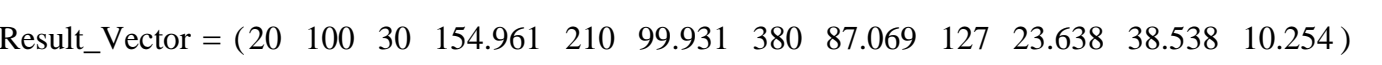
This is the result vector for transcription to the Excel case results tracking fille

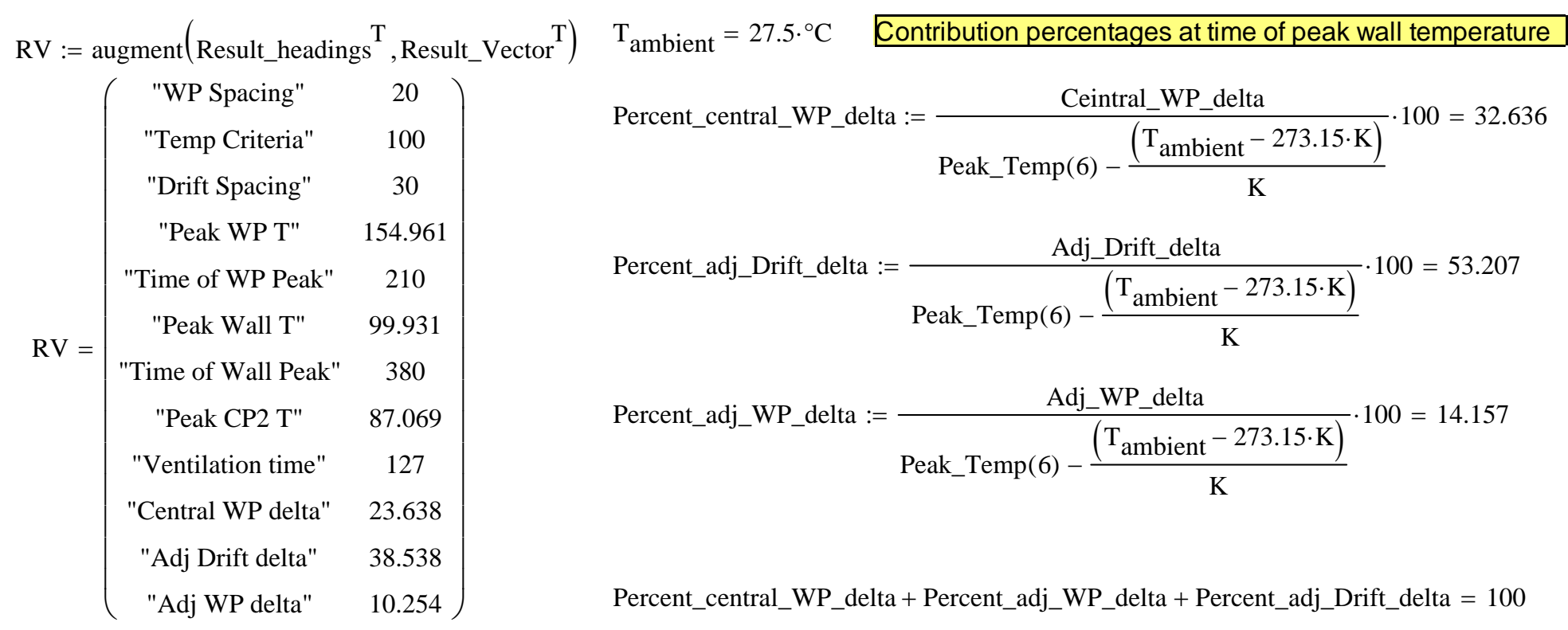




\section{Plot temperature results as a function of parameter dat}

ip $:=1$.. Cases
Peak_WP_Tip :=(Peak_values $\left.{ }^{\langle\text {ip } \cdot 2-1\rangle}\right)$

Peak_WP_T $=(157.563)$

Peak Wall Tip :=( Peak_values $\left.^{\langle i p \cdot 2-1\rangle}\right)_{2}$
Peak_CP2_Tip :=( Peak_values $^{\langle\text {ip.2-1〉})}$

Peak_EBS3_Tip := Peak_values $\left.^{\langle i p \cdot 2-1\rangle}\right)_{5}$

Peak_EBS3_T $=(157.563)$
Peak_EBS2_Tip :=( Peak_values $^{\langle\text {ip } \cdot 2-1\rangle)}$
Peak_EBS1_Tip := (Peak_values $\left.{ }^{\langle i p \cdot 2-1\rangle}\right)_{3}$ 
Peak Temperatures versus Parameter Study Data

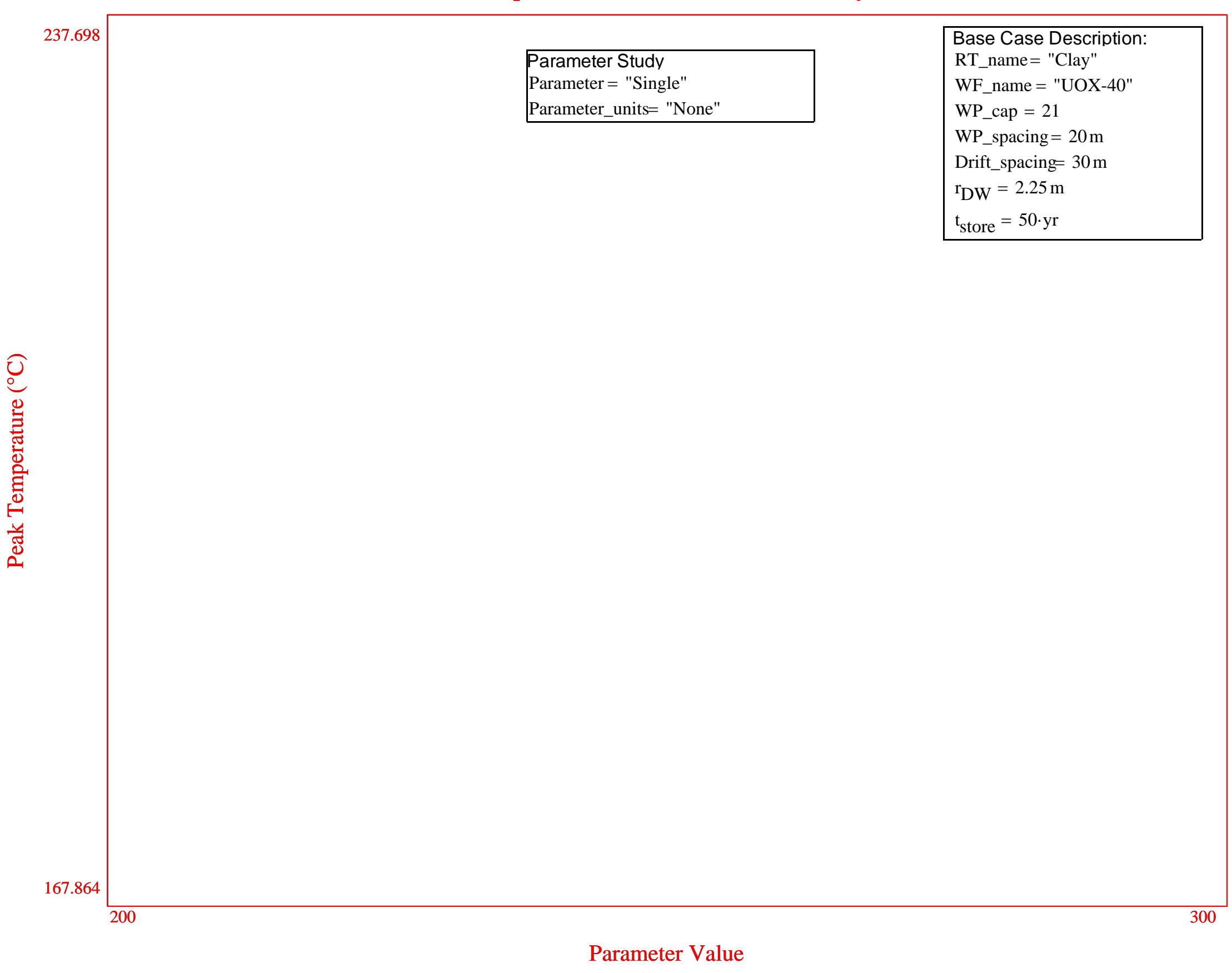




\section{B.4 The Mathcad model with temperature and time dependent EBS thermal properties}

This section documents a new DSEF Version 3.0 Mathcad model that allows temperature and time-dependent thermal properties within the EBS layers of the model. The PDF file and Mathcad document example shown applies these to salt for temperature-dependent thermal conductivity and time-dependent crushed salt porosity to model consolidation of the crushed salt layer with time and heat. The equations that implement these functions are shown on pages 2 and 3 of 24 in the PDF printout. The data for the time-dependent crushed salt consolidation comes from a finite element model in Hardin 2012b (Figure C-5). This model provides proof-ofprinciple that the thermal-analytical model can accommodate more complex thermal property modeling than the constant properties assumed in models and analysis using earlier versions of DSEF. The thermal results of this new model have a better fit to the FEM model results for the 12-PWR 40-GWd/MT burnup waste stream with 50 years of surface storage documented in Hardin 2012b than was possible with previous analyses using constant salt properties in the EBS (see Greenberg 2012b, Section G.6.2).

The EBS layer thermal conductivity values input by the DSEF Excel file have been replaced by the temperature and time-dependent functions at the beginning of the Mathcad document, and the programming loop shown on page 13 of 23 of the PDF file has been modified to use these new functions.

It should be noted that this model will work with all of the parametric study options except for parameter variations involving backfill thermal conductivity. The Mathcad model will convert any backfill thermal conductivity parameter study case into a "Single" analysis. The temperature and time-dependent EBS property functions will also work with the iterative convergence model.

With different temperature or time-dependence functions, this methodology could be used to model moisture-dependent properties covering dryout or re-wetting effects in other media. This would require other data or analysis to set the basic input functions, but then the benefits of the analytical-model approach could be applied to a broader class of problems. 


\section{DSEF R3.0 Single Model with collapsed areas - for rapid iteration cases}

Allow output transients to be written back to DSEF FILE

\section{Write_OK := "No"}

Variables for repository symmetry and extent:

NOTE - the Write_OK variable controls writing transient results back to Excel-DSEF, and Iterate_OK controls iterative

onvergence calculations for required ventilation times. This Mathcad model also allows temperature and time dependen

REQUIRED REPOSITORY INPUT DATA (from DSEF):

file := "DSEF R3.0C_2013Jul29_HRG-Salt_UOX-40_Enclosed mode variable kth_Case-Kth-1.xlsm"

sheet := "Thermal-Analytical!"

\section{READ DSEF INPUT FILE}

Input 1 = Operating Mode (enclosed or open)

Input_1 := READEXCEL(file, concat(sheet, "A5:B5" ))

Input_ 1 = ( "MODE = Open or Enclosed:" "Enclosed" $)$

Mode := Input_ $1{ }_{1,2}=$ "Enclosed"

\section{DATA FOR ITERATION ON TEMPERATURE ACCEPTANCE CRITERIA:}

$\mathrm{T}_{\text {criteria }}:=(\mathrm{TC}+273.15) \cdot \mathrm{K}=373.15 \mathrm{~K} \quad \mathrm{~T}_{\text {criteria }}=100 \cdot{ }^{\circ} \mathrm{C}$

\section{$\mathrm{t}_{\text {Convergence }}:=1 \cdot \mathrm{yI}$ CONVERGE CRITERIA FOR REQUIRED VENTILATION TIME IN YEARS}

SET THE VARIABLE ITERATE_OK TO "NO" TO TURN OFF THE AUTOMATIC CONVERGENCE

CALCULATION, AND MANUALLY RESET IT TO "YES" IF YOU WANT TO FINE TUNEYOUR ANSWER:

Input_2 := READEXCEL(file, concat(sheet, "A7:B16" ))Input 2 = Case Definitions

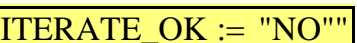

Input_2 $=\left(\begin{array}{cc}\text { "Host Media" } & \text { "Salt" } \\ \text { "Rock thermal conductivity, W/m-K" } & 5.4 \\ \text { "Rock thermal diffusivity, m2/sec" } & 2.661 \times 10^{-6} \\ \text { "Repository Depth, } \mathrm{m} " & 500 \\ \text { "Surface temperature, }{ }^{\circ} \mathrm{C} " & 15 \\ \text { "Geothermal gradient, }{ }^{\circ} \mathrm{C} / \mathrm{km} " & 25 \\ \text { "Ambient temperature at depth, }{ }^{\circ} \mathrm{C} " & 27.5 \\ \text { "Waste Package (axial) spacing, m" } & 20 \\ \text { "Drift / Borehole (lateral) spacing, m" } & 20 \\ \text { "Surface storage time, } \mathrm{y} & 50\end{array}\right)$

\section{Input 3 = Ventilation Parameters (for Open Modes)}

Input 3 := READEXCEL(file, concat(sheet, "e7:f11"))

Input_3 $=\left(\begin{array}{cc}\text { "Ventilation Duration, yr" } & \text { "N/A" } \\ \text { "Unventilated Closure Duration (Backfill Installation), yr" } & \text { "N/A" } \\ \text { "Ventilation Thermal Efficiency, \%" } & \text { "N/A" } \\ \text { "Rock Wall Emissivity" } & \text { "N/A" } \\ \text { "Waste Package Emissivity" } & \text { "N/A" }\end{array}\right)$

RT_name := Input_2 $1,2=$ "Salt"

Kth := Input $\_2,2 \frac{\mathrm{W}}{\mathrm{m} \cdot \mathrm{K}}=5.4 \frac{\mathrm{m} \cdot \mathrm{kg}}{\mathrm{K} \cdot \mathrm{s}^{3}}$

$\alpha:=$ Input $22_{3,2} \cdot \frac{\mathrm{m}^{2}}{\mathrm{~s}}=2.661 \times 10^{-6} \frac{\mathrm{m}^{2}}{\mathrm{~s}}$

WP_depth := Input_ $24,2 \cdot \mathrm{m}=500 \mathrm{~m}$

$\mathrm{T}_{\text {surface }}:=\left(\right.$ Input_ $\left.2_{5,2}+273.15\right) \cdot \mathrm{K}=288.15 \mathrm{~K}$

geothermal_gradient := Input_ $26,2 \frac{\mathrm{K}}{\mathrm{km}}=0.025 \frac{\mathrm{K}}{\mathrm{m}}$

$$
\begin{aligned}
& \mathrm{t}_{\text {vent }}:=\operatorname{if}[(\text { Mode }=\text { "Enclosed" }), 0, \text { Input_3 } 1,2] \cdot \mathrm{yr}=0 \cdot \mathrm{yr} \\
& \mathrm{t}_{\text {backfill }}:=\operatorname{if}[(\text { Mode }=\text { "Enclosed" }), 0, \text { Input_3 } 2,2] \cdot \mathrm{yr}=0 \cdot \mathrm{yr} \\
& \mathrm{V}_{\text {eff }}:=\operatorname{if}\left[(\text { Mode }=\text { "Enclosed" }), 0, \text { Input_3 }_{3,2}\right]=0 \\
& \varepsilon_{\text {wall }}:=\operatorname{if}\left[(\text { Mode }=\text { "Enclosed" }), .9, \text { Input_3 }{ }_{4,2}\right]=0.9 \\
& \varepsilon_{\mathrm{WP}}:=\operatorname{if}\left[(\text { Mode }=\text { "Enclosed" }), .6, \text { Input_3 }{ }_{5,2}\right]=0.6
\end{aligned}
$$

OVER-RIDE VENTILATION DURATION 
$\mathrm{T}_{\text {ambient }}:=\left(\right.$ Input $\left.\_27,2+273.15\right) \cdot \mathrm{K}=300.65 \mathrm{~K}$

WP_spacing $:=$ Input_2 $8,2^{\cdot m}=20 \mathrm{~m}$

Drift_spacing := Input_2 $9,2 \cdot \mathrm{m}=20 \mathrm{~m}$

$\mathrm{t}_{\text {store }}:=$ Input $\_210,2 \cdot \mathrm{yr}=50 \cdot \mathrm{yr}$

$\mathrm{t}_{\text {operate }}:=\left(\mathrm{t}_{\text {store }}+\mathrm{t}_{\text {vent }}\right)=50 \cdot \mathrm{yr}$

$\mathrm{t}_{\text {closure }}:=\mathrm{t}_{\text {operate }}+\mathrm{t}_{\text {backfill }}=50 \cdot \mathrm{yr}$

\section{Input 4 = ENGINEERED BARRIER SYSTEM DATA:}

Input_4 := READEXCEL(file, concat(sheet, "A20:F27"))

\section{T_OPERATE $=$ T_STORE + T_VENTILATE}

\section{TCLOSURE = TOPERATE + TIME TO BACKFILL}

\section{Input 5 = COMPLIANCE POINT 2 INPUT DATA}

Input_5 := READEXCEL(file, concat(sheet, "C32" ))

Input_4 = $\left.\begin{array}{cccccc}\text { "Waste Form Outer Radius, m" } & 0.555 & \text { "N/A" } & 0.555 & \text { "UOX-40" } & \text { "N/A" } \\ \text { "Canister" } & 0 & 0.555 & 0.555 & \text { "Carbon Steel" } & \text { "N/A" } \\ \text { "Waste Package" } & 0.03 & 0.555 & 0.585 & \text { "Carbon Steel" } & \text { "N/A" } \\ \text { "Salt Layer 1" } & 0.821 & 0.585 & 1.406 & \text { "75\% Intact Salt at T4 }{ }^{\circ} \mathrm{C} " & 3.16 \\ \text { "Salt Layer 2" } & 0.821 & 1.406 & 2.227 & \text { "75\% Intact Salt at T3 }{ }^{\circ} \mathrm{C} " & 3.16 \\ \text { "Salt Layer 3" } & 0.821 & 2.227 & 3.048 & \text { "75\% Intact Salt at T2 }{ }^{\circ} \mathrm{C} " & 3.16 \\ \text { "Salt Layer 4" } & 0.952 & 3.048 & 4 & \text { "Intact Salt } 100^{\circ} \mathrm{C} " & 4.2 \\ \text { "Host Rock Inner Radius, m ---->" } & \mathrm{NaN} & 4 & \mathrm{NaN} & \mathrm{NaN} & \mathrm{NaN}\end{array}\right)$

\section{DATA AND FORMULAS TO ALLOW TRANSIENT THERMAL CONDUCTIVITY WITHIN THE EBS $\quad$ Thermal conductivity of intact and crushed salt, based on Reference:}

3-D Thermal Analyses of High-Level Waste Emplaced in a Generic Salt Repository

AFCI-WAST-PMO-MI-DV-2009-000002; February, 2009. (D. J. Clayton, SNL, and C. W.

SALT THERMAL CONDUCTIVITY AS A FUNCTION OF TEMPERATURE AND POROSITY

$$
\text { Gable, Los Alamos). }
$$

$\mathrm{k}_{\text {intact }}(372.15 \cdot \mathrm{K})=4.224 \cdot \frac{\mathrm{W}}{\mathrm{m} \cdot \mathrm{K}}$

$\operatorname{kcs}(\varphi):=\left(-270 \varphi^{4}+370 \varphi^{3}-136 \varphi^{2}+1.5 \varphi+5\right) \cdot 1.08 \cdot \frac{\mathrm{W}}{\mathrm{m} \cdot \mathrm{K}} \quad$ Where $\varphi$ is porosity

$\mathrm{k}_{\text {crushed }}(\varphi, \mathrm{T}):=\mathrm{kcs}(\varphi) \cdot\left(\frac{300 \cdot \mathrm{K}}{\mathrm{T}}\right)^{1.14} \quad \mathrm{k}_{\text {crushed }}[0,(273.15+27.5) \cdot \mathrm{K}]=5.4 \cdot \frac{\mathrm{W}}{\mathrm{m} \cdot \mathrm{K}} \quad \mathrm{k}_{\text {crushed }}[0,(273.15+100) \cdot \mathrm{K}]=4.2 \cdot \frac{\mathrm{W}}{\mathrm{m} \cdot \mathrm{K}}$

Crushed salt thermal $\mathrm{k}$ at $100^{\circ} \mathrm{C}$ vs porosity

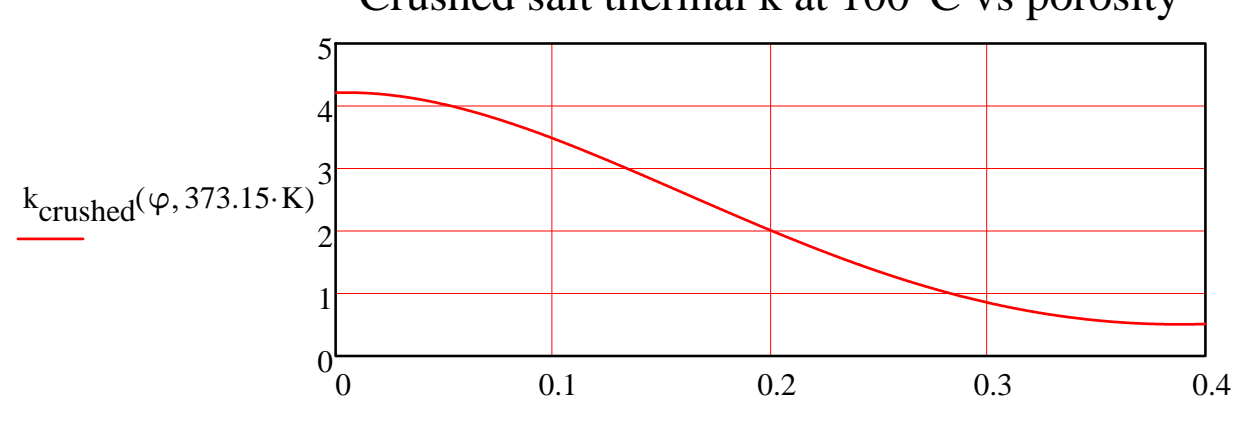

Intact salt thermal conductivity vs $\mathrm{T}\left({ }^{\circ} \mathrm{C}\right)$

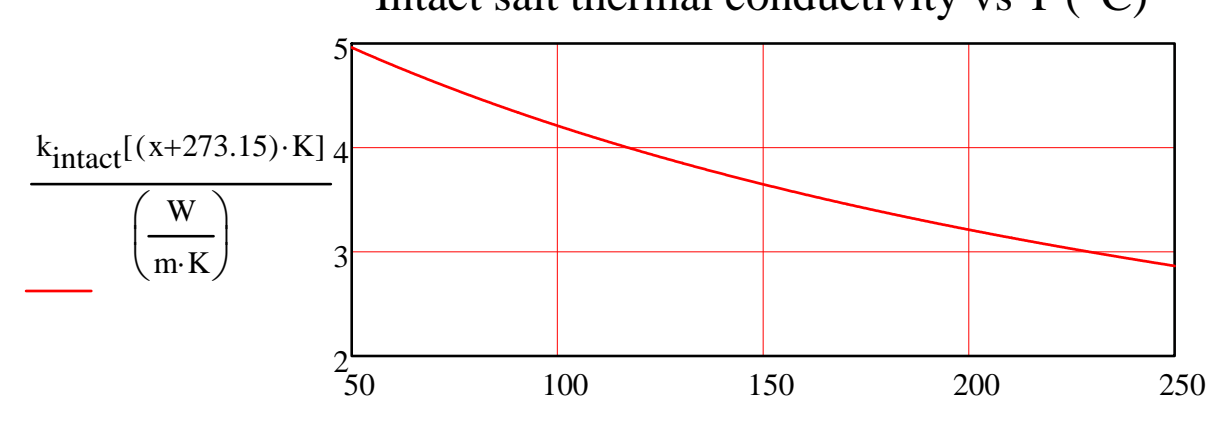


For comparison with SNL caclulation (E. Hardin, T. Hadgu, D. Clayton, R. Howard, H. Greenberg, J. Blink, M. Sharma, M. Sutton, J. Carter, M. Dupont, P. Rodwell. Repository Disposal Concepts and Thermal Load Management Analysis. FCRD-UFD-2012-00219 Rev. 2. November, 2012) assume an initial crushed salt porosity $\varphi_{0}=0.20$, and use a piece-wise linear function to fit an set of data representing the time-dependent consolidation of crushed salt (from FCRD-UFD-2012-00219 figure C-5), where the first column is time in years, and the second column is porosity fraction.

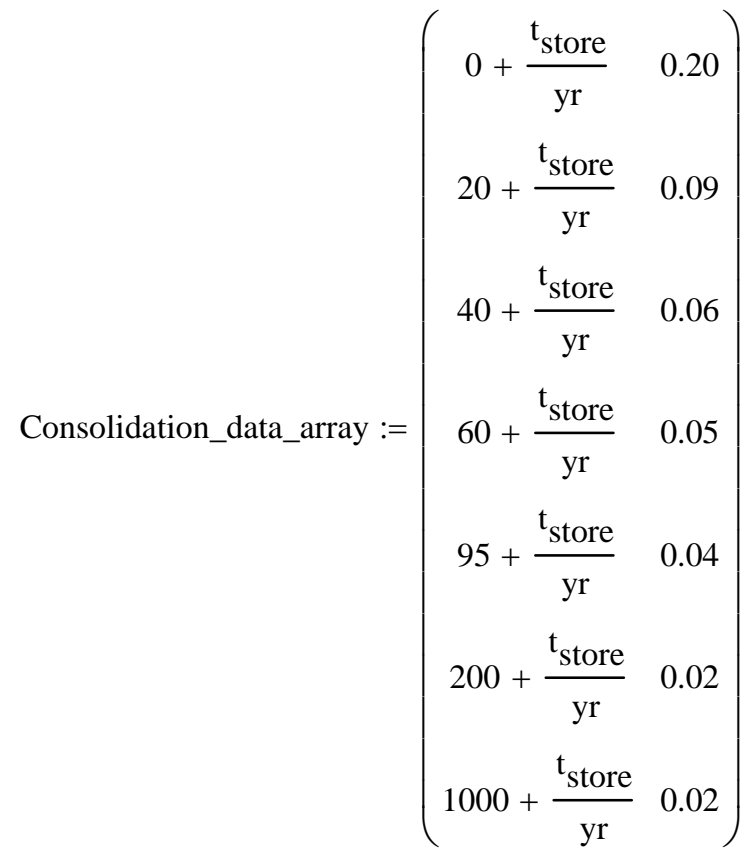

SS := lspline (Consolidation_data_array ${ }^{\langle 1\rangle}$,Consolidation_data_array $\left.{ }^{\langle 2\rangle}\right)$

Porosity $(\mathrm{t}):=$ interp $\left(\mathrm{SS}\right.$, Consolidation_data_array ${ }^{\left\langle{ }^{\prime}\right\rangle}$,Consolidation_data_array $\left.{ }^{\langle 2\rangle}, \mathrm{t}\right)$

Porosity $(50)=0.2 \quad$ Porosity $(80)=0.068$

$\mathrm{k}_{\text {consolidate }}(\mathrm{t}, \mathrm{T}):=\mid \mathrm{k}_{\text {crushed }}($ Porosity $(\mathrm{t}), \mathrm{T})$ if $\left[\mathrm{t} \leq\left(\text { Consolidation_data_array }\left\langle{ }^{\langle}\right\rangle\right)_{6}\right]$ $\mathrm{k}_{\text {crushed }}\left[(\text { Consolidation_data_array }\langle 2\rangle)_{6}, \mathrm{~T}\right]$ otherwise

$$
\mathrm{k}_{\text {consolidate }}\left(\frac{\mathrm{t}_{\text {store }}}{\mathrm{yr}}, 373.15 \cdot \mathrm{K}\right)=2.011 \cdot \frac{\mathrm{W}}{\mathrm{m} \cdot \mathrm{K}}
$$

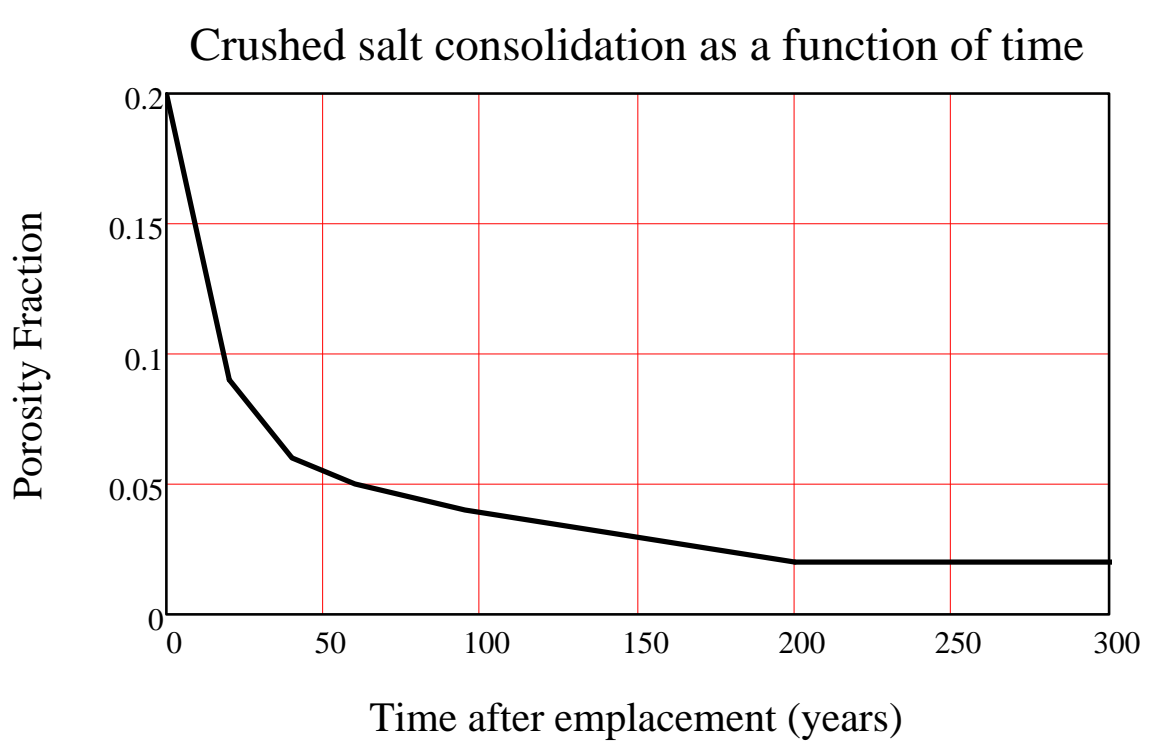

Mathcad Component of DSEF 3.0

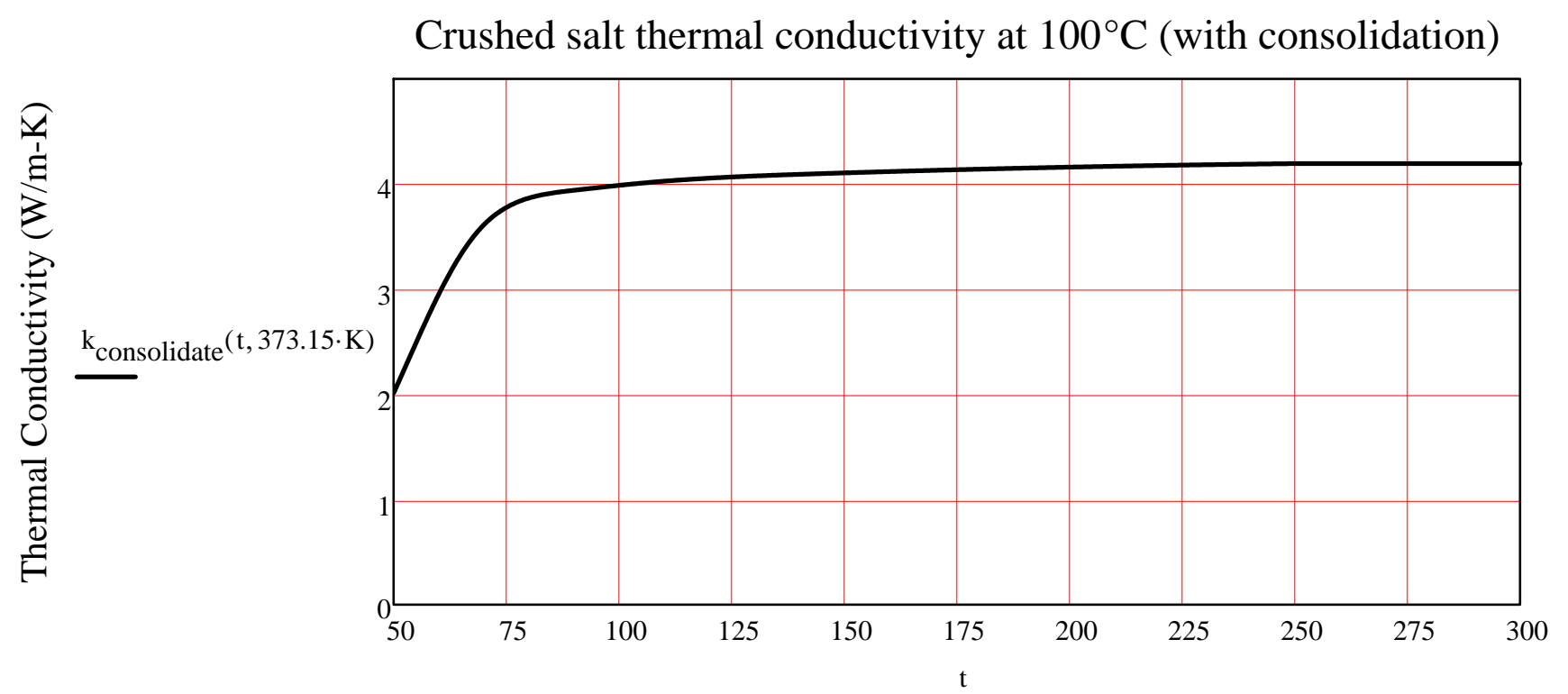

Time out of reactor (years) 
$\mathrm{r}_{\mathrm{DW}}:=$ Input $\_{ }_{8,3} \cdot \mathrm{m}=4 \mathrm{~m}$

$\mathrm{r}_{\mathrm{WP}}:=$ Input_ $4_{3,4} \cdot \mathrm{m}=0.585 \mathrm{~m}$

EBS_name $_{1}:=$ Input_ $4{ }_{7,1}=$ "Salt Layer 4"

thickness $1:=$ Input_ $_{7,2} \cdot \mathrm{m}=0.952 \mathrm{~m}$

$\mathrm{k} 1:=$ Input $\_4_{7,6}=4.2$

EBS_name $_{2}:=$ Input_ $4_{6,1}=$ "Salt Layer 3"

thickness $2:=$ Input $\_{ }_{6,2} \cdot \mathrm{m}=0.821 \mathrm{~m}$

$\mathrm{k} 2:=$ Input $\_{ }_{6,6}=3.16$

\section{$\mathrm{k}_{\text {radiation }}{ }^{(\mathrm{t}, \mathrm{T} 2)}:=\mathrm{if}\left[(\right.$ Mode $=$ "Enclosed" $), \mathrm{k}_{2}(\mathrm{t}, \mathrm{T} 2), 0$}

EBS_name $_{3}:=$ Input_4 $4_{5,1}=$ "Salt Layer 2"

thickness $_{3}:=$ Input_ $4_{5,2} \cdot \mathrm{m}=0.821 \mathrm{~m}$

$\mathrm{k} 3:=$ Input $4_{5,6}=3.16$

EBS_name $_{4}:=$ Input_ $44,1=$ "Salt Layer $1 "$

thickness ${ }_{4}:=$ Input $\_4{ }_{4,2} \cdot \mathrm{m}=0.821 \mathrm{~m}$

$\mathrm{k} 4:=$ Input $\_4,6=3.16$
EBS_material $_{1}:=$ Input_ $_{7,5}=$ "Intact Salt $100^{\circ} \mathrm{C} "$

$\mathrm{r}_{1}:=$ Input $\_47,4 \mathrm{~m}=4 \mathrm{~m}$

$\mathrm{k}_{1}:=$ if $[(\mathrm{k} 1=" \mathrm{~N} / \mathrm{A} "), 0, \mathrm{k} 1] \cdot \frac{\mathrm{W}}{\mathrm{m} \cdot \mathrm{K}}=4.2 \cdot \frac{\mathrm{W}}{\mathrm{m} \cdot \mathrm{K}}$

EBS_material $2:=$ Input_ ${ }_{6,5}=$ "75\% Intact Salt at T2 ${ }^{\circ} \mathrm{C} "$

$\mathrm{r}_{2}:=$ Input_ ${ }_{6,4} \cdot \mathrm{m}=3.048 \mathrm{~m}$

$\mathrm{k}_{2}:=$ if $[(\mathrm{k} 2=" \mathrm{~N} / \mathrm{A} "), 0, \mathrm{k} 2] \cdot \frac{\mathrm{W}}{\mathrm{m} \cdot \mathrm{K}}=3.16 \cdot \frac{\mathrm{W}}{\mathrm{m} \cdot \mathrm{K}}$

EBS_material $3:=$ Input_4 $4_{5,5}=" 75 \%$ Intact Salt at T3 ${ }^{\circ} \mathrm{C}^{\prime \prime}$

$\mathrm{r}_{3}:=$ Input_ $4_{5,4} \cdot \mathrm{m}=2.227 \mathrm{~m}$

$\mathrm{k}_{3}:=$ if $[(\mathrm{k} 3=" \mathrm{~N} / \mathrm{A} "), 0, \mathrm{k} 3] \cdot \frac{\mathrm{W}}{\mathrm{m} \cdot \mathrm{K}}=3.16 \cdot \frac{\mathrm{W}}{\mathrm{m} \cdot \mathrm{K}}$

$\mathrm{k}_{2 \mathrm{a}}(\mathrm{t}, \mathrm{T} 3):=\mathrm{if}\left[(\mathrm{k} 2=\right.$ "N/A" $\left.), 0,0.75 \cdot \mathrm{k}_{\text {intact }}(\mathrm{T} 3)+0.25 \cdot \mathrm{k}_{\text {consolidate }}\left(\frac{\mathrm{t}}{\mathrm{yr}}, \mathrm{T} 3\right)\right]$

EBS_material $_{4}:=$ Input_ $4{ }_{4,5}=" 75 \%$ Intact Salt at T4 ${ }^{\circ} \mathrm{C}$

$\mathrm{r}_{4}:=$ Input_ ${ }_{4}, 4 \cdot \mathrm{m}=1.406 \mathrm{~m}$

$\mathrm{k}_{4}:=$ if $[(\mathrm{k} 4=" \mathrm{~N} / \mathrm{A} "), 0, \mathrm{k} 4] \cdot \frac{\mathrm{W}}{\mathrm{m} \cdot \mathrm{K}}=3.16 \cdot \frac{\mathrm{W}}{\mathrm{m} \cdot \mathrm{K}}$

\section{$\mathrm{k}_{\mathrm{m}(\mathrm{s}}(\mathrm{T}):=\mathrm{if}\left[(\mathrm{k} 1=\right.$ "N/A" $), 0, \mathrm{k}_{\text {intact }}(\mathrm{T})$}

THE FOLLOWING FORMULAS ASSUME 75\% CONTACT WITH INTACT SALT AND 25\% CONTACT WITH CRUSHED SALT.

$\left.\mathrm{k}_{22 \mathrm{~s}} \mathrm{t}, \mathrm{T} 2\right):=\mathrm{if}\left[(\mathrm{k} 2=\right.$ "N/A" $\left.), 0,0.75 \cdot \mathrm{k}_{\text {intact }}(\mathrm{T} 2)+0.25 \cdot \mathrm{k}_{\text {consolidate }}\left(\frac{\mathrm{t}}{\mathrm{yr}}, \mathrm{T} 2\right)\right]$
$\mathrm{k}_{\mathrm{A} A \mathrm{t}}(\mathrm{t}, \mathrm{T} 4):=$ if $\left[(\mathrm{k} 2=\right.$ "N/A" $\left.), 0,0.75 \cdot \mathrm{k}_{\text {intact }}(\mathrm{T} 4)+0.25 \cdot \mathrm{k}_{\text {consolidate }}\left(\frac{\mathrm{t}}{\mathrm{yr}}, \mathrm{T} 4\right)\right]$

$\mathrm{k}_{4}[0 \cdot \mathrm{yr},(100+273.15) \cdot \mathrm{K}]=3.619 \cdot \frac{\mathrm{W}}{\mathrm{m} \cdot \mathrm{K}} \quad \mathrm{k}_{4}[1 \cdot \mathrm{yr},(100+273.15) \cdot \mathrm{K}]=3.578 \cdot \frac{\mathrm{W}}{\mathrm{m} \cdot \mathrm{K}}$

$\mathrm{k}_{4}[2 \cdot \mathrm{yr},(100+273.15) \cdot \mathrm{K}]=3.542 \cdot \frac{\mathrm{W}}{\mathrm{m} \cdot \mathrm{K}} \quad \mathrm{k}_{4}[10 \cdot \mathrm{yr},(100+273.15) \cdot \mathrm{K}]=3.372 \cdot \frac{\mathrm{W}}{\mathrm{m} \cdot \mathrm{K}}$ 
Define the total thermal resistance between the rock wall and the waste package surface based on a heat flux per unit area, it is then applied to a heat flux is per unit length adjusting to area per unit length and $\mathrm{q}_{\llcorner}(\mathrm{W} / \mathrm{m})$.
${ }^{\mathrm{WP}}=0.585 \mathrm{~m}$
$\mathrm{r}_{4}=1.406 \mathrm{~m} \quad \mathrm{r}_{3}=2.227 \mathrm{~m}$
$\mathrm{r}_{2}=3.048 \mathrm{~m}$
$r_{1}=4 \mathrm{~m}$
$\mathrm{r}_{\mathrm{DW}}=4 \mathrm{~m}$

$\mathrm{R}_{1}(\mathrm{~T}):=\operatorname{if}[$ thickness $\left.1=0 \vee(\mathrm{k} 1=\mathrm{N} / \mathrm{A} ")], 0, \frac{\mathrm{r}_{\mathrm{DW}}}{\mathrm{k}_{1}(\mathrm{~T})} \cdot \ln \left(\frac{\mathrm{r}_{1}}{\mathrm{r}_{2}}\right)\right]$

$\mathrm{R}_{1}[(100+273.15) \cdot \mathrm{K}]=0.258 \cdot \frac{\mathrm{m}^{2} \cdot \mathrm{K}}{\mathrm{W}}$ Thermal resistance

EBS_name $_{1}=$ "Salt Layer 4" EBS_material $1=$ "Intact Salt $100^{\circ} \mathrm{C} "$

\begin{tabular}{|c|c|}
\hline fill, T2) := & $\begin{array}{l}\mathrm{kk} \leftarrow \mathrm{k}_{\text {radiation }}(\mathrm{t}, \mathrm{T} 2) \cdot\left[\mathrm{t}<\left(\mathrm{t}_{\text {operate }}+\mathrm{t}_{\text {backfill }}\right)\right]+\mathrm{k}_{2}(\mathrm{t}, \mathrm{T} 2) \cdot\left[\mathrm{t} \geq\left(\mathrm{t}_{\text {operate }}+\mathrm{t}_{\text {backfill }}\right)\right] \\
\operatorname{return~if}\left[\left[\left(\text { thickness }_{2}=0\right) \vee(\mathrm{kk}=0)\right], 0, \frac{\mathrm{r}_{\mathrm{DW}}}{\mathrm{kk}} \cdot \ln \left(\frac{\mathrm{r}_{2}}{\mathrm{r}_{2}}\right)\right]\end{array}$ \\
\hline
\end{tabular}

$$
\frac{{ }^{\mathrm{D} W}}{\mathrm{k}_{2}[0 \cdot \mathrm{yr},(100+273.15) \cdot \mathrm{K}]} \cdot \ln \left(\frac{\mathrm{r}_{2}}{\mathrm{r}_{3}}\right)=0.347 \cdot \frac{\mathrm{m}^{2} \cdot \mathrm{K}}{\mathrm{W}}
$$

EBS_name $_{2}=$ "Salt Layer 3 EBS_material $2=$ "75\% Intact Salt at T2 ${ }^{\circ} \mathrm{C} "$

$$
\mathrm{R}_{2}(5 \cdot \mathrm{yr}, 300 \cdot \mathrm{yr}, 10 \cdot \mathrm{yr}, 373.15 \cdot \mathrm{K})=0.363 \cdot \frac{\mathrm{m}^{2} \cdot \mathrm{K}}{\mathrm{W}}
$$

$\mathrm{R}_{3}(\mathrm{t}, \mathrm{T} 3):=$ if $\left[\right.$ thickness $\left.\left._{3}=0 \vee(\mathrm{k} 3=\mathrm{N} / \mathrm{A} ")\right], 0, \frac{\mathrm{r}^{\mathrm{DW}}}{\mathrm{k}_{3}(\mathrm{t}, \mathrm{T} 3)} \cdot \ln \left(\frac{\mathrm{r}_{3}}{\mathrm{r}_{4}}\right)\right] \mathrm{R}_{3}(0 \cdot \mathrm{yr}, 373.15 \cdot \mathrm{K})=0.508 \cdot \frac{\mathrm{m}^{2} \cdot \mathrm{K}}{\mathrm{W}}$

EBS_name $_{3}=$ "Salt Layer 2" $\quad$ EBS_material ${ }_{3}=$ "75\% Intact Salt at T3 ${ }^{\circ} \mathrm{C} "$

$$
\left.\mathrm{R}_{4}(\mathrm{t}, \mathrm{T} 4):=\operatorname{if}[\text { thickness } 4=0 \vee(\mathrm{k} 4=" \mathrm{~N} / \mathrm{A} ")], 0, \frac{\mathrm{r}_{\mathrm{DW}}}{\mathrm{k}_{4}(\mathrm{t}, \mathrm{T} 4)} \cdot \ln \left(\frac{\mathrm{r}_{4}}{\mathrm{r}_{\mathrm{WP}}}\right)\right] \mathrm{R}_{4}(0 \cdot \mathrm{yr}, 373.15 \cdot \mathrm{K})=0.969 \cdot \frac{\mathrm{m}^{2} \cdot \mathrm{K}}{\mathrm{W}}
$$

EBS_name $_{4}=$ "Salt Layer 1" $\quad$ EBS_material $4=$ "75\% Intact Salt at T4 ${ }^{\circ} \mathrm{C}$ "

$\mathrm{R}_{\text {Total }}(\mathrm{t}, \mathrm{T} 1, \mathrm{~T} 2, \mathrm{~T} 3, \mathrm{~T} 4):=\mathrm{R}_{1}(\mathrm{~T} 1)+\mathrm{R}_{2}\left(\mathrm{t}, \mathrm{t}_{\text {operate }}, \mathrm{t}_{\text {backfill }}, \mathrm{T} 2\right)+\mathrm{R}_{3}(\mathrm{t}, \mathrm{T} 3)+\mathrm{R}_{4}(\mathrm{t},$. Total thermal resistance between wall and waste package

$\mathrm{t}_{\text {backfill }}=0 \cdot \mathrm{yr} \quad \mathrm{t}_{\text {operate }}=50 \cdot \mathrm{yr}$ 


\begin{tabular}{|c|c|}
\hline $\mathrm{R}_{\text {continuous }}(\mathrm{t}, \mathrm{r}, \mathrm{T} 1, \mathrm{~T} 2, \mathrm{~T} 3, \mathrm{~T} 4):=$ & 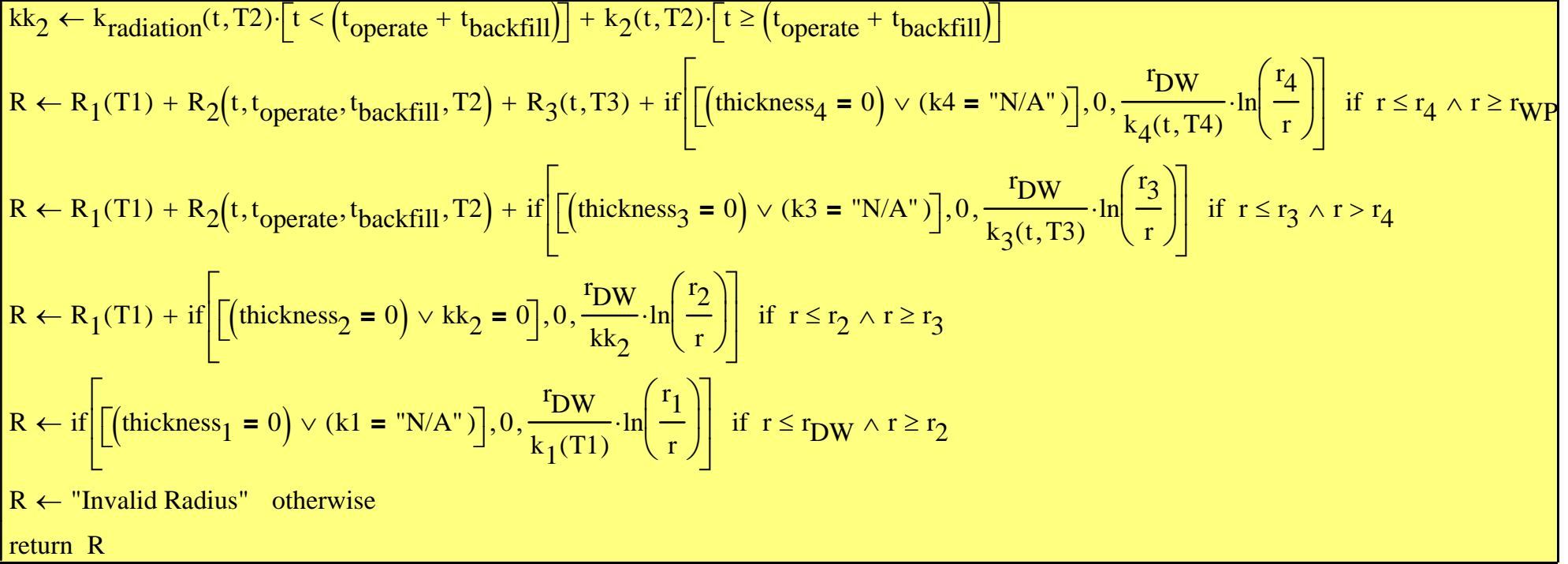 \\
\hline
\end{tabular}

$\mathrm{R}_{\text {continuous }}\left(5 \cdot \mathrm{yr}, \mathrm{r}_{\mathrm{WP}}, 373.15 \cdot \mathrm{K}, 373.15 \cdot \mathrm{K}, 373.15 \cdot \mathrm{K}, 373.15 \cdot \mathrm{K}\right)=2.169 \cdot \frac{\mathrm{m}^{2} \cdot \mathrm{K}}{\mathrm{W}} \quad \mathrm{R}_{\text {continuous }}\left(5 \cdot \mathrm{yr}, \mathrm{r}_{\mathrm{WP}}, 473.15 \cdot \mathrm{K}, 373.15 \cdot \mathrm{K}, 373.15 \cdot \mathrm{K}, 373.15 \cdot \mathrm{K}\right)=2.249 \cdot \frac{\mathrm{m}^{2} \cdot \mathrm{K}}{\mathrm{W}}$

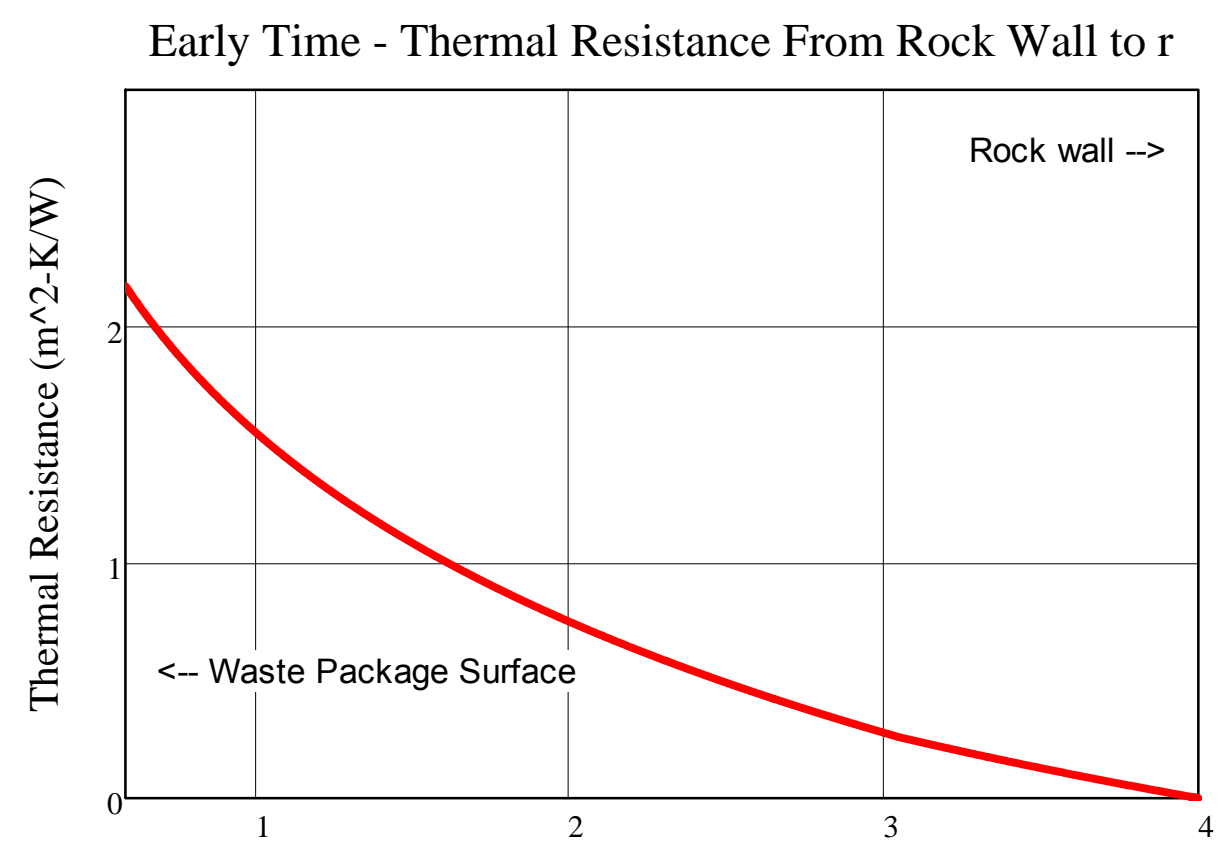

Radial Location Within the EBS (m)

— Thermal resistance prior to closure
$\mathrm{r}_{\mathrm{DW}}=4 \mathrm{~m}$

$\mathrm{r}_{1}=4 \mathrm{~m} \quad$ EBS_name $1=$ "Salt Layer 4" $\quad$ EBS_material $1=$ = Intact Salt $100^{\circ} \mathrm{C}$ "

$\mathrm{r}_{2}=3.048 \mathrm{~m} \quad$ Note that for "open modes", the backfill hasn't been emplaced at early time, and EBS-2 is only radiation.

$\mathrm{r}_{3}=2.227 \mathrm{~m} \quad$ EBS_name $_{3}=$ "Salt Layer 2" EBS_material $3=$ = "75\% Intact Salt at T3 ${ }^{\circ} \mathrm{C} "$

$\mathrm{r}_{4}=1.406 \mathrm{~m} \quad$ EBS_name ${ }_{4}=$ "Salt Layer EBS_material ${ }_{4}=$ "75\% Intact Salt at $\mathrm{T} 4^{\circ} \mathrm{C} "$

$\mathrm{r}_{\mathrm{WP}}=0.585 \mathrm{~m}$

$\mathrm{R}_{1}(373.15 \cdot \mathrm{K})=0.258 \cdot \frac{\mathrm{m}^{2} \cdot \mathrm{K}}{\mathrm{W}} \quad \mathrm{R}_{2}\left(5 \cdot \mathrm{yr}, \mathrm{t}_{\text {operate }}, \mathrm{t}_{\text {backfill }}, 373.15 \cdot \mathrm{K}\right)=0.363 \cdot \frac{\mathrm{m}^{2} \cdot \mathrm{K}}{\mathrm{W}}$

$\mathrm{R}_{3}(5 \cdot \mathrm{yr}, 373.15 \cdot \mathrm{K})=0.532 \cdot \frac{\mathrm{m}^{2} \cdot \mathrm{K}}{\mathrm{W}} \quad \mathrm{R}_{4}(5 \cdot \mathrm{yr}, 373.15 \cdot \mathrm{K})=1.015 \cdot \frac{\mathrm{m}^{2} \cdot \mathrm{K}}{\mathrm{W}}$

$\mathrm{R}_{\text {Total }}(5 \mathrm{yr}, 373.15 \cdot \mathrm{K}, 373.15 \cdot \mathrm{K}, 373.15 \cdot \mathrm{K}, 373.15 \cdot \mathrm{K})=2.169 \cdot \frac{\mathrm{m}^{2} \cdot \mathrm{K}}{\mathrm{W}}$ 


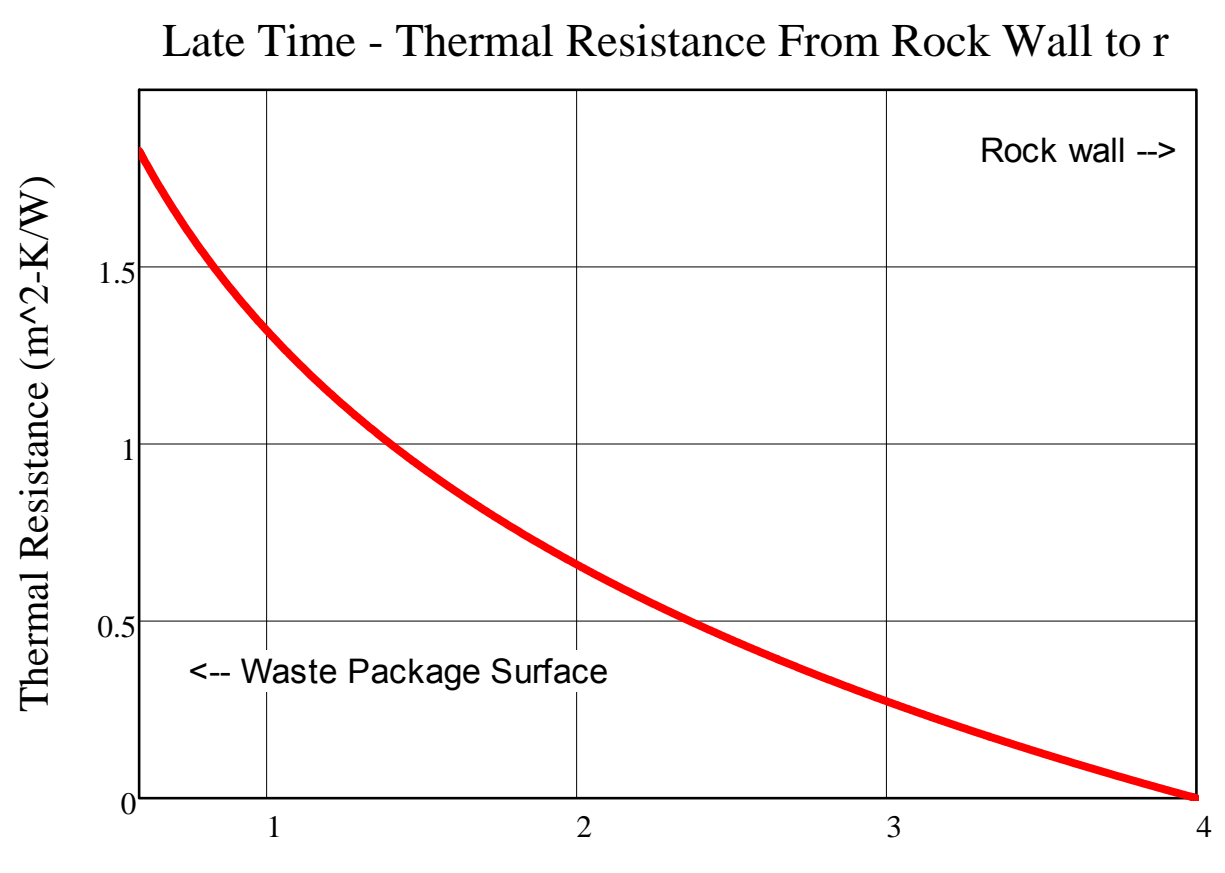

Radial Location Within the EBS (m)

— Thermal resistance prior to closure
$\mathrm{r}_{\mathrm{DW}}=4 \mathrm{~m}$

$\mathrm{r}_{1}=4 \mathrm{~m} \quad$ EBS_name $_{1}=$ "Salt Layer 4" $\quad$ EBS_material ${ }_{1}=$ "Intact Salt $100^{\circ} \mathrm{C} "$

$\mathrm{r}_{2}=3.048 \mathrm{~m}$ EBS_name $2=$ "Salt Layer 3" EBS_material $2=$ "75\% Intact Salt at $\mathrm{T}^{\circ} \mathrm{C}^{\mathrm{C}}$

$\mathrm{r}_{3}=2.227 \mathrm{~m} \quad$ EBS_name $_{3}=$ "Salt Layer 2" $\quad$ EBS_material ${ }_{3}=$ "75\% Intact Salt at T3 ${ }^{\circ} \mathrm{C} "$

$\mathrm{r}_{4}=1.406 \mathrm{~m} \quad$ EBS_name ${ }_{4}=$ "Salt Layer EBS_material ${ }_{4}=$ "75\% Intact Salt at $\mathrm{T} 4^{\circ} \mathrm{C} "$

${ }^{r} \mathrm{WP}=0.585 \mathrm{~m}$

$\mathrm{R}_{1}(373.15 \cdot \mathrm{K})=0.258 \cdot \frac{\mathrm{m}^{2} \cdot \mathrm{K}}{\mathrm{W}} \quad \mathrm{R}_{2}\left(1000 \cdot \mathrm{yr}, \mathrm{t}_{\text {operate }}, \mathrm{t}_{\text {backfill }}, 373.15 \cdot \mathrm{K}\right)=0.298 \cdot \frac{\mathrm{m}^{2} \cdot \mathrm{K}}{\mathrm{W}}$

$\mathrm{R}_{3}(1000 \cdot \mathrm{yr}, 373.15 \cdot \mathrm{K})=0.437 \cdot \frac{\mathrm{m}^{2} \cdot \mathrm{K}}{\mathrm{W}} \quad \mathrm{R}_{4}(1000 \cdot \mathrm{yr}, 373.15 \cdot \mathrm{K})=0.834 \cdot \frac{\mathrm{m}^{2} \cdot \mathrm{K}}{\mathrm{W}}$

$\mathrm{R}_{\text {Total }}(1000 \mathrm{yr}, 373.15 \cdot \mathrm{K}, 373.15 \cdot \mathrm{K}, 373.15 \cdot \mathrm{K}, 373.15 \cdot \mathrm{K})=1.828 \cdot \frac{\mathrm{m}^{2} \cdot \mathrm{K}}{\mathrm{W}}$

\section{INPUT 6 = WASTE FORM DATA}

Input_6 := READEXCEL(file, concat(sheet, "A35:B38" ))

Input_6 = $\left(\begin{array}{cc}\text { "Waste form short name" } & \text { "UOX-40" } \\ \text { "Waste form type" } & \text { "Assembly" } \\ \text { "Waste package capacity" } & 12 \\ \text { "Waste package length, m" } & 5\end{array}\right)$

WF_name := Input_6 $1,2=$ "UOX-40"

WF_type $:=$ Input_6 ${ }_{2,2}=$ "Assembly"

WP_cap := Input $\_6_{3,2}=12$

WP_length := Input_ $64,2 \cdot \mathrm{m}=5 \mathrm{~m}$

\section{Outside of the liner}

$\mathrm{A}_{1}:=2 \cdot \pi \cdot \mathrm{r}_{1} \cdot \mathrm{WP} \_$length $=125.66 \mathrm{~m}^{2}$

$\mathrm{A}_{\mathrm{DW}}:=2 \cdot \pi \cdot \mathrm{r}_{\mathrm{DW}} \cdot$ WP_length $=125.664 \mathrm{~m}^{2}$
Outside of the backfill Outside of the envelope

$\mathrm{A}_{2}:=2 \cdot \pi \cdot \mathrm{r}_{2} \cdot \mathrm{WP} \_$length $=95.76 \mathrm{~m}^{2} \quad \mathrm{~A}_{3}:=2 \cdot \pi \cdot \mathrm{r}_{3} \cdot \mathrm{WP} \_$length $=69.96 \mathrm{~m}^{2}$
Outside of the buffer

$\mathrm{A}_{4}:=2 \cdot \pi \cdot \mathrm{r}_{4} \cdot \mathrm{WP} \_$length $=44.17 \mathrm{~m}^{2}$

$A_{\text {WP }}:=2 \cdot \pi \cdot r_{\text {WP }} \cdot \mathrm{WP}_{-}$length $=18.378 \mathrm{~m}^{2}$ 


\section{Rock wall or cementitious liner emissivity $\quad \varepsilon_{\text {wall }}=0.9$}

Reference for radiation heat transfer coefficient, $\mathrm{h}_{\mathrm{rad}}$, is from Incropera and DeWitt, Table 13.3 for concentric infinite cylinders (based on the inner surface as the heat source), and is also referenced in the YMP Ventilation Model and Analysis Report, ANL-EBS-MD-000030 REV 04, Oct. 2004, page 6-8.
$\mathrm{h}_{\text {rad_infinite }}\left(\mathrm{r}_{\mathrm{i}}, \mathrm{r}_{\mathrm{o}}, \varepsilon_{\mathrm{i}}, \varepsilon_{\mathrm{o}}\right):=\frac{\sigma}{\frac{1}{\varepsilon_{\mathrm{i}}}+\left(\frac{1-\varepsilon_{\mathrm{o}}}{\varepsilon_{\mathrm{o}}}\right) \cdot \frac{\mathrm{r}_{\mathrm{i}}}{\mathrm{r}_{\mathrm{o}}}}$
$\mathrm{h}_{\text {rad_infinite }}\left({ }_{\mathrm{WP}}, \mathrm{r}_{\mathrm{DW}}, \varepsilon_{\mathrm{WP}}, \varepsilon_{\mathrm{wall}}\right)=3.369 \times 10^{-8} \cdot \frac{\mathrm{W}}{2}$
radiation betwen the liner and the envelope (both metal
Usage is $Q$ in watts $=h^{*} A_{i}^{*}\left(T_{i}^{\wedge} 4-T_{0}^{\wedge} 4\right)$
surfaces) use $r_{2}$ and $r_{3}$, and assume the same
emissivity for both surfaces.
$\mathrm{Q}_{\text {rad_infinite }}\left(\mathrm{r}_{\mathrm{i}}, \mathrm{r}_{\mathrm{O}}, \varepsilon_{\mathrm{i}}, \varepsilon_{\mathrm{O}}, \mathrm{L}, \mathrm{T}_{\text {cold }}, \mathrm{T}_{\text {hot }}\right):=\mathrm{h}_{\text {rad_infinite }}\left(\mathrm{r}_{\mathrm{i}}, \mathrm{r}_{\mathrm{o}}, \varepsilon_{\mathrm{i}}, \varepsilon_{\mathrm{O}}\right) \cdot\left(2 \cdot \pi \cdot \mathrm{r}_{\mathrm{i}} \cdot \mathrm{L}\right)\left(\mathrm{T}_{\text {hot }}{ }^{4}-\mathrm{T}_{\text {cold }}{ }^{4}\right) \quad \mathrm{Q}_{\text {rad_infinite }}\left(\mathrm{r}_{3}, \mathrm{r}_{2}, \varepsilon_{\mathrm{WP}}, \varepsilon_{\text {wall }}\right.$,WP_length, 300·K, 600.K) $=2.758 \times 10^{5} \mathrm{~W}$
$\mathrm{Q}_{\mathrm{L} \_ \text {rad_infinite }}\left(\mathrm{r}_{\mathrm{i}}, \mathrm{r}_{\mathrm{O}}, \varepsilon_{\mathrm{i}}, \varepsilon_{\mathrm{O}}, \mathrm{T}_{\text {cold }}, \mathrm{T}_{\text {hot }}\right):=\mathrm{h}_{\text {rad_infinite }}\left(\mathrm{r}_{\mathrm{i}}, \mathrm{r}_{\mathrm{O}}, \varepsilon_{\mathrm{i}}, \varepsilon_{\mathrm{O}}\right) \cdot\left(2 \cdot \pi \cdot \mathrm{r}_{\mathrm{i}}\right)\left(\mathrm{T}_{\text {hot }}{ }^{4}-\mathrm{T}_{\text {cold }}{ }^{4}\right) \quad \mathrm{Q}_{\mathrm{L} \_ \text {rad_infinite }}\left(\mathrm{r}_{3}, \mathrm{r}_{2}, \varepsilon_{\mathrm{WP}}, \varepsilon_{\mathrm{wall}}, 300 \cdot \mathrm{K}, 600 \cdot \mathrm{K}\right)=5.515 \times 10^{4} \cdot \frac{\mathrm{W}}{\mathrm{m}}$

Heat transfer by radiation from NIRAS/ONDRAF December 2005 Report: Eef Weetjens and Xavier Sillen; Thermal analysis of the Supercontainer concept $2 D$ axisymmetric heat transport calculations, Section 6.4.3. Pg 34, equation 29.

$\mathrm{Q}_{\mathrm{L} \_ \text {infinite }}\left(\mathrm{r}_{\mathrm{i}}, \mathrm{r}_{\mathrm{O}}, \varepsilon_{\mathrm{i}}, \varepsilon_{\mathrm{O}}, \mathrm{T}_{\text {cold }}, \mathrm{T}_{\text {hot }}\right):=\frac{2 \pi \sigma \cdot\left(\mathrm{T}_{\text {hot }}{ }^{4}-\mathrm{T}_{\text {cold }}{ }^{4}\right)}{\frac{1-\varepsilon_{\mathrm{i}}}{\varepsilon_{\mathrm{i}} \cdot \mathrm{r}_{\mathrm{i}}}+\frac{1}{\mathrm{r}_{\mathrm{i}}}+\frac{1-\varepsilon_{0}}{\varepsilon_{0} \cdot \mathrm{r}_{\mathrm{O}}}} \quad \mathrm{Q}_{\mathrm{L} \_ \text {infinite }}\left(\mathrm{r}_{3}, \mathrm{r}_{2}, \varepsilon_{\mathrm{WP}}, \varepsilon_{\text {wall }}, 300 \cdot \mathrm{K}, 600 \cdot \mathrm{K}\right)=5.515 \times 10^{4} \cdot \frac{\mathrm{W}}{\mathrm{m}}$ 


\section{INPUT 7 = PARAMETRIC STUDY VARIABLE INPUT DATA}

Input_7 := READEXCEL(file, concat(sheet, "F29:F41"))

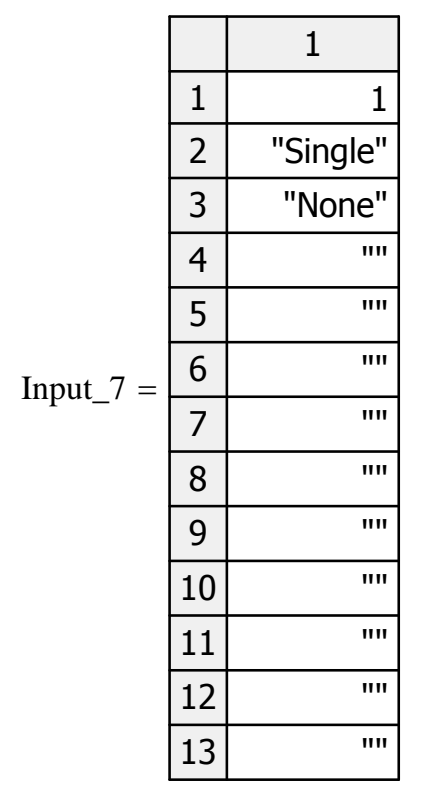

PARAMETRIC STUDIES OF "BACKFLLTHERMAL CONDUCTIVIY" NOT ALLOWED FOR TEMPERATURE AND TIME-DEPENDENT THERMAL PROPERTY ANALYSES. THEREFORE, PARAMETER TYPE IS RESET TO "SINGLE",

Cases := Input_7 ${ }_{1}$ if Input_7 ${ }_{2}$ \# "Backfill Thermal Conductivity"

1 otherwise

Parameter := |"Single" if Input_ $7{ }_{2}=$ "Backfill Thermal Conductivity"

Input $7{ }_{2}$ otherwise

Parameter_units := Input_7 ${ }_{3}=$ "None"

ij $:=1$.. Cases

Parameter_data ${ }_{\mathrm{ij}}:=$ Input_$_{\mathrm{ij}+3}$

Parameter_description $_{\mathrm{ij}}:=\mid$ "Single Base Case" if Cases $=1$

concat[num2str[ $\left[\right.$ Input_7 $\left.{ }_{(\mathrm{j} j+3)}\right]$, ," " , Input_7 3$]$ otherwise

INPUT 8 = DECAY HEAT INPUT DATA PER UNIT SOURCE (ASSEMBLY OR CANISTER):

Input_8_size := READEXCEL(file, concat(sheet, "C43" )) Input_8_size 1 = $58 \quad$ Decay_heat_range := concat["A43:B", num2str((Input_8_size $1+42))]=$ "A43:B100"

Input_8 := READEXCEL(file, concat(sheet, Decay_heat_range))

Time_out_of_Reactor := Input_ $8{ }^{\langle 1\rangle} \cdot \mathrm{yr}$

\begin{tabular}{|r|r|r|}
\hline & \multicolumn{1}{|c|}{1} & \multicolumn{1}{c|}{2} \\
\hline 1 & 5 & $1.028 \cdot 10^{3}$ \\
\hline 2 & 5.1 & $1.011 \cdot 10^{3}$ \\
\hline 3 & 5.5 & 949.125 \\
\hline 4 & 5.75 & 916.671 \\
\hline 5 & 6 & 887.984 \\
\hline 6 & 8 & 742.948 \\
\hline 7 & 10 & 670.028 \\
\hline 8 & 11.5 & 634.239 \\
\hline 9 & 15 & 576.929 \\
\hline 10 & 20 & $\ldots$ \\
\hline
\end{tabular}

Decay_Heat_per_Cnt :=Input_8 ${ }^{\langle 2\rangle} \cdot \mathrm{W}$

Time_out_of_Reactor $=$

\begin{tabular}{|r|r|}
\hline & \multicolumn{1}{|r|}{1} \\
\hline 1 & 5 \\
\hline 2 & 5.1 \\
\hline 3 & 5.5 \\
\hline 4 & 5.75 \\
\hline 5 & 6 \\
\hline 6 & 8 \\
\hline 7 & 10 \\
\hline 8 & 11.5 \\
\hline 9 & 15 \\
\hline 10 & $\ldots$ \\
\hline
\end{tabular}

Decay_Heat_per_Cnt

\begin{tabular}{|r|r|}
\hline & \multicolumn{1}{|c|}{1} \\
\hline 1 & $1.028 \cdot 10^{3}$ \\
\hline 2 & $1.011 \cdot 10^{3}$ \\
\hline 3 & 949.125 \\
\hline 4 & 916.671 \\
\hline 5 & 887.984 \\
\hline 6 & 742.948 \\
\hline 7 & 670.028 \\
\hline 8 & 634.239 \\
\hline 9 & 576.929 \\
\hline 10 & $\ldots$ \\
\hline
\end{tabular}


$\mathrm{Q}(\mathrm{t})$ := interp(cspline(Time_out_of_Reactor,Decay_Heat_per_Cnt),Time_out_of_Reactor, Decay_Heat_per_Cnt,t)

Ventilation efficiency for open systems is $\quad V_{\text {eff }}=0$ between $t_{\text {store }}$ and $t_{\text {operate }}$

FUNCTION DEFINITION FOR ONE OUTPUT FILE

FORMULAS FOR CALCULATING THE TRANSIENT DRIFT WALL TEMPERATURE:

Central waste package:

$\mathrm{Q}_{\mathrm{L}_{\text {}} \mathrm{wp}}\left(\mathrm{t}, \mathrm{t}_{\text {store }}, \mathrm{t}_{\text {operate }}, \mathrm{WP}_{-}\right.$cap $):=\frac{\mathrm{Q}(\mathrm{t}) \cdot \mathrm{WP} \_ \text {cap }}{\text { WP_length }} \cdot\left[1-1 \cdot\left(\mathrm{t} \leq \mathrm{t}_{\text {store }}\right)\right] \cdot\left[1-\mathrm{V}_{\text {eff }} \cdot\left(\mathrm{t} \leq \mathrm{t}_{\text {operate }}\right)\right]$

$$
\mathrm{Q}_{\mathrm{L}_{-} w \mathrm{w}}\left(55 \cdot \mathrm{yr}, \mathrm{t}_{\text {store }}, \mathrm{t}_{\text {operate }}, 12\right)=709.459 \cdot \frac{\mathrm{W}}{\mathrm{m}}
$$

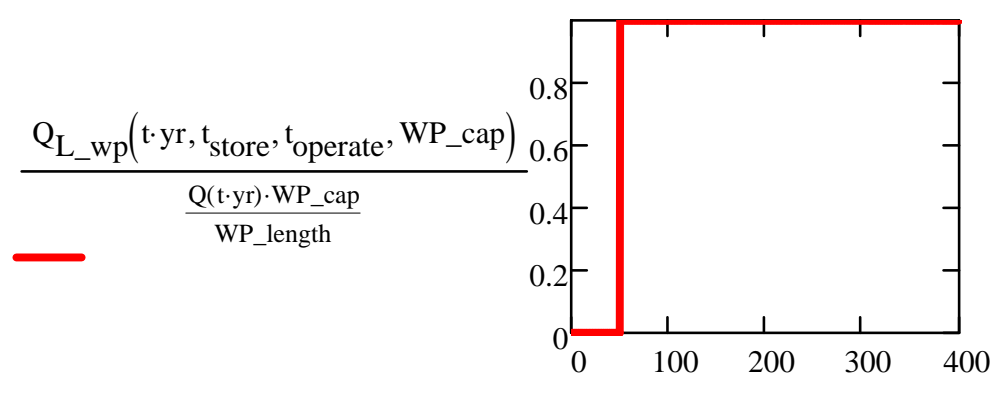

Note - added $\mathrm{r}_{\mathrm{DW}}$ as a function parameter to allow calculations at additional compliance points inside the rock, where $\mathrm{r}_{\mathrm{DW}}$ would be replaced with new radius value.

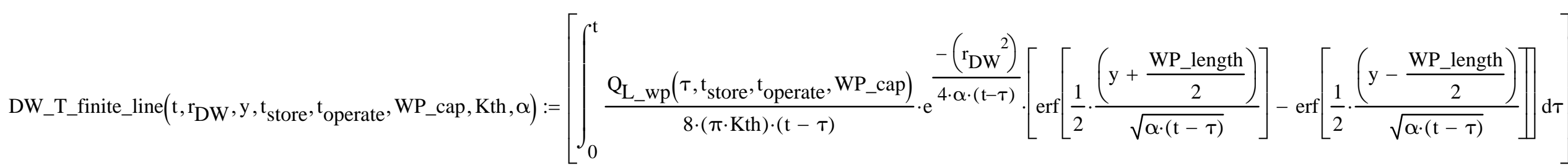


Adjacent drifts:

$\mathrm{Q}_{\mathrm{L} \_ \text {avg }}\left(\mathrm{t}, \mathrm{t}_{\text {store }}, \mathrm{t}_{\text {operate }}, \mathrm{WP}_{\text {_cap }}, \mathrm{WP} \_\right.$spacing $):=\frac{\mathrm{Q}(\mathrm{t}) \cdot \mathrm{WP} \_ \text {cap }}{\mathrm{WP}_{\text {spacing }}} \cdot\left[1-1 \cdot\left(\mathrm{t} \leq \mathrm{t}_{\text {store }}\right)\right] \cdot\left[1-\mathrm{V}_{\text {eff }} \cdot(\mathrm{t} \leq \mathrm{t}\right.$ operate $\left.)\right]$

Note - added $r_{D W}$ as a function parameter to allow calculations at additional compliance points inside the rock, where $r_{D W}$ would be replaced with new radius value.

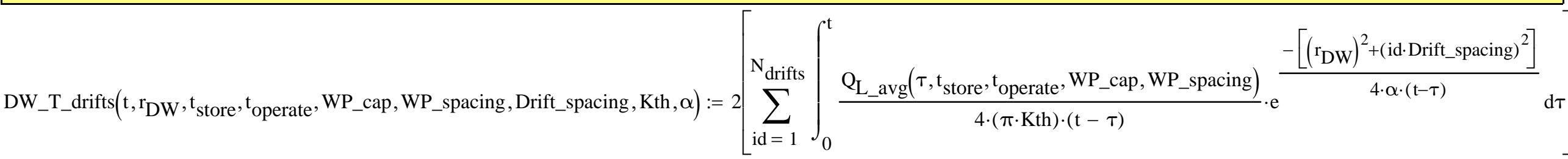

Adjacent waste packages:

$\mathrm{Q}_{\mathrm{wp}}\left(\mathrm{t}, \mathrm{t}_{\text {store }}, \mathrm{t}_{\text {operate }}, \mathrm{WP} \_\right.$cap $):=\mathrm{Q}(\mathrm{t}) \mathrm{WP} \_$cap $\cdot\left[1-1 \cdot\left(\mathrm{t} \leq \mathrm{t}_{\text {store }}\right)\right] \cdot\left[1-\mathrm{V}_{\text {eff }} \cdot\left(\mathrm{t} \leq \mathrm{t}_{\text {operate }}\right)\right]$

Note - added $\mathrm{r}_{\mathrm{DW}}$ as a function parameter to allow calculations at additional compliance points inside the rock, where $\mathrm{r}_{\mathrm{DW}}$ would be replaced with new radius value.

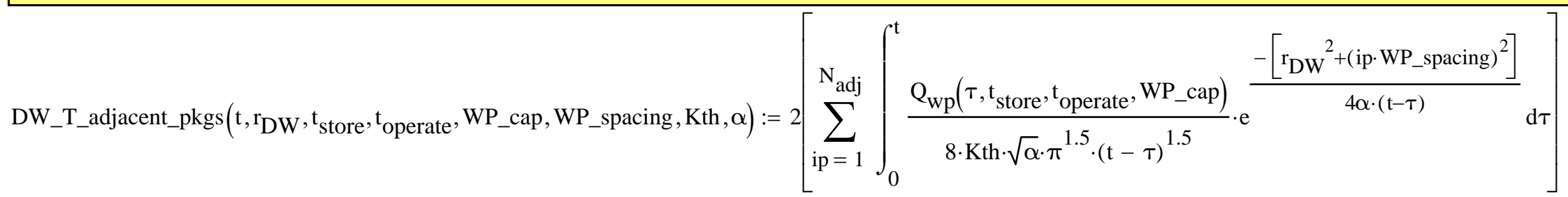

This command specifies two rows of column headings for output paramenter sensitivity runs

OuffileName := file = "DSEF R3.0C_2013Jul29_HRG-Salt_UOX-40_Enclosed mode variable kth_Case-Kth-1.xlsm"

Out_sheet := "Thermal-Analytical Output!"

This section specifies the column headings for output sensitivity studies

Cases $=1 \quad$ Read in from Thermal-Analytical sheet in DSEF (Inputs_7)

$\mathrm{i}:=1$.. Cases

Parameter_vector : : $\mid$ "Base Case" if Cases $=1$

concat(Parameter, " ", Parameter_description ${ }_{\mathrm{i}}$ ) otherwise 
Parameter_vector $=($ "Base Case" $)$

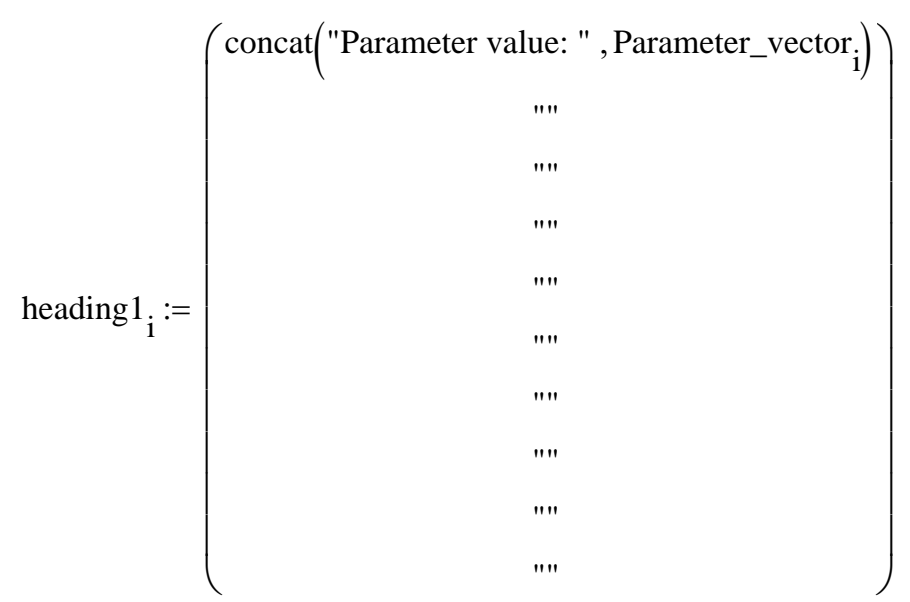

heading2 := $\left(\begin{array}{c}\text { "TooR (yr)" } \\ \text { "Wall } \Delta \text { T Central Line Src" } \\ \text { "Wall } \Delta \text { T Adj Drifts" } \\ \text { "Wall } \Delta \text { T Adj Pkgs" } \\ \text { "Compliance Point 2, C" } \\ \text { "Rock Wall Temp, C" } \\ \text { "EBS } 1 \text { inner Temp, C" } \\ \text { "EBS } 2 \text { inner Temp, C" } \\ \text { "EBS } 3 \text { inner Temp, C" } \\ \text { "Waste Pkg Temp, C" }\end{array}\right)$

heading $1_{\mathrm{i}}:=$ heading $_{\mathrm{i}}^{\mathrm{T}} \quad$ heading2 $:=$ heading2 $^{\mathrm{T}}$

Title_array $y_{\mathrm{i}}:=\operatorname{stack}\left(\right.$ heading $1_{\mathrm{i}}$, heading2)

Title_array $_{2}=\boldsymbol{\prime}$

For-Loop analysis returning the output time, three temperature contribution terms, and six temperatures
length(Parameter_data) $=1$
${ }^{\mathrm{r}} \mathrm{DW}=4 \mathrm{~m}$
$\mathrm{t}_{\text {store }}=50 \cdot \mathrm{yr}$
$\mathrm{t}_{\text {operate }}=50 \cdot \mathrm{yr}$
$\mathrm{t}_{\mathrm{vent}}=0 \cdot \mathrm{yr}$
Changed j vector to Parameter data, Inserted row 2
in row 5 changed to $\mathrm{k}_{\text {radiation }}$ and $\mathrm{k}_{2}$ from $\mathrm{k}_{2}$ and $\mathrm{k}_{\text {backfil }}$

$\mathrm{t}_{\text {closure }}=50 \cdot \mathrm{yr}$

Removed loop on "j", added r $\mathrm{DW}_{\text {into }}$ DW_T functions.

Note for enclosed modes $\mathrm{k}_{\text {radiation }}=$

DDED CORRECTION FOR PARAMETRIC $t_{\text {closure }}$

eplaced $t_{\text {closure }}$ with $\left(t_{\text {operate }}+t_{\text {backfill }}\right.$ 
outdata( $\left(\mathrm{r}_{\mathrm{DW}},{ }_{\mathrm{CP}}\right.$, $\mathrm{t}_{\text {store }}, \mathrm{t}_{\text {operate }}, \mathrm{WP}$ _cap, WP_spacing, Drift_spacing, Kth, $\left.\alpha\right):=\mid$ for $\mathrm{i} \in 1$.. Counter +1

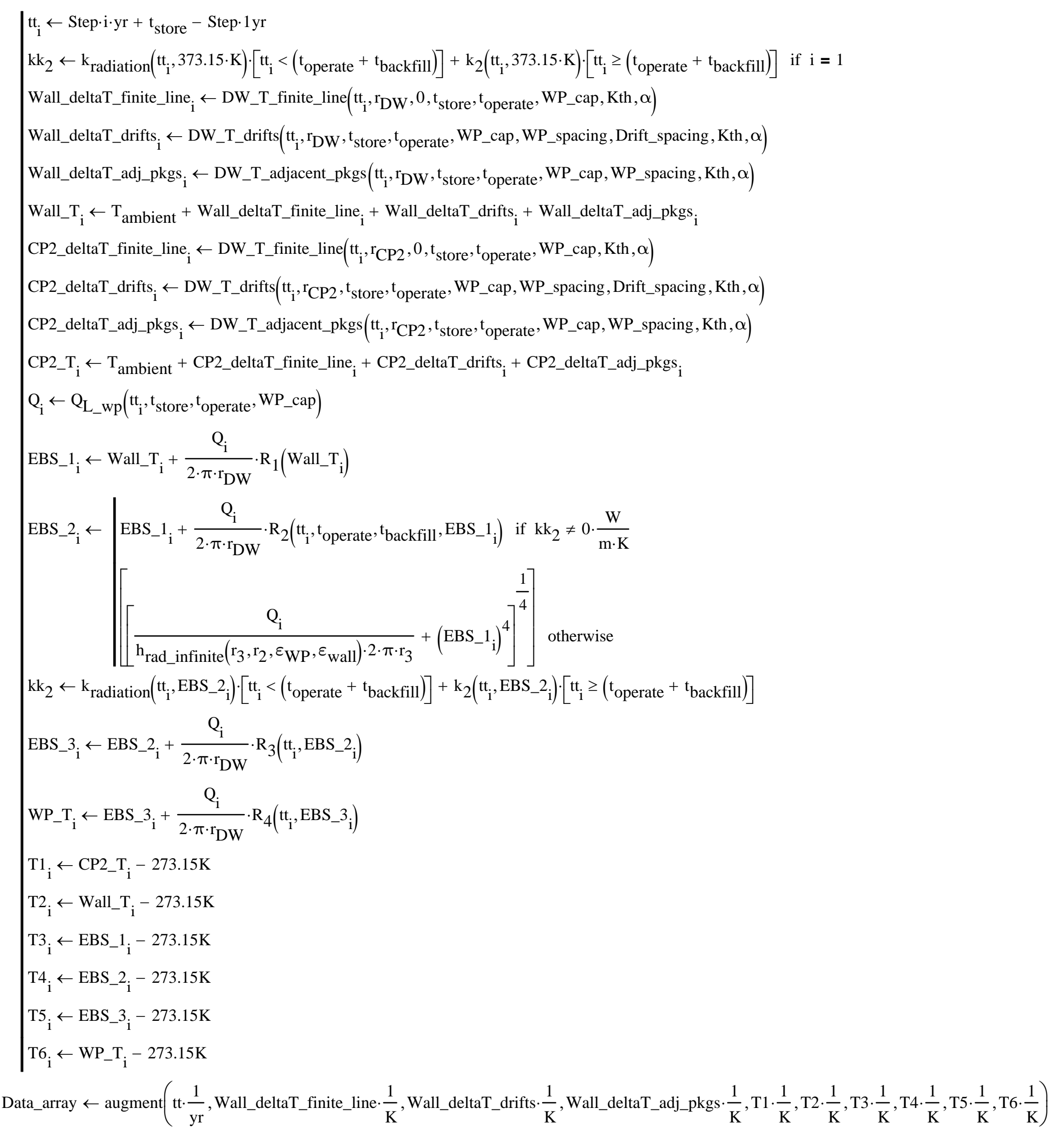




\begin{abstract}
$\mathrm{jij}:=1$.. Cases $\quad$ Cases $=1$
THEREFORE, PARAMETER TYPE IS RESET TO "SINGLE"
\end{abstract}

Temp_array $_{\mathrm{jij}}:=\mid$ outdata $\left({ }_{\mathrm{DW}},{ }_{\mathrm{CP}}\right.$, ${ }_{\text {store }},{ }^{\mathrm{t}}$ operate, WP_cap, WP_spacing, Drift_spacing, Kth, $\left.\alpha\right)$ if Parameter = "Single"

outdata $\left(\mathrm{r}_{\mathrm{DW}},{ }_{\mathrm{C}} \mathrm{C} 2, \mathrm{t}_{\text {store }}, \mathrm{t}_{\text {operate }}\right.$, WP_cap, WP_spacing, $\left.\mathrm{X}_{\mathrm{jjj}} \cdot \mathrm{m}, \mathrm{Kth}, \alpha\right)$ if Parameter $=$ "Drift Spacing"

outdata $\left({ }_{\mathrm{DW}},{ }_{\mathrm{C}} \mathrm{r}_{2}, \mathrm{t}_{\text {store }}, \mathrm{t}_{\text {operate }}, \mathrm{WP} \_\mathrm{Cap}, \mathrm{X}_{\mathrm{jjj}} \cdot \mathrm{m}\right.$, Drift_spacing, Kth, $\left.\alpha\right)$ if Parameter $=$ "WP Spacing"

outdata $\left({ }_{\mathrm{DW}}, \mathrm{r}_{\mathrm{CP} 2}, \mathrm{X}_{\mathrm{jjj}} \cdot \mathrm{yr}, \mathrm{t}_{\text {operate }}, \mathrm{WP}_{\text {_cap, }}\right.$ WP_spacing, Drift_spacing, Kth, $\left.\alpha\right)$ if Parameter $=$ "Storage Time"

outdata $\left({ }_{\mathrm{DW}},{ }_{\mathrm{CP} 2}, \mathrm{t}_{\text {store }}, \mathrm{t}_{\text {store }}+\mathrm{X}_{\mathrm{iji}} \cdot \mathrm{yr}, \mathrm{WP} \_\right.$cap, WP_spacing, Drift_spacing, Kth, $\left.\alpha\right)$ if Parameter $=$ "Ventilation Duration"

outdata $\left(\mathrm{r}_{\mathrm{DW}},{ }_{\mathrm{CP} 2}, \mathrm{t}_{\text {store }},{ }_{\text {operate }}\right.$, WP_cap, WP_spacing, Drift_spacing, $\left.\mathrm{X}_{\mathrm{jjj}} \cdot \frac{\mathrm{W}}{\mathrm{m} \cdot \mathrm{K}}, \alpha\right)$ if Parameter $=$ "Rock Conductivity"

"Undefined" otherwise

Temp_array 1 := outdata $\left({ }_{\mathrm{DW}},{ }_{\mathrm{CP}}, \mathrm{t}_{\text {store }},{ }_{\text {operate }}\right.$, WP_cap, WP_spacing, Drift_spacing, Kth, $\left.\alpha\right)$

File_array $_{\mathrm{jjj}}:=\operatorname{stack}\left(\right.$ Title_array $_{\mathrm{jjj}}$, Temp_array $\left.{ }_{\mathrm{jjj}}\right)$

\begin{tabular}{|c|c|c|c|c|c|c|}
\hline & 1 & 2 & 3 & 4 & 5 & 6 \\
\hline 1 & "Parameter value: Base Case" & "'"' & "'" & "'"' & "'"' & "'"' \\
\hline 2 & "TooR (yr)" & "Wall $\Delta \mathrm{T}$ Central Line Src" & "Wall $\Delta \mathrm{T}$ Adj Drifts" & "Wall $\Delta \mathrm{T}$ Adj Pkgs" & "Compliance Point 2, C" & "Rock Wall Temp, C" \\
\hline 3 & 50 & 0 & 0 & 0 & 27.5 & 27.5 \\
\hline 4 & 55 & 10.991 & 7.223 & 3.07 & 45.86 & 48.785 \\
\hline 5 & 60 & 10.687 & 12.867 & 4.27 & 52.544 & 55.323 \\
\hline 6 & 65 & 10.188 & 16.843 & 4.835 & 56.761 & 59.367 \\
\hline 7 & 70 & 9.666 & 19.727 & 5.112 & 59.55 & 62.005 \\
\hline 8 & 75 & 9.166 & 21.846 & 5.232 & 61.43 & 63.745 \\
\hline 9 & 80 & 8.695 & 23.415 & 5.259 & 62.685 & 64.868 \\
\hline 10 & 85 & 8.263 & 24.576 & 5.229 & 63.499 & 65.568 \\
\hline 11 & 90 & 7.871 & 25.432 & 5.163 & 63.997 & 65.966 \\
\hline 12 & 95 & 7.505 & 26.048 & 5.082 & 64.261 & 66.134 \\
\hline 13 & 100 & 7.171 & 26.493 & 4.977 & 64.355 & 66.141 \\
\hline 14 & 105 & 6.864 & 26.797 & 4.872 & 64.327 & 66.033 \\
\hline 15 & 110 & 6.584 & 26.984 & 4.759 & 64.193 & 65.827 \\
\hline 16 & 115 & 6.328 & 27.091 & 4.652 & 64.021 & $\ldots$ \\
\hline
\end{tabular}

$\nabla$

Mathcad Component of DSEF 3.0
LLNL-TR-629812 Rev. 1

Page 14 of 24
133 of 143 


\section{$\mathrm{iii}:=1 . .10$}

Peak_array $_{\mathrm{jjj}, \text { iii }}:=\max \llbracket\left(\text { Temp_array }_{\mathrm{jjj}}\right)^{(\text {iiii }} \rrbracket$

$$
\text { Peak_array }_{1,2}=10.991
$$

nitialize the peak value data array:

$$
\begin{aligned}
& \mathrm{i}:=1 . .6 \quad \mathrm{j}:=1 . .20 \\
& \text { Peak_values }_{\mathrm{i}, \mathrm{j}}:={ }^{\prime}="
\end{aligned}
$$

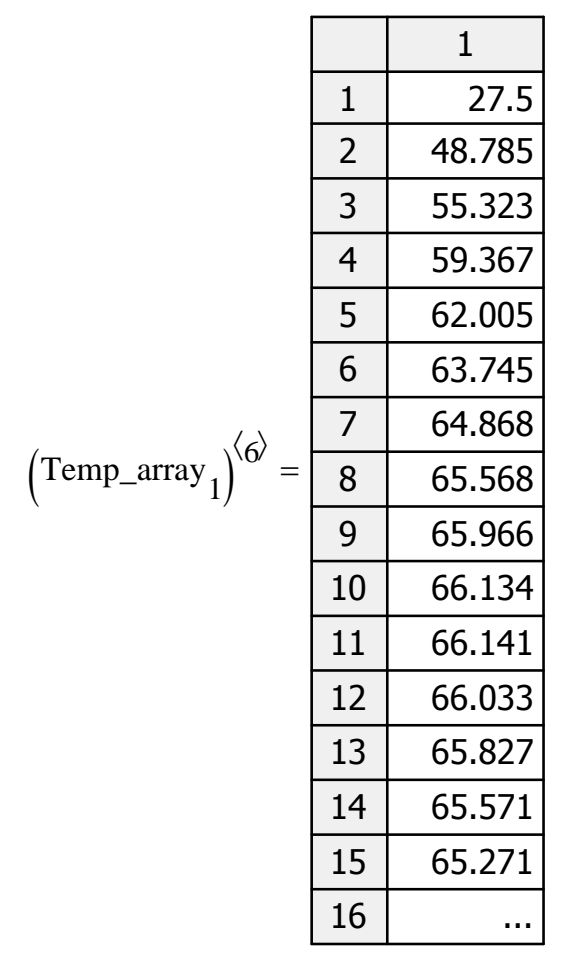

Time_array :=(Temp_array 1$)^{\langle 1\rangle}$

Peak_T $(\mathrm{m}, \mathrm{n}):=\max \left[\left(\text { Temp_array }_{\mathrm{m}}\right)^{\langle\mathrm{n}\rangle}\right]$

Peak_T $(1,5)=64.355$

Peak_time $(\mathrm{m}, \mathrm{n}):=$ lookup $\left[\right.$ Peak_T $(\mathrm{m}, \mathrm{n}),(\text { Temp_array } \mathrm{m})^{\langle\mathrm{n}\rangle}$,Time_array]

Peak_time $(1,5)=(100)$
Time_array

\begin{tabular}{|r|r|}
\hline & 1 \\
\hline 1 & 50 \\
\hline 2 & 55 \\
\hline 3 & 60 \\
\hline 4 & 65 \\
\hline 5 & 70 \\
\hline 6 & 75 \\
\hline 7 & 80 \\
\hline 8 & 85 \\
\hline 9 & 90 \\
\hline 10 & 95 \\
\hline 11 & 100 \\
\hline 12 & 105 \\
\hline 13 & 110 \\
\hline 14 & 115 \\
\hline 15 & 120 \\
\hline 16 & $\ldots$ \\
\hline
\end{tabular}

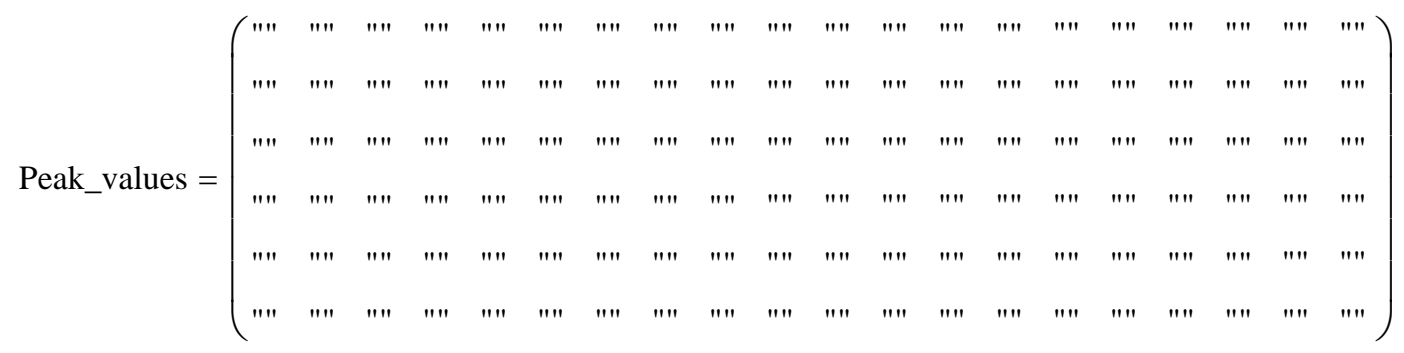

Fill in the peak temperatures and times:

$\mathrm{mj}:=1 .$. Cases $\quad \mathrm{nn}:=1 . .6$

Peak_values $_{n n, m j \cdot 2-1}:=$ Peak_T(mj, nn +4$)$

Peak_values ${ }_{n n, m j \cdot 2}:=$ Peak_time(mj, nn +4$)_{1}$

Parameter_vector ${ }^{\mathrm{T}}=($ "Base Case" $)$

$\mathrm{t}_{\text {vent }}=0 \cdot \mathrm{yr}$ 


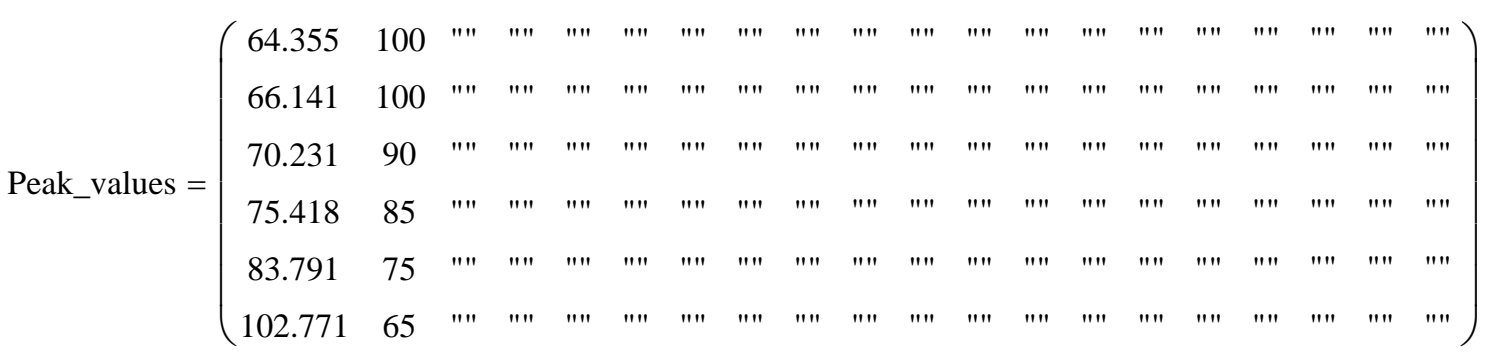

Peak_Wall_T $:=\left(\text { Peak_values }{ }^{\langle 1\rangle}\right)_{2}=66.141$

outsheet := "Thermal-Analytical Output!"

$\operatorname{rows}\left(\right.$ Temp_array $\left._{1}\right)=201 \quad$ rows $\left(\right.$ File_array $\left._{1}\right)=203 \quad$ Transient output starting row in DSEF on the Thermal-= 60

start_row := 100 end_row := start_row + rows $\left(\right.$ Temp_array $\left.{ }_{1}\right)-1=300$

NOTE - USE File_array to write to stand-alone Excel files, and Temp_array to write back to the DSEF Excel file.

transient_case_cols := $\left(\begin{array}{cc}\text { "A" } & \text { "J" } \\ \text { "L" } & \text { "U" } \\ \text { "W" } & \text { "AF" } \\ \text { "AH" } & \text { "AQ" } \\ \text { "AS" } & \text { "BB" } \\ \text { "BD" } & \text { "BM" } \\ \text { "BO" } & \text { "BX" } \\ \text { "BZ" } & \text { "CI" } \\ \text { "CK" } & \text { "CT" } \\ \text { "CV" } & \text { "DE" }\end{array}\right)$

iw $:=1$.. Cases

To write the transients for each case horizontally instead of vertically, the following location array

includes 10 columns for each case with one column separating the cases.

start_row $=100$

end_row $=300$

transient_write_range $_{\text {iw }}:=$ concat_ outsheet, $\left(\text { transient_case_cols }{ }^{\langle 1\rangle}\right)_{\text {iw }}$, num2str(start_row), $": ",\left(\text { transient_case_cols }{ }^{\langle 2\rangle}\right)_{\text {iw }}$, num2str(end_row)

transient_write_range ${ }_{2}=$

peaks_write_range := concat(outsheet, "C6:V11" ) = "Thermal-Analytical Output!C6:V11"

transient_write_range $=($ "Thermal-Analytical Output!A100:J300" $)$

Transient_size := (Counter Step $)$

Transient_size $=\left(\begin{array}{ll}200 & 5\end{array}\right)$

Transient_size_range := concat(outsheet, "B92:C92" ) = "Thermal-Analytical Output!B92:C92" 
Write_file := Write_OK $=$ "No"

OutfileName = "DSEF R3.0C_2013Jul29_HRG-Salt_UOX-40_Enclosed mode variable kth_Case-Kth-1.xlsm"

write_the_peaks(Write_file) $:=\mid \begin{aligned} & \text { write_it } \leftarrow \mid \begin{array}{l}\text { WRITEEXCEL(Peak_values, OutfileName,peaks_write_range) } \quad \text { if (Write_file = "Yes") } \vee(\text { Write_file = "YES") } \\ \text { "File written" }\end{array} \\ & \text { write_it } \leftarrow \text { "No file written" otherwise }\end{aligned}$

write_the_peaks(Write_file) $=$ "No file written"

write_the_transient_size(Write_file) $:=\|$ write_it $\leftarrow \mid \begin{aligned} & \text { WRITEEXCEL(Transient_size, OutfileName, Transient_size_range) } \quad \text { if }(\text { Write_file = "Yes" }) \vee(\text { Write_file = "YES") } \\ & \text { "File written" }\end{aligned}$ write_it $\leftarrow$ "No file written" otherwise

write_the_transient_size(Write_file) $=$ "No file written"

Write_file = "No"

Cases $=1$

iww := 1 ... Cases

NOTE - USE File_array to write to stand-alone Excel files, and Temp_array to write back to the DSEF Excel file.

write_the_transients $(\mathrm{jj}):=\mid$ write_array $\leftarrow$ Temp_array ${ }_{\mathrm{jj}}$

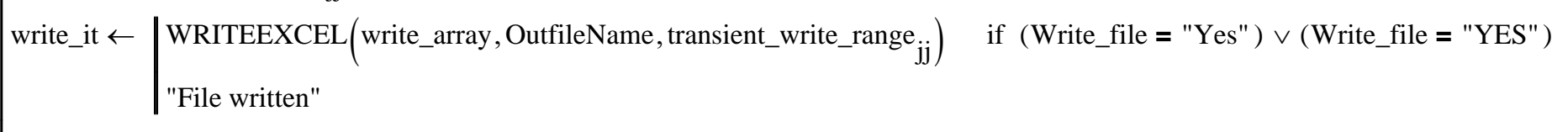

write_it $\leftarrow$ "No file written" otherwise

write_the_transients(iww) $=($ "No file written" $)$

Plot_case : $=1 \quad$ Select parametric study case to plot (default plot is for case 1)

WP_plot :=[(Temp_array $\left.\left.{ }_{\text {Plot_case }}\right)^{\langle 10\rangle}\right] \quad$ EBS3_T_plot :=[(Temp_array $\left.\left.{ }_{\text {Plot_case }}\right)^{\langle 9\rangle}\right] \quad$ EBS2_T_plot :=[(Temp_array $\left.\left.{ }_{\text {Plot_case }}\right)^{\langle 8\rangle}\right] \quad$ EBS1_T_plot :=[(Temp_array $\left.\left.{ }_{\text {Plot_case }}\right)^{\langle 7\rangle}\right] \quad$ Wall_T_plot :=[(Temp_array $\left.\left.{ }_{\text {Plot_case }}\right)^{\langle 6\rangle}\right]$

CP2_plot := $\left[\left(\text { Temp_array }_{\text {Plot_case }}\right)^{\langle 5\rangle}\right] \quad$ Delta_WPs_T_plot := $\left[\left(\text { Temp_array }_{\text {Plot_case }}\right)^{\langle 4\rangle}\right] \quad$ Delta_drifts_T_plot := $\left[\left(\text { Temp_array }_{\text {Plot_case }}\right)^{\langle 3\rangle}\right] \quad$ Delta_central_T_plot := $\left[\left(\text { Temp_array }_{\text {Plot_case }}\right)^{\langle 2\rangle}\right]$ 


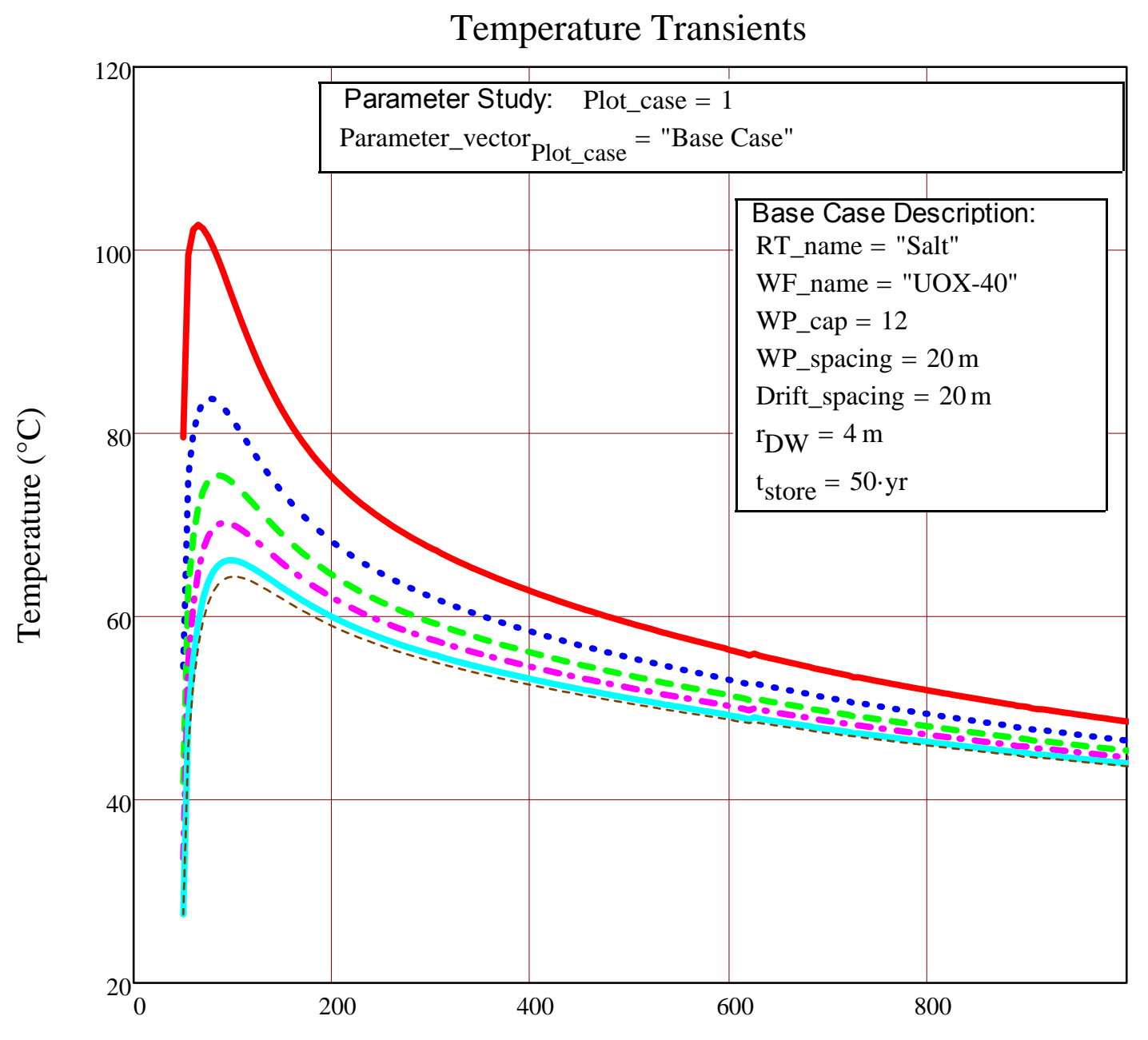

Time out of Reactor (yr)

— Waste Package Surface Temperature

.... EBS3 Temperature

- - EBS2 Temperature

-.- EBS1 Temperature

— Drift Wall Temperature

-.. Compliance point 2 Temperature

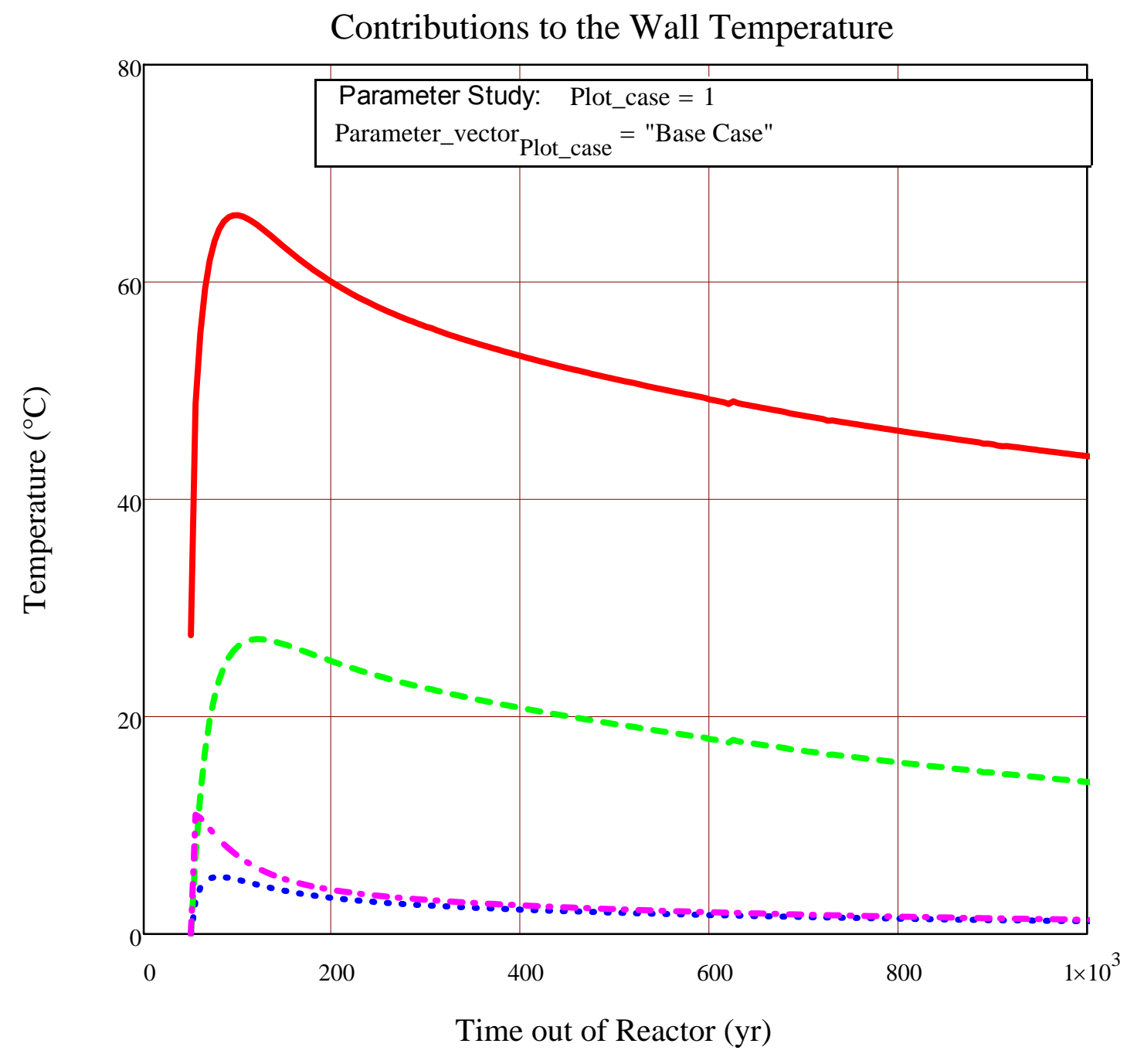

- Rock Wall Temperature (total)

.... Adjacent Waste Packages

- Adjacent Drifts / Boreholes

-. - Central Line Source 
$\mathrm{tt} \_\mathrm{rw}:=\left[(\text { Peak_values })^{\langle\text {Plot_case. } 2\rangle}\right]_{2}=100$

CP2_T_at_tt_rw : $=\left[\left(\text { Temp_array }_{\text {Plot_case }}\right)^{\langle 5\rangle}\right] \frac{\left(\frac{\left.\mathrm{tt}_{\mathrm{t}} \mathrm{rw}-\frac{\mathrm{t}_{\text {store }}}{\mathrm{yr}}\right)}{\text { Step }}+1\right.}{}=64.355$

Wall_T_at_tt_rw := $\left[\text { (Peak_values }^{\langle\text {Plot_case-2-1 }\rangle}\right]_{2}=66.141$

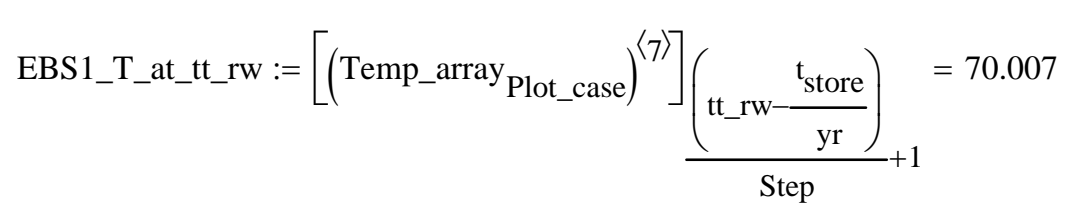

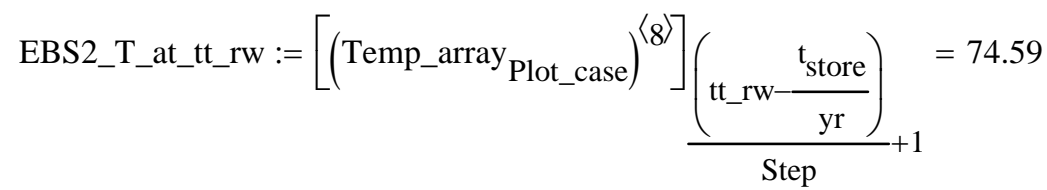

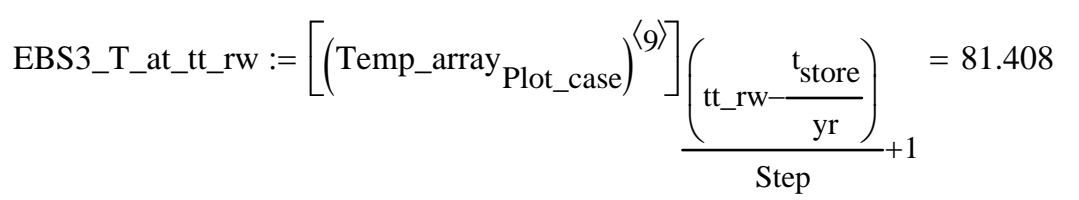

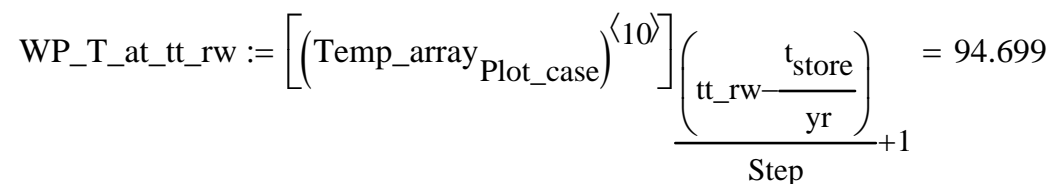

\begin{tabular}{|c|c|c|c|c|c|c|}
\hline \multirow{6}{*}{ r_array } & ${ }^{\mathrm{r}} \mathrm{WP}$ & \multicolumn{2}{|l|}{$(0.585)$} & \multirow{5}{*}{ T_at_tt_rw := } & (WP_T_at_tt_rw $)$ & (94.699 \\
\hline & ${ }^{1} 4$ & 1.406 & & & EBS3_T_at_tt_rw & 81.408 \\
\hline & $r_{3}$ & 2.227 & & & EBS2_T_at_tt_rw & 74.59 \\
\hline & 12 & \begin{tabular}{l|l}
- & 3.048
\end{tabular} & 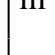 & & EBS1_T_at_tt_rw & 70.007 \\
\hline & & 4 & & & Wall_T_at_tt_rw & 66.141 \\
\hline & & 5.25 & & & ( CP2_T_at_tt_rw & 64.355 \\
\hline
\end{tabular}

tt_wp := $\left[\text { (Peak_values }^{\langle\text {Plot_case. } 22}\right]_{6}=65$

CP2_T_at_tt_wp :=[(Temp_array Plot_case $\left.)^{\langle 5\rangle}\right] \frac{\left(\frac{{ }^{(t t} \_w p-\frac{{ }_{\text {store }}}{\mathrm{yr}}}{\text { Step }}+1\right.}{1}=56.761$

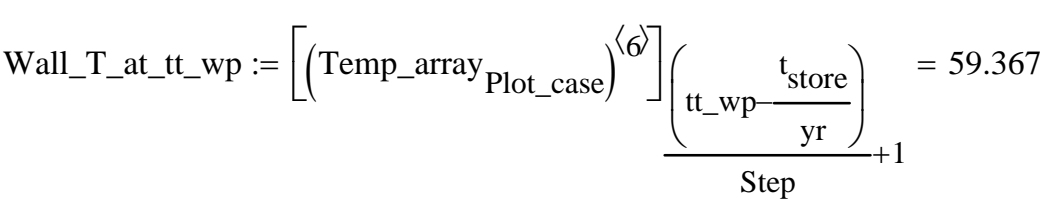

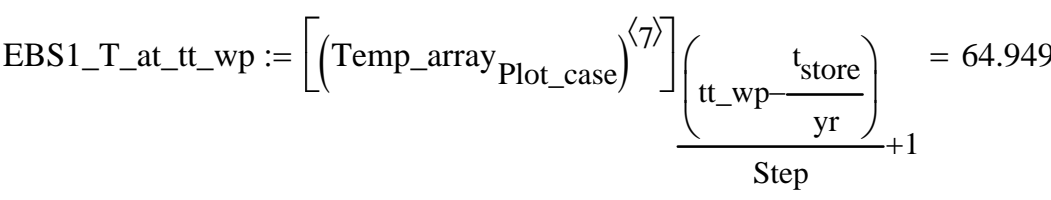

EBS2_T_at_tt_wp :=[(Temp_array Plot_case $\left.)^{\langle 8\rangle}\right] \frac{\left(\frac{t_{\text {tt_wp- }-\frac{t_{\text {store }}}{\mathrm{yr}}}^{\text {Step }}}{}+1\right.}{1}=71.879$

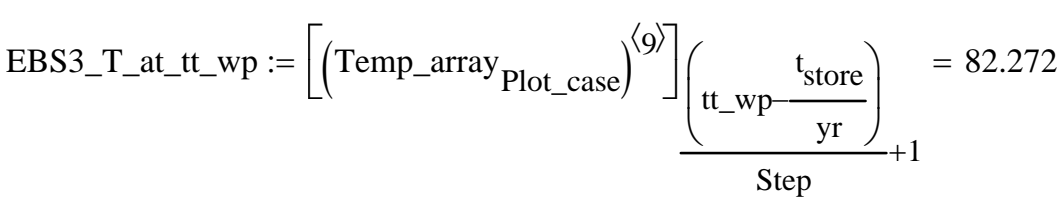

WP_T_at_tt_Wp := $\left[(\text { Peak_values })^{\langle\text {Plot_case } 2-21\rangle}\right]_{6}=102.771$

\begin{tabular}{|c|c|c|c|}
\hline \multirow{4}{*}{ at_tt_wp := } & 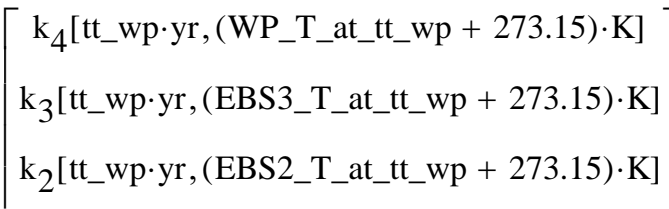 & $\left(\begin{array}{l}3.958 \\
4.219 \\
4.364\end{array}\right.$ & \\
\hline & $\mathrm{k}_{2}\left[\mathrm{tt} \_\mathrm{wp} \cdot \mathrm{yr},\left(\mathrm{EBS1} 1 \mathrm{~T} \_\mathrm{at} \_\mathrm{tt} \_\mathrm{wp}+273.15\right) \cdot \mathrm{K}\right]$ & 4.466 & $\overline{\mathrm{m} \cdot \mathrm{K}}$ \\
\hline & $\mathrm{k}_{1}[($ Wall_T_at_tt_wp +273.15$) \cdot \mathrm{K}]$ & 4.802 & \\
\hline & $\mathrm{k}_{1}\left[\left(\mathrm{CP} 2 \_\mathrm{T} \_\mathrm{at} \_\mathrm{tt} \_w p+273.15\right) \cdot \mathrm{K}\right]$ & (4.846 & \\
\hline \multirow{6}{*}{ k_at_tt_rw := } & {$\left[\mathrm{k}_{4}\left[\mathrm{tt} \_\mathrm{rw} \cdot \mathrm{yr},\left(\mathrm{WP} \_\mathrm{T} \_\mathrm{at} \_\mathrm{tt} \_\mathrm{wp}+273.15\right) \cdot \mathrm{K}\right]\right.$} & & \\
\hline & $\mathrm{k}_{3}\left[\mathrm{tt} \_\mathrm{rw} \cdot \mathrm{yr},(\right.$ EBS3_T_at_tt_rw +273.15$\left.) \cdot \mathrm{K}\right]$ & & \\
\hline & $\mathrm{k}_{2}\left[\mathrm{tt} \_\mathrm{rw} \cdot \mathrm{yr},(\right.$ EBS2_T_at_tt_rw +273.15$\left.) \cdot \mathrm{K}\right]$ & 4.502 & $\mathrm{~W}$ \\
\hline & $\mathrm{k}_{2}\left[\mathrm{tt} \_\mathrm{rw} \cdot \mathrm{yr},\left(\mathrm{EBS1} 1 \mathrm{~T} \_\mathrm{at} \_\mathrm{tt} \_\mathrm{rw}+273.15\right) \cdot \mathrm{K}\right]$ & 4.571 & $\overline{\mathrm{m} \cdot \mathrm{K}}$ \\
\hline & $\mathrm{k}_{1}[($ Wall_T_at_tt_rw +273.15$) \cdot \mathrm{K}]$ & 4.693 & \\
\hline & $\mathrm{k}_{1}\left[\left(\mathrm{CP} 2 \_\mathrm{T} \_\mathrm{at} \_\mathrm{tt} \_\mathrm{rw}+273.15\right) \cdot \mathrm{K}\right]$ & 4.721 & \\
\hline
\end{tabular}




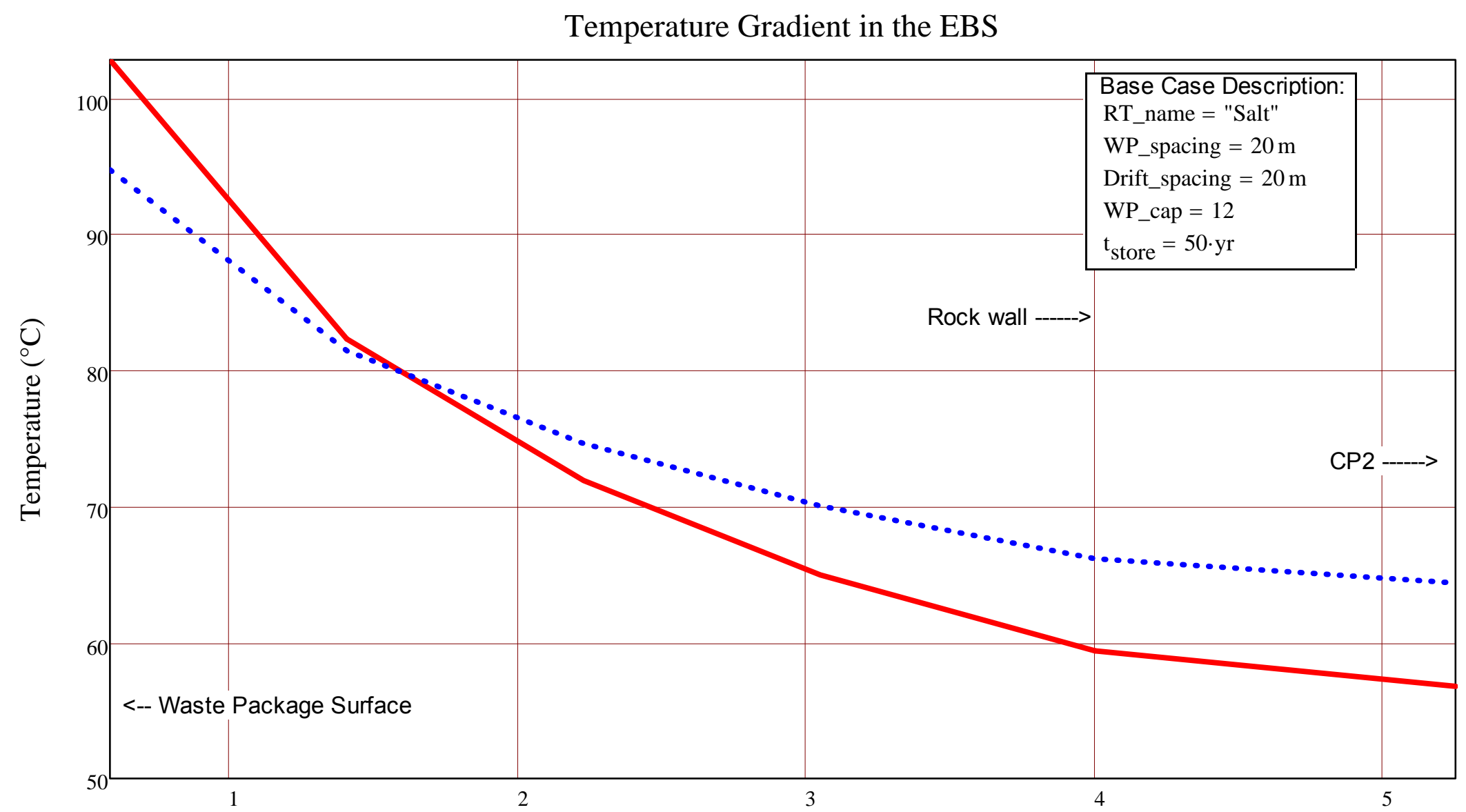

Radial Location in the EBS (m)

— Gradient at the time of the Waste Package Peak T

... Gradient at the time of the Rock Wall Peak T 


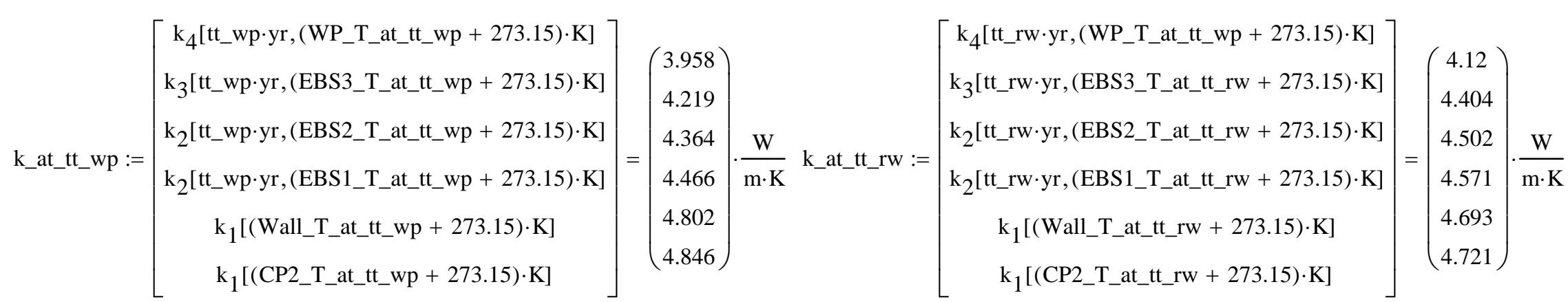

$0.75 \cdot k_{\text {intact }}[($ WP_T_at_tt_wp +273.15$) \cdot \mathrm{K}]+0.25 \cdot \mathrm{k}_{\text {crushed }}\left[\right.$ Porosity $\left(t \mathrm{tt} \_\mathrm{wp}\right),($ WP_T_at_tt_wp +273.15$\left.) \cdot \mathrm{K}\right]=3.958 \cdot \frac{\mathrm{W}}{\mathrm{m} \cdot \mathrm{K}}$

Thermal Conductivity Variation in the EBS

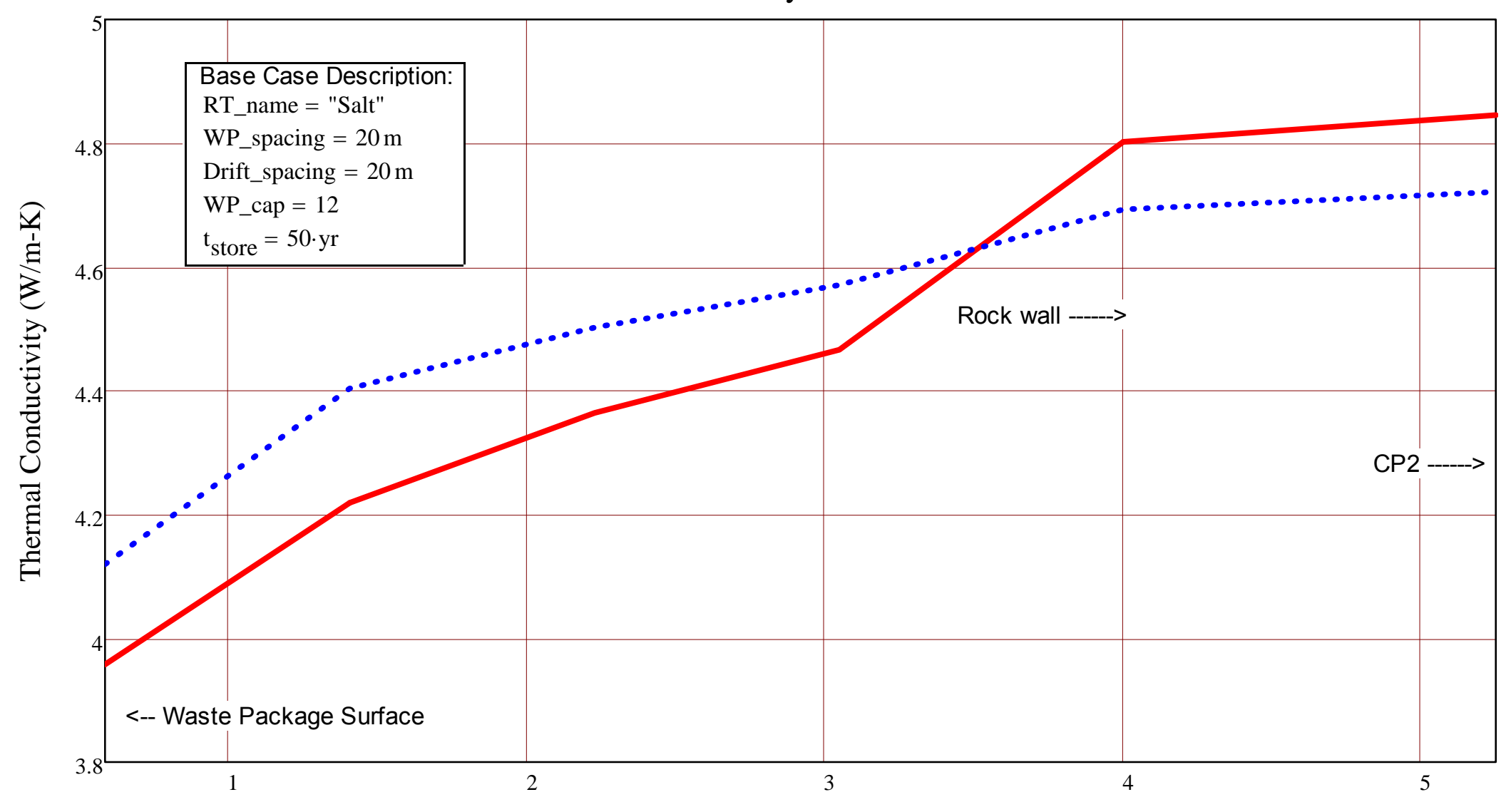

Radial Location in the EBS (m)

- At the time of the Waste Package Peak

.... At the time of the Rock Wall Peak T

\section{OVERRIDE COUNTER AND STEP SIZE TO GET FINER CONVERGENCE ON THE ANSWER}

$0.75 \cdot \mathrm{k}_{\text {intact }}[($ WP_T_at_tt_wP +273.15$) \cdot \mathrm{K}]=3.132 \cdot \frac{\mathrm{W}}{\mathrm{m} \cdot \mathrm{K}}$

Porosity(tt_wp) $=0.111$

$0.25 \cdot \mathrm{k}_{\text {crushed }}\left[\right.$ Porosity $\left(\mathrm{tt} \_w p\right),($ WP_T_at_tt_wp +273.15$\left.) \cdot \mathrm{K}\right]=0.826 \cdot \frac{\mathrm{W}}{\mathrm{m} \cdot \mathrm{K}}$

$0.25 \cdot \mathrm{k}_{\text {consolidate }}\left[\mathrm{ft} \_\mathrm{wp},\left(\mathrm{WP} \_\mathrm{T} \_\mathrm{at} \_\mathrm{tt} \_\mathrm{wp}+273.15\right) \cdot \mathrm{K}\right]=0.826 \cdot \frac{\mathrm{W}}{\mathrm{m} \cdot \mathrm{K}}$

Previous analysis with constant salt thermal properties in the EBS assumed $75 \%$ surface contact with intact salt, and took no credit for conduction through the crushed salt.

$0.75 \mathrm{k}_{\text {intact }}[(100+273.15) \cdot \mathrm{K}]=3.158 \cdot \frac{\mathrm{W}}{\mathrm{m} \cdot \mathrm{K}}$

$0.75 \mathrm{k}_{\text {intact }}[(200+273.15) \cdot \mathrm{K}]=2.409 \cdot \frac{\mathrm{W}}{\mathrm{m} \cdot \mathrm{K}}$

$\mathrm{k}_{\text {crushed }}[$ Porosity(tt_wp),(WP_T_at_tt_wp +273.15$\left.) \cdot \mathrm{K}\right]=3.305 \cdot \frac{\mathrm{W}}{\mathrm{m} \cdot \mathrm{K}}$

$\mathrm{k}_{\text {consolidate }}\left[\right.$ Porosity $\left.\left(\mathrm{tt} \_w \mathrm{wP}\right),\left(\mathrm{WP} \_\mathrm{T} \_\mathrm{at} \_\mathrm{tt} \_\mathrm{wp}+273.15\right) \cdot \mathrm{K}\right]=1.809 \cdot \frac{\mathrm{W}}{\mathrm{m} \cdot \mathrm{K}}$ 


\begin{tabular}{|c|c|}
\hline OPTIONALLY OVERF & ENTILATION TIME TO SHORTEN ITERATION CONVERGENGE \\
\hline ITERATE_OK = "NO"'" & $\mathrm{t}_{\text {convergence }}=1 \cdot \mathrm{yr}$ \\
\hline $\mathrm{t}_{\text {required_storage }}\left(\mathrm{t}_{\text {operate }}, \mathrm{T}_{\text {criteria }}, \mathrm{t}_{\text {convergence }}\right):=$ & 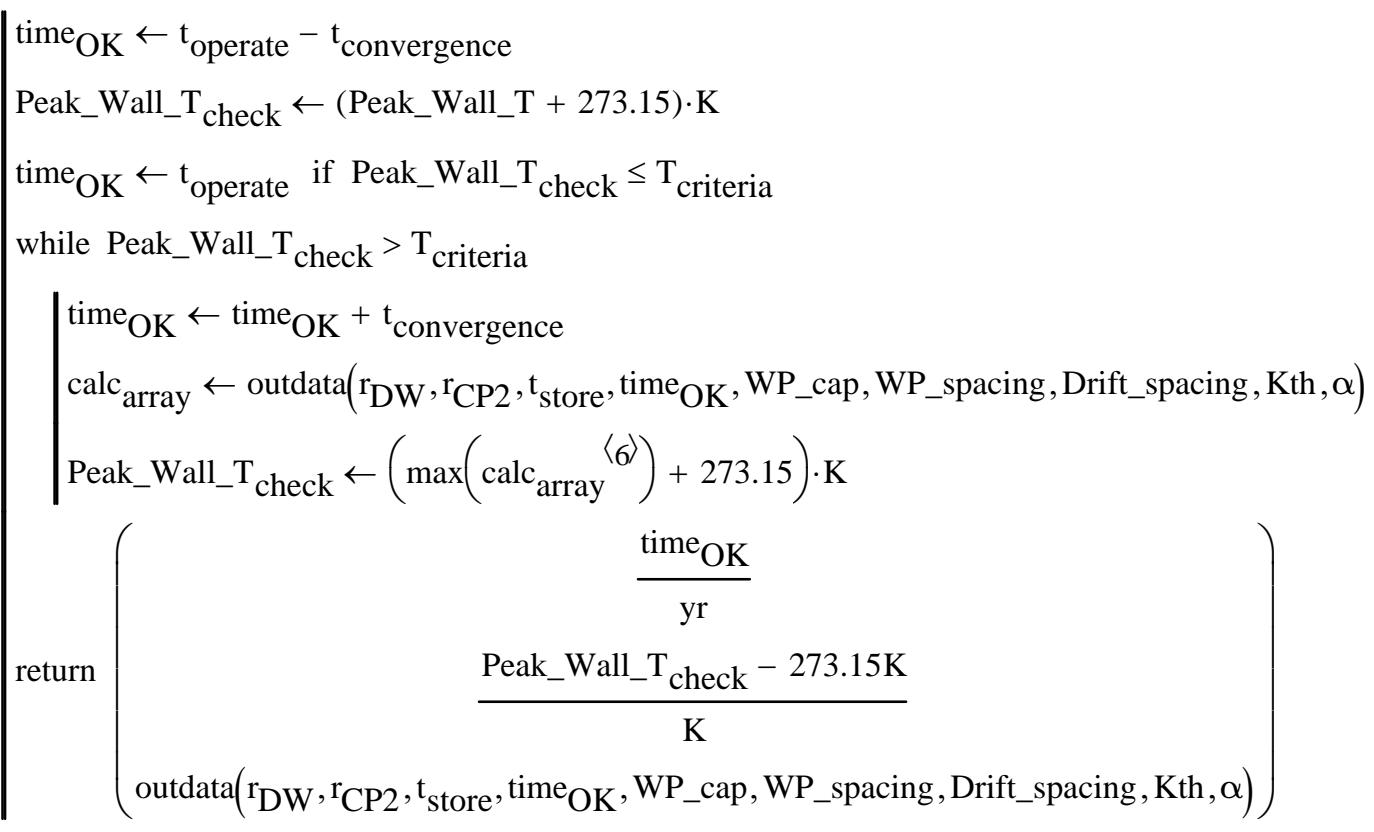 \\
\hline
\end{tabular}

Final_array $:=\mid \begin{aligned} & t_{\text {required_storage }}\left(t_{\text {operate }}, T_{\text {criteria }},{ }_{\text {convergence }}\right) \text { if ITERATE_OK = "YES" } \\ & \text { "No Iteration Performed" otherwise }\end{aligned}$

$\mathrm{t}_{\text {operate_required }}$ := Final_array 1 yr $=\boldsymbol{P} \cdot \mathrm{yr}$

$t_{\text {vent_required }}:=t_{\text {operate_required }}-t_{\text {store }}=\boldsymbol{e} \cdot y r$

Peak_Wall_T $\mathrm{T}_{\text {check }}:=\left(\right.$ Final_array $\left._{2}+273.15\right) \cdot \mathrm{K}=\mathbf{I} \cdot{ }^{\circ} \mathrm{C}$

REQUIRED VENTILATION TIME NEEDED TO MEET

$\mathrm{T}_{\text {criteria }}=100 \cdot{ }^{\circ} \mathrm{C}$

Result := stack(Title_array ${ }_{1}$,Final_array ${ }_{3}$ ) 


$$
\begin{aligned}
& \text { Time_array := (Final_array } 3)^{\langle 1\rangle} \\
& \text { Peak_Temp(n) }:=\max \left[\left(\text { Final_array }_{3}\right)^{\langle\mathrm{n}\rangle}\right] \quad \text { Peak_Temp(6) }=\mathbf{~}
\end{aligned}
$$

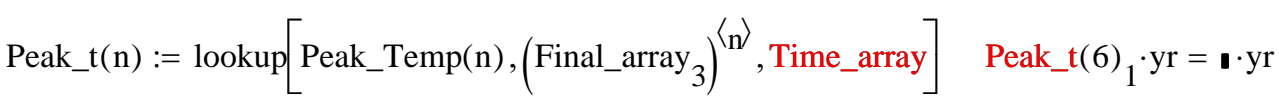

$$
\begin{aligned}
& \mathrm{nn}:=5 \ldots 10 \quad \text { Peak_results }{ }_{\mathrm{nn}-4,1}:=\text { Peak_Temp(nn) Peak_results }{ }_{\mathrm{nn}-4,2}:=\text { Peak_t(nn) }
\end{aligned}
$$

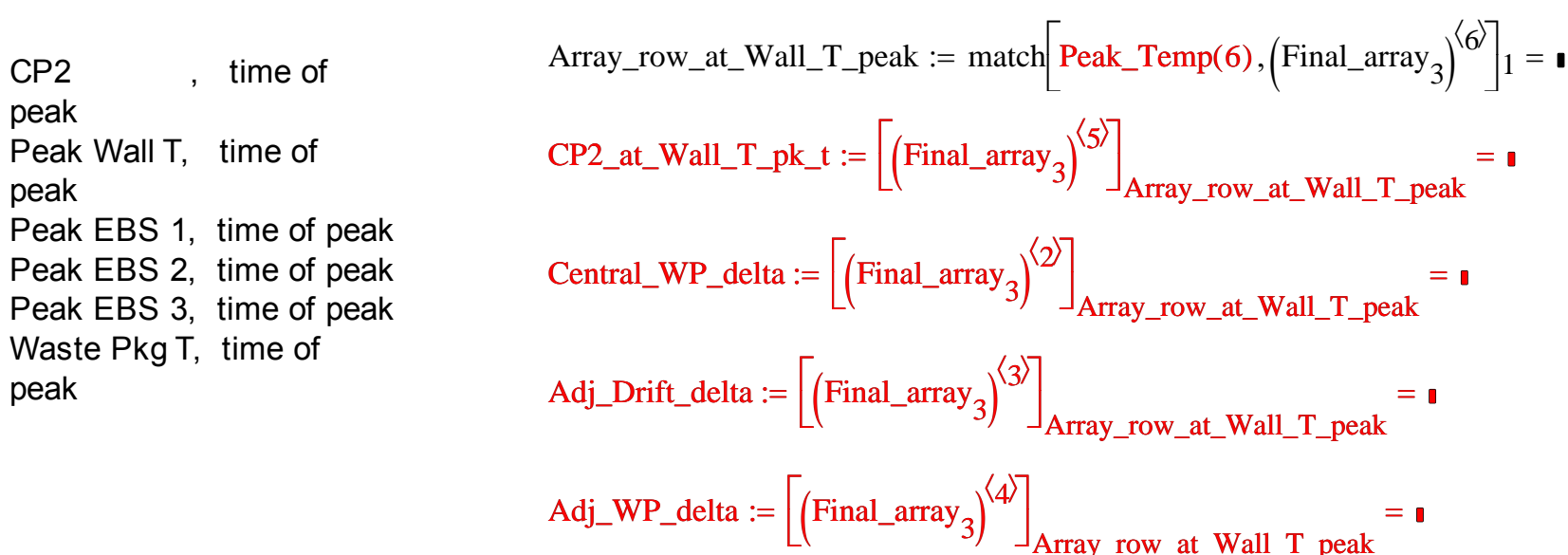

Result_Vector $:=\left(\frac{\text { WP_spacing }}{\mathrm{m}}\right.$ TC $\frac{\text { Drift_spacing }}{\mathrm{m}}$ Peak_results $_{6,1}$ Peak_results 6,2 Peak_results 2,1 Peak_results ${ }_{2,2}$ CP2_at_Wall_T_pk_t $\frac{\mathrm{t}_{\text {vent_required }}}{\text { yr }}$ Central_WP_delta Adj_Drift_delta Adj_WP_delta $)$

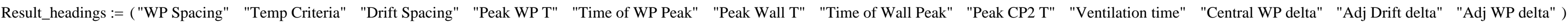


Result_Vector $=\mathbf{~}$

RV := augment(Result_headings ${ }^{\mathrm{T}}$, Result_Vector $\left.{ }^{\mathrm{T}}\right)$

$\mathrm{RV}=$
This is the result vector for transcription to the Excel case results

tracking file

Contribution percentages at time of peak wall temperature

Percent_central_WP_delta := $\frac{\text { Central_WP_delta }}{\text { Peak_Temp(6) }-\frac{\left(\mathrm{T}_{\text {ambient }}-273.15 \cdot \mathrm{K}\right)}{\mathrm{K}}} \cdot 100=$

Percent_adj_Drift_delta := $\frac{\text { Adj_Drift_delta }}{\text { Peak_Temp(6) }-\frac{\left(\mathrm{T}_{\text {ambient }}-273.15 \cdot \mathrm{K}\right)}{\mathrm{K}}} \cdot 100=\mathbf{~}$

Percent_adj_WP_delta $:=\frac{\text { Adj_WP_delta }}{\text { Peak_Temp }(6)-\frac{\left(T_{\text {ambient }}-273.15 \cdot K\right)}{\mathrm{K}}} \cdot 100=\mathbf{~}$

Percent_central_WP_delta + Percent_adj_WP_delta + Percent_adj_Drift_delta =
NOTE THAT THESE RESULTS WILL BE MISSING IF

lterate_OK $=$ "No" 